\title{
NBS Calibration Services Users Guide 1986-88
}

U.S. Department of Commerce National Bureau of Standards

REW NES PUB

AUG 271986

$+x^{2}$
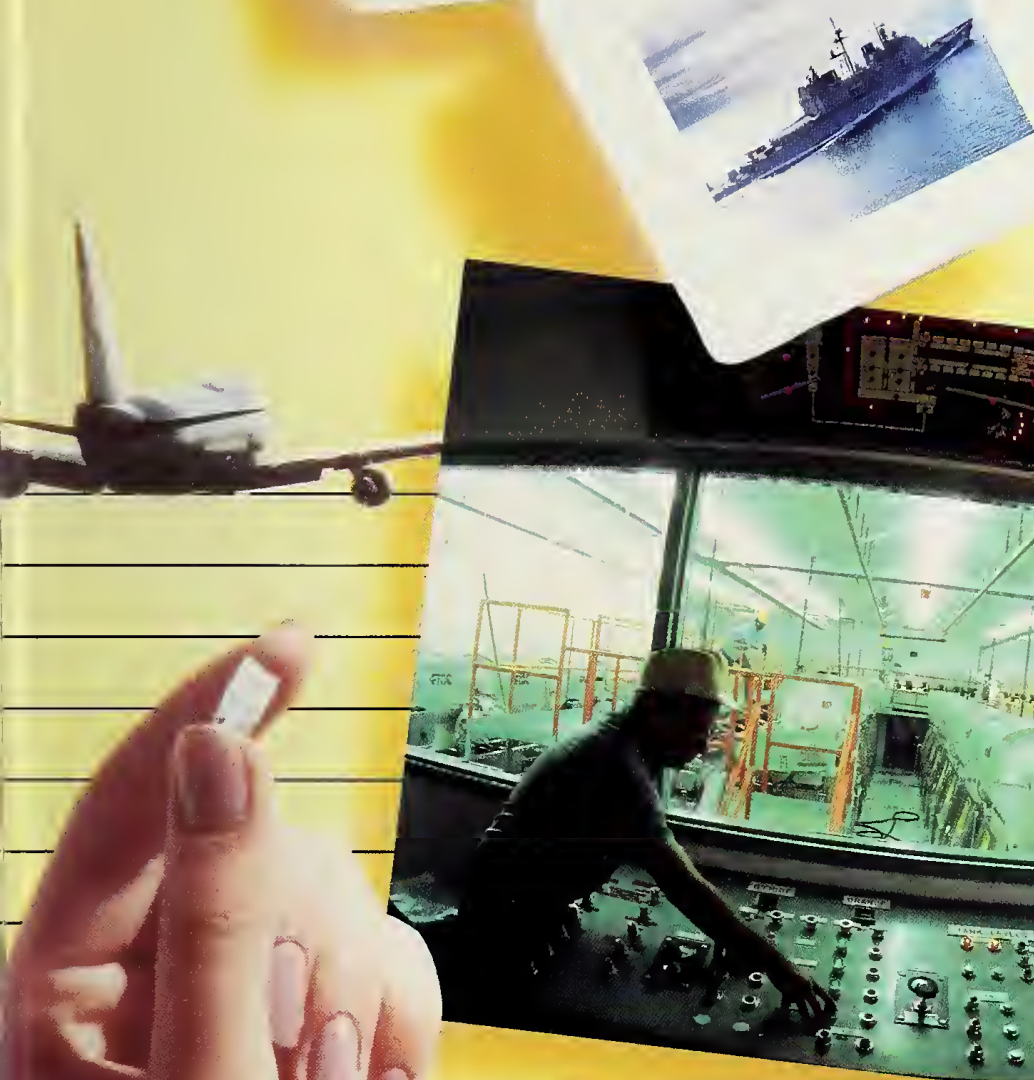


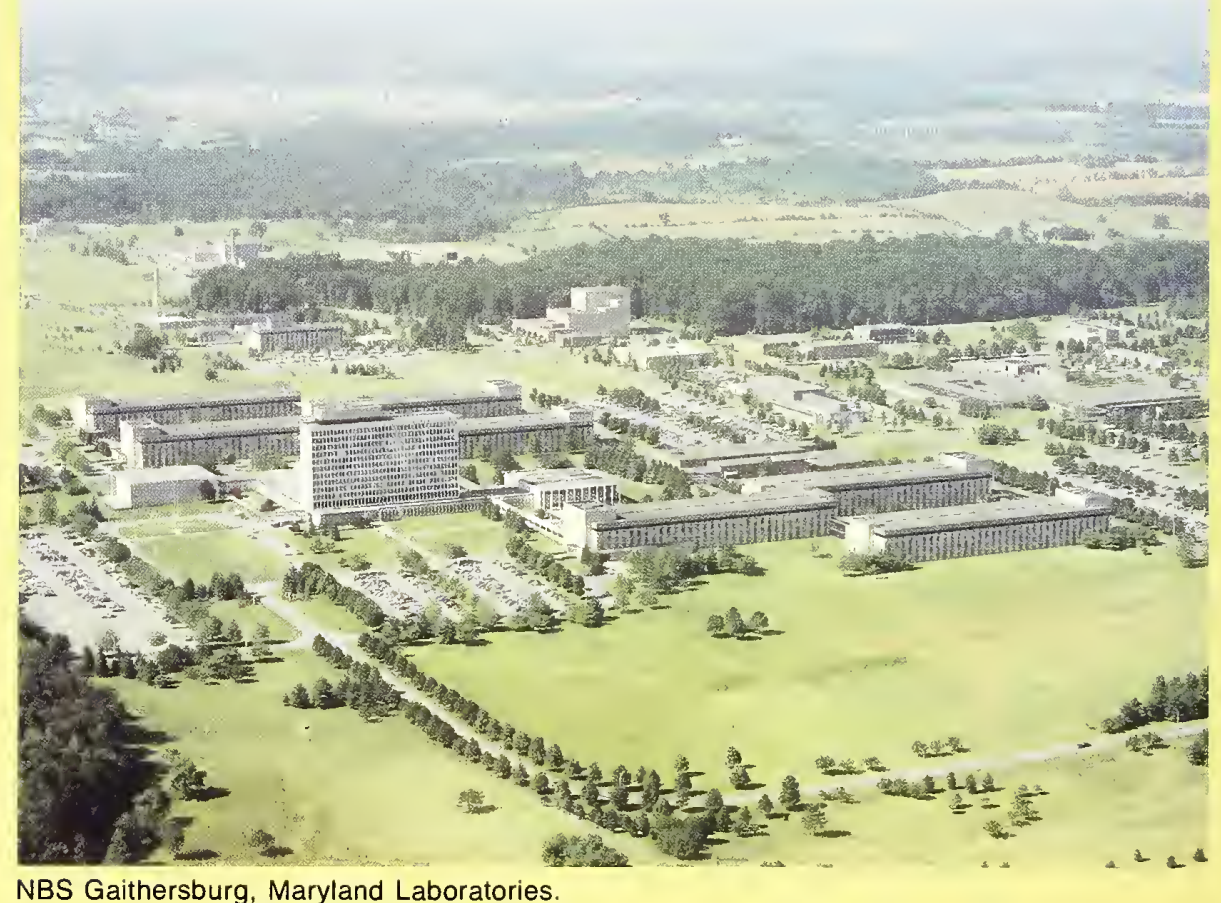

NBS Gaithersburg, Maryland Laboratories.

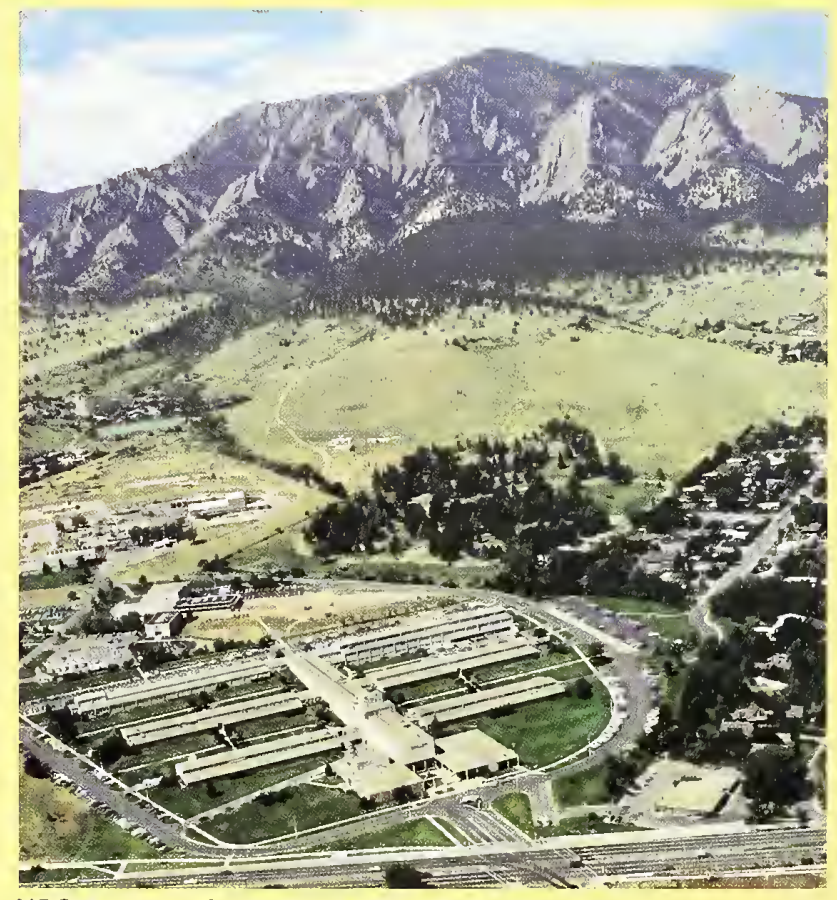

NBS Boulder, Colorado Laboratories. 


\title{
NBS Calibration Services Users Guide 1986-1988 Edition
}

\author{
George A. Uriano \\ Ernest L. Garner \\ R. Keith Kirby \\ William P. Reed, Editors
}

Office of Physical Measurement Services

National Bureau of Standards

Gaithersburg, MD 20899

NBS Special Publication 250

Issued July, 1986

(Supersedes 1982 Edition)

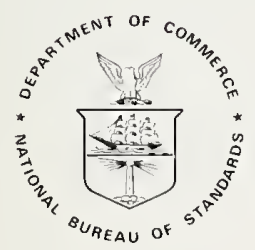

U.S. Department of Commerce Malcolm Baldrige, Secretary

National Bureau of Standards

Ernest Ambler, Director

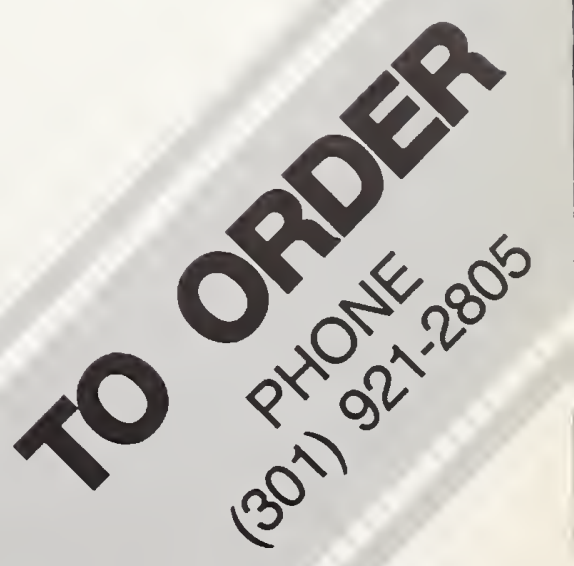


National Bureau of Standards

Special Publication 250 - 1986 Edition

Nat. Bur. Stand. (U.S.), Spec. Publ. 250, 1986 Ed.,

204 pages (July 1986)

CODEN: XNBSAV

U.S. GOVERNMENT PRINTING OFFICE

WASHINGTON: 1986

For sale by the Superintendent of Documents,

U.S. Government Printing Office, Washington, DC 20402

U.S. Government Printing Office

Washington: 1986 
The NBS Calibration Service Users Guide provides detailed descriptions of the currently available NBS calibration services, special test services, and measurement assurance programs. This document is a revised edition of NBS Special Publication 250. It describes the NBS services available as of the second quarter of 1986 and reflects a number of important changes since the 1982 edition was published. A detailed description is given of each measurement service. A new numbering system is used to uniquely identify each of the services. Addendum I to this document is a crossreference index that links the new NBS test numbers to those used previously to identify the services. Also cited are a large number of NBS technical experts (including addresses and telephone numbers) who may be contacted for further information concerning services or measurement problems. Future editions will be published periodically as NBS services change.

This document also presents a detailed description of a number of Measurement Assurance Program (MAP) services. These are carefully designed quality control programs for critical measurements that allow the user to achieve a high level of confidence that the measurements being made in the user's laboratory are consistent with national standards and adequate for intended use. MAP services are available for some basic measurement quantities (e.g., laser power and energy). New MAP services for luminous intensity of retroreflectors and spectral transmittance have been introduced since the last edition of this document.

A Fee Schedule for the services described in this Users Guide is published every six months (April and October). It lists current prices for the services described here. NBS will notify users of changes in services or proposed changes in services by means of announcements in the semi-annual Fee Schedule. In addition, information about upcoming NBS Measurement Seminars is announced there. If you are not already on the NBS physical measurement services mailing list and wish to be, fill in and return the card below. It is important that you refer to the current issue of the Fee Schedule in order to have up-to-date information with respect to NBS points of contact.

A companion document to this guide is NBS Special Publication 260, NBS Standard Reference Materials Catalog. This document describes over 900 Standard Reference Materials (SRMs) certified by NBS for use in industrial quality control, materials testing, environmental testing, and clinical testing applications. A copy of SP 260 may be obtained by indicating interest on the mailing list card and returning it to NBS.

The Office of Physical Measurement Services welcomes suggestions on how this publication can be made more useful to those who rely on NBS physical measurement services. Suggestions are also welcome concerning needs for new calibration services, measurement assurance programs, or other measurement services.

George A. Uriano, Director Measurement Services
Ernest L. Garner, Chief

Office of Physical Measurement Services 


\section{Abstract}

The National Bureau of Standards (NBS) Calibration Services Users Guide provides detailed descriptions of currently available NBS calibration services, measurement assurance programs, and special test services. The following measurement areas are covered: (1) dimensional, (2) mechanical including flow, acoustic, and ultrasonic, (3) thermodynamic, (4) optical radiation, (5) ionizing radiation, and (6) electromagnetic including dc, ac, rf, and microwave. A separate Fee Schedule is issued every six months, which provides current prices for the services offered, updates on points-ofcontact, and information on measurement seminars.

Key words: calibration; measurement assurance; measurement services; standards; traceability. 


\section{Acknowledgments}

Many NBS staff members contributed to the development and preparation of this guide. Over 50 members of the NBS technical staff contributed data and information that have been incorporated into the guide. Significant contributions were made by John Mayo-Wells and Norman Belecki, who helped gather data for and review many of the sections in Chapter VII on Electromagnetic Measurements. Peter de Bruyn thoroughly reviewed the manuscript and made many suggestions for its improvement. Julianne Chappell provided a number of excellent editorial suggestions and coordinated the preparation of the final document. We are deeply indebted to Margaret Musick, for an excellent job in typing what seemed like an endless number of drafts, and to Verna Moore for considerable assistance in preparing the many drafts. We also are grateful for the help of Marilyn Ugiansky and Ernie Kunz for contributions to the graphic design and layout of the final document and to Nancy Gogniat and Ilse Putman for typesetting the final draft.

The Editors 


\section{List of Tables}

Table

Page

1. Piston Gage and Pressure Transducer Uncertainties.............. 43

2. Thermometer Calibration Uncertainties ...................... 48

3. Calibration Uncertainties for Radionuclides Having Half-Lives

Greater than 15 Days . . . . . . . . . . . . . . . . . . . .

4. Calibration Uncertainties for Radionuclides Having Half-Lives

Less than 15 Days ............................... 79

5. Specifications for Calibrations of Alpha-Particle-Emitting Samples. . . . . . 79

6. Specifications for Special Tests of Beta-Particle-Emitting

Solution Sources............................ 80

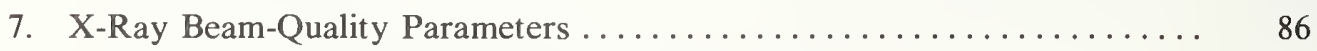

8. Calibration Uncertainties for DC Resistance Standards ............. 96

9. Specifications and Estimated Uncertainties for Low-Frequency

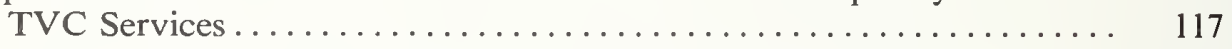

10. Specifications and Estimated Uncertainties for High-Frequency

TVC Services ................................ 117

11. Specifications and Estimated Uncertainties for Peak-to-Peak

Detector Services............................... 118

12. Specifications and Estimated Uncertainties for RF

Micropotentiometer Calibrations....................... 118

13. Specifications and Estimated Uncertainties for Data Converter Calibrations .................................. 121

14. Available Values of the Parameters for Routine Wattmeter and Watthour Meter Testing .......................... 136

15. Summary of NBS Standard Field Strength Facilities............. 158

16. NBS Impulse Generator Spectrum Amplitude Measurement Service Capabilities ................................. 160

17. Limits of Uncertainties for Calibration of Fast Repetitive

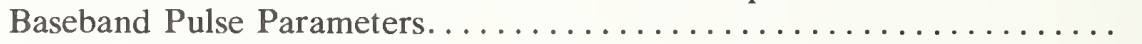




\section{List of Figures}

Figure

Page

1. Accuracy of Length Measurements at NBS . . . . . . . . . . . . . 8

2. Precision of Angle Calibrations for Master

Angle Gage Blocks and Polygons................... 17

3. Uncertainty of NBS Measurements for Air

4. Uncertainty of NBS Measurements for Water

5. Uncertainty of NBS Measurements for Liquid

Hydrocarbon Flow Rate Standards ..................... 24

6. Accuracy of Airspeed Measurements for
Calibration of Airspeed indicators $\ldots \ldots \ldots \ldots \ldots \ldots \ldots \ldots \ldots \ldots$

7. NBS Precision of Weighing for Mass Standards
Ranging from $10^{-8}$ to $10^{4}$ Kilograms ...................... 29

8. Uncertainties of NBS Low Pressure and Vacuum Standards .......... 45

9. Uncertainties for NBS Calibration of Temperature

Measuring Instruments ......................... 48

10. NBS Uncertainties for Measurement of Humidity
Standards with Atmospheric Air at Atmospheric Temperature . . . . . . 57

11. Uncertainties for NBS Spectral Radiance Calibrations. . . . . . . . . . 65

12. Uncertainties for NBS Spectral Irradiance Calibrations. . . . . . . . . . . 66

13. Uncertainties of NBS DC Voltage Measurments . . . . . . . . . . . . . 109

14. NBS Uncertainties for AC Voltage Measurements................ 113

15. Uncertainty for NBS Data Converter Test System for Resolutions from $12-18$ Bits . . . . . . . . . . . . . . . . . 121

16. Estimated Total Uncertainties of the NBS Phase

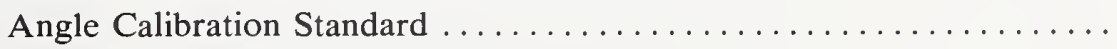




\section{Contents}

\section{Chapter 1- Policies}
A. Introduction
B. Questions and Inquiries
C. Fees
D. Types of Services
E. Criteria
F. Reports of Test Results
G. References to NBS in Advertisements
H. Traceability
I. Disclaimer
J. Ordering and Scheduling
K. Purchase Order
L. Shipping
M. Special Instructions for Foreign Customers

Chapter 2-

\section{Dimensional Measurements}

A. Length Measurements

$10010 \mathrm{C}$......... Gage Blocks

10020C ......... Line Standards

10030C .......... Surveying and Oil Gaging Tapes

10040S ......... Special Tests of Surveying Leveling Rods

10050S .......... Special Tests of Length Standards

10060S .......... Special Tests of Sieves

10070M. ..........Measurement Assurance Program for Gage Blocks

B. Diameter Measurements

11010S ..........Special Tests for Plug Gages: External

$11020 \mathrm{C} . . . . .$. . Measuring Wires for Threads and Gears

11030 S ......... Special Tests for Spherical Diameter Standards: Balls

11040S .......... Special Tests for Internal Diameter Standards:

Ring Gages

11050 S .........Special Tests of Length and Diameter

11060 S ......... Special Tests of End Standards

11070 S . . . . . . Special Tests of Step Gages

11080 S ...........Special Tests of Thread Measuring Wires

C. Complex Dimensional Standards

12010C . . . . . . A API Threaded Plug and Ring Gages

12020S .......... Special Tests of Plain Conical Plug and Ring Gages

12030S ........ Special Tests of Threaded Plug and Ring Gages

12040S ......... Special Tests of Calipers and Gages

12050S ......... Special Tests of Micrometer Screws and Dial

Micrometers

12060S . . . . . . S Special Tests of Penetration Needles

12070 S . . . . . . . Special Tests of Two Dimensional Gages 
D. Optical Reference Planes \& Roundness Standards

13010S ..........Special Tests of Optical Reference Planes (Flats)

13020S ......... Special Tests of Roundness

13030S .......... Special Tests of Roundness Calibration Specimens

E. Angular Measurements

14010C ..........Angle Gage Blocks

14020S ......... Special Tests of Optical Polygons

14030S .......... Special Tests of Rotary and Indexing Tables

14040S .......... Special Tests of Wedges

14050S ......... Special Tests of Autocollimators

14060S ......... Special Tests of Angle Generators

F. Surface Texture

15010C .........Roughness Calibration Specimens

15020C . . . . . . . . Surface Roughness Comparison Specimens

15030C ......... Step Height Measurements

G. Hydrometers

16010C .........Reference Standard Hydrometers

H. Volume and Density

17010C ......... Volume Standards

17020S ......... Special Tests of Volume Standards

17030S ......... Special Tests of Density: Solids

17040S .......... Special Tests of Density: Liquids

\section{Chapter 3-}

\section{Mechanical Measurements}

A. Flow Rate Measurements

18010C ......... Single Turbine Meters

18020C . . . . . . . . Tandem Turbine Meters

18030C .......... Flow Rate Meters (Direct Reading in Flow

Rate Units)

18040C . . . . . . . . Head Class Flow Measurement Devices

18050S ......... Special Tests for Liquid and Gas Flow Rates

B. Flow Measurements at Cryogenic Temperatures

18800S ......... Special Tests of Cryogenic Liquid Flow

C. Airspeed Measurements

19010C . . . . . . . Pitot-Static Tubes

19020C . . . . . . . . Low Airspeed Measurements

19030S ......... Special Tests for Airspeed Measurements 
D. Mass Standards

22010C-22030C. . Weight Sets (1 mg to $30 \mathrm{~kg}$ )

$22040 \mathrm{C}-22120 \mathrm{C}$. . .Single Weights ( $1 \mathrm{mg}$ to $30,000 \mathrm{~kg}$ )

22130C-22160C. . .Single Weight for Dead-Weight Pressure Testers

22170S . . . . . . . Special Mass Measurement Services

22180M..........Measurement Assurance Program for Mass

E. Force Measurements

23010C-23240C...Force Transducers (to 1,000,000 lbf, 1 or 2 Modes)

23250C . . . . . . . Force Transducers (over 1,000,000 lbf)

23260S .......... Special Tests of Force Transducers

23270 S .........Pattern Evaluation Test of Load Cells in Compression

F. Vibration Measurements

24010C-24030C. . Vibrations (Pickup Sensitivity, 2 to $10,000 \mathrm{~Hz}$ )

24040S .......... Special Shock Measurement Services

24050S ......... Special Tests of Pickup Sensitivity

24060S ..........Special Vibration Tests

G. Acoustic Measurements

25010C-25020C. . Pressure Response: WE Type 640AA

Microphones or Equivalent

25030C-25040C. . Pressure Response: Tokyo Riko Type ECL

MR 112, or Equivalent Half-Inch Microphones

25050C ...........Free-Field Response: Tokyo Riko Type ECL

MR 112, B\&K Types 4133, 4134, 4165, 4166, or

Equivalent Half-Inch Microphone

25060S ......... Special Tests of Acoustic Devices

25070 S ......... Special Tests of Earphones

H. Ultrasonic Measurements

26010C .........Ultrasonic Transducer Power and Frequency

26020 C . . . . . . Acoustic Emission Sensors

26030S . . . . . . . Special Tests of Aluminum Reference Blocks

26050S ........ Distance Amplitude Set

26070S .......... Special Tests of Ultrasonic Transducer Power

\section{Chapter 4-}

Thermodynamic Quantities

A. Pressure Measurements

29010C . . . . . . . Deadweight Piston Gages

29020C . . . . . . . Controlled Clearance Piston Gages

29030 C . . . . . . . Pressure Gages and Transducers

29035C . . . . . . Mercurial Barometers and Manometers

29040S ......... Special Tests of Pressure Gages 
B. Vacuum and Low Pressure Measurements 30010C ..........Absolute Low Pressure Gages

30020C . . . . . . . . Differential Low Pressure Gages

30030C ..........High Vacuum Gages

30040S ......... Special Tests of Low Pressure Gages

30050S ......... Special Tests of Vacuum Gages

C. Laboratory Thermometers

31010C-31061C. . Laboratory Thermometers

31070C-31071C. . . Calorimetric Thermometers

31080C-31081C. ..Beckman Thermometers

31100 S ..........Special Tests of Liquid-in-Glass Thermometers

31110S-31161S ...Special Tests of Thermometers

31260S ..........Special Thermometry Services by Prearrangement

D. Thermocouples, Thermocouple Materials, and

Pyrometer Indicators

32010C-32044C. . Type S, R, B, E, J, K, N, and T, Measured with

Standard Thermocouples Covering $0-1750^{\circ} \mathrm{C}$

32070C ........Thermocouple Materials Tests against Pt

Standard with PRT $\left(-100\right.$ to $\left.300^{\circ} \mathrm{C}\right)$

$32090 \mathrm{C}$......... Type S Measured with Freezing-Point Standards

$\left(0-1450^{\circ} \mathrm{C}\right)$

32100C ..........Pyrometer Indicators (Portable Potentiometers, First Dial or Range

32110C-32147C. . . Thermocouple Materials Tested against PT

Standard with PRT-Varian Temperature

Ranges

32150S ..........Special Tests of Thermocouples and Thermocouple Materials

E. Resistance Thermometry

33010C-33020C. . Long Stem Platinum Resistance Thermometers

$33030 \mathrm{C}$........ Calorimetric Type PRT $\left(-50\right.$ to $\left.+150^{\circ} \mathrm{C}\right)$

33040C-33050C. . .Capsule Type Platinum Resistance Thermometers

33060S .........Special Tests of Germanium Resistance

Thermometers

33100S .........Special Tests of Resistance Thermometers

33110S ..........Special Tests of Thermometric Fixed-Point

Devices

33120M.........Measurement Assurance Program for Temperature 
F. Radiation Thermometry

35010C-35040C... Optical Pyrometers

$35050 \mathrm{C}-35060 \mathrm{C}$. . Ribbon Filament Lamps $\left(800\right.$ to $2300^{\circ} \mathrm{C}$ )

35070S ......... Special Tests of Radiation Pyrometers

G. Humidity Measurements

36010C-36020C. . . Dew-Point Hygrometers

36030C .......... Electric Hygrometers

36040C . . . . . . . . . Coulometric Hygrometers

$36050 \mathrm{C}$..........Aspirated Hygrometers

36060C . . . . . . . . Pneumatic Bridge Hygrometers

36070S ..........Special Tests of Humidity

Chapter 5-

Optical Radiation Measurements

A. Photometric Measurements

37010C-37070C. . . Luminous Intensity Standard (100-1000W Frosted

Tungsten Lamp, 90-1400 candelas, 2700K and $2856 \mathrm{~K}$ color temp.)

37080C ...........Luminous Flux Standards (25W Vacuum Lamp)

37090C-37120C. . .Luminous Flux Standards (60-500W, Gas Filled Lamps)

37130C ..........Luminous Flux Standards (Miniature Lamps)

37140C ..........Airway Beacon Lamps

37170C . . . . . . Opal Glass Luminous Directional Transmittance Standards

37180S .........Special Photometric Tests

B. Spectrophotometric Measurements

38010C-38040C. . . Spectral Transmittance Filters

38050C . . . . . . . Wavelength Standards (Holmium Oxide Glass)

38060S ......... Special Tests of Spectral Transmittance and

Reflectance

38070M-38074M. .Measurement Assurance Program for

Retroreflectance

38080M. .........Measurement Assurance Program for

Transmittance

38090S ......... Special Tests of Photographic Step Tablets

38100S ..........Special Tests of Microcopy Resolution Test Charts

C. Radiometric Measurements

39010C-39030C. . .Spectral Radiance Ribbon Filament Lamps

39040C . . . . . . . Spectral Irradiance Quartz-Halogen Lamps

$(250-1600 \mathrm{~nm})$

39050C . . . . . . . Spectral Irradiance Deuterium Lamps

(200-350 nm)

39060C ..........Photodiode Spectral Response Rental Package

39070S . . . . . . . Special Tests of Radiometric Sources 
D. Radiometric Standards in the Ultraviolet

40010S ... . . . . Special Test, Spectral Irradiance Standard, Argon

Mini-Arc

40020S ......... Special Test, Spectral Radiance Standard, Argon

Mini-Arc

40030S ........ Special Test, Spectral Irradiance Standard,

Deuterium Arc Lamp

40040S ......... Special Test, Radiometric Devices in the Near and

Vacuum Ultraviolet

E. Optical Fiber Attenuation and Bandwidth

41010S ......... Special Tests for Attenuation of

Telecommunication-Grade Multimode Graded-

Index Optical Fibers at 850 and $1300 \mathrm{~nm}$, by

Prearrangement

41020S ......... Special Tests for Bandwidth of

Telecommunication-Grade Multimode

Graded-Index Optical Fiber Having an

Operating Wavelength of $1300 \mathrm{~nm}$, by

Prearrangement

F. Laser Power and Energy

42010S ......... Special Tests of Laser Power and Energy, by

Prearrangement

42020M-42090M. . Measurement Assurance Programs for Laser

Power, Covering Wavelengths from $514.5 \mathrm{~nm}$

to $10.6 \mu \mathrm{m}$ for Various Power Levels

\section{Chapter 6-}

\section{Ionizing Radiation Measurements}

A. Radioactivity Sources

43010C-43020C. . Gamma-Ray-Emitting Radionuclides in Solution

43030C-43050C. . Alpha-Particle-Emitting Solid Sources

43060S-43070S ... Special Tests of Beta-Particle-Emitting Solution

Sources

43090S ......... Special Tests of Alpha-Particle-Emitting Solid

Sources

B. Neutron Sources and Dosimeters

44010C-44020C. . . Natural Standard Neutron Sources

44030S . . . . . . . . Special Tests of Activated Foil Irradiation with

Thermal Neutrons

44040S-44070S . . Special Tests of Neutron Dosimeters

$44080 \mathrm{C}$..........Activated Foil Irradiation, Californium

Fission Neutrons

44090C ......... Activated Foil Irradiation, Cavity Fission Source

44100 S .........Special Tests of Neutron Sources and Dosimeters 
C. Dosimetry of X Rays, Gamma Rays, and Electrons

C.O Special Instructions for Using Electron and Photon Dosimetry Services

C.1 X-Ray and Gamma-Ray Measurements 46010C-46011C. . Radiation Detectors-Calibration/Correction Factor 46020C-46021C. . .Passive Dosimeters

46030S ......... Special Tests of High-Gain Electrometers-Charge Sensitivity

46040S ......... Special Tests of X-Ray Penetrameters, Ardran-Crookes-Type

46050S ......... Special Tests of X-Ray and Gamma-Ray Measuring Instruments

C.2 Gamma-Ray and Beta-Particle Sources 47010C ......... Gamma-Ray Sources

47030C ..........Beta-Particle Sources Calibrated for Surface

Dose Rate

47040S ......... Special Tests of Gamma-Ray and

Beta-Particle Sources

C.3 Dosimetry of High-Energy Electron Beams

48010 C . . . . . . . Irradiation of Ferrous-Ferric Dosimeters

48020S ......... Special Tests of Electron-Beam Dosimeters

D. Dosimetry for High-Dose Applications

49010S ......... Special Tests of Customer-Supplied Dosimeters

Irradiated with ${ }^{60} \mathrm{Co}$ Gamma Rays

49020S-49030S ... Dose Interpretation of NBS-Packaged Dosimeters

Irradiated by Customer

49040S-49041S . . .Special Tests of Dosimeters By Reading with Spectrophotometer

49050S . . . . . . . Special Measurement Services for Dosimeter Response

\section{Chapter 7-}

\section{Electromagnetic Measurements}

A. Resistance Measurements

A.1 DC Resistance Standards and Measurements

51100S ......... Special Resistance Measurement Services by

Prearrangement

51110M..........Measurement Assurance Program Services for Resistance

51130C .........Standard Resistor, Thomas-Type, $1 \Omega$

51131C .........Standard Resistor, Evanohm Wirewound

High-Precision, $10 \mathrm{k} \Omega$

51132C-51138C. . Standard Resistors, Four-Terminal, 0.0001-100 $\Omega$

51139C-51154C. . Standard Resistors, $1 \mathrm{k} \Omega-1 \mathrm{~T} \Omega$

51160C-51163C. . .Standard Resistors, for Current Measurements

(Shunts) 
A.2 High-Voltage Standard Resistors

$51210 \mathrm{C} \ldots \ldots \ldots$.......High Voltage Standard Resistors

A.3 High-Frequency Standard Resistors

51310C ..........High-Frequency Standard Resistors,

Two-Terminal

A.4 Special Tests of AC Resistors

51410S ..........Special Tests of AC Resistors, by Prearrangement

B. Impedance Measurements

B.1 Low-Frequency Capacitance and Inductance Measurements and Standards

52110 S ......... Special LF Impedance Measurements by Prearrangement

52130C . . . . . . . Standard Fixed, Fused Silica, Dielectric Capacitor

52140C ..........Fixed Three-Terminal Standard Capacitors with Coaxial Connectors, High-Accuracy

52150C . ......... Physical Tests to Qualify Three-Terminal Air Capacitors for Measurement

52160C ..........Fixed Three-Terminal Standard Capacitors with Coaxial Connectors

$52170 \mathrm{C} \ldots . . . \ldots$. Two- or Three-Terminal Solid Dielectric Standard Capacitors

$52180 \mathrm{C} \ldots \ldots \ldots$. . . Fixed Inductors, Self or Mutual

B.2 High-Frequency Standard Capacitors and Inductors

52210C-52211C. . Two-Terminal, Low-Loss, Standard Capacitors

52220C-52221C. . . Three-Terminal, Low-Loss, Standard Capacitors

52222C-52223C. . . Three-Terminal (MacLeod and Hanopol) Capacitors

52310 S .........Two-Terminal, High-Q Standard Inductors

B.3 Power Frequency Capacitors

$52400 \mathrm{C}$..........Power-Frequency Capacitors

B.4 Eddy-Current Conductivity

52610C .........Eddy-Current Conductivity Standards, $15-100 \%$

IACS

B.5 Q Standards

52710C-52711C...Inductive Q-Standards

C. Voltage Measurements

C.1 DC Voltage Measurements and Standards

53110 S ..........Special DC Voltage Measurements, by Prearrangement

53120M..........Measurement Assurance Program for DC Voltage

53130C .......... Saturated Standard Cells

53140C ..........Pt. Resistance Thermometer Temp. Determination for Standard Cell Calibration 
$53150 \mathrm{C} \ldots . . . .$. . Unsaturated Standard Cells

$53160 \mathrm{C}$...........Tests of Solid-State Voltage Reference Standards

C.2 Low-Frequency AC Voltmeters and Sources

53200 S ......... Special Tests of Low-Frequency AC Voltmeters and Sources, by Prearrangement

C.3 AC-DC Thermal Voltage and Current Converters (to $1 \mathrm{MHz}$ )

53310 S .........Special AC-DC Measurement Services, by Prearrangement

53340C-53343C. . AC-DC Thermal Voltage and Current Converters

C.4 RF-DC Thermal Voltage and Current Converters (100 Hz-1 GHz)

53405S ......... Special Tests of AC Thermal Current and Voltage Converters, by Prearrangement

53410C-53415C. . Low-Frequency TVC Calibrations

53420C-53421C. . .High-Frequency TVC Calibrations

53430S-53431S ...Peak-tc-Peak Detector Calibrations

53440C-53445S ... .RF Micropotentiometer Calibrations

C.5 Data Converters

53500S ......... Special Data Converter Services by Prearrangement

53510C .........A/D or D/A Converters, Linearity Errors, 10-Bit Correction Coefficients, and Superposition Errors

53520C .........A/D or D/A Converters, Differential Linearity Errors

53530C .........A/D Converter, Equivalent RMS Input Noise

53540 S ..........A/D or D/A Converters, Offset and Gain Errors Relative to Legal Volt

D. Precision Ratio Measurements

D. 1 Inductive Dividers

54110 S .......... Special Ratio Measurements and Tests of Inductive

Voltage Dividers, by Prearrangement

54120C-54131C. . Inductive Voltage Dividers

D.2 Resistive Dividers

54210C .........Resistor and Resistive Dividers, Total Resistance or Voltage Ratio

D.3 Capacitive Dividers

54310 S ......... Capacitive Dividers

D.4 Mixed Dividers

54410S .........Pulse-Voltage-Measuring Systems Including Kerr Cells

54420 S ..........X-Ray Unit, Voltage Dividers

D.5 Voltage and Current Transformers

54510C $-54513 \mathrm{C} . . .$. Voltage Transformers, Ratio and Phase Angle 54520C-54522C..... Current Transformers, Ratio and Phase Angle

54600 S ............. Special Tests of Dividers and Transformers, by Prearrangement 
E. Phase Angle Measurements

E. 1 Phase Angle Meters

55110 S ......... Special Tests of Phase Angle Meters, by Prearrangement

E.2 Very-High-Frequency Omnidirectional Range (VOR) Measurements

$55210 \mathrm{C}-55211 \mathrm{C} .$. . VOR Bearing-Angle Indicators

55220C-55221C. . VOR Generators

$55230 \mathrm{~S} \ldots \ldots$.......Special VOR Tests

F. Power and Energy Measurements, Low Frequency

56110 S ......... Special Tests of AC-DC Wattmeters by

Prearrangement

$56120 \mathrm{C} \ldots \ldots$....Wattmeter Calibrations at Power Frequencies

56200C-56203C. . .Watthour Meters, Determination of Percentage

Registration at $60 \mathrm{~Hz}$

56210M..........Measurement Assurance Program for Watthour

Meters

G. RF and Microwave Measurements

G.1 Power Meters, RF and Microwave

61110S-61128S . . . Coaxial Power Meters, Combinations of Calibration

Factor, Effective Efficiency

Factor, and Reflection Coefficient

at Specified Frequencies in Range $0.1 \mathrm{MHz}$

to $18 \mathrm{GHz}$

61130S-61155S . . Rectangular-Waveguide Power Meters,

Combinations of Effective Efficiency,

Efficiency Factor and Reflection Coefficient

within Specified Frequency Bands Covering 2.6-96 GHz

61160S ..........Measurement of Output of Power Reference in TE Power Meters

61190S .........Special Microwave and RF Power Measurement

Services by Prearrangement

G.2 Attenuators, $R F$ and Microwave

61210C .........Coaxial Fixed and Variable Attenuators, Measured by ANA, 0.1 to $18 \mathrm{GHz}$

61211C .........Coaxial Fixed and Variable Attenuators, Measured at $30 \mathrm{MHz}$

61215C ........Waveguide Circular (Below Cutoff) Piston Attenuator, Coaxial Connector, Measured at $30 \mathrm{MHz}$

$61220 \mathrm{~S}$......... Special Attenuation Measurements in Range $30 \mathrm{kHz}$ to $10 \mathrm{MHz}, \mathrm{GR} 874$ Connectors

61230C ........ Variable Rectangular Waveguide Attenuators, Attenuation Difference, WR28-WR284 Waveguide Bands

61240S ......... Special Attenuation Measurements of Three-Port and Two-Port Devices at $1.25 \mathrm{MHz}$

61250S .........Special Attenuation Measurements by

Prearrangement 
G.3 Coaxial and Waveguide Terminations, Reflection Coefficient

61310C ......... Complex Reflection Coefficient, Impedance, and Voltage Standing Wave Ratio of Coaxial Terminations by ANA, 0.1 to $18 \mathrm{GHz}$

61320C .........Magnitude of Reflection Coefficient of Rectangular Waveguide Reflectors (Mismatches) with Standard Flange Connectors at Frequencies within WR15-WR284 Waveguide Bands

61330C-61331S . . Magnitude of Reflection Coefficient of Non-Reflecting Waveguide Ports and Matched Loads at Frequencies within WR15-WR284 Waveguide Bands

G.4 Phase Shifters, RF and Microwave

61410C .........Coaxial Fixed and Variable Phase Shifters: Char icteristic Phase Shift Difference; Precision Connectors; Measured at $30 \mathrm{MHz}$

61411C ........ Coaxial Fixed and Variable Phase Shifters: Characteristic Phase Shift Difference; Precision Connectors; Measured by ANA over $1-18 \mathrm{GHz}$, Range $0-360^{\circ}$

$61420 \mathrm{C}$.........Variable Rectangular Waveguide Phase Shifters: Phase Shift Difference at Frequencies within WR62-WR284 Waveguide Bands

61450S ......... Special Tests of Phase Shifters, by Prearrangement

G.5 N-Port Scattering Measurements

61520 S ......... Linear, Reciprocal 2-Port Devices, 2-18 GHz

H. Noise Temperature Measurements

62020S ........ Special Noise Temperature Measurements

(Electromagnetic), by Prearrangement

62100S-62111S ... Noise Temperature of Coaxial Noise

Generators, Type N Precision or $14 \mathrm{~mm}$

Connectors, at $30 \mathrm{MHz}$ or $60 \mathrm{MHz}$

62120S-62121S ... Noise Temperature of Rectangular Waveguide

Noise Sources at Specified Frequencies within

WR62 and WR90 Waveguide Bands

62130S .......... Noise Temperature of WR10 and WR15

Waveguide Noise Generators

62140 S ......... Special Services for Earth Terminals Used in

Satellite Communications

I. Electromagnetic Field-Strength and Antenna Measurements

I.1 Microwave Antenna Parameter Measurements

63100S .........Gain and Polarization of Standard Antennas Using Extrapolation Range

63200S ........Pattern, Gain, and Polarization of Arbitrary

Antennas Using Near-Field Scanning Techniques

63300S ......... Special Test Service for Calibration of Probes

Used with Near-Field Scanning Techniques

63400 S ......... Special Consulting, Advisory, and Other Services 
I.2 Electromagnetic Field-Strength Parameter Measurements

64100S ......... Special Test Services for Antennas/Field Strength

Measurements, Using Transverse Electro-

magnetic Cell Method

64200S ........ Special Test Service for Antennas/Field Strength

Measurements, Utilizing the Open Field

Method

64300S ......... Special Test Service for Antennas/Field-

Strength/Reflectivity Measurements, Utilizing

the Anechoic-Chamber Method

64400S ......... Special Test Services for Electromagnetic

Interference

J. Pulse Waveform Measurements

65100S ......... Impulse Generator Spectrum Amplitude (50 Ohm)

65200S .........Fast Repetitive Baseband Pulse Parameters

(50 Ohm)

65300S-63301S . . Network Impulse Response of Coaxial Networks, $10 \mathrm{MHz}$ to $10.0 \mathrm{GHz}$

65400 S .........Pulse Time Delay Through Coaxial Transmission Lines

\section{Chapter 8-}

\section{Time and Frequency Measurements}

A. Time and Frequency Dissemination

76100S ..........Special Frequency Measurement Service

76110 S ......... Special Global Time Service

B. Oscillator Characterization

77100C ..........Precision Oscillator Frequency Calibration

$77110 \mathrm{C}$.......... Characterization of Atomic Time and Frequency

Standards

77120C-77130C...Characterization of Precision Oscillators: Time

and Frequency Domain

77140 S .........Special Time/Frequency Measurements

\section{Addendum-Numerical Cross-Index}

(Old vs. New Test Numbers) 


\title{
Chapter
}

\author{
A Introduction \\ $B$ Questions and Inquiries \\ $C$ Fees \\ $D$ Types of Services \\ E Criteria \\ $F$ Reports of Test Results \\ $G$ References to NBS in Advertisements \\ $H$ Traceability \\ I Disclaimer \\ $J$ Ordering and Scheduling \\ $K$ Purchase Order \\ $L$ Shipping \\ $M$ Special Instructions for Foreign \\ Customers
}




\section{Introduction}

The physical measurement services of the National Bureau of Standards are designed to help the makers and users of precision instruments achieve the highest possible levels of measurement quality and productivity. The hundreds of individual services you will find listed and described in this Users Guide constitute the highestorder calibration services available in the United States. They directly link a customer's precision equipment or transfer standards to national measurement standards. These services are offered to public and private organizations and individuals alike.

\section{Q. Questions and Inquiries}

This Users Guide is designed to make the task of selecting and ordering an appropriate calibration service as quick and easy as possible. Nevertheless, questions will arise. When they do, we urge you to call or write for immediate clarification. Address general questions and lengthy inquiries to:

Ernest Garner, Chief

Office of Physical Measurement

Services

National Bureau of Standards

Physics Building B362

Gaithersburg, MD 20899

(301) 921-2805.

If you have a technical question concerning a specific service, contact directly one of the NBS staff members responsible for that calibration area. Consult the section of this guide that describes the service in question for names and addresses.

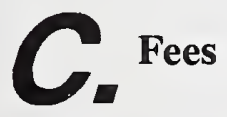

NBS recovers the cost of providing calibration services by charging a fee for each calibration performed. These fees range from a low of less than $\$ 100$ for calibration of a laboratory thermometer to $\$ 50,000$ or more for special tests of large microwave antenna systems.

PLEASE NOTE: The costs of services are not stated in this Users Guide. Instead, they are listed in a separate Fee Schedule, which is updated twice yearly to reflect changes in prices and services. Request a free copy of the current Fee Schedule by writing or calling the Office of Physical Measurement Services (see above address) or the

Program Information Office National Bureau of Standards Boulder, CO 80303

(303) 497-3239.

\section{Types of Services}

You will find three types of physical measurement services described in this guide: Calibration Services, Special Tests, and Measurement Assurance Programs.

Calibrations and Special Tests generally designate those NBS services that check, adjust, or characterize particular instruments, devices, and sets of standards on a one-time-perrequest basis. The customer, in most cases, ships an item requiring calibration to the appropriate NBS laboratory in Gaithersburg, MD, or Boulder, $\mathrm{CO}$, as noted in this Users Guide and in the separate Fee Schedule. The calibrated item is shipped back to the customer, followed, under separate cover, by a report of test procedures and results.

Measurement Assurance Programs, or MAPs, are quality control programs for calibrating a customer's entire measurement system. In a typical MAP, a stable artifact or set of artifacts-called transfer standardsare first measured by NBS and sent to 
a customer's laboratory for a series of measurements. The transfer standards are then returned to NBS for remeasurement, along with the participating laboratory's results. The Bureau reports its comparative findings to the customer and, when necessary, offers guidance on how to achieve and maintain measurement quality.

Successful use of an NBS MAP requires that the customer make periodic measurements of in-house check standards to estimate the random error and to ensure that the measurement process remains in a state of statistical control. Unless a laboratory has a measurement quality control program to continously monitor its own measurement process parameters, there is little point in participating in a MAP.

PLEASE NOTE: NBS does not audit, regulate, or accredit metrology laboratories as part of the MAP service. Whatever steps a participating laboratory may take to improve its measurement process are undertaken voluntarily.

\section{Criteria}

All the measurement services described in this guide meet rigorous criteria for quality assurance. Calibration Services and MAPs satisfy the most demanding and explicit requirements in that these services are carried out regularly under pre-established and well-defined conditions; the measurement processes involved are well-characterized, stable, and statistically controlled; and quality-control procedures are welldefined and strictly followed. Furthermore, each Calibration Service or MAP is planned and documented to permit continuity of service over time. A Special Test is so designated for one or more of the following rea- sons: 1) the specific type of calibration is seldom requested, thus precluding the maintenance of a reliable statistical base for controlling the measurement process, 2) the test requested is unique, or 3 ) the service is still under development-meaning the measurement or calibration methods are still being perfected or all the quality-control documentation has yet to be completed.

\section{- Reports of Test Results}

Reports on calibrations or other services are regarded as the property of the customer. Copies are not supplied to other parties except as required by federal law or requested in writing by the customer. The results of calibrations and tests performed by NBS apply only to a particular instrument or standard at the time of test unless otherwise clearly stated.

\section{(7) References to NBS in Advertisements}

NBS test results or reports shall not be used to indicate or imply that the National Bureau of Standards approves, recommends, or endorses the manufacturer, supplier, or user of any instruments or standards or that NBS in any way guarantees or predicts the future performance of items after calibration or test. No reference shall be made to NBS or to reports or results furnished by NBS in any advertising or sales promotions which would indicate or imply that NBS approves, recommends, or endorses any proprietary product or proprietary material.

\section{Traceability}

Traceability is a term often used to designate a relationship between field measurements or instruments and 
NBS measurements or national standards. NBS does not define, determine, regulate, or require traceability. Moreover, the Bureau is not legally required to comply with traceability requirements of other federal agencies; nor do we state what must be done to comply with another party's contract or regulation calling for such traceability. However, NBS can and does provide technical advice on how to make measurements consistent with national standards.

\section{Disclaimer}

Commercial products-materials and instruments-are identified in this document for the sole purpose of adequately describing experimental or test procedures. In no event does such identification imply recommendation or endorsement by the $\mathrm{Na}$ tional Bureau of Standards of a particular product; nor does it imply that a named material or instrument is necessarily the best available for the purpose it serves.

\section{Ordering and Scheduling}

Services are best arranged in advance, beginning with a call or letter from the customer to an NBS staff member directly responsible for the desired service. See the appropriate technical section of this Users Guide or the separate Fee Schedule to determine whom to call or write. This advance communication can clear up any questions you may have, clarify the policies and procedures briefly described here, and permit you to tentatively schedule a calibration date. Following the initial communication, you will immediately need to fill out and send in a purchase order and prepare and ship the item according to the procedures described below. If a calibration must be sched- uled far in advance, you may arrange to delay shipment of the item until shortly before the scheduled date; you must however, submit the purchase order-complete with the name and number of the desired servicebefore a firm calibration date can be assigned. When NBS receives your valid purchase order and assigns a firm service date, you will be notified by mail to confirm the order.

\section{PLEASE NOTE: Normal} turnaround time for NBS calibration services varies greatly-from one week to three months-depending on the type of service requested and fluctuations in workload. Query and schedule in advance to avoid unnecessary delays.

\section{P. Purchase Order}

Send a purchase order to the address listed in the appropriate technical section of this Users Guide, or in the separate Fee Schedule, before you ship an item for calibration. The purchase order must:

1) State both the name and number of the NBS service being requested. FAILURE TO INCLUDE THE ORDER NUMBER WILL SERIOUSLY IMPEDE SCHEDULING AND SERVICE.

2) Clearly identify the item(s) being sent for calibration, including any serial number.

3) Give the name, address, and telephone number of the requesting company's procurement officer.

4) Give the name, address, and telephone number of the requesting company's technical contact, if different from above.

5) List separately the instructions for return shipment, insurance, mailing of the test report, and billing. (Federal or state agency requests for calibration services should be accompanied by a document authorizing that the 
cost of the service be billed to the agency.)

6) Clearly state any special or necessary conditions of testsuch as operating frequency or temperature.

PLEASE NOTE: Receipt of orders by NBS does not imply acceptance of any provisions set forth in the order that are contrary to the policy, practice, or regulations of the National Bureau of Standards or the U.S. government. In general, NBS will not sign any affidavits, acknowledgement forms, or other documents that may be required by company policy governing the procurement of goods and services.

\section{$\triangle$ Shipping}

Ship an instrument or standard to the address to which you mailed your purchase order. Adhere rigorously to the following procedures:

1) Ship only items in good repair. Apparatus in disrepair will not be calibrated. If defects are found after calibration has begun, the procedure will be terminated, a report issued, and a charge levied for work completed.

2) Use strong, reusable packing materials and containers marked clearly and indelibly on the outside with the requestor's name and address and the following notation: REUSABLE CONTAINER, DO NOT DESTROY.

3) Follow any special shipping procedures given in the technical sections of this guide, in particular those sections covering radiation and dosimetry measurements.

4) Insure the shipments to and from NBS and clearly state the method of return shipment. NBS will not assume liability for loss or damage unless such loss and damage result solely from the negligence of NBS personnel. If return shipment by parcel post is requested or is suitable, NBS will prepay the return shipment but will not insure it. When no shipping or insurance instructions are furnished, NBS will return the shipment by common carrier, collect and uninsured.

PLEASE NOTE: Fees for NBS services do not include shipping costs.

\section{Special Instructions for Foreign Customers}

The National Bureau of Standards is authorized to provide measurement services, including calibrations, for organizations or individuals located outside the United States. NBS policy requires a thorough review of each request to determine if a comparable service is available in the requestor's country. Foreign customers must, therefore, provide the following information to the Office of Physical Measurement Services (see address under Section B):

1) If a national or official standards laboratory in the country of the requesting organization is available and provides identical or similar service to that requested from NBS, state why NBS should provide the service.

2) Provide a detailed description of the instrument or standard to be tested, particularly if it is not manufactured in the United States.

3) Provide a detailed description of the measurements that are needed or indicate the test order number as contained in this Users Guide or in the separate Fee Schedule.

4) Provide a description of any special requirements that might affect the decision to provide the service. For example, will there be a need for special ad- 
justments, or will the length of time in which the device is available for measurement be restricted?

If the request for the measurement service is accepted by NBS, the requesting organization will be notified of the cost of service and will be given the identification of the NBS laboratory that will perform the measurements. The requesting organization must then complete the following steps:

1) Contact the NBS technical unit that will provide the service to determine the schedule.

2) Send a purchase order to the Office of Physical Measurement Services. Complete addresses should be provided for returning the instrument and for mailing the calibration or test report. Send a check payable in U.S. dollars to the Office of Physical Measurement Services for the full cost of the service. The check must be drawn on a U.S. bank. NBS cannot begin the service until full payment has been received.
3) Ship the instrument or standard to the appropriate NBS technical unit. Air freight is most satisfactory. You must prearrange shipment with a customs broker for entry of the instrument into the United States with prepaid transportation from the port of entry. Entry bond is required for instruments not manufactured in the United States. If arrangements are made with a broker in the country of origin, that broker should, in turn, have a U.S. customs broker in or near the port of entry who will arrange for the entry of the instrument and its transportation to NBS. Direct arrangements can be made with customs brokers located in the Washington, DC/ Baltimore, Maryland metropolitan area or in the Denver, Colorado, area, as appropriate. These brokers can also arrange for transportation to the port of exit after NBS has completed the tests.

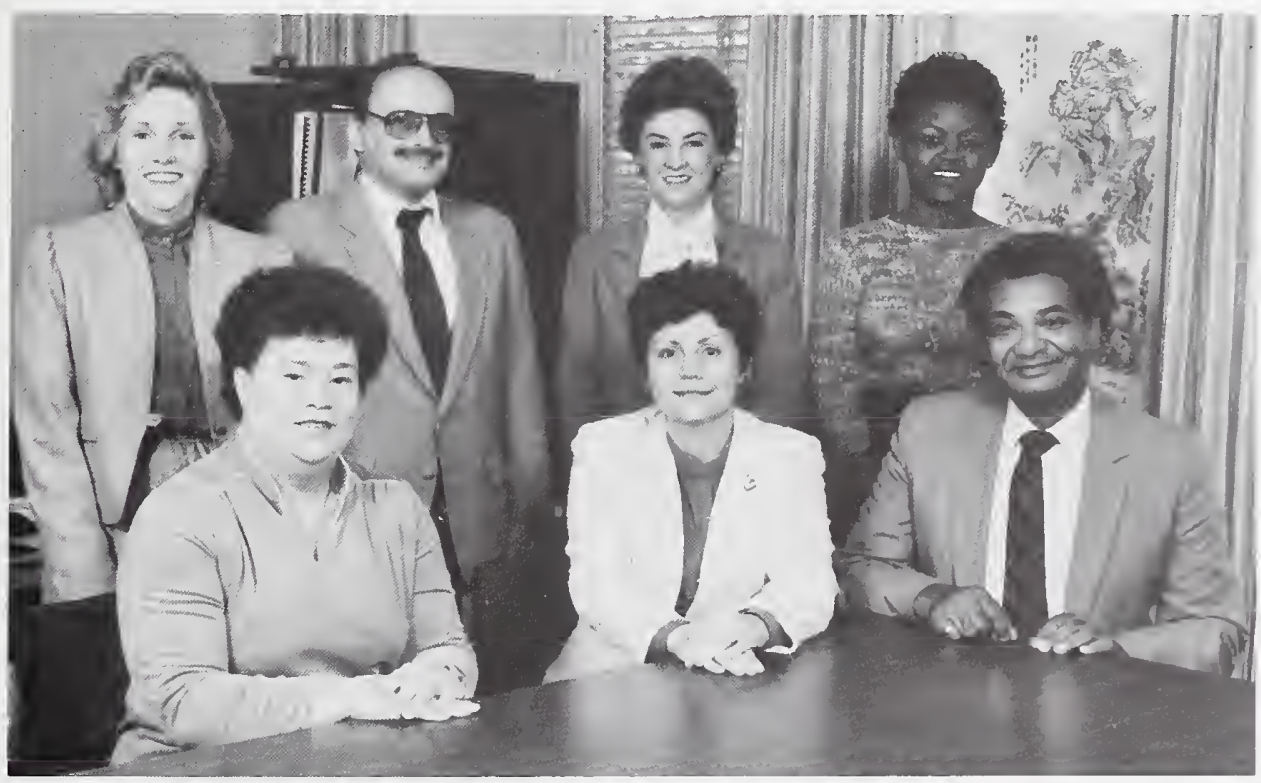

Members of the Measurement Services staff, clockwise from upper left: Joanne Marshall, computer assistant; George Uriano, director, Measurement Services; Treva Siedling, administrative officer; Vickie Weedon, calibration assistant; Ernest Garner, chief, Office of Physical Measurement Services; Verna Moore and Margaret Musick, secretaries. 


\title{
Chapter
}

\author{
A Length Measurements \\ $B$ Diameter Measurements \\ C Complex Dimensional Standards \\ D Optical Reference Planes \& \\ Roundness Standards \\ $E$ Angular Measurements \\ $F$ Surface Texture \\ $G$ Hydrometers \\ $H$ Volume and Density
}


Length Measurements

- Precision Engineering Division Center for Manufacturing Engineering

\section{Technical Contacts:}

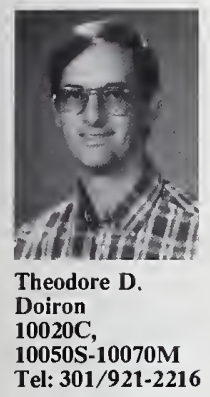

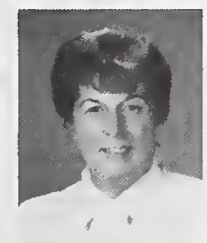

Grace Chaconas $10010 \mathrm{C}$

Tel: 301/921-2216

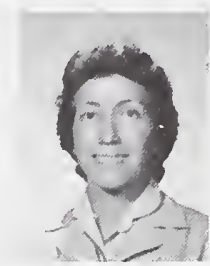

Linda Peake $10010 \mathrm{C}$

Tel: $301 / 921-2216$

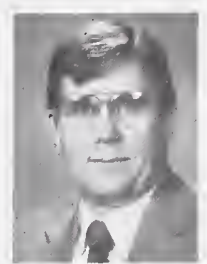

Ronald

Hartsock

10030C-10040C

Tel: 301/921-2216
Mailing Address: A107 Metrology, National Bureau of Standards, Gaithersburg, MD 20899

Test No. Items

\section{C Gage Blocks}

10020C Line Standards

10030C Surveying and Oil Gaging Tapes

10040S Special Tests of Surveying Leveling Rods

10050S Special Tests of Length Standards

10060S Special Tests of Sieves

10070M Measurement Assurance Program for Gage Blocks

Gage Blocks (10010C)

This calibration service provides for measurement of the length of gage blocks by either comparison to NBS master gage blocks or by direct interferometry. Generally, the length is transferred from known master blocks by a systematic intercomparison procedure using mechanical comparators. Comparators with laser scales are also available.

All gage blocks submitted for test should be in substantially new block condition and each block should be marked with an identification number. In shipping gage blocks, extreme care should be taken against both corrosion and damage by contact with other gage blocks. All defining steel surfaces should be greased and blocks padded with waxed paper or volatile rust inhibitor treated paper. A greased steel surface coming in contact with newspaper, wrapping paper (unwaxed), or excelsior is likely to corrode. Sets of gage blocks should have packing inside the case and the case should be bound shut, as the clasps frequently open or break during shipment.

Square or rectangular blocks or lengths up to 20 inches are routinely calibrated and the lengths reported in English or metric units. For blocks longer than 20 inches, the NBS technical contact should be consulted in advance to discuss alternative measurement techniques, approximate costs, and scheduling.

The measurement uncertainty reported is the sum of the random error in the measurement of the block under test and the estimated systematic error in the measurement process.

The process used to estimate this systematic error is documented in publications referenced in this catalog. Although the uncertainty varies slightly with each measurement, the variation is usually small. A reasonable estimate for the accuracy of the calibration is 2 microinches ( 0.05 micrometer) for blocks under 2 inches, and with accuracy decreasing with length to $20 \mathrm{mi}$ croinches for the 20-inch blocks.

\section{Line Standards $(10020 \mathrm{C})$}

Line standards of 1 meter or less are measured on an instrument called a line scale interferometer which is used to measure the distance between suitable lines on a flat surface. The instrument employs a fixed photoelectric microscope to determine the position of the scale lines, a linearly mobile carriage in the focal plane of the microscope to carry the scales, two interferometers (one commercial unit and one NBS-made Michelson) that can be used separately or in tandem to measure carriage displacement, and a temperature-controlled housing enclosing the whole apparatus.

The system is now highly automated using a laboratory micro- 
computer, NBS-developed optical processing, and servo electronics. With the microscope focused on the scale zero line, a servo moves the carriage until a null signal indicates the line is centered in the microscopic field. A stepping motor then drives the carriage until the next line on the scale is reached. Servoed line centering again takes place. The carriage is now moved precisely the distance between scale lines and the inter-

ferometer has now measured this distance in laser light wavelengths.

Proceeding down the scale in this manner results in the measurement of the line spacings.

The maximum length of line standards that can be measured is 1 meter, and the maximum width of any part of the piece being calibrated cannot exceed 150 millimeters. The accuracy of the calibration depends significantly on the shape and optical properties of the line, the background, and the geometric flatness of the artifact being calibrated. If the lines have straight edges, are 2 to 10 micrometers wide, there is good contrast between the line and the background, and the reference surface of the artifact is flat, then the accuracy of the calibration will be near optimum. Uncertainties as low as 0.006 micrometer have been achieved on short intervals and on 1-meter lengths uncertainties of 0.1 micrometer can be achieved. The current overall system accuracy is limited by imprecise knowledge of the refractive index of air.

\section{Surveying and Oil Gaging Tapes (10030C)}

The calibration of surveying tapes and oil gaging tapes is carried out in a laboratory that houses two permanent working standards, a laser interferometer and a 50-meter (200-foot) stainless steel bench. Measurements are performed for the most part using a laser system that is referenced

against a cube-corner rectroreflector attached to a microscope which is used manually for line location. The laboratory is maintained at $20^{\circ} \mathrm{C}$, but a control system can vary the chamber temperature from 15 to $40{ }^{\circ} \mathrm{C}$ for special tests. Calibration of tapes will normally be made with the tape under tension and supported on a horizontal-flat surface. Unless otherwise requested, the total length and each 15 -meter or 50-foot subinterval will be measured and reported. Each interval calibrated on a surveying tape will have computed lengths for two (single catenary), three, four, and five equidistant points of support.

The laser standard is capable of calibrating tapes with scribed graduations to an accuracy of 2 parts per million (ppm). Calibrations made with respect to the stainless steel tape bench are normally reported to an accuracy of $10 \mathrm{ppm}$. An NBS serial number will be engraved on each calibrated tape for identification.

Figure 1 summarizes the accuracy of length measurements at NBS. Included are the NBS 5-meter bar, gage

\section{Figure 1. Accuracy of Length Measurements at NBS}

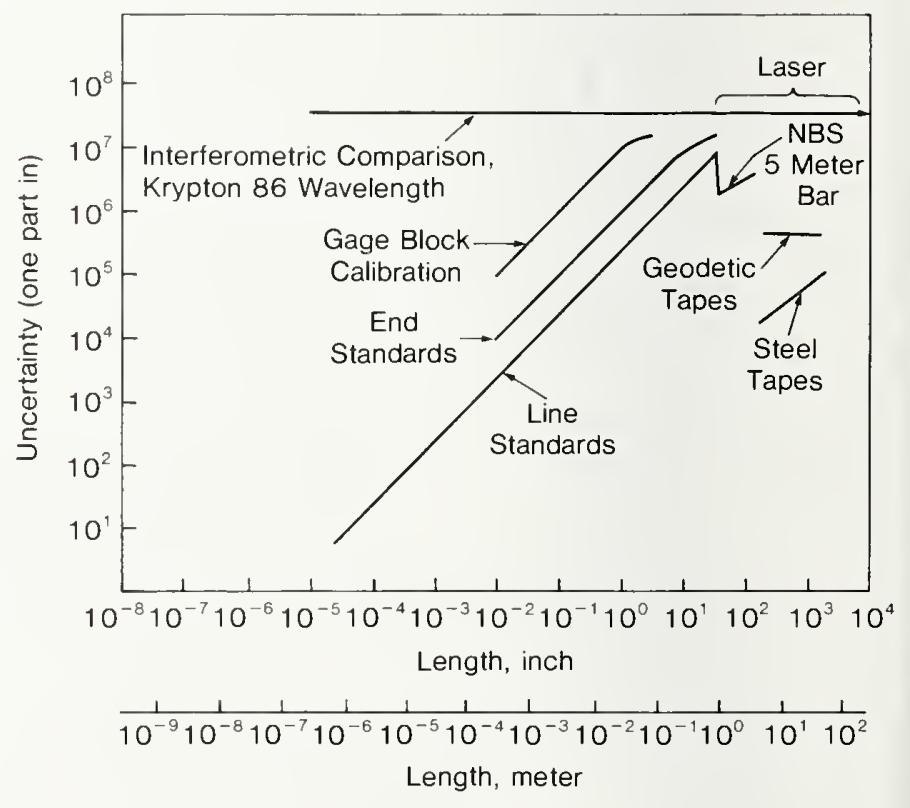


block calibrations, end line standards, and geodetic/steel tapes.

\section{Special Tests of Surveying Leveling Rods (10040S)}

Leveling rods are currently calibrated using two methods. One method involves the comparison of the rod to a 3-meter standard at the 1-, 2-, and 3-meter intervals. A second system provides measurement at multiple intervals and automatic report generation. This automated system incorporates a 7-meter one-dimensional measuring machine, a motorized carriage, a photoelectric microscope and a helium-neon laser interferometer interfaced to a minicomputer. Measurements can be made on virtually any type of linear scale or leveling rod with scribed, engraved, or painted graduations. The random error of measuring high quality leveling rods is plus or minus 6 micrometers for new rods and plus or minus 12 micrometers for used rods at the one standard deviation level. The systematic errors are largely unevaluated, and to account for their existence the total error being reported by NBS at present is plus or minus 50 micrometers for new rods. The length of intervals will be reported as measured at $20^{\circ} \mathrm{C}$ unless otherwise requested. The report can be supplied in either written or computer-readable form.

\section{Special Tests of Length Standards (10050S)}

Includes linear thermal expansion of gage blocks and line scales and radius of gage-block comparator stylus tips.

\section{Special Tests of Sieves (10060S)}

To determine conformity to ASTM E11 specifications.

Measurement Assurance Program for Gage Blocks (10070M)

The Measurement Assurance Program (MAP) for gage blocks is intended for laboratories that need to document, on a continuing basis, the measurement uncertainty of their gage block calibration process. Check standards, redundant measurements, and statistical analyses form the basis for monitoring the in-house calibration process. Offset from the defined unit of length is determined from the participant's measurements on transfer standards from NBS. Two eighty-eight piece sets of steel gage blocks, spanning the range from 0.100 to 4.0 inches, are available as transfer standards. Metric transfer standard sets are also a vailable. Detailed instructions for participating in the program under three different options are provided in NBS Monograph 163. The three options allow for varying degrees of rigor in operating a MAP, and the choice of option depends on a number of factors including: 1 . availability of master standards; 2 . availability of time to operate the program; 3. equipment; and 4. accuracy requirements. In principle, the participant can choose to operate the MAP using any of the three options, but only the second option is fully supported by NBS. The three options are briefly discussed below.

Option 1 is best suited for interferometric measurement processes. One master set of steel blocks and 10 steel check standard blocks are provided by the participant. The process is monitored through the inclusion of check standards in the calibration workload at roughly equal size intervals. Transfer standards of the same nominal size as the check standards are provided by NBS. The analysis of data is the responsibility of the participant.

Option 2 is intended for electromechanical comparators or interferometers used as comparators. Two 
master sets of steel gage blocks provided by the participant are required. Duplicate measurements are achieved by comparing each test block with each master block, and process control is maintained on the difference in observed length between master blocks of the same nominal size. Two sets of transfer standards are furnished by NBS, and complete data analysis along with a report of test is also furnished.

Option 3 is intended for electromechanical comparators. Two master sets of steel gage blocks provided by the participant are required. Option 3 is a more complicated procedure than Option 2 as it involves comparisons among two test blocks and two master blocks of the same nominal size. Process control is maintained on the difference in length between two master blocks of the same nominal size as calculated from the design. Control is also maintained on process variability as computed from each set of intercomparisons. Two sets of transfer standards are furnished by NBS. Data analysis is the responsibility of the participant.

The purpose of the MAP is to maintain a continuous check on the state of the calibration process thereby guaranteeing that measurements are properly related to the defined unit of length within the stated uncertainty. This process implies that the daily calibration procedure is identical to the MAP procedure. Because considerable time and effort may be required to implement a transition from single measurements to a MAP procedure and to establish the database for the program, the prospective participant is urged to weigh potential benefits of the program against the investment of time and effort before committing to it.

\section{References-Length Measurements}

Interferometric Measurement of Length Scales at the National Bureau of Standards, J. S. Beers and K. B. Lee, Prec. Eng., 4, No. 4, 205 (Oct. 1982).

Measurement Assurance for Gage Blocks, C. Croarkin, J. Beers, and C. Tucker, Natl. Bur. Stand. (U.S.), Monogr. 163 (Feb. 1979).

Contact Deformation of Gage Block Comparisons, J. S. Beers and J. E. Taylor, Natl. Bur. Stand. (U.S.), Tech. Note 962 (May 1978).

Intercomparison Procedures for Gage Blocks Using Electromechanical Comparators, J. S. Beers and C. D. Tucker, Natl. Bur. Stand. (U.S.), Int. Report, NBSIR 76-979 (Jan. 1976).

A Gage Block Measurement Process Using Single Wavelength Interferometry, J. S. Beers, Natl. Bur. Stand. (U.S.), Monogr. 152 (Dec. 1975).

Measurement Assurance Program-A Case Study: Length Measurements. Part 1. Long Gage Blocks ( 5 in to 20 in), P. E. Pontius, Natl. Bur. Stand. (U.S.), Mongr. 149 (Nov. 1975).

Preparations for Gage Block Comparison Measurements, C. D. Tucker, Natl. Bur. Stand. (U.S.), Int. Report, NBSIR 74-523 (July 1974).

Gage Block Flatness and Parallelism Measurement, J. S. Beers and C. D. Tucker, Natl. Bur. Stand. (U.S.), Int. Report, NBSIR 73-239 (Aug. 1973).

An Automatic Fringe Counting Interferometer for Use in the Calibration of Line Scales, H. D. Cook and L. A. Marzetta, J. Res. Natl. Bur. Stand. (U.S.), 65C, 129 (1961). 
Diameter Measurements

Precision Engineering Division Center for Manufacturing Engineering

Technical Contacts:
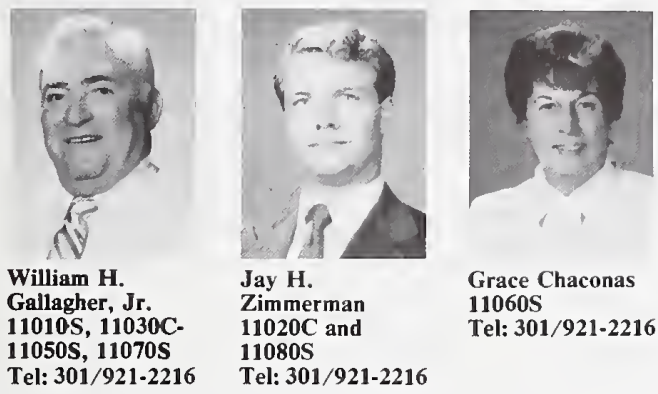

Grace Chaconas $11060 \mathrm{~S}$

Tel: 301/921-2216

Mailing Address: A107 Metrology, National Bureau of Standards, Gaithersburg, MD 20899

\begin{tabular}{|c|c|}
\hline it No. & Items \\
\hline $11010 \mathrm{~S}$ & $\begin{array}{l}\text { Special Tests for Plug Gages: External Diameter } \\
\text { Standards }\end{array}$ \\
\hline $11020 \mathrm{C}$ & Measuring Wires for Threads and Gears \\
\hline $11030 S$ & Spherical Diameter Standards: Balls \\
\hline $11040 \mathrm{~S}$ & $\begin{array}{l}\text { Special Tests for Internal Diameter Standards: Rin } \\
\text { Gages }\end{array}$ \\
\hline $11050 \mathrm{~S}$ & Special Tests of Length / Diameter \\
\hline $11060 S$ & Special Tests of End Standards \\
\hline $\begin{array}{l}11070 S \\
11080 S\end{array}$ & $\begin{array}{l}\text { Special Tests of Step Gages } \\
\text { Special Tests of Thread Measuring Wires }\end{array}$ \\
\hline
\end{tabular}

General Information

For controlling dimensions in the manufacture of all products, various types of dimensional gages are used. The variety of such gages measured includes cylindrical plug gages, ring gages, balls for diameter, and screw thread gages. The diameter standards and gages, with the exception of thread and gear measuring wires, are in general intended to be used as comparison masters.

Special Tests for Plug Gages: External Diameter Standards (11010S)

NBS will provide calibrations of external diameter standards by special arrangement. Please consult with the technical contact listed above.

Measuring Wires for Threads and Gears (11020C)

This service provides for measurement of the diameter of thread and gear measuring wires by intercomparison to NBS Master wires. The diameter is transferred from known Master wires using a systematized intercomparison sequence with a mechanical comparator.

All measuring wires submitted for test should be in substantially new condition, each wire should be appropriately bottled, and the bottle should be labeled with an identification number. In shipping thread wires, extreme care should be taken to prevent corrosion; all wires should be properly greased and their bottles rigidly contained inside an appropriate packing case.

Thread measuring wires for 60-degree and 29-degree threads are tested for compliance with the latest specifications in commercial use. These wires, which are supplied in 3 -wire sets, are calibrated and the pitch diameter correction factor is computed for the average diameter for three wires in the set. Gear measuring wires in the $1.92^{\prime \prime} / \mathrm{P}, 1.728^{\prime \prime} / \mathrm{P}$, $1.68^{\prime \prime} / \mathrm{P}$, and $1.44^{\prime \prime} / \mathrm{P}$ series supplied in sets of two wires are tested for compliance with the latest specifications in commercial use and the mean diameter reported. Accuracies are reported to a 3-sigma confidence level of 10 microinches for English wires and 0.25 micrometer for metric wires.

Special Tests for Spherical Diameter Standards: Balls (11030S)

Balls used in precision bearings and master balls used as transfer diameter 
standards are calibrated according to current commercial practice. The ball diameters reported are the undeformed sizes as calculated with the Hertz relations to maintain a consistency in reported sizes.

\section{Internal Diameter Standards: Ring Gages (11040S)}

NBS will provide calibrations of ring gages by special arrangement. Please consult with the technical contact listed above.

\section{Special Tests of Length and Diameter (11050S)}

NBS has a wide variety of state-ofthe-art metrology equipment and can provide services associated with dimensional quality control as special tests. A three-dimensional measuring machine is available for calibration of two- and three-dimensional ball plates, two-dimensional grid plates, and other artifacts of complex shape. The machine has a working volume of $48 \times 24 \times 12$ inches and can detect a length difference of 0.013 micrometer Reference to the international standard of length is through interferometers. Uncertainties in the calibrations are variable. Spherical diameter standards, such as balls used in precision bearings and master balls used as transfer diameter standards, are calibrated using a laser-based mechanical comparator.

\section{Special Tests of End Standards (11060S)}

Standards up to 20 feet in length, having spherical, flat or pointed ends can be measured; lengths are reported with a $2.5 \mathrm{lb}$. measuring force unless otherwise requested.

\section{Special Tests of Step Gages (11070S)}

Step gages having flat parallel faces can be measured in lengths up to one meter.

\section{Special Tests of Thread Measuring Wires (11080S)}

Wires for unusual thread sizes and for threads finer than 80 tpi are measured in a manner consistent with current commercial practice.

\section{References-Diameter Measurements}

Federal Standard H-28, Screw

Thread Standards for Federal Services. English and metric versions. These handbooks are available from the General Services Administration (GSA).

American National Standard B1.2, Amer. Natl. Stand. Inst., New York. Designs for the Calibration of Small Groups of Standards in the Presence of Instrumental Drift, J. M. Cameron and G. E. Hieles, Natl. Bur. Stand. (U.S.), Tech. Note 844 (Aug. 1974).

On the Measurement of Thread Measuring Wires, B. N. Norden, Natl.

Bur. Stand. (U.S.), Report 10987 (Jan. 1973).

Measurements of Cylindrical Standards, R. C. Veale, Natl. Bur. Stand. (U.S.), Int. Report, NBSIR 73-136 (1973).

On the Comparison of Cylinder in Contact with a Plane Surface, B. Norden, Natl. Bur. Stand. (U.S.), Int. Report, NBSIR 73-243 (1973). 


\section{Complex Dimensional Standards \\ Precision Engineering Division Center for Manufacturing Engineering}

Technical Contacts:
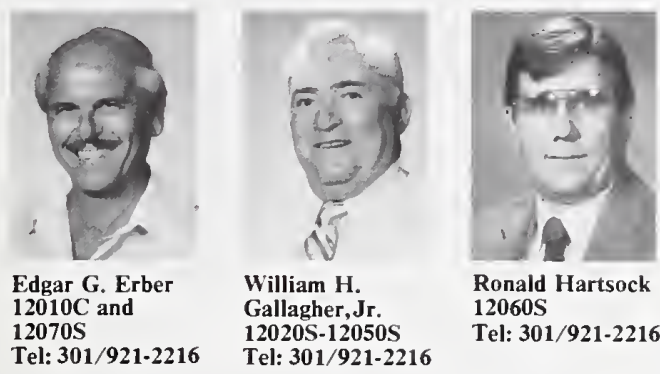

Ronald Hartsock $12060 \mathrm{~S}$

Tel: 301/921-2216
Mailing Address: A107 Metrology, National Bureau of Standards, Gaithersburg, MD 20899

\begin{tabular}{|c|c|}
\hline & ns \\
\hline $12010 \mathrm{C}$ & API Threaded Plug and Ring Gages \\
\hline $12020 \mathrm{~S}$ & Special Tests of Plain Conical Plug and Ring Gage \\
\hline $12030 \mathrm{~S}$ & Special Tests of Threaded Plug and Ring Gages \\
\hline $12040 \mathrm{~S}$ & Special Tests of Calipers and Gages \\
\hline $12050 \mathrm{~S}$ & $\begin{array}{l}\text { Special Tests of Micrometer Screws and Dial } \\
\text { Micrometers }\end{array}$ \\
\hline $12060 \mathrm{~S}$ & Special Tests of Penetration Needles \\
\hline $12070 \mathrm{~S}$ & Special Tests of Two-Dimensional Gages \\
\hline
\end{tabular}

\section{API Threaded Plug and Ring Gages (12010C)}

NBS provides calibration and certification services for API threaded plug and ring gages, casing, tubing and line pipe plug and ring gages as well as sucker rod gages. NBS is the custodian of the American Petroleum Institute (API) Grand Master rotary thread gages. These Grand Master gages are maintained and have been recalibrated at NBS for more than 40 years. They can be considered an international standard since all API Regional Master Gages throughout the world are referenced to NBS. Foreign product manufacturers can have their Reference Master Gages calibrated and certified by NBS or by one of the other national standard laboratories listed below:

National Physical Laboratory, Teddington, England

National Research Laboratory of
Metrology, Tokyo, Japan

National Standards Laboratory, Chippendale, N.S.W., Australia

Physikalisch Technische Bundesanstalt, Braunschweig, Germany

Laboratoire National d'Essais, Paris France

Instituto Nacional de Technologia Industrial, San Martin, Argentina

As required, the API lab is temperature-controlled at $20^{\circ} \mathrm{C}$. Parameters measured for plug gages are: length of plug, taper, pitch diameter, major diameter, thread lead, lead and following thread half-angles, and depth of thread, pitch line width, and radius of curvature.

Parameters measured for ring gages are: length of ring, taper, thread lead, minor diameter, lead and following thread half-angles, counter bore,

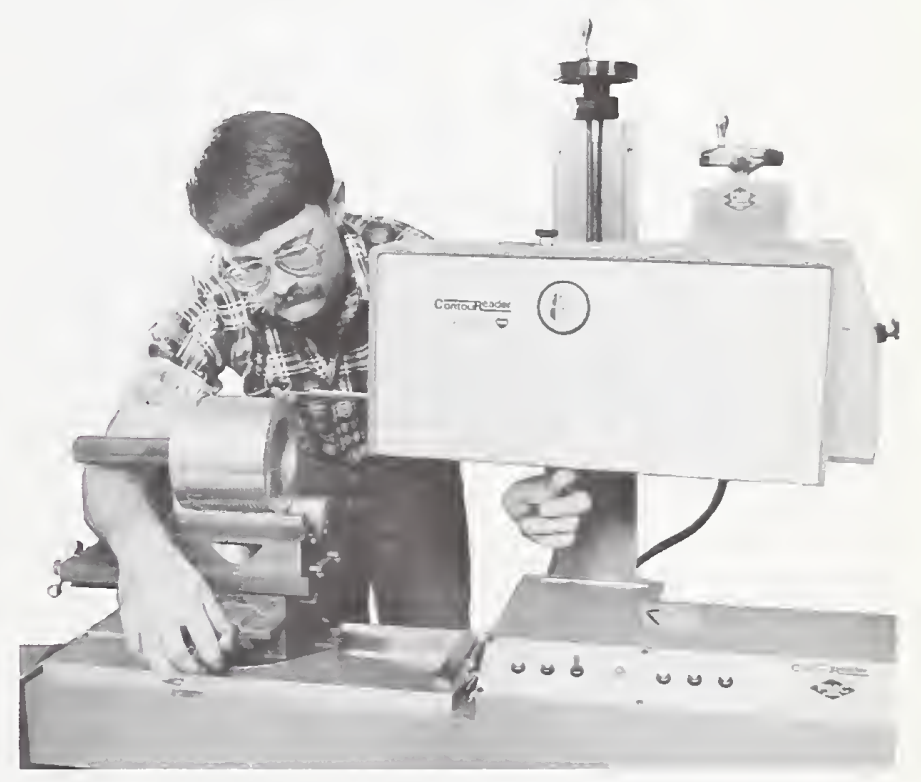

Brian Scace, calibrating American Petroleum Institute gage.

depth of thread, pitch line width, radius of curvature, and standoff.

These calibrations are based on a three standard deviation confidence level and are accurate to plus or minus 0.0003 inch.

All gages received must be marked with the API monogram and the API registration number. If not so marked 
the gages will be returned to the customer uncalibrated. Gages which meet the specifications will be marked as specified in the API Standards. All thread gages must be submitted in sets of plug and ring. The name of the gage owner should be given for inclusion in the Report of Calibration.

\section{Special Tests of Plain Conical Plug and Ring Gages (12020S)}

NBS will provide special tests of plain conical plug and ring gages by special arrangement. Please consult the technical contact listed above.

\section{Special Tests of Threaded Plug and} Ring Gages (12030S)

NBS will provide special tests of threaded plug and ring gages. Please consult the technical contact listed above.

\section{Special Tests of Calipers and Gages (12040S)}

Vernier calipers and similar gages can be accepted for test.

Special Tests of Micrometer Screws and Dial Micrometers (12050S)

Standard procedures using gage blocks for calibration of micrometers are available in many standard documents such as U.S. Standard GGG-C1056. If necessary, however, NBS can provide special tests on micrometer screws and dial micrometers on request.

\section{Special Tests of Penetration Needles (12060S)}

Needles and cones are tested for compliance with ASTM specifications. All devices must have individual identification numbers.

\section{Special Tests of Two-Dimensional Gages (12070S)}

NBS can provide special tests of twodimensional gages, ball plates or grid plates, with dimensions up to 24 inches by 24 inches. The accuracy of such calibrations depends substantially on the quality of the gage, but accuracies of one micrometer or better are obtainable.

\section{References-Complex Dimensional Standards}

On Characterizing Measuring Machine Geometry, R. J. Hocken and B. R. Borchardt, Natl. Bur. Stand. (U.S.), Int. Report, NBSIR 79-1752 (1979).

Three-Dimensional Metrology, R. Hocken, J. Simpson, et al., Annals of the CIRP, 26-1 (1977).

Unified Three-Dimensional Program-Two Useful NonContacting Probes, J. A. Simpson, Natl. Bur. Stand. (U.S.), Report 10597 (1971). 


\section{Optical Reference Planes \& Roundness Standards Precision Engineering Division Center for Manufacturing Engineering}

Technical Contact:

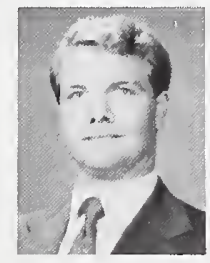

Jay $\mathbf{H}$.

Zimmerman

Tel: 301/921-2216

Mailing Address: A107 Metrology, National Bureau of Standards, Gaithersburg, MD 20899

\section{Test No. Items}

13010 S Special Tests of Optical Reference Planes (Flats)

13020S Special Tests of Roundness

13030S Special Tests of Roundness Calibration Specimens

\section{Special Tests of Optical Reference} Planes (13010S)

Optical reference planes are tested interferometrically, horizontally supported with test surface supported on three equally spaced pads located at 0.7 of the radius from the center. The measurement is performed along two marked diameters at $90^{\circ}$ to each other on each surface when each diameter is parallel to two of the support pads.

Roundness Calibration Specimens and Measurements; Special Tests of Roundness (13020S and 13030S)

The deviation from roundness at eight or more positions around nominally round standards is determined. The size of the calibration step or deviation from roundness on calibration standards is determined. The departure from roundness of components and gages is measured and the results are reported in graphical form.

NBS will provide special tests of roundness calibration specimens by request. Consult with technical contact listed above.

References-Optical Reference Planes The Calibration of an Optical Flat by Interferometric Comparison to a Master Optical Flat, C. P. Reeve, Natl. Bur. Stand. (U.S.), Int. Report, NBSIR 75-975 (Dec. 1975).

A Survey of the Stability of Optical Flats, C. P. Reeve and R. C. Veale, Natl. Bur. Stand. (U.S.), Int. Report, NBSIR 73-232 (June 1973). 
Angular Measurements Precision Engineering Division Center for Manufacturing Engineering

Technical Contact:

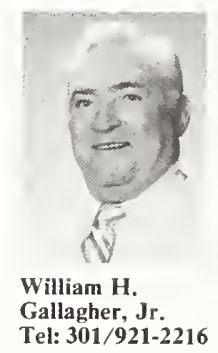

Mailing Address: A107 Metrology, National Bureau of Standards, Gaithersburg, MD 20899

\begin{tabular}{ll}
\hline Test No. & Items \\
\hline $14010 \mathrm{C}$ & Angle Gage Blocks \\
$14020 \mathrm{~S}$ & Special Tests of Optical Polygons \\
$14030 \mathrm{~S}$ & Special Tests of Rotary and Indexing Tables \\
$14040 \mathrm{~S}$ & Special Tests of Wedges \\
$14050 \mathrm{~S}$ & Special Tests of Autocollimators \\
$14060 \mathrm{~S}$ & Special Tests of Angle Generators
\end{tabular}

\section{Angle Gage Blocks (14010C)}

This service provides for the measurement of the angle of angle gage blocks by direct comparison to NBS master angle blocks using a dualautocollimator system. Current autocollimators have resolution to 0.01 arc-second and electronic readout. The blocks are enclosed in a special chamber during intercomparison to minimize air currents, and the laboratory is maintained at $20^{\circ} \mathrm{C}$ to within plus or minus 0.1 degree.

All angle gage blocks submitted for test should be in substantially new block condition and each block should be marked with an identification number. In shipping angle blocks the same care as is exercised in gage block shipment should be used, as the surfaces are subject to corrosion.

All standard sizes of angle blocks can be calibrated in the NBS facilities. Blocks with angles ranging from 1 arc-second to 45 degrees are routinely handled; however, optical squares and other standards can also be accommodated. Accuracy at the 3-sigma level is approximately 0.1 arc-second; this value, however, varies with the condition of the gaging surface on the standard.

\section{Special Tests of Optical Polygons (14020S)}

The calibration of polygons is done with autocollimation techniques. It consists of the determination of flatness of each face, variation of the angle between each face and the base 
(where possible the polygon will be adjusted for minimum variation), and the angle between faces. Figure 2 summarizes the precision of angle calibration for master angle gage blocks and polygons.

\section{Special Tests of Rotary and Indexing Tables (14030S)}

Instruments and tools used for the precise measurement of angle, such as precision angular rotary and indexing tables, autocollimating telescopes, or angle generating equipment, are calibrated at specific angular settings.

\section{Special Tests of Wedges (14040S)}

Solid angle calipers and step mirrors are calibrated by autocollimation or interferometric techniques as to the angle between faces. Wedges are calibrated by autocollimating or interferometric techniques at a specified wavelength for deviation angle. Mechanical angular references such as

Figure 2. Precision of Angle Calibrations for Master Angle Gage Blocks and Polygons

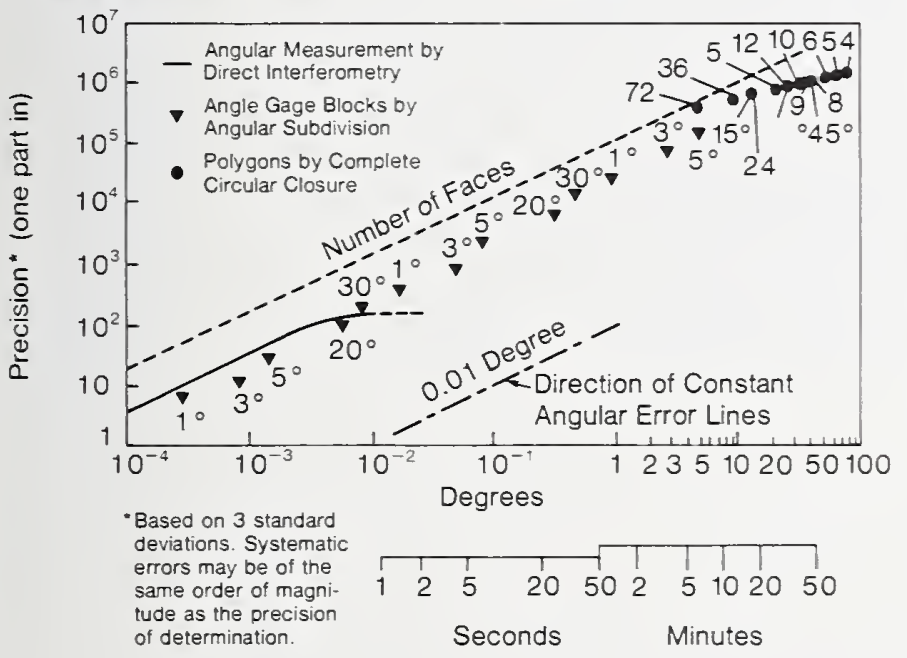

cylindrical squares and machinist's squares are usually calibrated by mechanical techniques.

Special Tests of Autocollimators (14050S)

Special tests of autocollimating telescopes may be made by special arrangement. Please consult the technical contact listed above.

\section{Special Tests of Angle Generators (14060S)}

Precision equipment, including transducers, are measured at specific angular settings.

\section{References-Angular Measurements}

The Calibration of Angle Blocks by Intercomparison, C. P. Reeve, Natl. Bur. Stand. (U.S.), Int. Report, NBSIR 80-1967 (1980).

The Calibration of Indexing Tables by Subdivision, C. P. Reeve, Natl. Bur. Stand. (U.S.), Int. Report, NBSIR 75-750 (July 1975).

A Survey of the Temporal Stability of Angle Blocks, R. C. Veale and C. P. Reeve, Natl. Bur. Stand. (U.S.), Int. Report, NBSIR 74-601 (Nov. 1974). 
Surface Texture

Precision Engineering Division Center for Manufacturing Engineering

\section{Technical Contacts:}
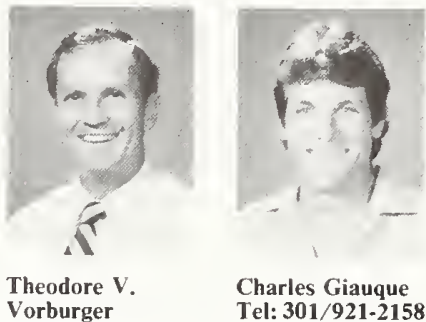

Vorburger

Tel: 301/921-2158

Mailing Address: A117 Metrology, National Bureau of Standards, Gaithersburg, MD 20899

\section{Test No. Items}

15010C Roughness Calibration Specimens

15020C Surface Roughness Comparison Specimens

$15030 \mathrm{C}$ Step Height Measurements

\section{Roughness (15010C-15030C)}

NBS provides measurement services in three categories: instrument calibration specimens (with regular geometric profiles); roughness comparison (and other types of roughness

specimens); and step height specimens.

The property of surface roughness in the $10 \mu \mathrm{m} \mathrm{R}_{\mathrm{a}}$ range and below and height up to $25 \mu \mathrm{m}$ are measured by means of a minicomputer/stylus instrument system. Using an interferometrically measured step, the system is calibrated at each value of magnification employed during a measurement.

In measurements of roughness, surface profiles are taken according to American National Standard B46.1-1978 using a $0.76 \mathrm{~mm}$ cutoff length, and a traversing length of 3.8 $\mathrm{mm}$. A number of other statistical parameters and functions may be calculated from the stored profile data including the rms roughness, average slope, average wavelength, skewness, amplitude density function, autocorrelation function, and power spectral density.

In step height measurements, a straight line is fitted by the method of least squares to each side of the profile of the step and the height is calculated from the position of these two lines.

The NBS calibration uncertainty for step height or $\mathbf{R}_{\mathrm{a}}$ depends on a number of factors, the most important being the step or $R_{a}$ value itself. The uncertainties range from approximately $0.3 \mu \mathrm{m}$ at a step height of 25 $\mu \mathrm{m}$ to $0.003 \mu \mathrm{m}$ at the smallest step 
heights. Comparable uncertainties are achieved for measurements of $R_{a}$.

\section{References-Surface Texture}

Sinusoidal Profile Precision Roughness Specimens, E. C. Teague, F. E. Scire and T. V. Vorburger, Wear, 83, 61 (1982).

Three-Dimensional Stylus Profilometry, E. C. Teague, F. E. Scire, S. M. Baker and S. W. Jensen, Wear, 83, 1 (1982).

FASTMENU: A set of FORTRAN Programs for Analyzing Surface Texture, T. V. Vorburger, Natl. Bur. Stand. (U.S.), Int. Report, NBSIR 83-2703 (July 1982).

Optical Techniques for On-Line Measurement of Surface Topography, T. V. Vorburger and E. C. Teague, Prec. Eng., 3, 611 (1981).

Uncertainties in Calibrating a Stylus Type Surface Texture Measuring Instrument With an Interferometrically Measured Step, E. C. Teague, Metrologia, 14, 39 (1979).

Measurements of Stylus Radii, T. V. Vorburger, E. C. Teague, F. E. Scire and F. W. Rasberry, Wear, 57, 39 (1979).

FAST Facility Available for Engineering Needs, T. V. Vorburger, E.
C. Teague and F. E. Scire, Dimensions/NBS, 62, 18 (1978).

Evaluation, Revision and Application of the NBS Stylus/Computer System for the Measurement of Surface Roughness, E. C. Teague, Nat1. Bur. Stand. (U.S.), Tech. Note 902 (Apr. 1976).

Surface Finish Measurements: An Overview, E. C. Teague, Soc. Manuf. Eng., Tech. Pap. IQ75-137, 1 (1975).

The Measurement and Characterization of Surface Finish, R. D. Young and E. C. Teague, Chapter 2 in Properties of Electrodeposits. Their Measurement and Significance, R. Sard, H. Leidheiser, and F. Ogburn, Eds., 22, Electrochem. Soc., Princeton, NJ (1975).

Precision Reference Specimens of Surface Roughness: Some Characteristics of the Cali-Block, R. D. Young and F. E. Scire, J. Res. Natl. Bur. Stand. (U.S.), 76C (Eng. and Instr.), Nos. 1 and 2, 21 (Jan.-June 1972). 


\section{Hydrometers}

Chemical Process Metrology Division Center for Chemical Engineering

Technical Contact:
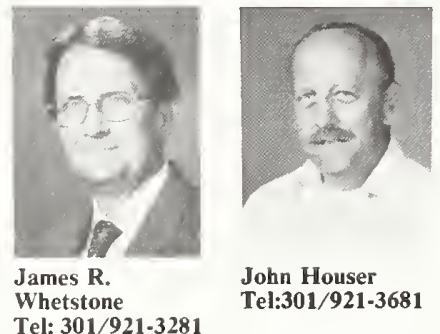

Mailing Address: B312 Physics, National Bureau of Standards, Gaithersburg, MD 20899

Test No. Items

16010C Reference Standard Hydrometers

\section{Reference Standard Hydrometers (16010C)}

Specific gravity hydrometers covering the range 0.62 to $3 \mathrm{~g} / \mathrm{cm}^{3}$ and proof spirit hydrometers in the range 0 to 200 proof, which are designed and used as reference standard hydrometers (used to test other hydrometers), normally are accepted for calibration. A limited number of other types of reference standard hydrometers will be accepted for multipoint calibration, subject to discussion. Instruments accepted must comply essentially with the requirements of NBS Circular 555, "Testing of Hydrometers."
Volume and Density

Chemical Process Metrology Division Center for Chemical Engineering

\author{
Technical Contact: \\ John Houser \\ Tel: 301/921-3681
}

Mailing Address: 105 Fluid Mechanics, National Bureau of Standards, Gaithersburg, MD 20899

Test No. Items

17010C Volume Standards

17020S Special Tests of Volume Standards

17030S Special Tests of Density: Solids

17040S Special Tests of Density: Liquids

\section{Volume Standards (17010C)}

The procedure used for testing glass volumetric apparatus is to weigh the amount of distilled water contained or delivered with reference to the graduations marked on the instrument, the volume being computed from the density of the water (for tables see NBS Circular 19). The quality of the markings and the care exercised in reading or setting the liquid level are major factors in test calibration and usage. Normally the Bu- 
reau will accept for calibration instruments that have volumes in the range $1 \mathrm{~mL}$ to $1 \mathrm{gal}$ and which conform essentially to requirements contained in NBS Circular 602, "Testing of Glass Volumetric Apparatus," Federal Procurement Specifications NNN-B00789 (Buret, straight, precision), NNN-F-00289a (Pipet, volumetric), NNN-P-0035a (Pipet measuring), or NNN-F-00289a (Flask, volumetric), if such instruments are to be used as reference or transfer standards.

The usual calibration procedure for metal volumetric apparatus consists of determining the value "to contain" or "to deliver" by either gravimetric means or by the use of transfer standards. Normally the Bureau will accept for calibration instruments that have values in the range 1 gill to 1500 gal, which comply essentially with the specifications contained in NBS Monograph 62, "Testing of Volumetric Standards," and which are free from dents, bumps, or scratches. While it is preferred that the zero index or the gage scale be adjusted and scaled prior to calibration, these operations can be incorporated into the calibration procedure if requested. Slicker plate type standards should be adjusted by the manufacturer.

\section{Special Tests of Volume Standards (17020S)}

Special tests may be made of volume standards by prearrangement with NBS.

\section{Special Tests of Density: Solids (17030S)}

NBS does not normally determine density of solids for customers. However, special arrangements can be made for customers to use the NBS solid density measurement equipment to make their own tests. The technical contact cited in this section should be consulted concerning special arrangements for use of NBS equipment.

\section{Special Tests of Density: Liquids (17040S)}

NBS will accept requests for density determinations of liquids if the need is critical. Limitations on the mass, physical, dimensions, or volume of the sample are available on request. At NBS, liquid densities usually are determined by gravimetric, or weighing methods. Other methods are available depending on the requirements.

\section{References-Volume and Density Measurements}

Reevaluation of the Densities of the Four NBS Silicon Crystal Standards, H. A. Bowman, R. M. Schoonover, and C. L. Carroll, Int. Report, NBSIR 75-768 (Aug. 1975).

The Utilization of Solid Objects as Reference Standards in Density Measurements, H. A. Bowman, R. M. Schoonover, and C. L. Carroll, Metrologia 10, 117 (1974).

A Density Scale Based on Solid Objects, H. A. Bowman, R. M. Schoonover, and C. L. Carroll, J. Res. Natl. Bur. Stand. (U.S.), 78A, No. 1, 13 (Jan.-Feb. 1974).

Calibration of Small Volumetric Laboratory Glassware, J. Lembeck, Natl. Bur. Stand. (U.S.), Int. Report, NBSIR 74-461 (Oct. 1974).

The Equivalence of Gravimetric and Volumetric Test Measure Calibration, R. M. Schoonover, Natl. Bur. Stand. (U.S.), Int. Report, NBSIR 74-454 (Feb. 1974).

Procedures for the Calibration of Volumetric Test Measures, J. F. Houser, Natl. Bur. Stand. (U.S.), Int. Report, NBSIR 73-287 (Aug. 1973). 


\title{
Chapter
}

\author{
A Flow Rate Measurements \\ $B$ Flow Measurements at Cryogenic \\ Temperatures \\ C Airspeed Measurements \\ $D$ Mass \\ E Force Measurements \\ $F$ Vibration Measurements \\ $G$ Acoustic Measurements \\ $H$ Ultrasonic Measurements
}




\section{Mechanical Measurements}

Flow Rate Measurements

Chemical Process Metrology Division Center for Chemical Engineering

Technical Contacts:
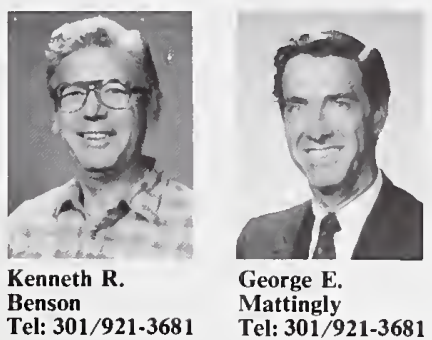

Mailing Address: 105 Fluid Mechanics, National Bureau of Standards, Gaithersburg, MD 20899

\section{Test No. Items}

18010C Single Turbine Meters

18020C Tandem Turbine Meters

18030C Flow Rate Meters (Direct Reading in

Flow Rate Units)

18040C Head Class Flow Measurement Devices

18050S Special Tests for Liquid and Gas Flow Rates

Flow Meters (18010C-18040C)

NBS provides calibration services for liquid flow meter systems which include a flow meter and pertinent adjacent tubing, auxiliary measurement instrumentation, and readout equipment.

Flow meter systems having demonstrated precision and temporal stability commensurate with the quality of the calibrations are accepted for calibration. Calibration tests usually include five different flow rates, although additional rates can be included on request. At each flow rate, five determinations of meter indication and flow rate are made; each flow rate is tested two times.

Meter systems submitted should have connections for $\mathrm{A} / \mathrm{N}$ flare fittings up to 2 -in $(5 \mathrm{~cm})$ nominal diameters, or with connections for $\mathrm{Na}$ tional Pipe Thread fittings up to 3 -in $(7.6 \mathrm{~cm})$ nominal diameter. Larger meters must terminate with ASA 150-lb steel flanges, or grooved-end steel pipe compatible with Victaulic couplings (for water meters), or with adapters thereto: For air, flanges must terminate with ASA $300-1 b$ steel flanges except for laminar element flowmeters operated near ambient pressure levels. Connections other than these should not be submitted unless special arrangements have been made in advance.

Meters must be submitted with connections for $\mathrm{A} / \mathrm{N}$ flange fittings up to 3 -in nominal diameters, or with connections for National Pipe Thread fittings up to 3 -in nominal diameter. For pipe sizes 4-in nominal diameter and larger, meters must terminate with ASA 150-steel flanges, or grooved-end steel pipe compatible with Victaulic couplings (for water meters), or with adapters thereto. Meters with connections other than these should not be submitted unless special arrangements have been made in advance.

Small Air Lab: Calibration of devices in this laboratory covers the air flow range up to approximately 100 standard cubic feet per minute (SCFM). The mass flow rate of gas passing through a metering device during its calibration is determined from PVT and transit time measurement of displaced volumes of gas. Two types of displacers are used, bell gasometers and mercury-sealed piston/cylinder provers. Determination of the displaced volume in either case is based on diameter and stroke measurement. Currently, these are done using fixed switching positions of optical or mechanical switch mechanisms for eight provers with volumes ranging from $200 \mathrm{~cm}^{3}$ to $20 \mathrm{ft}^{3}$. Measurements of pressure are done using manometers and barometers. Temperature measurements are made using contacting techniques, i.e., thermocouples, thermistors, etc.

Large Air Flow Facility: The large air flow facility consists of a compressor as the pressure source, a dryer, settling chamber, meter runs ( 2 to 8 inch pipe sizes), and a collection tank. 
Flow rates from 35 to 3000 SCFM are attainable at pressures up to 90 psig. Calibration measurements are based upon the use of a set of working standards which are flow nozzles operated under critical conditions, i.e., at sonic velocity in the throat of the nozzle. These provide an extremely stable flow which is not influenced by variations in downstream pressure and temperature conditions. Determination of the mass flow rate through these nozzles is based upon measured discharge coefficients. Measurement of the discharge coefficient for each nozzle over the range of throat Reynolds numbers used has been done in PVT experiments in which the gas flowing through the nozzle is diverted into the collection tank of the facility for a measured period of time. Once the gas has been collected, a PVT measurement is used to determine the mass of gas in the tank. This value of the mass of gas is used with the diversion time to com-

Figure 3. Uncertainty of NBS Measurements for Air Flow Rate Standards

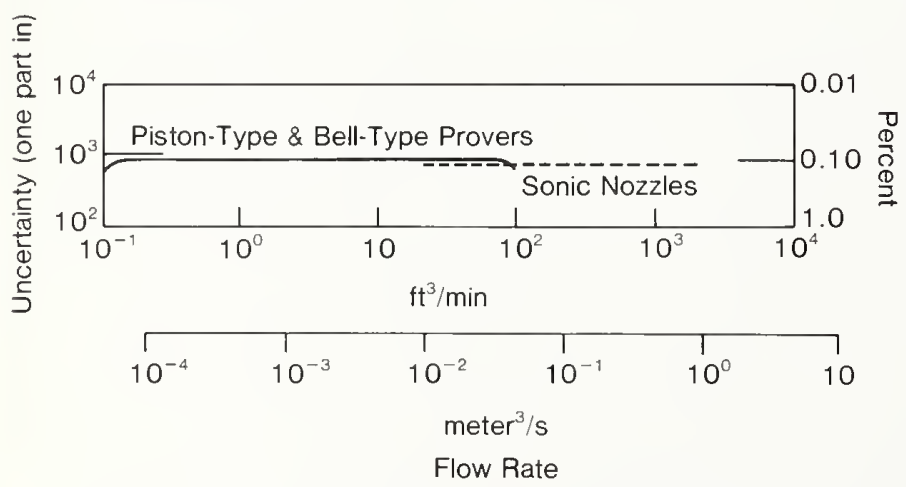

Figure 4. Uncertainty of NBS Measurements for Water Flow Rate Standards$$
\text { 드 }
$$

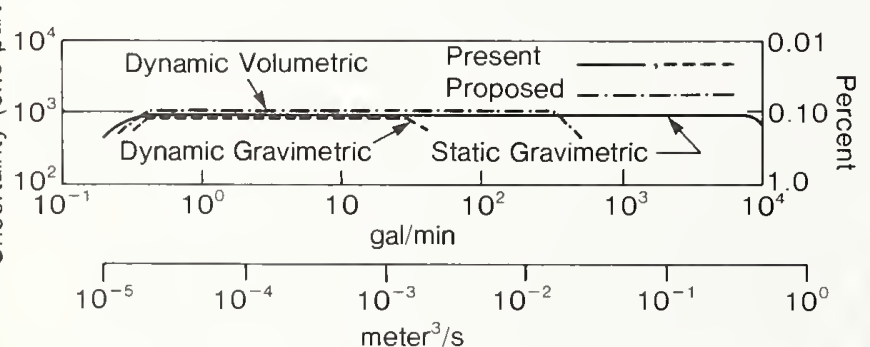

pute the average mass flow rate through the nozzle. Figure 3 summarizes the NBS measurement uncertainty for air flow rate standards.

Water Flow Facility: The water flow facility consists of reservoir, pumps, meter runs and weigh tanks necessary to make primary flow measurements. Pipeline sizes up to 16 inches in diameter are available. The system operates as a constant flow rate facility using bypass and meter-run control valves to control the pressure and flow rate in the system. Diversion into the weigh tanks is accomplished with pneumatically driven diverter valves fitted to each of the four weighing systems used. Figure 4 summarizes the NBS measurement uncertainty for water flow rate standards.

Hydrocarbon Flow Facility: This facility has the ability to handle a variety of hydrocarbon liquids. The majority of the calibration requests pertain to the use of a surrogate liquid for JP-4 and JP-5 jet fuels as the liquid used in the calibration. The flow rate range of this laboratory extends from 0.01 to approximately 200 gallons per minute. Several types of devices are calibrated, although turbine meters predominate. Figure 5

Figure 5. Uncertainty of NBS Measurements for Liquid Hydrocarbon Flow Rate Standards

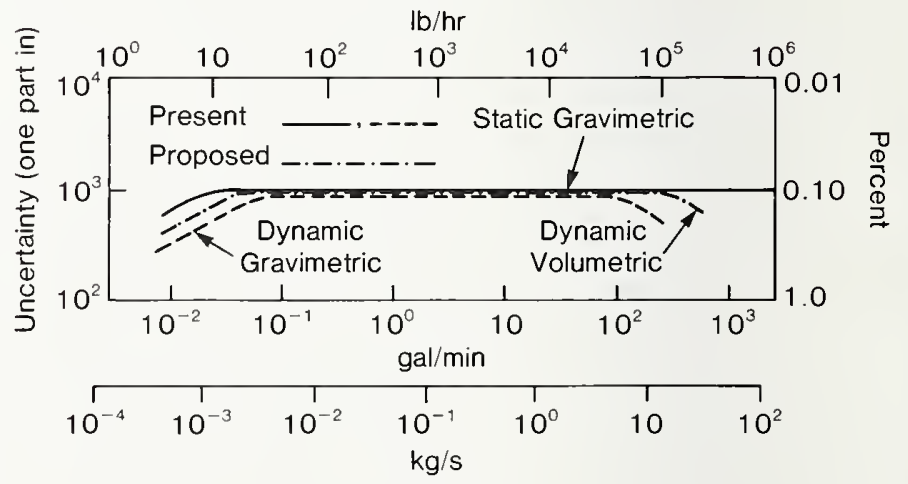

Flow Rate 
summarizes the NBS measurement uncertainty for liquid hydrocarbon flow rate standards.

\section{Special Tests for Liquid and Gas Flow Rates (18050S)}

Special tests for liquid and gas flow rates can be arranged. Examples can include "in-situ" calibration of flowmeter, proving other fluid measurement systems, etc. Details can be obtained and arrangements made through the technical contact listed at the beginning of this section.

\section{References-Flow Rate Measurements}

A Laboratory Study of Turbine Meter Uncertainty, G. E. Mattingly, P. E. Pontius, H. H. Allion, and E. F. Moore, Natl. Bur. Stand. (U.S.), Spec. Publ. 484 (Oct. 1977).

The National Measurement System for Fluid Flow, W. C. Haight, P. S. Klebanoff, F. W. Ruegg, and G. Kulin, Natl. Bur. Stand. (U.S.), Int. Report, NBSIR 75-930 (Aug. 1976).

Introduction to Liquid Flow Metering and Calibration of Liquid Flowmeters, L. O. Olsen, Natl. Bur. Stand. (U.S.), Tech. Note 831 (June 1974).

Flow Measurement: Procedures and Facilities at the National Bureau of Standards, F. W. Ruegg and M. R. Shafer, (Proc. Symp. Flow Measurement, San Francisco, CA, Jan. 19-22, 1970). Chapter in ASHRAE (Amer. Soc. Heat Refrig. Air-Cond.
Eng.), Bull. Flow Measurement Part 1, SF70-7, 1 (1972).

Gas Flow Measurement by Collection Time and Density in a Constant Volume, L. Olsen and G. Baumgarten, Symposium on Flow, Its Measurement and Control in Science and Industry, ISA, 1, Part 3, 1287 (1972).

Evaluation of a Low Flow Generator and Calibrator as a Flow Measurement Standard, G. Baumgarten, Natl. Bur. Stand. (U.S.), Tech. Report 10921 (1972).

Practical Considerations for Gas Flow Measurement, M. R. Schafer, Jr. and D. W. Baker, Proc. 3rd Annual Prec. Meas. Assoc. Metrology Conf., Natl. Bur. Stand., Gaithersburg, MD, June 17-18, 1970, 1, 187 Prec. Meas. Assoc., Burbank, CA (1970).

Flow Measurement Engineering Handbook, R. W. Miller, McGraw Hill, New York (Jan. 1983).

Fundamentals of Flow Measurements, J. P. DeCarlo, Instr. Soc. of America, Research Triangle Park, NC (1984). Liquid-Flowmeter Calibration Techniques, M. R. Shafer and F.W. Ruegg, ASME Paper No. 57-A-70. Performance Characteristics of Turbine Flowmeters, M. R. Shafer, ASME Paper No. 61-WA-25. 
Flow Measurements at Cryogenic Temperature

Chemical Engineering Science Division Center for Chemical Engineering

Technical Contact:

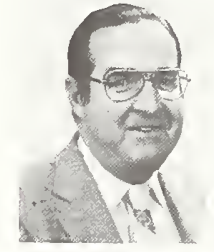

James A. Brennan

Tel: 303/497-3611

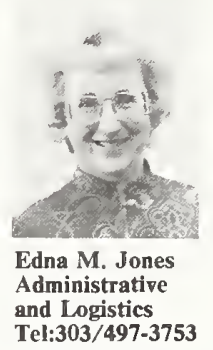

Mailing Address: MC 773.20, National Bureau of Standards, 325 Broadway, Boulder, CO 80303

Test No. Items

18800S Special Tests of Cryogenic Liquid Flow

Special Tests of Cryogenic Liquid Flow (18800S)

Limited measurement services are provided for cryogenic liquid flow. Mass flow measurements are performed using liquid nitrogen flow rates of 76 to 757 liters per minute.

References-Flow Measurements at Cryogenic Temperature

Cryogenic Fluids Density Reference System: Provisional Accuracy Statement (1980), J. D. Siegwarth and J. K. LaBrecque, Natl. Bur. Stand. (U.S.), Tech. Note 1041 (Apr. 1981). LNG Materials and Fluids-A User's
Manual of Property Data in Graphic Format, 1st Edition, D. B. Mann, Ed.; Suppl. 1, D. E. Diller, Ed., Suppl. 2, N. A. Olien, Ed. (1980). Progress Report on Cryogenic Flowmetering at the National Bureau of Standards, J. A. Brennan, J. F. LaBrecque, and C. H. Kneebone, Proc. lst Bienial Symp. Instrumentation in the Cryogenic Industry, Houston TX, Oct. 11-14, 1976, 1, 621, Instr. Soc. of America, Pittsburgh, PA (1976).

NBS-CGA Cryogenic Flow Measurement Program, J. A. Brennan, R. W. Stokes, C. H. Kneebone, and D. B. Mann, (Proc. ISA Intl. Instrument. Automation Conf. and Exhibit, New York, NY, Oct. 28-31, 1974), Paper in Adv. in Instrument. 29, 612.1 (Instr. Soc. of America, Pittsburgh, PA, 1974).

Cryogenic Flow Research Facility Provisional Accuracy Statement, J. W. Dean, J. A. Brennan, D. B. Mann, and C. H. Kneebone, Natl. Bur. Stand. (U.S.), Tech. Note 606 (July 1971).

Cryogenic Liquid-Measuring Devices, Sec. 3.34, 3-57, in Specifications, Tolerances, and Other Technical Requirements for Weighing and Measuring Devices, O. K. Warnlof, Ed., Natl. Bur. Stand. (U.S.), Handbook 44 (1986). 
Airspeed Measurements

Chemical Process Metrology Division Center for Chemical Engineering

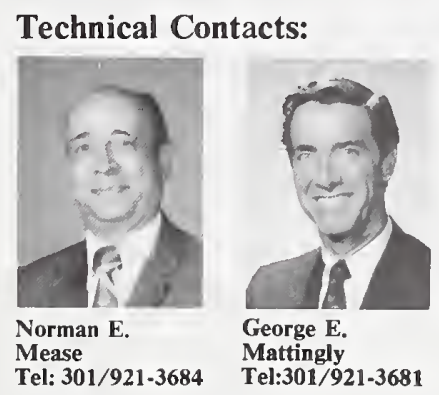

Mailing Address: 105 Fluid Mechanics, National Bureau of Standards, Gaithersburg, MD 20899

Test No. Items

19010C Pitot-Static Tubes (3 to $150 \mathrm{mph}$ )

19020C Low Airspeed Instruments (15 to 2,000 fpm)

$19030 \mathrm{~S}$ Special Tests for Airspeed Instruments

Airspeed Instruments (19010C and 19020C)

Calibration of airspeed measuring devices is performed in the dual test section and low velocity wind tunnels. Elliptical-nose Pitot-static tubes provide the basis of airspeed measurement in both tunnels. Low velocity airspeed measurements are based upon laser velocimeter measurements in the low speed wind tunnel. Calibration of the laser velocimeter is done using the Pitot-static tube at velocities which produce a sufficiently large pressure in the tube that the uncertainty in the pressure measurement does not propagate a large error into the velocity determination. Extension of the laser velocimeter to the low velocity region, where the Pitot-static tube has large measurement errors due to the inability to accurately measure the extremely small pressures produced in the tube, allows considerably improved measurement uncertainty. Air density values in the tunnels are computed from pressure, temperature, and humidity measurements in the tunnel's settling chamber.
Uncertainty levels for the range of airspeed currently offered are shown in Figure 6.

Special Tests of Airspeed Instruments (19030S)

Special tests for airspeed instruments can be arranged. Examples include "in-situ" calibration of air speed instrumentation; proving other air speed measurement systems, etc. Details can be obtained and arrangements made through the technical contacts cited at the beginning of this section.

\section{References-Airspeed Measurement} Experimental Investigation of Drag on a Compliant Surface, J. M. McMichael, P. S. Klebanoff, and N. E. Mease, Viscous Flow Drag Reduction, Gary R. Hough, Ed., Progress in Astronautics and Aeronautics, 72 (1980).

A Low-Velocity Airflow Calibration and Research Facility, L. P. Purtell and P. S. Klebanoff, Natl. Bur. Stand. (U.S.), Tech. Note 989, (Mar. 1979). Low-Velocity Performance of Anemometers, L. P. Purtell, Natl. Bur. Stand. (U.S.), NBSIR 79-1759 (May 1979).

Low-Velocity Performance of a Magnetic Pick-up Vane Anemometer, L. P. Purtell, Natl. Bur. Stand. (U.S.), NBSIR 79-1566 (Dec. 1978).

Low-Velocity Performance of a Ball Bearing Vane Anemometer, L. P. Purtell, Natl. Bur. Stand. (U.S.), NBSIR 78-1485 (June 1978).

Figure 6. Accuracy of Airspeed Measurements for Calibration of Airspeed Indicators

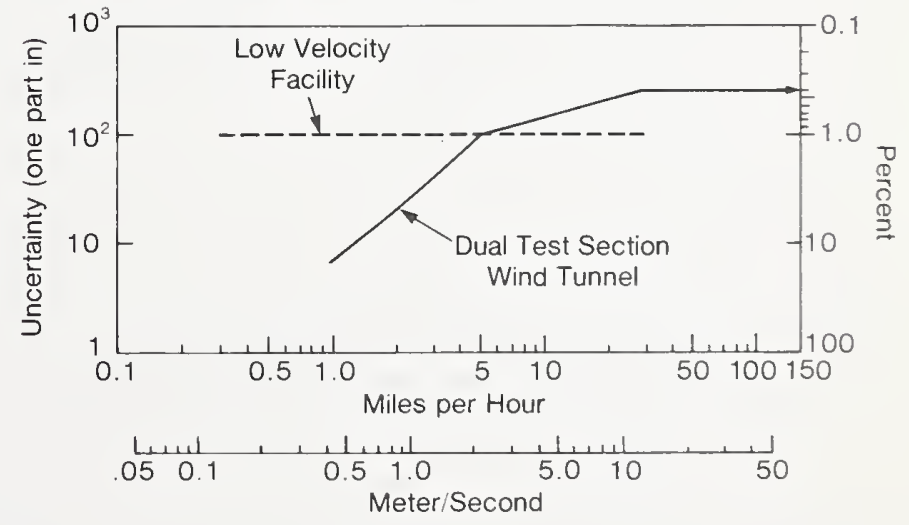




\section{Mass Standards \\ Length and Mass Division Center for Basic Standards}

\section{Technical Contact:}

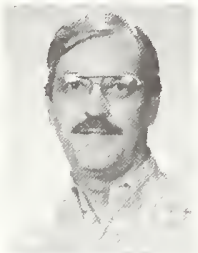

Jerry G. Keller

Tel: 301/921-3118

Mailing Address: B160 Physics, National Bureau of

Standards, Gaithersburg, MD 20899

Shipping Address: National Bureau of Standards, I-270 at Quince Orchard Road, B33 Metrology, Gaithersburg, MD 20899

Attn: J.G. Keller

Note: For weights larger than $50 \mathrm{lb}(30 \mathrm{~kg})$, contact J.G. Keller prior to shipment.

\begin{tabular}{|c|c|}
\hline Test No. & Items \\
\hline $22010 \mathrm{C}$ & Weight Set $(1 \mathrm{mg}$ to $100 \mathrm{~g})$ \\
\hline $22020 \mathrm{C}$ & Weight Set $(1 \mathrm{mg}$ to $1 \mathrm{~kg})$ \\
\hline $22030 \mathrm{C}$ & Weight Set $(2$ to $30 \mathrm{~kg})$ \\
\hline $22040 \mathrm{C}$ & Single Weights ( $1 \mathrm{mg}$ to $1 \mathrm{~kg}$ ) \\
\hline $22050 \mathrm{C}$ & Each additional weight \\
\hline $22060 \mathrm{C}$ & Single Weights ( $2 \mathrm{~kg}$ to $30 \mathrm{~kg}$ ) \\
\hline $22070 \mathrm{C}$ & Each additional weight \\
\hline $22080 \mathrm{C}$ & $\begin{array}{l}\text { Single Weights ( }>30 \mathrm{~kg} \text { to } 1200 \mathrm{~kg}, 2 \text { double } \\
\text { substitution weighings) }\end{array}$ \\
\hline $22090 \mathrm{C}$ & Each additional weight \\
\hline $22100 \mathrm{C}$ & Single Weights $(>1200 \mathrm{~kg}$ to $30,000 \mathrm{~kg}$ ) \\
\hline $22110 \mathrm{C}$ & $\begin{array}{l}\text { Single Weights (> }>30 \mathrm{~kg} \text { to } 1200 \mathrm{~kg} \text {, calibrated in a } \\
\text { weighing design) }\end{array}$ \\
\hline $22120 \mathrm{C}$ & Each additional weight \\
\hline $22130 \mathrm{C}$ & $\begin{array}{l}\text { Single Weights for Dead Weight Pressure Testers } \\
(\geq 13 \mathrm{lb})\end{array}$ \\
\hline $22140 \mathrm{C}$ & Each additional weight \\
\hline $22150 \mathrm{C}$ & $\begin{array}{l}\text { Single Weights for Dead Weight Pressure Testers } \\
(<13 \mathrm{lb})\end{array}$ \\
\hline $22160 \mathrm{C}$ & Each additional weight \\
\hline $22170 S$ & Special Mass Measurement Services \\
\hline $22180 \mathrm{M}$ & Measurement Assurance Program for Mass \\
\hline
\end{tabular}

\section{Mass (22010C-22120C)}

NBS maintains the national standards for mass in the form of the prototype kilograms (K4 and $\mathrm{K} 20)$ and provides services to support the parts of the national measurement system that rely directly or indirectly on mass measurements. These services include the calibration of suitable weight sets. A calibration consists of establishing a mass value and the appropriate uncertainty for that value for each weight which has been designated to be a reference standard. It is desirable, but not necessary, that a weight meet the adjustment tolerances established for Classes A, B, M, or S-1 prior to submission. Weights are available from manufacturers, many of whom can directly furnish documentation suitable for meeting quality assurance contracts and requirements.

For periodic recalibrations of reference mass standards, the user need measure only differences between weights or groups of weights within a set and compare them with computed differences. As long as the agreement is within allowable limits, the values can be considered constant within the precision of the comparison process. Mass standards which are submitted to NBS for recalibration frequently are tested in this manner. If these tests indicate that no significant changes have occurred, a continuation report so stating and referring to the previous NBS Report of Calibration will be issued.

NBS calibrates individual weights or sets in the range of $1 \mathrm{mg}$ to $30 \mathrm{~kg}$ or $1 \mathrm{lb}$ to $50 \mathrm{lb}$ in decimal subdivisions. If the weights are designated as reference standards, they must be of design, material, and surface finish comparable to present Classes A, B, M, S, or S-1. These include ASTM Type I and II, grade S and $\mathrm{O}$, and $\mathrm{OIML} \mathrm{E} 1, \mathrm{E} 2$, and $\mathrm{F} 1$. NBS also calibrates large mass standards (60 to $60,000 \mathrm{lbs}$ ) if the design, material, and surface finish are compatible with the intended usage. For these large mass standards, an adjustment with reference to a nominal or 
desired value can be included as a part of the calibration procedure.

The values of true mass (and an apparent mass correction) included in the report will be determined by using computed volumes based on the manufacturer's statement of density of the material, or on the density computed from measured volumes, or, in the absence of this information, on estimated density values. However, 1 $\mathrm{kg}$ mass standards fabricated from stainless steel and of one-piece construction will have their density determined as part of a "first-time" calibration at NBS. The apparent mass corrections are computed for $20^{\circ} \mathrm{C}$ with reference to Normal Brass (density $8.4 \mathrm{~g} / \mathrm{cm}^{3}$ and volume coefficient of expansion $0.000054 /{ }^{\circ} \mathrm{C}$ ) and to stainless steel (density $8.0 \mathrm{~g} / \mathrm{cm}^{3}$ and volume coefficient of expansion $0.000045 /{ }^{\circ} \mathrm{C}$ ) in an ideal air density of $1.2 \mathrm{mg} / \mathrm{cm}^{3}$. Apparent mass corrections to any other basis can be furnished if requested. Typical uncertainties range from 50 parts per billion at 1 kilogram up to 500 parts per million at one milligram and 1 part per million for weights from 2 kilograms to 30 kilograms. Figure 7 shows the NBS precision of weighing for mass standards over the range $10^{-8}$ to $10^{4}$ ) kilograms.

\section{Single Weights for Dead-Weight Pres-} sure Testers $(22130 \mathrm{C}-22160 \mathrm{C})$

Weights less than six (6) pounds are determined by comparing them with calibrated built-in-weights of appropriate analytical balances by the double substitution method. Weights larger than six (6) pounds are compared to discrete standards by the method of single transposition weighing.

\section{Special Tests of Mass (22170S)}

For tests not covered by the previous descriptions, the NBS technical contact cited at the beginning of this section should be consulted to determine whether a test can be performed and to negotiate a price for the test.

Measurement Assurance Program for Mass (22180M)

This service is most appropriate for primary calibration laboratories. Total uncertainties ranging from a few parts in $10^{7}$ to a few parts in $10^{5}$ for $1 \mathrm{~kg}$ can be obtained. Unlike most other NBS MAP services, the Mass MAP

Figure 7. NBS Precision of Weighing for Mass Standards Ranging from $10^{-8}$ to $10^{4}$ Kilograms

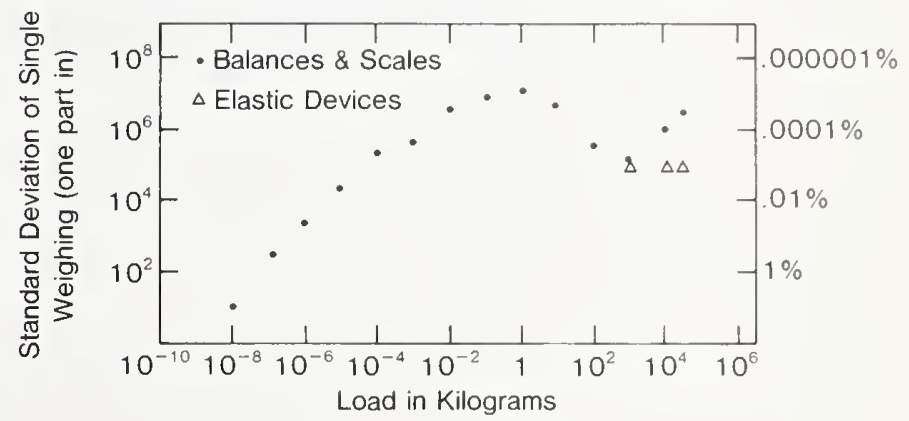

service does not involve the use of an NBS-owned transport standard that is shipped to participants for measurement. The transfer standards in the mass MAP are a set of mass standards owned by the participant and sent to NBS for calibration. These standards are referred to as the "starting standards." In addition to the starting standards, the mass MAP participant must also furnish a set of much smaller weights called "sensitivity weights." The choice of both the starting standards and the sensitivity weights will depend on the particular mass range of interest to the participant; NBS staff can provide advice regarding suitable starting standards and sensitivity weights for a 
particular range of mass weighings. In addition to the starting standards and the sensitivity weights, the participating facility should have a working set of weights known as the "test set" and a set of weights to be used as check standards. This set usually consists of weights in the range 1 to $1000 \mathrm{~g}$.

This service, like other NBS MAP services, samples the participant's measurement process and establishes its uncertainty. Once the participant has become well-established in the Mass MAP, two options are possible:

a. NBS personnel do all of the data analysis and record keeping for the participant and provide periodic reports on the uncertainty of the participant's mass measurements.

b. The participant keeps all records and calculates the uncertainties of his measurements using NBS methods and computer codes.

The implementation of the Mass Measurement Assurance Program in its most complete form typically proceeds in four distinct phases which may be abbreviated somewhat if the participant already has a suitable mass measurement quality control system.

Phase I: Each new participant completes a questionnaire on equipment and facilities and receives a written description of the NBS process, methods and procedures to be used, an introduction to the interpretation of results, and information on the use of these results in measurement decisions. At the participating laboratory, the suitability of the weighing equipment is verified, the "starting standards" selected or procured, and if the procedures are entirely new, operators are trained. The starting standards and sensitivity weights are sent to NBS for calibration. If the starting standards have a prior NBS calibration history, those data are reviewed, and if satisfactory, they are considered, along with the data from the more recent determinations, in arriving at assigned values for the starting standards. NBS will recommend a weighing design to be used for calibrating the test weight. This weighing design prescribes the set of observations for intercomparing the test weights with known weights. NBS will also supply data sheets that are used throughout the first three phases of the program for recording data taken using the design. The objective of the first phase is to ensure that the new participant is familiar with good laboratory practices for high precision weighing. If the participating laboratory has an established mass measurement capability and an existing quality control procedure for mass measurements, Phase I is abbreviated considerably.

Phase II: The starting standards and sensitivity weights are returned to the participant and, following the prescribed procedures, measurements are made over a period of time by the participant to verify that a state of statistical control exists. The data sheets are sent to NBS for review, 
comments, and processing after each measurement. If there are unanticipated problems, or the procedure has not been followed exactly, more measurements may be required. After three or more successful calibrations in the user's facility, NBS analyzes the data to determine the values of the check standards.

Phase III: A comprehensive report is issued by NBS which contains a review of the actions and decisions in each of the phases, control charts for the check standards to be used in the participant's facility, and a comparison of the values assigned to the starting standards by NBS and by the participant. It is assumed at this point that the participating facility is now ready to extend the operation of the MAP to its regular workload.

Phase IV: Having thus established measurement comparability, the MAP user can then, in principle, operate independently of NBS. As long as there is no indication of a loss of statistical control of the process, no further checking with NBS should be necessary. Most participants request a recheck of the starting standards every few years to ensure that no undetected long-term drift has taken place.

For work that differs from the items normally calibrated by the participant, NBS can provide consulting help and assistance such as might be necessary to accommodate a greater range of weights, calibrate pound standards, and extend pound standards to large weights normally associated with force measurement. Although the usual Mass MAP service uses two one-kilogram masses as the starting standards, the program is sufficiently flexible that the same methods can be used with other mass values.

\section{References-Mass Measurements}

Air Buoyancy Correction in HighAccuracy Weighing on Analytical Balances, R. M. Schoonover and F. E. Jones, Anal. Chem., 53, No. 6, 900 (May 1981).

National Bureau of Standards Mass Calibration Computer Software, R. N. Varner and R. C. Raybold, Natl. Bur. Stand. (U.S.), Tech. Note 1127 (July 1980).

Quick and Accurate Density Determination of Laboratory Weights, R. M. Schoonover and R. S. Davis, Proceedings of the 8th Conference of IMEKO, Krakow, Poland (1980).

Precision Laboratory Standards of Mass and Laboratory Weights. A reprint of NBS Circular 547, Section 1, T. W. Lashof and L. B. Macurdy, August 1954, Natl. Bur. Stand. (U.S.), Int. Report, NBSIR 78-1476 (Oct. 1978).

The National Measurement System for Mass, Volume, and Density, P. E. Pontius, J. R. Whetstone, and J. A. Simpson, Natl. Bur. Stand. (U.S.), Int. Report, NBSIR 75-928 (May 1978).

Direct Determination of Air Density in a Balance Through Artifacts Characterized in an Evacuated Weighing Chamber, W. F. Koch, R. S. Davis, 
and V. E. Bower, J. Res. Natl. Bur. Stand. (U.S.), 83, No. 5, 407

(Sept.-Oct. 1978).

The Air Density Equation and the Transfer of the Mass Unit, F. E. Jones, J. Res. Natl. Bur. Stand. (U.S.), 83, No. 5, 419 (Sept.-Oct. 1978).

Designs for the Calibration of Standards of Mass, J. M. Cameron, M. C. Croarkin, and R. C. Raybold, Natl. Bur. Stand. (U.S.), Tech. Note 952 (June 1977).

The Air Density Equation and the Transfer of the Mass Unit, F. E. Jones, Natl. Bur. Stand. (U.S.), Int. Report, NBSIR 77-1278 (July 1977).

Measurement Assurance, J. M. Cameron, Natl. Bur. Stand. (U.S.), Int. Report, NBSIR 77-1240 (1977).

Surveillance Test Procedures, H. W. Almer, Natl. Bur. Stand. (U.S.), Int. Report, NBSIR 76-999 (Feb. 1976). Mass and Mass Values, P. E. Pontius,
Natl. Bur. Stand. (U.S.), Monogr. 133, (Jan. 1974).

On Uncertainty in Mass Measurement, J. R. Donaldson, Natl. Bur. Stand. (U.S.), Int. Report, NBSIR 73-151 (Mar. 1973).

Weight Cleaning Procedures, H. E. Almer, Natl. Bur. Stand. (U.S.), Int. Report, NBSIR 74-443 (Nov. 1973). Method of Calibrating Weights for Piston Gages, H. E. Almer, Natl. Bur. Stand. (U.S.), Tech. Note 577 (May 1971).

Introduction to Intercomparison Methods in Mass Measurement, H. E. Almer, Natl. Bur. Stand (U.S.), Report 9487 (Feb. 1967).

Realistic Uncertainties and the Mass Measurement Process, P. E. Pontius and J. M. Cameron, Natl. Bur. Stand. (U.S.), Monogr. 103 (Aug. 1967).

Measurement Philosophy of the Pilot Program for Mass Calibration, P. E. Pontius, Natl. Bur. Stand. (U.S.), Tech. Note 288 (May 1966).

A Primer for Mass Metrology, K. B. Jaeger and R. S. Davis, Natl. Bur. Stand. (U.S.), Spec. Publ. 700-1 (Nov. 1984). 
Force Measurements

Automated Production Technology Division Center for Manufacturing Engineering

\section{Technical Contacts:}

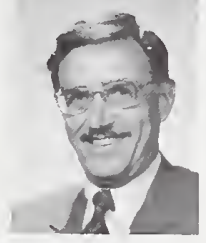

Richard A. Mitchell

Tel: 301/921-3884

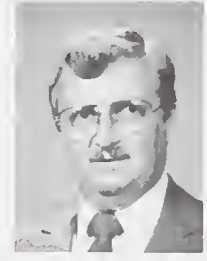

Robert W.

Peterson

Tel: 301/921-3884
Mailing Address: 221 Engineering Mechanics, National Bureau of Standards, Gaithersburg, MD 20899

\begin{tabular}{|c|c|}
\hline Test No. & Items \\
\hline $23010 \mathrm{C}$ & Force Transducers (to $25,000 \mathrm{lbf}, 1$ mode) \\
\hline $23020 \mathrm{C}$ & Extra observation \\
\hline $23030 \mathrm{C}$ & Additional bridges \\
\hline $23040 \mathrm{C}$ & Force Transducers (to $25,000 \mathrm{lbf}, 2$ modes) \\
\hline $23050 \mathrm{C}$ & Extra observation \\
\hline $23060 \mathrm{C}$ & Additional bridges \\
\hline $23070 \mathrm{C}$ & Force Transducers (25,001 to $112,000 \mathrm{lbf}, 1$ mode) \\
\hline $23080 \mathrm{C}$ & Extra observation \\
\hline $23090 \mathrm{C}$ & Additional bridges \\
\hline $23100 \mathrm{C}$ & Force Transducers (25,001 to $112,000 \mathrm{lbf}, 2$ modes) \\
\hline $23110 \mathrm{C}$ & Extra observation \\
\hline $23120 \mathrm{C}$ & Additional bridges \\
\hline $23130 \mathrm{C}$ & Force Transducers (112,001 to $300,000 \mathrm{lbf}, 1$ mode) \\
\hline $23140 \mathrm{C}$ & Extra observation \\
\hline $23150 \mathrm{C}$ & Additional bridges \\
\hline $23160 \mathrm{C}$ & Force Transducers ( 112,001 to $300,000 \mathrm{lbf}, 2$ modes) \\
\hline $23170 \mathrm{C}$ & Extra observation \\
\hline $23180 \mathrm{C}$ & Additional bridges \\
\hline $23190 \mathrm{C}$ & $\begin{array}{l}\text { Force Transducers }(300,001 \text { to } 1,000,000 \mathrm{lbf}, 1 \\
\text { mode) }\end{array}$ \\
\hline $23200 \mathrm{C}$ & Extra observation \\
\hline $23210 \mathrm{C}$ & Additional bridges \\
\hline $23220 \mathrm{C}$ & $\begin{array}{l}\text { Force Transducers }(300,001 \text { to } 1,000,000 \mathrm{lbf}, 2 \\
\text { modes) }\end{array}$ \\
\hline $23230 \mathrm{C}$ & Extra observation \\
\hline $23240 \mathrm{C}$ & Additional bridges \\
\hline $23250 \mathrm{C}$ & Force Transducers (over $1,000,000 \mathrm{lbf}$ ) \\
\hline $23260 \mathrm{~S}$ & Special Tests of Force Transducers \\
\hline $23270 \mathrm{~S}$ & $\begin{array}{l}\text { Pattern Evaluation Test of Load Cells in Com- } \\
\text { pression }\end{array}$ \\
\hline
\end{tabular}

Force Transducers (23010C-23250C)

NBS provides calibration services for force measuring devices by applying known forces, either tension or compression, to the elastic device and recording the sensed deformation. Practically all of the devices calibrated are either proving rings or load cells. The deformation of proving rings is usually measured by means of a micrometer screw and vibrating reed which are an integral part of the device. Load cells, which utilize strain gauge bridges, produce an electrical output approximately proportional to the applied force. The calibration report describes the relationship between the applied force and the measured deformation, in electrical or mechanical units. A load cell can be calibrated using: (1) a readout device furnished by the customer (the load cell and the readout device are calibrated as a system and the calibration is only valid when they are used together); or (2) instrumentation furnished by NBS and the data reported in terms of the ratio of the output voltage to the DC excitation voltage $(\mathrm{mV} / \mathrm{V})$. In the latter case, the customer must possess the necessary electrical instruments and expertise to utilize the calibration results.

Tension or compression calibrations in the range of 10 pounds-force (lbf) to $1,000,000 \mathrm{lbf}$ are performed using deadweight machines. NBS has six such deadweight machines with maximum capacities of $500 ; 6,100 ; 25,300$; 112,$000 ; 300,000$; and 1,000,000 lbf. The three larger machines allow the force applied to the unit being calibrated to be incremented or decremented without having to go to zero 
load between force applications. When using the three smaller machines it is necessary to go to zero load before the load is changed. The estimated uncertainty of the vertical component of the applied force is 20 ppm.

Comparison calibrations in the range of $1,000,000 \mathrm{lbf}$ to $12,000,000$ lbf in compression only are performed in a universal testing machine. In this case, the system being calibrated is loaded in series with one or more load cells that have been previously calibrated in a deadweight machine.

\section{Special Tests of Force Transducers} (23260S)

Temperature sensitivity, pressure sensitivity, eccentric-load sensitivity, and creep tests of force transducers are measured. The ranges of test parameters and environmental conditions may be limited by the characteristics of the force transducer and the availability of special test fixtures. These special tests should be discussed with the designated NBS technical contact before the work is scheduled.

Pattern Evaluation Test of Load Cells in Compression (23270S)

Pattern evaluation tests of load cells are performed in compression, following the procedures of OIML International Recommendation No. 60 over the loading ranges provided by the NBS $112,000 \mathrm{lbf}, 300,000 \mathrm{lbf}$, and $1,000,000 \mathrm{lbf}$ deadweight machines. This test should be discussed with appropriate NBS staff before the work is scheduled.

\section{References-Force Measurements}

Inherent Problems in Force Measurements, P. E. Pontius and R. A. Mitchell, Exper. Mech., 22, No. 3 (Mar. 1982).

Force Sensor-Machine Interaction, R. A. Mitchell and P. E. Pontius, Proceedings of the 27th International Instrumentation Symposium (ISA),
Indianapolis, IN, Instrumentation in the Aerospace Industry, 27, 225 (1981).

Characterizing the Creep Response of Load Cells, R. A. Mitchell and S. M. Baker, VDI-Berichte 312, 43 (1978). Interlaboratory Comparison of Force Calibrations Using ASTM Method E74-74. Phase II., R. W. Peterson and R. L. Bloss, Natl. Bur. Stand. (U.S.), NBSIR 76-1145 (Aug. 1976).

A Study of the National Force Measurement System, D. E. Marlowe, Natl. Bur. Stand. (U.S.), Int. Report, NBSIR 75-929 (June 1975).

Universal Testing Machine of 12-Million-lbf Capacity at the $\mathrm{Na}$ tional Bureau of Standards, A. F. Kirstein, Natl. Bur. Stand. (U.S.), Spec. Publ. 355 (Sept. 1971).

Studies of Calibration Procedures for Load Cells and Proving Rings as Weighing Devices, G. B. Anderson and R. C. Raybold, Natl. Bur. Stand. (U.S.), Tech. Note 436 (Jan. 1969). Gravity Measurements and the Standards Laboratory, D. R. Tate, Natl. Bur. Stand. (U.S.), Tech. Note 491 (Aug. 1969).

Absolute Value of $g$ at the National Bureau of Standards, D. R. Tate, Natl. Bur. Stand. (U.S.), Monogr. 107 (June 1968).

Uncertainties Associated with Proving Ring Calibration, T. E. Hockersmith and $\mathbf{H}$. H. Ku, Preprint No. 12.3-2-64: ISA Conference, Instr. Soc. of America, Res. Triangle Park, NC (Oct. 1964).

Interlaboratory Comparison of Force Calibrations Using ASTM Method E74-74, R. W. Peterson, L. Jenkins, and R. A. Mitchell, Natl. Bur. Stand. (U.S.), Tech. Note 1211 (Apr. 1985).

Metrological Regulations for Load Cells, OIML International Recommendation No. 60, Intl. Org. for Legal Metrol., Paris (Oct. 1984). Progress in Force Measurement at NBS, R. A. Mitchell, Proc. 10th Conf. IMEKO TC-3 on Measurement of Force and Mass, Kobe, Japan (Sept. 1984). 
Vibration Measurements

Automated Production Technology Division Center for Manufacturing Engineering

Technical Contact:

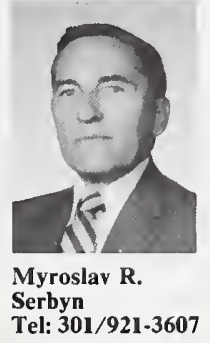

Mailing Address: A149 Sound, National Bureau of Standards, Gaithersburg, MD 20899

\section{Test No. Items}

24010C Vibrations (Pickup Sensitivity, 2 to $100 \mathrm{~Hz}$ )

24020C Vibrations (Pickup Sensitivity, 10 to $3,500 \mathrm{~Hz}$ )

24030C Vibrations (Pickup Sensitivity, 10 to $10,000 \mathrm{~Hz}$ )

24040S Special Shock Measurement Services

24050S Special Tests of Pickup Sensitivity

24060S Special Vibration Tests
Pickup Sensitivity (24010C-24030C)

NBS calibrations of vibration exciters and pickups are performed by comparison with the response characteristics of NBS standards or by absolute measurements. The measurement is the transfer function of the instrument, usually referred to as the sensitivity. For a pickup it is the ratio of the electrical output to a mechanical input. In the case of an accelerometer the practice has been to express the output in millivolts, and the input in units of $g$, the standard acceleration of free fall. The acceleration sensitivity is then given in $\mathrm{mV} / \mathrm{g}$. Other units are sometimes used; for example, the calibration of piezoelectric and piezoresistive accelerometers without signal conditioners is stated in picocoulombs per $\mathrm{g}(\mathrm{pC} / \mathrm{g})$.

The calibration of an accelerometer is reported in tabular form as the sensitivity of the transducer at the discrete frequencies. Because sensitivity is a phasor quantity, which may be represented as a complex number, a complete calibration consists of a measurement of both magnitude and phase of the sensitivity. Only the magnitude of the sensitivity is usually reported. However, the phase component can be furnished on request.

The NBS vibration standards have been calibrated by reciprocity and interferometric techniques, two independent and absolute methods. Their calibration is periodically checked using both techniques. The use of these standards in the calibration of stable transducers furnishes calibration data with a typical uncertainty of from one to three percent depending on the frequency range.

\section{Special Shock Measurement Services (24040S)}

The shock facility provides a comparison calibration of accelerometers by subjecting them to half-sinewave pulses with peak amplitudes of 50 to $5000 \mathrm{~g}$ and pulse widths from 0.2 to 40 milliseconds. Both time and frequency domain measurements can be performed.

\section{Special Tests of Pickup Sensitivity (24050S)}

High accuracy measurements of pickup sensitivity, magnitude only, from 4 to $10 \mathrm{kHz}$ and a peak acceleration of $10 \mathrm{~g}$, normally requested with test $24020 \mathrm{C}$.

Special Vibration Tests (24060S)

Calibration of vibration and shock measuring instruments to specifica- 
tions different from those of the above as well as other measurements can be performed by prearrangement. Consult with technical contact cited at the beginning of this section.

\section{References-Vibration Measurements}

An Automated System for the Measurement of Pickup Sensitivity, B. F. Payne and M. R. Serbyn, NCSL 1983 Workshop and Symposium Proceedings, II-II.1-II-II.22 (July 1983).

The Application of Back-to-Back Accelerometers to Precision Vibration Measurements, B. F. Payne, J. Res. Natl. Bur. Stand. (U.S.), 88, No. 3, 171 (May-June 1983).

A Real-Time Active Vibration Controller, M. R. Serbyn and W. P. Penzes, ISA Transactions, 21 , No. 3, 55 (1982).

Absolute-Calibration of Accelerometers at the National Bureau of Standards, B. F. Payne and M. R. Serbyn, Proc. 10th Transducer Workshop: Telemetry Group, Inter-Range Instrumentation Group, Range Commanders Council, June 12-14, 1979, Colorado Springs, CO, 136 (1979).

Piezoelectric Accelerometer LowFrequency Response by Signal Insertion Methods, R. S. Koyanagi and J. D. Pollard, Natl. Bur. Stand. (U.S.), Int. Report, NBSIR 74-597 (May 1975).

Shock Calibration of Accelerometers, C. Federman, W. Walston, and J. Ramboz, Minutes of the 8th Transducer Workshop: Telemetry Group, Inter-Range Instrumentation Group, Range Commanders Council, WrightPatterson AFB, OH (Apr. 1975).

Accelerometer Calibration at the $\mathrm{Na}$ tional Bureau of Standards, B. F.
Payne, R. S. Koyanagi, C. Federman, and $\mathbf{E}$. Jones, 21 st Intl. Instrument. Symp. ASD/TMD, May 19-21, 1975, Philadelphia, PA, 1 (1975).

Development of a Low-FrequencyVibration Calibration System, R. S. Koyanagi, Exp. Mech., 15, 443 (Nov. 1975).

A Systematic Study of Vibration Transfer Standards--Mounting Effects, R. S. Koyanagi, J. D. Pollard, and J. D. Ramboz, Natl. Bur. Stand. (U.S.), Int. Report, NBSIR 73-291 (Sept. 1973).

An Automated Precision Calibration System for Accelerometers, B. F. Payne, Instrum. Soc. Am. 17th Natl. A erospace Instrument. Symp., Instr. Soc. of America, Res. Triangle Park, NC (May 1971).

Piezoelectric Shakers for WideFrequency Calibration of Vibration Pickups, E. Jones, B. Yelon, and S. Edelman, J. Acoust. Soc. Am., 46, No. 6, 1556 (June 1969).

Accelerometer Resonances Affecting Vibration Measurement, E. T. Pierce, O. W. Price, S. Edelman, and E. Jones, J. Environ. Sci., 10, No. 6, 17 (Dec. 1967).

Improved Transfer Standard for Vibration Pickups, E. Jones, D. Lee, and S. Edelman, J. Acoust. Soc. Am., 41, No. 2, 354 (Feb. 1967).

Electrodynamic Vibration Standard with a Ceramic Moving Element, T. Dimoff, J. Acoust. Soc. Am., 40, No. 3, 671 (Sept. 1966).

Calibration of Vibration Pickups at Large Amplitudes, E. Jones, S. Edelman, and K. S. Sizemore, J. Acoust. Soc. Am., 33, No. 11, 1462 (Nov. 1961).

Calibration of Vibration Pickups by the Reciprocity Method, S. Levy and R. R. Bouche, J. Res. Natl. Bur. Stand. (U.S.), 57, No. 4, 227 (Oct. 1956). 
Acoustic Measurements

\section{Automated Production Techniology Division Center for Manufacturing Engineering}

Technical Contact:

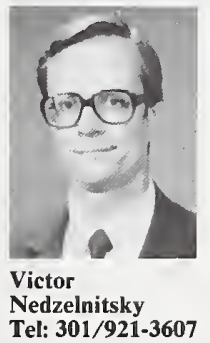

Mailing Address: A149 Sound, National Bureau of Standards, Gaithersburg, MD 20899

\section{Test No. Items}

25010C Pressure Response: WE Type 640AA microphones or equivalent (e.g., Tokyo Riko Type ECL MR 103; B\&K Types 4144 or 4132 with DB0111 adapter). 50 to $10,000 \mathrm{~Hz}$.

25020C Pressure Response: WE Type 640AA microphones or equivalent (e.g., Tokyo Riko Type ECL MR 103; B\&K Type 4160; B\&K Types 4144 or 4132 with DB0111 adapter). 50 to $20,000 \mathrm{~Hz}$.

25030C Pressure Response: Tokyo Riko Type ECL MR112, microphones. B\&K Type 4134, or equivalent halfinch. 50 to $10,000 \mathrm{~Hz}$.

25040C Pressure Response: Tokyo Riko Type ECL MR112, B\&K Type 4134, or equivalent half-inch microphones. 50 to $20,000 \mathrm{~Hz}$.

25050C Free-Field Response: Tokyo Riko Type ECL MR112, B\&K Types $4133,4134,4165,4166$, or equiv alent half-inch microphones. 2,500 to $20,000 \mathrm{~Hz}$.

25060S Special Tests of Acoustic Devices

25070S Special Tests of Earphones

Pressure and Free-Field Response of Microphones (25010C-25050C)

Pressure calibrations are performed on type-L (one-inch microphones satisfying the requirements of American National Standard S1.12-1967 (R1977), Specifications for Laboratory Standard Microphones and its impending revision. The microphones submitted for pressure calibration must be suitable for use with the calibrating couplers shown in figures 7 and 11 of the applicable American
National Standard S1.10-1966 (R1976).

Pressure calibrations are reported in terms of open-circuit voltage per unit sound pressure applied uniformly to the diaphragm. The open-circuit voltage at the electrical terminals of a microphone may be influenced by stray capacitance evident at these terminals. For type-L microphones, these capacitances are defined by the geometrical configuration of the ground shield shown in figures 6 and 13 of S1.10-1966 (R1976). If the ground shield dimensions are not adhered to in making use of the response levels reported by NBS, errors may result. Pressure calibrations of type-L microphones exhibit typical uncertainties of approximately $0.1 \mathrm{~dB}$ or less at frequencies from $50 \mathrm{~Hz}$ to $8 \mathrm{kHz}, 0.2 \mathrm{~dB}$ or less at frequencies from $8 \mathrm{kHz}$ to $20 \mathrm{kHz}$. Further information is contained in the references for acoustic measurements.

Since American National Standards Institute publications S1.10-1966 (R1976) and S1.12-1967 (R1977) were issued, certain types of half-inch diameter precision microphones have attained widespread use. Therefore, NBS has developed procedures for determining the pressure response levels of half-inch microphones by comparison with NBS type-L standard microphones, which in turn are calibrated periodically by the reciprocity technique. The technique used, precautions to be observed, and uncertainties of measurement are essentially the same as those given above for one-inch microphones. Significant differences such as ground shield configuration are described in the test report. Since several half-inch laboratory standard microphones have only been available for a relatively short time, their long-term stability has yet to be determined.

The free-field response levels of certain type-L microphones (e.g., Western Electric Type 640AA condenser microphones) can be computed from pressure response levels reported by NBS. However, certain 
precautions must be taken and there is some degradation in accuracy. Therefore, for the most demanding freefield measurement requirements, NBS offers a calibration service for determining the free-field response levels for half-inch microphones. The calibrations are made at normal incidence over the frequency range of $2.5 \mathrm{kHz}$ to $20 \mathrm{kHz}$. They are reported in terms of open-circuit voltage per unit sound pressure of a plane progressive wave whose direction of propagation is normal to the plane of the diaphragm. The calibrations are performed in a well characterized anechoic chamber. A typical uncertainty in this calibration is approximately $0.15 \mathrm{~dB}$ at each frequency within the range of $2.5 \mathrm{kHz}$ to $20 \mathrm{kHz}$. Calibrations can be performed with or without protective grids on the microphone. For the most precise free-field measurements, the customer should contact the NBS staff person cited at the beginning of this section for recommendations prior to submitting the microphone to NBS for calibration.

\section{Special Tests of Acoustic Devices (25060S)}

Acoustical measurement services are available by special arrangement. These services include extended frequency ranges, additional data points, and calibration of certain pistonphones and acoustic calibrators. NBS has a large general purpose anechoic chamber available for special calibrations requiring such a facility. The frequency-dependent and position-dependent acoustical performance of this chamber, including extremely low background noise, has been carefully controlled during design and construction and is documented.

Special Tests of Earphones (25070S) Earphones are tested on an NBS 9-A Coupler from 125 to $8000 \mathrm{~Hz}$.

References-Acoustic Measurements Specifications for Laboratory Stan- dard Microphones, American National Standards Institute, S1.12-1967 (R1977), New York, N.Y.

Method for Calibration of Microphones, American National Standards Institute, S1.10-1966 (R1976), New York, N.Y.

Calibrations of Microphones, Vibration Pickups, and Earphones, R. K. Cook, S. Edelman, and W. Koidan, J. Audio Eng. Soc., 13, No. 4 (Oct. 1965).

Method of Measurement of E/I in the Reciprocity Calibration of Condenser Microphones, W. Koidan, J. Acoust. Soc. Am., 32, No. 5, 611 (May 1960). Hydrogen Retention System for Pressure Calibration of Microphones in Small Couplers, W. Koidan, J. Acoust. Soc. Am., 35, No. 4, 614 (Apr. 1963).

Free-Field Correction for Condenser Microphones, W. Koidan and D. S. Siegel, J. Acoust. Soc. Am., 36, No. 11, 2233 (Nov. 1964).

Calibration of Standard Condenser Microphones: Coupler Versus Electrostatic Actuator, W. Koidan, J. Acoust. Soc. Am., 44, No. 5, 1451 (Nov. 1968).

Calibration of Laboratory Condenser Microphones, V. Nedzelnitsky, E. Burnett, and W. Penzes, Proceedings of the 10th Transducer Workshop, Transducer Committee, Telemetry Group, Range Commanders Council, Colorado Springs, CO (June 1979).

Traceability of Acoustical Instrument Calibration to the National Bureau of Standards, V. Nedzelnitsky, Proc. INTER-NOISE 80, II, Dec. 8-10, 1980, Miami, FL, G. C., Maling, Jr., Ed., Poughkeepsie, NY: Noise Control Foundation, 1043 (1980).

Wedge Design for the National Bureau of Standards Anechoic Chamber, W. Koidan, G. R. Hruska, and M. A. Pickett, J. Acoust. Soc. Am., 52, No. 4 (Part 1), 1071 (1972).

Acoustical Properties of the National Bureau of Standards Anechoic Chamber, W. Koidan and G. R. Hruska, J. Acoust. Soc. Am., 64, No. 2 (Aug. 1978). 
Ultrasonic Measurements

Automated Production Technology Division Center for Manufacturing Engineering

Technical Contact:

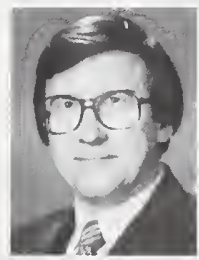

Gerald V.

Blessing

Tel: 301/921-3646

Mailing Address: A147 Sound, National Bureau of Standards, Gaithersburg, MD 20899

\section{Test No. Items}

26010C Ultrasonic Transducer Power and Frequency

26020C Acoustic Emission Sensors

26030S Special Tests of Area Amplitude of Aluminum

Reference Blocks-Set of Eight Blocks

26040S Each additional block/measurement

26050S Distance amplitude set

26060S Each additional block/measurement

26070S Special Tests of Ultrasonic Transducer Power

Ultrasonic Transducer Power and Frequency (26010C)

Measurements of total ultrasonic forward power radiated into a water load are offered for the purpose of characterizing ultrasonic systems and transducers. Ultrasonic systems are characterized by measurement of output under operating conditions specified by the customer. Transducers for which the continuous-wave electrical input voltage can be accurately and reproducibly measured are characterized by a radiation conductance determined from measurements of input voltage and output power. A typical calibration report for an ultrasonic system provides the results of at least three measurements of output power for each operating condition specified. Calibration reports for transducers typically present a single value of radiation conductance derived from at least 15 measurements of out- put power spanning an appropriate range of power. Resonance frequencies of transducers are determined from the results of iterative spot-frequency relative measurements of radiation conductance.

Continuous-wave ultrasonic power is measured using a modulatedradiation force balance. Output power is determined from the force required to arrest the motion of a conical target which diverts the output beam of the transducer under test into a bank of absorbers. Absolute power can thus be measured at spot frequencies between 1 and $20 \mathrm{MHz}$. The overall uncertainty varies from $2.2 \%$ at 1 $\mathrm{MHz}$ to $7.6 \%$ at $20 \mathrm{MHz}$. These estimates of uncertainty apply to measurements made at power levels ranging from a few milliwatts to a few watts; the minimum detectable power is about 10 microwatts while high-power measurements are limited by the onset of cavitation in the water load. Transducers of diameter no greater than $45 \mathrm{~mm}$ can be tested in this apparatus.

Pulsed ultrasonic power is measured using a specially designed calorimeter. With pulsed excitation, only ultrasonic systems comprising a transducer and an electrical driver can be tested. Transducers by themselves cannot be independently characterized with pulsed drive waveforms since the electrical input signals cannot at present be adequately measured or characterized. Power levels ranging from $1 \mathrm{~mW}$ to several watts at frequencies between 1 and $15 \mathrm{MHz}$ can be measured with an overall uncertainty less than $7 \%+0.2 \mathrm{~mW}$. Transducers with diameters as great as $26 \mathrm{~mm}$ can be accommodated. Measurements of continuous-wave power are also possible with the calorimeter. The length of its response time precludes swept-frequency tests.

Acoustic Emission Sensors (26020C)

The NBS acoustic emission transducer calibration provides the voltage 
output of a transducer per unit of motion (displacement or velocity) of the mounting surface as a function of frequency. The calibration is based upon the normal component of motion which would occur in the absence of the transducer. The test method is as follows: a step function of "point" force is generated on the surface of a large steel block by breaking a glass capillary. The transducer under test and the NBS standard capacitive transducer are located on this same surface and are equidistant from the source. Both transducers experience the motion of the seismic surface pulse generated by the step function force. The transient voltage outputs from both transducers are recorded and analyzed for frequency content. The frequency response of the transducer under test is obtained by dividing the spectral amplitude from it by that from the standard transducer, frequency by frequency. The calibration is absolute, since the sensitivity of the standard transducer is known. The magnitude and phase of the sensitivity of the transducer under test are obtained at discrete frequencies, $f_{n}=9765.625 n(\mathrm{~Hz})$, where $\mathrm{n}=1,2,3 \ldots$ The customer is provided with the results in the form of graphs of magnitude and phase. These are piecewise linear functions constructed through the data points. Within the valid range of 0.1 to $1 \mathrm{MHz}$, the uncertainty is approximately $10 \%$. At the option of the customer, the results will be given with respect to normal displacement of velocity of the mounting surface, on a magnitude scale or on a decibel scale.

\section{Special Tests of Aluminum Reference} Blocks (26030S-26040S)

The ultrasonic response of 7075 aluminum alloy reference blocks of 0.50 inch and greater metal path distances is determined relative to an NBS interim reference standard. The immersion, pulse-echo, longitudinal wave, $5 \mathrm{MHz}$ quartz transducer test- ing system defined in the ASTM E-127 calibration document is used with some procedural modifications. In the NBS-developed procedure, the interim reference standards are calibrated along with the customer's blocks. System precision and stability over time are provided by the set of check standard blocks with flatbottom hole sizes of $3 / 64,5 / 64$, and $8 / 64$ inch diameter. Standard deviation data, representing random errors associated with the NBS system, are provided for the respective block and hole sizes. The plus or minus two standard deviation uncertainty levels range from about 3 to 10 percent of block response, depending on the block and hole sizes of the respective check standards. A comparison of the customer's block value to the data base of all blocks measured by NBS is also available. Response following the procedures of the ASTM Recommended Practice E-127 can also be determined. In addition, the response of some blocks with metal path distances less than 0.50 inch can be obtained by special arrangement.

\section{Special Tests of Ultrasonic Transducer} Power (26070S)

This service includes consultation, customized testing, and the lending of air-backed transducers for the purpose of transferring power measurements. Quartz transducers characterized by radiation conductance and thus suited for the reproduction of arbitrary power levels are available for frequencies of 2,3 , and $5 \mathrm{MHz}$ and can be specially calibrated for operation at odd overtones. Lithium niobate transducers with built-in circuitry allowing the field user to reproduce prearranged power levels while measuring only dc voltage are available for use at frequencies below $20 \mathrm{MHz}$ approximated by odd multiples of $0.5 \mathrm{MHz}$.

\section{References-Ultrasonic Measurement}

An Assessment of Ultrasonic Reference Block Calibration Methodology, G. V. Blessing, Natl. Bur. Stand. 
(U.S.), Int. Report, NBSIR 83-2710 (June 1983).

Standard Practice for Fabricating and Checking Aluminum Alloy Ultrasonic Standard Reference Blocks, E-127-81, in Annual Book of ASTM Standards, Vol. 03.03, Philadelphia, PA, Amer.

Soc. for Testing and Materials (1982).

Acoustic Emission Transducer Calibration by Means of the Seismic Surface Pulse, F. R. Breckenridge, J. Acoust. Emission, 1, No. 2 (Apr. 1985).

Characterization and Calibration of Acoustic Emission Sensors, N. N. Hsu and F. R. Breckenridge, Matls. Eval., 39, No. 1, 60 (Jan. 1981). Surface-Wave Displacement: Absolute Measurements Using a Capacitive Transducer, F. R. Breckenridge and M. Greenspan, J. Acoust. Soc. Am., 69, No. 4, 1177 (Apr. 1981).

Calibration and Sensor Activities, D. G. Eitzen, F. R. Breckenridge, R. B. Clough, E. R. Fuller, N. N. Hsu, and J. A. Simmons, Chapter 2.0 in Fundamental Developments for Quantitative Acoustic Emission Measurements, EPRI NP-2089, Research Project 608-1, Palo Alto, CA, Electric Power Research Institute, 2-1-2-52 (Oct. 1981).

Traceability of Acoustical Instrument Calibration to the National Bureau of Standards, V. Nedzelnitsky, Proc. INTER-NOISE 80, II, Dec. 8-10, 1980, Miami, FL, G. C., Maling, Jr., Ed., Poughkeepsie, NY; Noise Control Foundation, 1043 (1980).

Ultrasonic Transducer Characterization at the NBS, E. R. Miller and D. G. Eitzen, IEEE Trans. Sonics and Ultrasonics, SU-26, No. 1, 28 (Jan. 1979).

Recent Improvements to the ASTMType Ultrasonic Reference Block System, D. J. Chwirut, Natl. Bur. Stand. (U.S.), Int. Report, NBSIR 79-1742 (Feb. 1979).

The Evaluation of Search Units Used for Ultrasonic Reference Block Calibrations, D. J. Chwirut and G. D. Boswell, Natl. Bur. Stand. (U.S.), Int.
Report, NBSIR 78-1454 (Feb. 1978).

Ultrasonic Transducer Power Output by Modulated Radiation Pressure, $\mathbf{M}$. Greenspan, F. R. Breckenridge, and C. E. Tschiegg, J. Acoust. Soc. Am., 63, No. 4, 1031 (Apr. 1978).

Ultrasonic Transducer Power Output by Modulated Radiation Pressure (with details), M. Greenspan, F. R. Breckenridge, and C. E. Tschiegg, Natl. Bur. Stand. (U.S.), Int. Report, NBSIR 78-1520 (July 1978).

Improved Ultrasonic Standard Reference Blocks, G. F. Sushinsky, D. G. Eitzen, D. J. Chwirut, C. J. Bechtoldt, and A. W. Ruff, Natl. Bur. Stand. (U.S.), Int. Report, NBSIR 76-984 (Nov. 1976).

Procedures for the Calibration of ASTM E127-Type Ultrasonic Reference Blocks, D. J. Chwirut, G. F. Sushinsky, and D. G. Eitzen, Natl. Bur. Stand. (U.S.), Tech. Note 924 (Sept. 1976).

Ultrasonic Calorimeter for Beam Power Measurements from 1 to 15 Megahertz, T. L. Zapf, M. E. Harvey, N. T. Larsen, and R. E. Stoltenberg, 1976 Ultrasonics Symposium Proceedings, IEEE Cat. 76, CH1120-ISU, Inst. for Electron. and Electric. Engrs., New York, NY (1976).

Ultrasonic Calorimeter for Beam Power Measurements, T. L. Zapf, M. E. Harvey, N. T. Larsen, and R. E. Stoltenberg, Natl. Bur. Stand. (U.S.), Tech. Note 686 (Sept. 1976).

Acoustic Emission: Some Applications of Lamb's Problem, F. R.

Breckenridge, C. E. Tschiegg, and M. Greenspan, J. Acoust. Soc. Am., 57, No. 3, 626 (Mar. 1975).

Calibration of Quartz Transducers as Ultrasonic Power Standards by an Electrical Method, T. L. Zapf, 1974 Ultrasonics Symposium Proceedings, IEEE Cat. 74, CH0896-ISU, Inst. for Electron. and Electric. Engrs., New York, NY (1974). 


\section{Chapter}

A Pressure Measurements

$B$ Vacuum and Low Pressure Measurements

C Laboratory Thermometers

$D$ Thermocouples, Thermocouple Materials, and Pyrometer Indicators

E Resistance Thermometry

$F$ Radiation Thermometry

$G$ Humidity Measurements 


\section{Thermodynamic Quantities}

1 Pressure Measurements

Temperature and Pressure Division

Center for Basic Standards

\section{Technical Contact:}

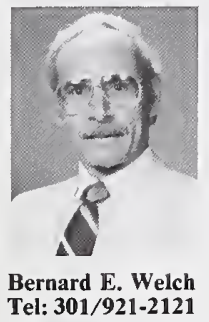

Mailing Address: A55 Metrology, National Bureau of Standards, Gaithersburg, MD 20899

Test No. Items

29010C Deadweight Piston Gages

29020C Controlled Clearance Piston Gages

29030C Pressure Gages and Transducers

29035C Mercurial Barometers and Manometers

29040S Special Tests of Pressure Gages

Piston Gages and Pressure Transducers (29010C-29035C)

The NBS provides measurement services for the calibration of piston gages and transducers operating with gas in the range of $1.4 \mathrm{kPa}$ to $17 \mathrm{MPa}$ and with oil in the range of $700 \mathrm{kPa}$ to $400 \mathrm{MPa}$. Calibrations are done by the cross-floating technique using
NBS piston gages. Uncertainties are shown in Table 1.

Table 1: Gage and Pressure Measurement Uncertainties

\begin{tabular}{lcc}
\hline Type of Instrument & \multicolumn{1}{c}{ Range } & Uncertainty \\
\hline Gas-operated PG & $1.4 \mathrm{kPa}$ to $17 \mathrm{MPa}$ & $\pm 57 \mathrm{ppm}$ \\
Oil-operated PG & $\begin{array}{l}700 \mathrm{kPa} \text { to } 100 \mathrm{MPa} \\
100 \mathrm{MPa} \text { to } 280 \mathrm{MPa}\end{array}$ & \pm 60 to $\pm 150 \mathrm{ppm}$ \\
Oil-operated PG & 40 to $400 \mathrm{MPa}$ & $\pm 186 \mathrm{ppm}$
\end{tabular}

\section{Special Tests of Pressure Gages} (29040S)

Special tests of pressure gages and other pressure measuring devices can be performed on request.

\section{References-Pressure Measurements}

An Intercomparison of Pressure Standards Between IMGC and NBS, J. C. Houck, G. F. Molinar, and R. Maghenzani, J. Res. Natl. Bur. Stand. (U.S.), 88, 253 (1983).

An Intercomparison of Pressure Standards Between LNE and NBS, R. G. Driver, J. C. Houck and B. E. Welch, J. Res. Natl. Bur. Stand. (U.S.), 86, No. 3 (May-June 1981).

Absolute High Pressure Measurements, V. E. Bean, High Pressure Science and Technology, B. Vodar and 


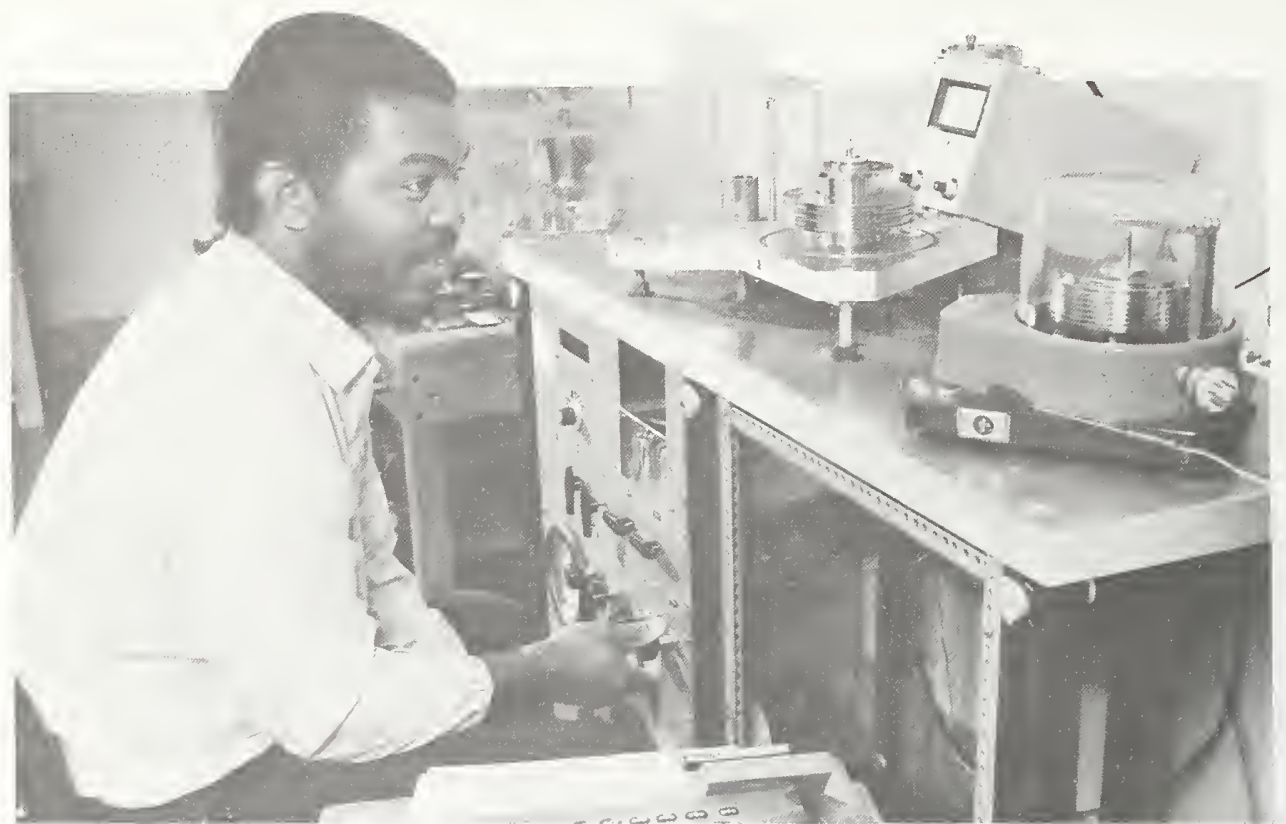

Greg Driver, calibrating deadweight tester.

Ph. Mardeau, Eds., 231, Pergamon Press, Oxford, England (1980).

Piston Gages, P. L. M. Heydemann and B. E. Welch, Chapter 4, Experimental Thermodynamics, Vol. II. Experimental Thermodynamics of NonReacting Fluids, B. Le Neindre and B. Vodar, Eds., Part 3, 147, Butterworth and Co., London (1975).

Reduction of Data for Piston Gage Measurement, J. L. Cross, Natl. Bur. Stand. (U.S.), Monogr. 65 (1963).

A Method to Determine the Pressure Dependent Distortion of a Simple Piston Gage Based on Dimensional Metrology, B. E. Welch and V. E. Bean, High Pres. Sci. and Tech., 22, II, 261, C. Homan, R. K. MacCrone, and E. Whalley, Eds., Elsevier Science Publishing Co., Inc., New York (1984).

Effects of Viscosity, Temperature, and Rate of Rotation on Pressure Generated by a Controlled-Clearance Piston Gauge, J. K. N. Sharma, K. K. Jain, V. E. Bean, B. E. Welch, and R. J. Lazos, Rev. Sci. Instrum. 55, 563 (1984).

Pressure and Temperature Measurements in the Annulus Between the Piston and Cylinder of a Simple Dead-Weight Piston Gauge, B. E.
Welch and V. E. Bean, Rev. Sci. Instrum. 55, 1901 (1984).

International Comparison in the Pressure Range 20-100 MPa Organized by the High Pressure Working Group of the Comite Consultatif pour la Masse, J. C. Legras, V. E. Bean, J. Jager, S. L. Lewis, and G. F. Molinar, BIPM Internal Technical Report 84/2, Intl. Bur. of Weights and Meas., Paris (1984).

Note on the Results of the First Phase of an International Comparison in the Pressure Range 20-100 MPa Organized by the High Pressure Working Group of the Comite Consultatif pour la Masse, J. C. Lagras, V. E. Bean, J. Jager, S. L. Lewis, and G. F. Molinar, J. Phys. E: Sci. Instrum. 18, 361 (1985).

Factors Affecting the Precision of Gas Operated Piston Gages at the Part Per Million Level, B. E. Welch, L. A. Guildner, and V. E. Bean, Proc. 31st Intl. Instrum. Symp., San Diego, CA, 9 (May 1985).

Elastic Distortion of Piston Gages, J. Lazos-Martinez and V. E. Bean, Proc. Xth Conf. of the Intl. Assoc. for the Advanc. of High Pressure Sci. and Tech., Amsterdam (July 1985). Pressure Metrology: Primary Standard Piston Gages, V. E. Bean, Proc. Xth Conf. of the Intl. Assoc. for the Advanc. of High Pressure Sci. and Tech., Amsterdam, (July 1985). 
Vacuum and Low Pressure

Measurements

Temperature and Pressure Division Center for Basic Standards

\section{Technical Contacts:}

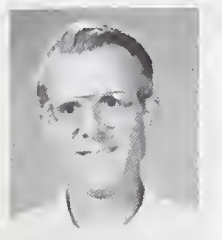

Richard W.

Hyland

Tel:301/921-2121

Tel:301/921-2121

30040S, 30050S

Mailing Address: A55 Metrology, National Bureau of Standards, Gaithersburg, MD 20899

Test No. Items

30010C Absolute Low Pressure Gages

30020C Differential Low Pressure Gages

30030C High Vacuum Gages

30040S Special Tests of Low Pressure Gages

30050S Special Tests of Vacuum Gages
Low Pressure Gages (30010C and 30020C)

Absolute low pressure gages including capacitance diaphragm gages and quartz spiral gages are calibrated against the NBS Ultrasonic Interferometer Manometer. This standard covers a range limited at the low end by its $10 \mathrm{mPa}$ instability and extending up to $1600 \mathrm{kPa}$ (1200 Torr). The uncertainty of the standard is $0.01 \%$ of reading plus $10 \mathrm{mPa}$. This standard is also used for the calibration of low range differential gages, including ball gages.

\section{High Vacuum Gages (30030C)}

A standard of the orifice flow type covers the range from $10^{-1}$ to $10^{-6} \mathrm{~Pa}$ $\left(10^{-3}\right.$ to $10^{-8}$ Torr) for most gases with an uncertainty of $1 \%$ between $10^{-1}$ and $10^{-5} \mathrm{~Pa}$, increasing to $10 \%$ at $10^{-6} \mathrm{~Pa}$. Ion gages and spinning rotor or spinning ball gages are accepted for calibration but all gages must be bakeable to $250^{\circ} \mathrm{C}$ and should be welded to "Conflat" type flanges. Standard procedure is to calibrate the sensor and electronics as a package although ion gage controllers that do not regulate the emission current or deliberately change it will not be accepted for calibration. An extra fee will be charged for ion gage calibration below $10^{-4} \mathrm{~Pa}$.

For an additional fee NBS will provide tabulated Bayard-Alpert gages with tungsten filaments and 2.75 in.

Figure 8. Uncertainties of NBS Low Pressure and Vacuum Standards

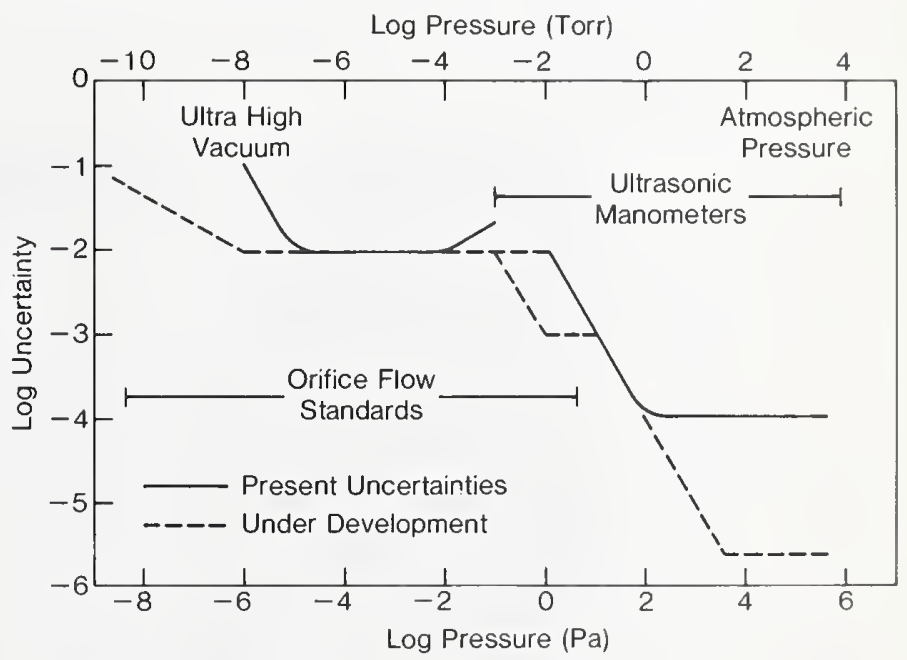

"Conflat-type" flanges. These will be calibrated with the user's electronics.

Special Tests of Gages (30040S and 30050S)

Instruments requiring special calibration procedures or prolonged testing can often be accommodated as a special test. Consult with technical contact listed at the beginning of the section.

Figure 8 summarizes the uncertainties of the NBS low pressure and 
vacuum standards. Dashed lines are target uncertainties expected from new standards under development or improvements to existing standards.

\section{References-Vacuum and Low Pressure Measurements}

Reliability of High Vacuum Measurements, C. R. Tilford, J. Vac. Sci. Technol., Al(2), 152 (Apr.-June 1983).

Calibration of Molecular Drag Vacuum Gages, K. E. McCulloh, J. Vac. Sci. Technol. A1(2) (Apr.-June 1983). Performance Characteristics of a Broad Range Ionization Gage Tube, C. R. Tilford, K. E. McCulloh and H. S. Woong, J. Vac. Sci. Technol., 20, 1140 (1982).

Ultrasonic Manometers for Low and Medium Vacua Under Development at NBS, P. L. M. Heydemann, C. R. Tilford and R. W. Hyland, J. Vac. Sci. Technol., 14, 597 (Jan.-Feb. 1977).

Zero Stability and Calibration Results for a Group of Capacitance Diaphragm Gages, R. W. Hyland and C. R. Tilford, J. Vac. Sci. Technol., A3, 1731 (1985).

Sensitivity of Hot Cathode Ionization Gages, C. R. Tilford, J. Vac. Sci.

Technol., A3, 546 (1985).

Long-Term Stability of Two Types of Hot Cathode Ionization Gages, S. D. Wood and C. R. Tilford, J. Vac. Sci. Technol., A3, 542 (1985).

Zero Stability of Spinning Rotor Vacuum Gages, K. E. McCulloh, S. D. Wood, and C. R. Tilford, J. Vac. Sci. Technol., A3, 1738 (1985).

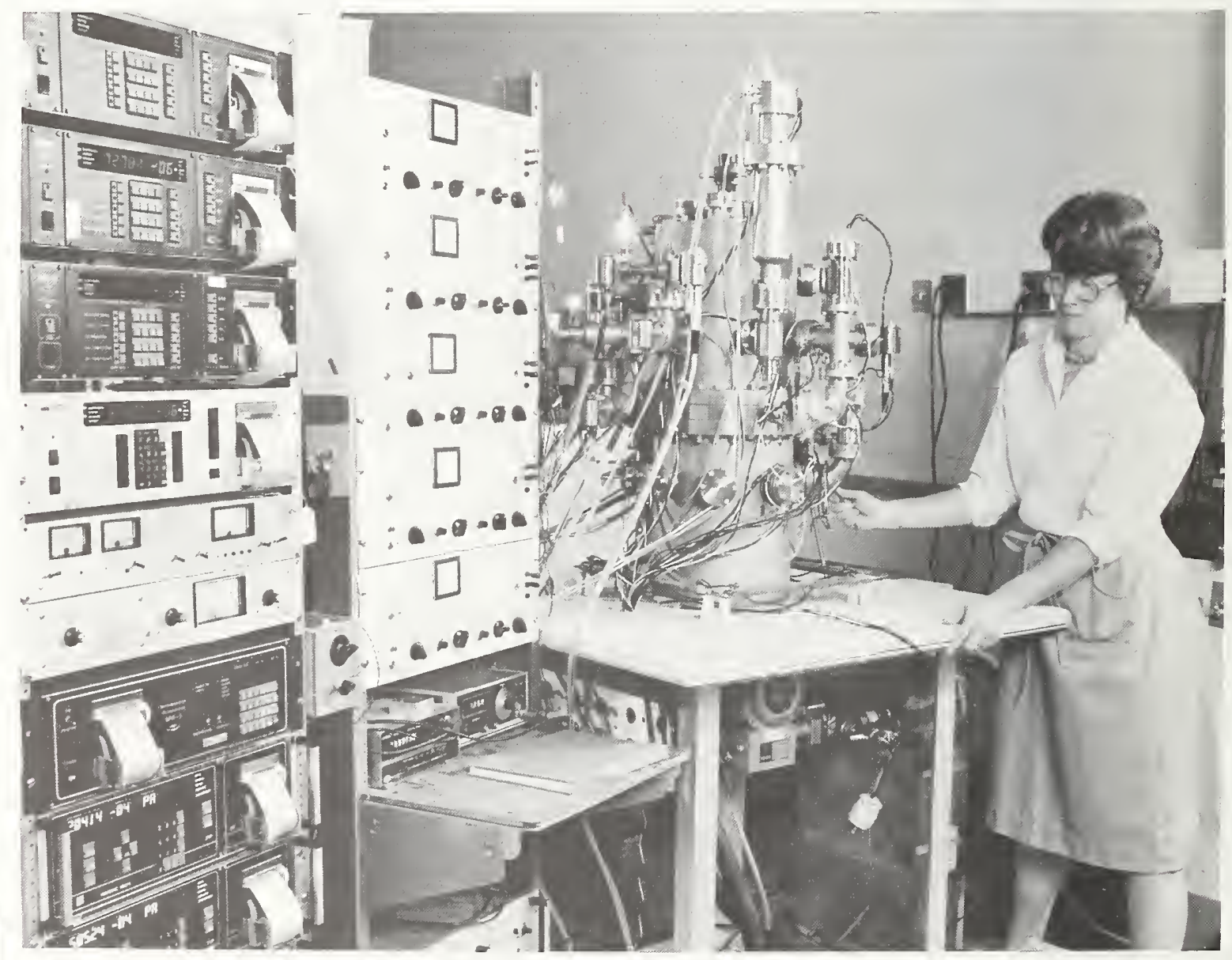

Sharrill Wood, calibrating spinning rotor vacuum gages. 
Laboratory Thermometers

Temperature and Pressure Division

Center for Basic Standards

\section{Technical Contact:}

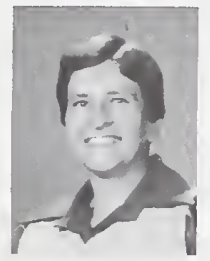

Jacquelyn A. Wise Tel: 301/921-2087

Mailing Address: B128 Physics, National Bureau of Standards, Gaithersburg, MD 20899

Shipping Address: National Bureau of Standards, I-270 at Quince Orchard Road, A242 Physics, Gaithersburg, MD 20899

Attn: J. Wise

Test No. Items

$31010 \mathrm{C}$ Laboratory Thermometers $\left(0\right.$ to $\left.150^{\circ} \mathrm{C}\right)\left(32\right.$ to $\left.300^{\circ} \mathrm{F}\right)$

31011C Each additional point

$31020 \mathrm{C}$ Laboratory Thermometers $\left(151\right.$ to $300^{\circ} \mathrm{C}$ )

(301 to $600^{\circ} \mathrm{F}$ )

31021C Each additional point

$31030 \mathrm{C}$ Laboratory Thermometers $\left(301\right.$ to $538^{\circ} \mathrm{C}$ )

$\left(601\right.$ to $\left.1000^{\circ} \mathrm{F}\right)$

31031C Each additional point

$31040 \mathrm{C}$ Laboratory Thermometers $\left(-1\right.$ to $\left.-110^{\circ} \mathrm{C}\right)$

(31 to $-166^{\circ} \mathrm{F}$ )

31041C Each additional point

31050C Laboratory Thermometers (Liquid $\mathrm{N}_{2}$ )

$\left(-196^{\circ} \mathrm{C}\right.$ or $\left.-320^{\circ} \mathrm{F}\right)$

$31051 \mathrm{C}$ Each additional point

31060C Laboratory Thermometers (Liquid $\mathrm{O}_{2}$ )

$\left(-183^{\circ} \mathrm{C}\right.$ or $\left.-297{ }^{\circ} \mathrm{F}\right)$

$31061 \mathrm{C}$ Each additional point

31070C Calorimetric Thermometer

31071C Each additional Calorimetric Thermometer

31080C Beckmann Thermometer

31081C Each additional Beckmann Thermometer

31100 S Special Tests of Liquid-In-Glass Thermometers

\section{Laboratory Thermometers} (31010C-31100S)

This service provides for the calibration of a variety of thermometers

\author{
Test No. Items \\ $31110 \mathrm{~S}$ Special Tests of Thermometers $\left(0\right.$ to $\left.150^{\circ} \mathrm{C}\right)$ \\ (32 to $300{ }^{\circ} \mathrm{F}$ ) \\ 31111S Each additional point \\ $31120 \mathrm{~S}$ Special Tests of Thermometers $\left(151\right.$ to $\left.300^{\circ} \mathrm{C}\right)$ \\ (301 to $600^{\circ} \mathrm{F}$ ) \\ 31121S Each additional point \\ $31130 \mathrm{~S}$ Special Tests of Thermometers $\left(301\right.$ to $\left.538^{\circ} \mathrm{C}\right)$ \\ (601 to $1000^{\circ} \mathrm{F}$ ) \\ 31131S Each additional point \\ $31140 \mathrm{~S}$ Special Tests of Thermometers $\left(-1\right.$ to $\left.-110^{\circ} \mathrm{C}\right)$ \\ (31 to $-166^{\circ} \mathrm{F}$ ) \\ 31141S Each additional point \\ $31150 \mathrm{~S}$ Special Tests of Thermometers (Liquid $\left.\mathrm{N}_{2}\right)\left(-196^{\circ} \mathrm{C}\right.$ \\ or $-320^{\circ} \mathrm{F}$ ) \\ 31151S Each additional point \\ $31160 \mathrm{~S}$ Special Tests of Thermometers (Liquid $0_{2}$ ) \\ $\left(-183^{\circ} \mathrm{C}\right.$ or $\left.-297^{\circ} \mathrm{F}\right)$ \\ $31161 \mathrm{~S}$ Each additional point \\ 31200S Preliminary Exam or Ineligible Thermometer \\ 31250S Additional copy of report \\ 31260S Special Thermometry Services by Prearrangement
}

covering the range from -196 to $+538^{\circ} \mathrm{C}\left(-320\right.$ to $\left.+1000^{\circ} \mathrm{F}\right)$.

Thermometers belonging to the large and varied group, which may 
be classed as laboratory or "chemical" thermometers, are regularly accepted. These are of the liquid-inglass type with either solid-stem or enclosed scale. Ordinary household or meteorological thermometers will not, in general, be accepted unless the scale is graduated on the glass stem itself and the thermometer can be readily detached from its mounting for insertion in a testing bath. Every thermometer submitted must be uniquely identified by a serial number and must pass a preliminary examination for fineness and uniformity of graduation; for cleanliness of the mercury and capillary bore; for freedom from moisture, gas bubbles, and cracks in the glass; for adequacy or omission of gas filling where needed; for insufficient annealing; and for misnumbered graduations. When these or other serious defects are found, the thermometer is returned untested.

The thermometers to be calibrated are placed in a constant temperature bath along with the NBS primary standard-a calibrated platinum resistance thermometer. The primary standard maintains calibrations traceable to the International Practical Temperature Scale of 1968 (IPTS-68) with an accuracy of $\approx 5 \mathrm{mK}$ at the lower range and $\approx 2 \mathrm{mK}$ at the higher range. (See Table 2).

Table 2: Thermometer Calibration Uncertainties

\begin{tabular}{|c|c|c|}
\hline $\begin{array}{l}\text { Type of Thermometer } \\
\text { (Total Immersion) }\end{array}$ & Range & Uncertainty \\
\hline $\begin{array}{l}\text { Mercury in-glass } \\
\text { (graduations: } \\
0.1-0.2^{\circ} \mathrm{C} \text { ) }\end{array}$ & 0 to $100^{\circ} \mathrm{C}$ & \pm 0.03 to $\pm 0.05^{\circ} \mathrm{C}$ \\
\hline $\begin{array}{l}\text { Mercury in-glass } \\
\text { (graduations: } \\
1-2^{\circ} \mathrm{C} \text { ) }\end{array}$ & $\begin{array}{r}0 \text { to } 300^{\circ} \mathrm{C} \\
300 \text { to } 500^{\circ} \mathrm{C}\end{array}$ & $\begin{array}{l} \pm 0.2 \text { to } \pm 0.3^{\circ} \mathrm{C} \\
\pm 0.5 \text { to } \pm 1.0^{\circ} \mathrm{C}\end{array}$ \\
\hline Organic liquid-in-glass & -200 to $0^{\circ} \mathrm{C}$ & \pm 0.2 to $\pm 0.5^{\circ} \mathrm{C}$ \\
\hline
\end{tabular}

\section{Special Tests of Thermometers} (31110S-31161S)

Special tests may be conducted on temperature measuring devices such as industrial grade platinum resistance thermometers, digital thermometers, thermistors, etc. Laboratory personnel should be contacted before submitting items.

Figure 9 summarizes the relative NBS uncertainties for different types of temperature-measuring instruments including thermometers, thermocouples, and pyrometers. See also following sections.

\section{References-Laboratory Thermo-} meters

Liquid-in-Glass Thermometry, J. A. Wise, Natl. Bur. Stand. (U.S.), Monogr. 150, (Jan. 1976).

ASTM Standard E1-85, Specification for ASTM Thermometers, Annual Book of ASTM Standards 14.01, 89,

Figure 9. Uncertainties for NBS Calibration of Temperature Measuring Instruments

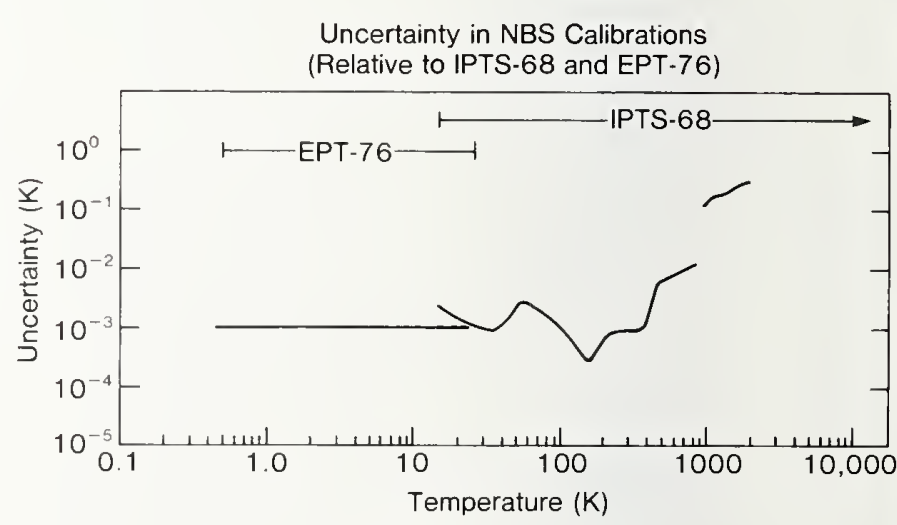

Amer. Soc. for Test.and Matls., Phil. PA (1985).

ASTM Standard E77-84 Methods of Verification and Calibration of Liquid-in-Glass Thermometers, Annual Book of ASTM Standards 14.01, 150, Amer. Soc. for Test. and Matls., Phil., PA (1985). 

Thermocouples, Thermocouple Materials,
and Pyrometer Indicators

Temperature and Pressure Division

Center for Basic Standards

Technical Contacts:

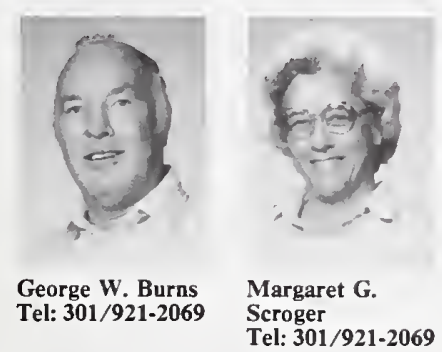

Mailing Address: B128 Physics, National Bureau of Standards, Gaithersburg, MD 20899

Shipping Address: National Bureau of Standards, I-270 at Quince Orchard Road, B229 Physics, Gaithersburg, MD 20899

Attn: G. Burns or M. Scroger

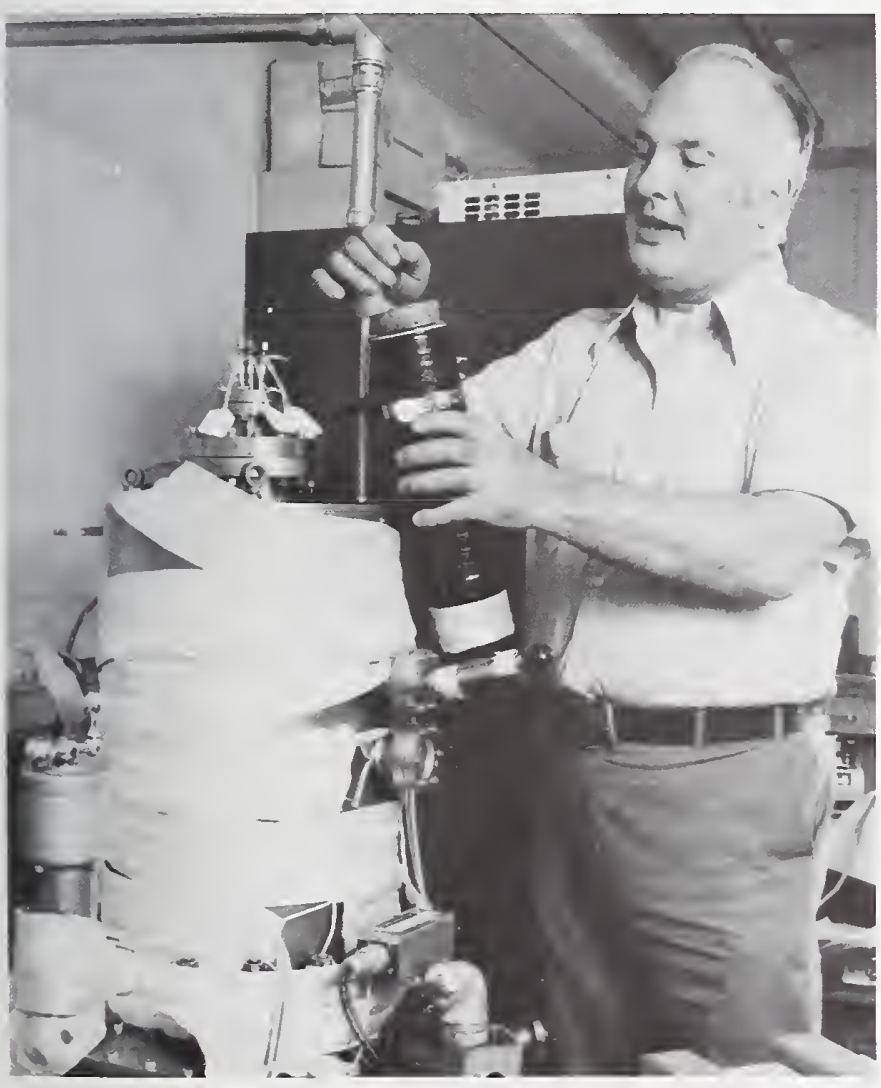

George Burns, making reference junction connections in an ice bath, in preparation for thermocouple calibration.
Comparison Calibrations, Temperature Measured with Thermocouple:

Test No. Items

\begin{tabular}{|c|c|c|c|c|c|c|c|}
\hline & $\begin{array}{c}\text { TC } \\
\text { Гуре }\end{array}$ & $\begin{array}{l}\text { Temp. } \\
\text { Range } \\
{ }^{\circ} \mathrm{C}\end{array}$ & \multicolumn{2}{|r|}{ Points } & $\begin{array}{l}\text { Min. } \\
\text { Length } \\
\text { mm }\end{array}$ & \multicolumn{2}{|c|}{ 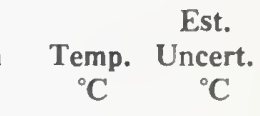 } \\
\hline $2010 \mathrm{C}$ & $S$ & $0-1450$ & \multicolumn{2}{|c|}{$1^{\circ}$ interv. Table } & 700 & $\begin{array}{l}0 \text { to } 1100 \\
1450\end{array}$ & $\begin{array}{r}0.5 \\
2\end{array}$ \\
\hline $32020 \mathrm{C}$ & $\mathrm{R}$ & $0-1450$ & " & $"$ & 700 & $\begin{array}{l}0 \text { to } 1100 \\
1450\end{array}$ & $\begin{array}{r}0.5 \\
2\end{array}$ \\
\hline $32030 \mathrm{C}$ & B & $0-1750$ & " & $"$ & 1000 & $\begin{array}{c}0 \text { to } 600 \\
600 \text { to } 1100 \\
1450 \\
1750\end{array}$ & $\begin{array}{c}(3 \mu V) \\
0.5 \\
2 \\
3\end{array}$ \\
\hline $2031 C$ & B 8 & $00-1750$ & $"$ & $"$ & 1000 & $\begin{array}{c}800 \text { to } 1100 \\
1450 \\
1750\end{array}$ & $\begin{array}{c}0.5 \\
2 \\
3\end{array}$ \\
\hline $32040 \mathrm{C}$ & $\mathrm{E}$ & $0-1000$ & & to 15 & 700 & & 1 \\
\hline $32041 \mathrm{C}$ & $\mathbf{J}$ & $0-760$ & & to 15 & 700 & & 1 \\
\hline $32042 \mathrm{C}$ & $\mathbf{K}$ & $0-1100$ & & to 15 & 700 & & 1 \\
\hline $32043 C$ & $\mathbf{N}$ & $0-1100$ & & to 15 & 700 & & 1 \\
\hline $32044 C$ & $\mathrm{~T}$ & $0-400$ & & to 15 & 700 & & 1 \\
\hline $2050 \mathrm{C}$ & \multicolumn{7}{|c|}{$\begin{array}{l}\text { Comparison calibration, two point minimum, per } \\
\text { point, for all items above }\end{array}$} \\
\hline $32051 \mathrm{C}$ & \multicolumn{7}{|c|}{$\begin{array}{l}\text { Comparison calibration, each additional point for } \\
\text { above }\end{array}$} \\
\hline $32060 \mathrm{C}$ & \multicolumn{7}{|c|}{$\begin{array}{l}\text { Each additional table of results at } 1^{\circ} \text { intervals, for } \\
\text { Type S, R, or B }\end{array}$} \\
\hline $2070 \mathrm{C}$ & \multicolumn{7}{|c|}{$\begin{array}{l}\text { Thermocouple materials tested against Pt standard, } 4 \\
\text { to } 15 \text { points, } 700 \mathrm{~mm} \text { minimum lengths }\end{array}$} \\
\hline
\end{tabular}

Calibration at Metal Freezing Points, Minimum

Diameter $0.4 \mathrm{~mm}$, Freezing Point Determination at

$\mathrm{Au}, \mathrm{Ag}, 630.74^{\circ} \mathrm{C}$, and $\mathrm{Zn}$

$32090 \mathrm{C} S \mathrm{0}-1450$ Table, $1^{\circ}$ interv. 1000 at freezing 0.2 and equations to points generate table

$$
\begin{array}{rl}
0 \text { to } 1100 & 0.3 \\
1450 & 2
\end{array}
$$

32091C Type S, freezing point determination, per point, two point minimum

32092C Type S, freezing point determination, each additional point for above

Calibration of Pyrometer Indicators

$32100 \mathrm{C}$ Portable Potentiometer, first dial or range

$32101 \mathrm{C}$ Portable Potentiometer, each additional dial or range 
Comparison Calibrations, Temperature Measured with Thermocouple:

Test No. Items

Comparison Calibration of Thermocouples or

Thermocouple Materials Tested Against Pt

Thermoelectric Standard, Temperature Measured

with Platinum Resistance Thermometer, Minimum

Length 36 Inches, Two Point Minimum

$32110 C^{*}$ Range -110 to $+300^{\circ} \mathrm{C}$ and Liquid $\mathrm{N}_{2}\left(-196^{\circ} \mathrm{C}\right)$ or -166 to $600^{\circ} \mathrm{F}$ and Liquid $\mathrm{N}_{2}\left(-320^{\circ} \mathrm{F}\right)$

$32111 \mathrm{C}^{*}$ Each additional point for test $32110 \mathrm{C}$

$32120 \mathrm{C}^{*} 301$ to $538{ }^{\circ} \mathrm{C}$ or 601 to $1000^{\circ} \mathrm{F}$

$32121 \mathrm{C}^{*}$ Each additional point for test $32120 \mathrm{C}$

$32130 \mathrm{C}^{*}$ Liquid $\mathrm{O}_{2}\left(-183^{\circ} \mathrm{C}\right)$ or $\left(-297^{\circ} \mathrm{F}\right)$

$32131 C^{*}$ Each additional point for test $32130 \mathrm{C}$

Table at one degree intervals for Type T thermocouple for any of the following options:

(The cost of the table will be in addition to the calibration per point covered under fee schedule items numbered 32110C-32131C.)

$32141 C^{*}$ Option 1: Table from -190 to $+300^{\circ} \mathrm{C}(-310$ to $\left.+572{ }^{\circ} \mathrm{F}\right)$, calibration points at $-183,-110,-50$, $+100,+200,+300^{\circ} \mathrm{C}$.

$32142 \mathrm{C}^{*}$ Option 2: Table from -190 to $+100{ }^{\circ} \mathrm{C}(-310$ to $+212^{\circ} \mathrm{F}$ ), calibration points at $-183,-110,-50$, $+50,+100^{\circ} \mathrm{C}$.

32143C* Option 3: Table from -110 to $+300{ }^{\circ} \mathrm{C}(-166$ to $\left.+572^{\circ} \mathrm{F}\right)$, calibration points at $-110,-50,+100$, $+200,+300^{\circ} \mathrm{C}$.

$32144 \mathrm{C}^{*}$ Option 4: Table from -110 to $+100^{\circ} \mathrm{C}(-166$ to $\left.+212^{\circ} \mathrm{F}\right)$, calibration points at $-110,-50,+50$, $+100^{\circ} \mathrm{C}$.

$32145 \mathrm{C}^{*}$ Option 5: Table 0 to $300^{\circ} \mathrm{C}\left(32\right.$ to $\left.572{ }^{\circ} \mathrm{F}\right)$, calibration points at $+100,+200,+300^{\circ} \mathrm{C}$.

32146C* Option 6: Table from -110 to $0{ }^{\circ} \mathrm{C}\left(-166\right.$ to $\left.+32{ }^{\circ} \mathrm{F}\right)$, calibration points at $-110,-50^{\circ} \mathrm{C}$.

$32147 \mathrm{C}^{*}$ Option 7: Table from -190 to $0^{\circ} \mathrm{C}(-310$ to $\left.+32{ }^{\circ} \mathrm{F}\right)$, calibration points at $-183,-110,-50{ }^{\circ} \mathrm{C}$.

32150S Special Tests of Thermocouples and Thermocouple Materials

* Jacquelyn Wise (Tel: 301/921-2087) is the technical contact for these tests. See Section C of this chapter for her mailing and shipping addresses.
Thermocouples, Thermocouple

Materials, and Pyrometer Indicators (32010C-32147C)

Calibration services for all commonly used types of thermocouples are provided by NBS from -196 to $1750^{\circ} \mathrm{C}$ depending upon the wire or thermocouple type. The thermocouples are calibrated by one or a combination of three general methods, depending on the thermocouple type, the temperature range, and the accuracy required. All three methods provide traceability to the IPTS-68. In the first method, thermocouples are calibrated by comparison with a standard thermocouple maintained at NBS. In the second method, thermocouples are calibrated by comparison with a standard platinum resistance thermometer. In the third method, thermocouples are calibrated at three defining temperatures on the IPTSthe freezing points of $\mathrm{Zn}, \mathrm{Ag}$, and $\mathrm{Au}$, as well as at $630.74^{\circ} \mathrm{C}$. Below $0{ }^{\circ} \mathrm{C}$ the thermocouple calibration is carried out in a cryostat, while above $0{ }^{\circ} \mathrm{C}$ stirred liquid baths, metal freezing-point cells, and electric tubetype furnaces are employed for the calibrations. Vacuum or inert gas furnaces are also available for testing thermocouples.

Only the bare wires are required to perform the thermocouple calibrations. It is preferable not to send insulating and protecting tubes as the rate of breakage of these in shipment is high. If the thermocouple is furnished mounted (as in a protection 
tube assembly) a nominal charge will be made for dismantling the mounting and the various parts will be returned to the sender without reassembling them. Thermocouple length requirements listed in the appendix are exclusive of lead wire. Lead wire need not be sent with thermocouples. All thermocouple calibration data furnished in reports will be on the basis of a reference junction temperature of $0{ }^{\circ} \mathrm{C}$ or $32^{\circ} \mathrm{F}$. The calibration results will be given in degrees $\mathrm{C}$ or $\mathrm{F}$, as requested by the customer. The calibration of a thermocouple will not be undertaken if it will likely not yield the specified accuracy or if it possesses such unusual characteristics as to prevent the carrying out of the calibration or test at a reasonable cost. Only unused base-metal thermocouples and thermocouple materials will be accepted for test.

\section{Special Tests of Thermocouples and Thermocouple Materials (32150S)}

For requirements not covered by calibrations described above, special arrangements may be made by contacting one of the Temperature and Pressure Division staff members identified at the beginning of this section.

\section{References-Thermocouples}

ASTM Standard E220-80, Standard Method for Calibration of Thermocouples by Comparison Techniques, Annual Book of ASTM Standards, 14.01, 255, Amer. Soc. for Test. and Matls., Phil., PA (1983).

ASTM Standard E230-77, Temperature-Electromotive Force (EMF) Tables for Thermocouples,
Annual Book of ASTM Standards, 14.01, 271, Amer. Soc. for Test. and Matls., Phil., PA (1983).

American National Standard, Temperature Measurement Thermocouples, ANSI-MC96.1-1982, Instr. Soc. of Amer., Res. Triangle Park, NC (1982).

Manual on the Use of Thermocouples in Temperature Measurement, ASTM STP 470B, Amer. Soc. for Test. and Matls., Philadelphia, PA (1981).

Accurate Thermocouple Thermometry, L. A. Guildner and G. W. Burns, High Temperatures-High Pressures, 11, 173 (1979).

International Electrotechnical Commission Standard, Thermocouples, Part 1: Reference Tables. IEC Publication 584-1, Intl. Electrotech. Com., Geneva (1977).

Thermocouple Reference Tables Based on the IPTS-68, R. L. Powell, W. J. Hall, C. H. Hyink, Jr., L. L. Sparks, G. W. Burns, M. G. Scroger, and H. H. Plumb, Natl. Bur. Stand. (U.S.), Monogr. 125 (1974).

Methods of Testing Thermocouples and Thermocouple Materials, W. F. Roeser and S. T. Lonbarger, Natl. Bur. Stand. (U.S.), Circular 590 (1958). 
Resistance Thermometry

Temperature and Pressure Division Center for Basic Standards

Technical Contact:

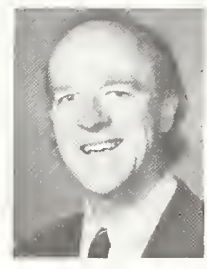

William R. Bigge
Tel: 301/921-2757

Mailing Address: B128 Physics, National Bureau of Standards, Gaithersburg, MD 20899

Shipping Address: National Bureau of Standards, I-270 at Quince Orchard Road, B04 Physics, Gaithersburg, MD 20899

Attn: W. Bigge

\section{Test No. Items}

$33010 \mathrm{C}$ Long Stem PRT $\left(-50^{\circ} \mathrm{C}\right.$ to +500 or $\left.+630^{\circ} \mathrm{C}\right)$

$33020 \mathrm{C}$ Long Stem PRT $\left(-183^{\circ} \mathrm{C}\right.$ to +500 or $\left.+630^{\circ} \mathrm{C}\right)$

$33030 \mathrm{C}$ Calorimetric Type PRT $\left(-50\right.$ to $\left.+150^{\circ} \mathrm{C}\right)$

$33040 \mathrm{C}$ Capsule Type PRT (13 K to $600 \mathrm{~K}$ )

$33050 \mathrm{C}$ Capsule Type PRT $\left(-183^{\circ} \mathrm{C}\right.$ to $\left.+300^{\circ} \mathrm{C}\right)$

$33060 \mathrm{~S}$ Special Tests of Germanium Resistance

Thermometers ( 2 to $20 \mathrm{~K}$ )

33070C Additional Copy of Table from Results of

33010C-33050C at Time of Test

33080C Additional Copy of Table from Results of 33010C-33050C at Later Date

33090C Minimum Charge for Unsuitable Thermometer

33100S Special Tests of Resistance Thermometers

33110 Special Tests of Thermometric Fixed-Point Devices

33120M Measurement Assurance Program for Temperature

Platinum Resistance Thermometers (33010C-33050C)

NBS provides calibration services for standard platinum resistance thermometers (SPRTs) from 13.81 to 903
K. Both long-stem and capsule-type SPRTs are calibrated, providing direct access to the IPTS-68. The reproducibility of the calibration measurements of SPRTs is better than $\pm 0.3 \mathrm{mK}$ and the accuracy of overall calibration is $\pm 1 \mathrm{mK}$. The reproducibility of triple point of water cells used for calibration of SPRTs is $\pm 50 \mu \mathrm{K}$ or better while that for zinc and tin freezing-point cells is \pm 0.1 $\mathrm{mK}$. The precision of comparison calibration of long-stem type SPRTs in terms of the reference standard SPRTs at the oxygen boiling point $\left(-183^{\circ} \mathrm{C}\right)$ is better than $\pm 0.1 \mathrm{mK}$. The stability of the reference SPRTs in this temperature range is also about $\pm 0.1 \mathrm{mK}$. The NBS temperature scale in the range 13 to $90 \mathrm{~K}$ is based on stable reference standard SPRTs of the capsule type and has a precision of about $\pm 0.1 \mathrm{mK}$ down to about $20 \mathrm{~K}$. Below $20 \mathrm{~K}$, the precision degrades to about $\pm 0.3 \mathrm{mK}$ as the SPRTs become less sensitive.

To qualify for testing, either longstem or capsule platinum resistance thermometers must meet two conditions. They must reasonably be expected to meet the requirements of the IPTS-68 for a standard interpolating instrument (i.e., a four lead resistor of high-purity platinum hermetically sealed in a protecting tube). Second, they must be compatible with the NBS highest-precision calibration equipment. It is important that, insofar as possible, resistance thermometers be protected from any mechanical shock which will alter their calibration. To be shipped, the thermometer must be softly supported within a case but not be free to rattle. This necessitates the use of packing material that does not become compacted. The thermometer case should in turn be softly packed inside a shipping container. The outside shipping container must be sufficiently rigid and strong that it will not appreciably deform under the treatment usually 
given by shippers. Styrofoam is not sufficiently rigid to be used as an outside container. Thermometers will not be returned in containers which are obviously unsuitable, such as those closed by nailing. Suitable containers will be provided, for a fee, when a thermometer shipping container is not satisfactory for reuse.

\section{Special Tests of Germanium Resistance Thermometers and Thermometric Fixed Point Devices (33060.S, 33100S, and 33110S)}

Special tests of various resistance thermometers and thermometric fixed point devices may be made by prearrangement with the Temperature and Pressure Division.

\section{Measurement Assurance Program for Temperature (33120M)}

The purpose of this MAP service is to assure the accuracy of the calibration of temperature standards made by participating laboratories in the -183 to $+630^{\circ} \mathrm{C}$ temperature range when using platinum resistance thermometry. Special arrangements may be made if participants are interested in only a portion of this temperature range.

The MAP transport standard consists of a set of three commercial glass-sheathed standard-type platinum resistance thermometers (SPRTs) packaged in a special shock-proof shipping container (mechanical shock or sudden temperature excursions may result in shifts in calibration). These SPRTs are used to assess both the reproducibility and the accuracy of calibrations performed by the participating laboratory.

MAP participants should use the techniques in NBS Monograph 126 and the same fixed points as in the NBS calibrations, or an SPRT previously calibrated by NBS. In order to achieve high accuracy, SPRTs used as standards should be of the matte-finish type to avoid systematic errors arising from light pipe effects in the glass sheath. The participant must have a triple point cell and a calibrated resistance bridge.

After unpacking the transport standard and inspecting it for damage the participant should measure the resistance of the SPRTs at the triple point of water using the triple-point cell. A preliminary check of the resistances at the water triple point is used as a "go/no go" check to ensure that the thermometers have not been damaged in shipment.

These measurements are reported by telephone to NBS; if the values are consistent with the data taken by NBS before shipment, the participant should proceed with further measurements. Data are taken by NBS and the participants at the fixed points defined in the IPTS-68. NBS provides a worksheet on which the participant can record the data. The participant then calculates the thermometer constants from the experimental data, records them, and prepares tables of resistance versus temperature.

The SPRTs are recalibrated upon return to NBS and the data are compared to NBS's calibrations. NBS provides a plot of the participating laboratory's temperature deviation from NBS values and a written analysis of the data including any pertinent observations. In a typical transfer, the participant makes several measurements over a period of two to three months. A typical turnaround time from the date NBS receives the participant's data until a test report is sent to the participant is three to four weeks.

The best NBS SPRT calibrations have precisions of about 0.1 to 0.2 $\mathrm{mK}$. Sources of error that may contribute to the total uncertainty include 
changes in the calibration of the measurement instruments, changes in the SPRT itself, and uncertainty of the degree of purity of the materials used as fixed-point references (e.g., zinc). As a result of quantifying these sources of error, NBS currently assigns an uncertainty of $1 \mathrm{mK}$ to the values assigned to the MAP transport standards. A standards laboratory conscientiously participating in this MAP and having suitable equipment should be able to closely approximate this uncertainty figure. Participants in the temperature MAP have uncertainties that range from close to $1 \mathrm{mK}$ to hundredths of a kelvin.

No rigid recommendations can be given concerning how often a participant should utilize the temperature MAP service. Experience has indicated that when temperature measurements are in a state of statistical control using in-house check standards and control charts to monitor the process, the participant should be able to go at least three years between transfers from NBS without significantly degrading the confidence in the correctness of the measurements.

\section{References-Resistance Thermometry}

Reproducibility of Some Triple Point of Water Cells, G. T. Furukawa and W. R. Bigge, Temperature, Its Measurement and Control in Science and Industry, Vol. 5, 291, Amer. Inst. Phys., New York, NY (1982).

Standard Reference Materials: Application of Some Metal SRM's as Thermometric Fixed Points, G. T. Fur- ukawa, J. L. Riddle, W. R. Bigge and E. R. Pfeiffer, Natl. Bur. Stand. (U.S.), Spec. Publ. 260-77 (Aug. 1982).

A Measurement Assurance ProgramThermometer Calibration, G. T. Furukawa and W. R. Bigge, in Testing Laboratory Performance, Evaluation and Accreditation, Natl. Bur. Stand. (U.S.), Spec. Publ. 591, 137 (Aug. 1980).

Comparison of Freezing Temperature of National Bureau of Standards SRM-740 Zinc Standards, G. T. Furukawa and J. L. Riddle, Comité Consultatif de Thermométrie, May 9-11, 1978, Sévres, France.

The International Practical Temperature Scale of 1968 in the Region $90.188 \mathrm{~K}$ to $903.89 \mathrm{~K}$ as Maintained at the National Bureau of Standards, G. T. Furukawa, J. L. Riddle, and W. R. Bigge, J. Res. Natl. Bur. Stand. (U.S.), 80A, 477 (May-June 1976). The International Practical Temperature Scale of 1968 in the Region $12.81 \mathrm{~K}$ to $90.188 \mathrm{~K}$ as Maintained at the National Bureau of Standards, G. T. Furukawa, J. R. Riddle, and W. R. Bigge, J. Res. Natl. Bur. Stand. (U.S.), 80A, 477 (May-June 1973). Platinum Resistance Thermometry, J. L. Riddle, G. T. Furukawa, and H. H. Plumb, Natl. Bur. Stand. (U.S.), Monogr. 126 (Apr. 1973).

Investigation of Freezing Temperatures of National Bureau of Standards Tin Standards, G. T. Furukawa, J. L. Riddle and W. R. Bigge, Vol. 4 of Temperature, Part 1, 247, Instr. Soc. of Amer., Pittsburgh, PA (1972). 
Radiation Thermometry

Radiometric Physics Division

\section{Center for Radiation Research}

\section{Technical Contact:}

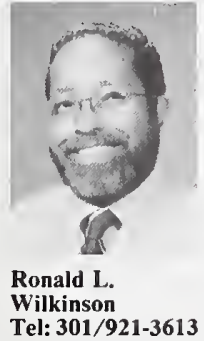

Mailing Address: A223 Physics, National Bureau of Standards, Gaithersburg, MD 20899

\section{Test No. Items}

$35010 \mathrm{C}$ Optical Pyrometers (1 range between 800 to $2400{ }^{\circ} \mathrm{C}$, 4 to 12 points)

35020C Optical Pyrometers (per range in addition up to $\left.4200^{\circ} \mathrm{C}\right)$

35030C Additional interpolated values

35040C Optical Pyrometers ( 3 or fewer points, 800 to $4200^{\circ} \mathrm{C}$ )

$35050 \mathrm{C}$ Ribbon Filament Lamp (6 to 16 points, 800 to $2300^{\circ} \mathrm{C}$ )

35060C Ribbon Filament Lamp (5 or fewer points, 800 to $2300^{\circ} \mathrm{C}$ )

35070S Special Tests of Radiation Pyrometers

Optical Pyrometers and Ribbon Filament Lamps (35010C-35060C)

These calibration services provide access to the IPTS-68 as realized by NBS for the temperature range $800^{\circ} \mathrm{C}$ to $4200^{\circ} \mathrm{C}$. High precision monochromatic visual and automatic optical pyrometers are calibrated in that temperature range. Uncertainties in routine testing vary from $\pm 3{ }^{\circ} \mathrm{C}$ at $1064^{\circ} \mathrm{C}$, and $\pm 8^{\circ} \mathrm{C}$ at $2800{ }^{\circ} \mathrm{C}$, to $\pm 30^{\circ} \mathrm{C}$ at $4200^{\circ} \mathrm{C}$. Ribbon filament lamps are calibrated using the NBS photoelectric pyrometer, and reports of brightness temperature at $655 \mathrm{~nm}$ versus direct current are issued. Uncertainties in routine testing vary from $\pm 0.75^{\circ} \mathrm{C}$ at $1064{ }^{\circ} \mathrm{C}$ to $\pm 2{ }^{\circ} \mathrm{C}$ at $2300^{\circ} \mathrm{C}$.

The radiation thermometry portion of IPTS-68 is defined in terms of a fixed temperature for the freezing point of gold $\left(1064.43^{\circ} \mathrm{C}\right)$ and the Planck equation for the radiation of a blackbody source. In practice, temperature scales are realized by constructing a gold point blackbody and a variable temperature blackbody, and then measuring spectral radiance ratio at a red wavelength (approximately $650 \mathrm{~nm}$ ) in terms of the Planck equation. Gold point blackbodies are reproducible to $\pm 0.02{ }^{\circ} \mathrm{C}$, but the temperature assignment of the freezing point of gold is uncertain by about $\pm 0.5^{\circ} \mathrm{C}$. The spectral radiance ratio measurements can be performed with an uncertainty of 0.2 to $.3 \%$. Higher accuracies than available in the routine tests described above can be provided as special tests subject to the IPTS uncertainties noted. Calibrations at wavelengths other than $650 \mathrm{~nm}$ can be provided in the wavelength range 250 to $2500 \mathrm{~nm}$ subject to an additional uncertainty due to the quality of the variable temperature blackbody.

Special Tests of Radiation Pyrometers (35070S)

Calibrations at wavelengths other than $650 \mathrm{~nm}$ can be provided in the wavelength range $250 \mathrm{~nm}$ to $2500 \mathrm{~nm}$ subject to an additional uncertainty due to the quality of the variable temperature blackbody. Absorbing glass 
filters used for range changing in optical pyrometers can also be calibrated as special tests.

\section{References-Radiation Thermometry} The International Practical Temperature Scale of 1968, Amended Edition of 1975, Metrologia, 12, 7 (1976).

Corrections in Optical Pyrometry and Photometry for the Refractive Index of Air, W. R. Blevin, Metrologia, 8, 146 (1972).

Vacuum Tungsten Strip Lamps with Improved Stability as Radiance Temperature Standards, T. J. Quinn and R. D. Lee, 5th Symposium on Temperature, 395, Instr. Soc. Am., Res. Triangle Park, NC (1971).

High-Accuracy Spectral Radiance Calibration of Tungsten-Strip Lamps, H. J. Kostkowski, D. E. Erminy, and A. E. Hattenburg, Adv. Geophys. 14, 111 (1970).

The NBS Photoelectric Pyrometer and Its Use in Realizing the International Practical Temperature Scale above $1063^{\circ} \mathrm{C}$, R. D. Lee, Metrologia, 2, No. 4, 150 (Oct. 1966).

Theory and Methods of Optical Pyrometry, H. J. Kostkowski and R. D. Lee, Natl. Bur. Stand. (U.S.), Monogr. 41 (Mar. 1962).

\section{Humidity Measurements} Chemical Process Metrology Division Center for Chemical Engineering

\section{Technical Contact:}

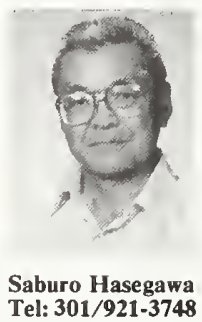

Mailing Address: B312 Physics, National Bureau of Standards, Gaithersburg, MD 20899

\section{Test No. Items}

$36010 \mathrm{C}$ Dew-Point Hygrometers $\left(+25\right.$ to $\left.-15^{\circ} \mathrm{C}\right)$

$36020 \mathrm{C}$ Dew-Point Hygrometers $\left(-70\right.$ to $-15^{\circ} \mathrm{C}$ )

36030C Electric Hygrometers

36040C Coulometric Hygrometers

36050C Aspirated Hygrometers

36060C Pneumatic Bridge Hygrometers

36070S Special Tests of Humidity

\section{Hygrometers (36010C-36060C)}

NBS provides calibration services for a wide variety of humidity-measuring instruments. Calibrations are performed by subjecting the instrument under test to atmospheres of known moisture content produced by the NBS two-pressure humidity generator. The instruments and ranges of calibration are listed below:

A. Dew-Point Hygrometers calibrated over the dew/frost range of -80 to $+80^{\circ} \mathrm{C}$.

B. Electric Hygrometers classified under this category are sensors which 
sorb water vapor as a function of relative humidity; associated with this sorption is a corresponding change in an electric parameter (that is, resistance, capacitance). The range of calibration is 3 to 98 percent relative humidity over the temperature range -55 to $+80^{\circ} \mathrm{C}$.

C. Psychrometers are a wet-dry bulb hygrometer (aspirated psychrometers). The contact person should be consulted for the special features of the psychrometer which are necessary before the instrument can be calibrated at NBS.

D. Coulometric Hygrometers are devices which electrolyze water into gaseous oxygen and hydrogen by the application of a voltage in excess of the thermodynamic decomposition voltage for water, and then measure the electrolysis current. The range of calibration is 1 to $31,000 \mathrm{ppm}$ by volume.

E. Pneumatic Bridge Hygrometers are instruments which measure the variation of the pressure drop across two combinations of nozzles, operating at critical flow, with a desiccant between one pair of nozzles. The range of calibration in mixing ratio (gram water vapor/gram dry air) is 0.0005 to 0.015 .

Figure 10 illustrates typical NBS uncertainties for measurement of humidity standards with atmospheric air at atmospheric pressure.

Special Tests of Humidity (36070S)

Tests such as response time, hysteresis, stability, can be provided upon request.

References-Humidity Measurements Vapor Pressure Formulation for Ice, A. Wexler, J. Res. Natl. Bur. Stand.
(U.S.), 81A (Phys. and Chem.), No. 1, 5 (Jan.-Feb. 1977).

The NBS Two-Pressure Humidity

Generator, Mark 2, S. Hasegawa and J. W. Little, J. Res. Natl. Bur. Stand. (U.S.), $81 \mathrm{~A}$ (Phys. and Chem.), No .1, 81 (Jan.-Feb. 1977).

Vapor Pressure Formulation for Water in Range 0 to $100^{\circ} \mathrm{C}$. A revision, A. Wexler, J. Res. Natl. Bur. Stand. (U.S.), 80A (Phys. and Chem.), Nos. 5 and 6, 775 (Sept.-Dec. 1976).

A Correlation for the Second Interaction Virial Coefficients and Enhancement Factors for Moist Air, R. W. Hyland, J. Res. Natl. Bur. Stand. (U.S.), 79A (Phys. and Chem.), No. 4, 551 (July-Aug. 1975).

The NBS Standard Hygrometer, A. Wexler and R. W. Hyland, Natl. Bur. Stand. (U.S.), Monogr. 73 (May 1964).

Figure 10. NBS Uncertainties for Measurements of Humidity Standards with Atmospheric Air at Atmospheric Temperature

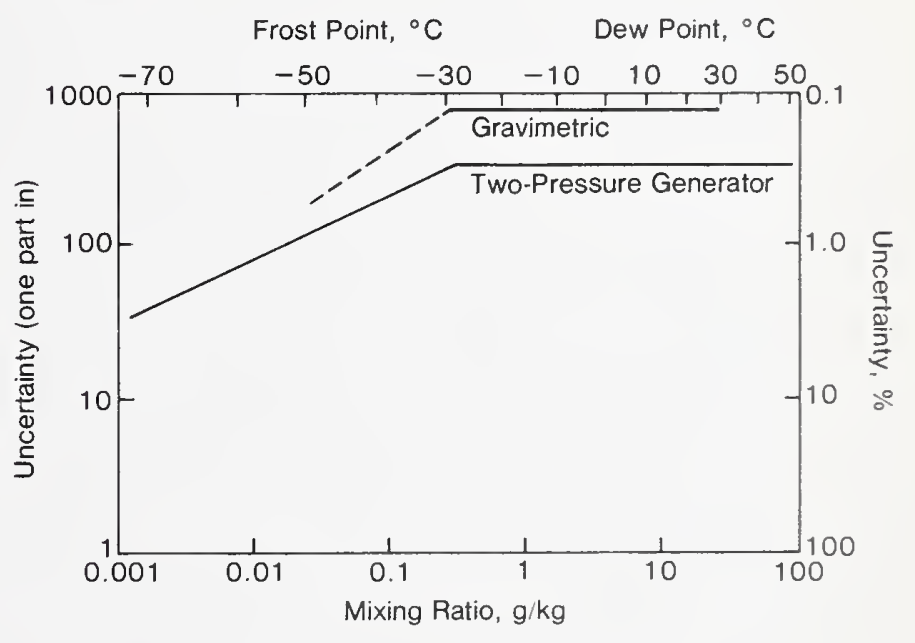




\title{
Chapter
}

\author{
A Photometric Measurements \\ $B$ Spectrophotometric Measurements \\ C Radiometric Measurements \\ $D$ Radiometric Standards in the \\ Ultraviolet \\ $E$ Optical Fiber Attenuation and \\ Bandwidth \\ $F$ Laser Power and Energy
}




\section{Optical Radiation Measurements}

Photometric Measurements

Radiometric Physics Division

Center for Radiation Research

Technical Contact:

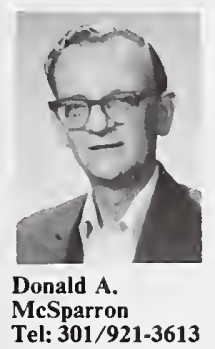

Mailing Address: B306 Metrology, National Bureau of Standards, Gaithersburg, MD 20899

Test No. Items

37010C Luminous Intensity Standard (100 W Frosted Tungsten Lamp, 90 candelas)

37020C Luminous Intensity Standard (100 W Frosted

Tungsten Lamp, color temp., $2700 \mathrm{~K}$ )

37030C Luminous Intensity Standard (100 W Frosted Tungsten Lamp, color temp., $2856 \mathrm{~K}$ )

37040C Luminous Intensity Standard (500 W Frosted Tungsten Lamp, 700 candelas)

37050C Luminous Intensity Standard (500 W Frosted Tungsten Lamp, color temp., $2856 \mathrm{~K}$ )

37060C Luminous Intensity Standard (1000 W Frosted Tungsten Lamp, 1400 candelas)

37070C Luminous Intensity Standard (1000 W Frosted Tungsten Lamp, color temp., $2856 \mathrm{~K}$ )

37080C Luminous Flux Standard (25 W Vacuum Lamp about 270 lumens)

37090C Luminous Flux Standard (60 W Gas-Filled Lamp about 870 lumens)

\section{General Information}

Calibration services in this area provide access to the photometric scales realized and maintained at NBS. Lamp standards of luminous intensity, luminous flux, and color temperature

\begin{tabular}{|c|c|}
\hline Test No. & Items \\
\hline $37100 \mathrm{C}$ & $\begin{array}{l}\text { Luminous Flux Standard ( } 100 \mathrm{~W} \text { Gas-Filled Lamp } \\
\text { about } 1600 \text { lumens) }\end{array}$ \\
\hline $37110 \mathrm{C}$ & $\begin{array}{l}\text { Luminous Flux Standard ( } 200 \mathrm{~W} \text { Gas-Filled Lamp } \\
\text { about } 3300 \text { lumens) }\end{array}$ \\
\hline $37120 \mathrm{C}$ & $\begin{array}{l}\text { Luminous Flux Standard ( } 500 \mathrm{~W} \text { Gas-Filled Lamp } \\
\text { about } 10,000 \text { lumens) }\end{array}$ \\
\hline $37130 \mathrm{C}$ & $\begin{array}{l}\text { Luminous Flux Standard (Miniature Lamps } 7 \text { sizes } \\
6 \text { to } 400 \text { lumens) }\end{array}$ \\
\hline $37140 \mathrm{C}$ & $\begin{array}{l}\text { Airway Beacon Lamps for Color Temperature } \\
(500 \mathrm{~W}, 1 \text { point in range, } 2000-3000 \mathrm{~K})\end{array}$ \\
\hline $37150 \mathrm{C}$ & Each additional color temp. \\
\hline $37160 \mathrm{C}$ & $\begin{array}{l}\text { Color temperature equation ( } 4 \text { points and } \\
\text { interpolation equation) }\end{array}$ \\
\hline $37170 \mathrm{C}$ & $\begin{array}{l}\text { Opal Glass Luminous Directional Transmittance } \\
\text { Standards }\end{array}$ \\
\hline $37180 S$ & Special Photometric Tests \\
\hline
\end{tabular}

as described below are calibrated on a routine basis.

\section{Luminous Intensity Standards (37010C-37070C)}

Luminous intensity standard lamps supplied by NBS [100-W (90-140 cd), 
500-W (approximately $700 \mathrm{~cd}$ ) and 1000-W (approximately $1400 \mathrm{~cd}$ ) tungsten filament lamps with C-13B filaments in inside-frosted bulbs and having medium bipost bases] are calibrated at either a set current or a specified color temperature in the range 2700 to $3000 \mathrm{~K}$. Approximate uncertainties are 2 percent relative to the SI unit of luminous intensity and 1.5 percent relative to NBS standards.

\section{Luminous Flux Standards} (37080C-37130C)

Luminous flux standards-lamps (geometrically total) submitted by the customer. Vacuum tungsten lamps of $25 \mathrm{~W}$ and 60-, 100-, 200-, and 500-W gas filled tungsten lamps are calibrated. Lamps must be basc-up burning and rated at $120 \mathrm{~V}$. Approximate uncertainties are 2.5 percent relative to SI units and 1.5 percent relative to NBS standards. Luminous flux standards for miniature lamps producing 6 to $400 \mathrm{~lm}$ are calibrated with uncertainties of 3 percent.

\section{Airway Beacon Lamps (37140C-37160C)}

Color temperature standard lamps supplied by NBS (airway beacon
500-W medium bipost lamps) are calibrated for color temperature in the range 2000 to $3000 \mathrm{~K}$ with an uncertainty of 10 degrees.

\section{Opal Glass Luminous Directional Transmittance Standards (37170C)}

Flashed opal glasses, $51 \mathrm{~mm} \times 51 \mathrm{~mm}$, are calibrated for luminous directional transmittance (exitant luminance per incident illuminance). The glasses are masked with a diaphragm limiting the useful area to a circle $1.9 \mathrm{~cm}$ in diameter.

\section{Special Tests of Photometric Devices} (37180S)

Lamp standards of luminous intensity can be calibrated at any color temperature in the range $2000 \mathrm{~K}$ to 3200 $\mathrm{K}$. Photometric values can be computed for special sources measured spectrally on the Facility for Automatic Spectral Calibrations (FASCAL). See test 39070 S for details.

\section{Reference-Photometric} Measurements

Photometric Calibration Procedures, V. I. Burns and D. A. McSparron, Natl. Bur. Stand., (U.S.), Tech. Note 594-3 (Nov. 1972). 
Spectrophotometric Measurements

Radiometric Physics Division

Center for Radiation Research

Technical Contact:

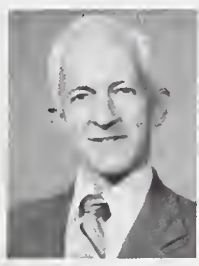

Victor R. Weidne

Tel: 301/921-2453

Mailing Address: B306 Metrology, National Bureau of Standards, Gaithersburg, MD 20899

\begin{tabular}{|c|c|}
\hline est No. & Items \\
\hline $38010 \mathrm{C}$ & $\begin{array}{l}\text { Spectral Transmittance Filters (Cobalt Blue } \\
\text { Glass) }\end{array}$ \\
\hline $38020 \mathrm{C}$ & $\begin{array}{l}\text { Spectral Transmittance Filters (Copper Green } \\
\text { Glass) }\end{array}$ \\
\hline $38030 \mathrm{C}$ & $\begin{array}{l}\text { Spectral Transmittance Filters (Carbon Yellow } \\
\text { Glass) }\end{array}$ \\
\hline $38040 \mathrm{C}$ & $\begin{array}{l}\text { Spectral Transmittance Filters (Selenium } \\
\text { Orange Glass) }\end{array}$ \\
\hline $38050 \mathrm{C}$ & Wavelength Standards (Holmium Oxide Glass) \\
\hline $38060 \mathrm{~S}$ & $\begin{array}{l}\text { Special Tests of Spectral Transmittance and } \\
\text { Reflectance }\end{array}$ \\
\hline $38070 \mathrm{M}$ & $\begin{array}{l}\text { Measurement Assurance Program for } \\
\text { Retroreflectance-Complete Package }\end{array}$ \\
\hline $38071 \mathrm{M}$ & $\begin{array}{l}\text { Retroreflectance MAP-Sheeting Standards or } \\
\text { Prismatic Standard with Colored Filters }\end{array}$ \\
\hline $38072 \mathrm{M}$ & $\begin{array}{l}\text { Retroreflectance MAP-Sheeting Standards } \\
\text { and Prismatic Standard Without Colored Filters }\end{array}$ \\
\hline $38073 \mathrm{M}$ & $\begin{array}{l}\text { Retroreflectance MAP-Sheeting Standards or } \\
\text { Prismatic Standard Without Colored Filters }\end{array}$ \\
\hline $38074 \mathrm{M}$ & Retroreflectance MAP-Colored Filters Only \\
\hline $38080 \mathrm{M}$ & $\begin{array}{l}\text { Measurement Assurance Program for } \\
\text { Transmittance }\end{array}$ \\
\hline $38090 \mathrm{~S}$ & Special Tests of Photographic Step Tablets \\
\hline $38100 \mathrm{~S}$ & $\begin{array}{l}\text { Special Tests of Microcopy Resolution } \\
\text { Test Charts }\end{array}$ \\
\hline
\end{tabular}

Spectral Transmittance Filters (38010C-38040C)

NBS supplies standards of spectral transmittance for checking the photometric scale of spectrophotometers.

These are either $30 \mathrm{~mm}$ polished glass disks or $51 \mathrm{~mm}$ polished glass squares, 2 to $3 \mathrm{~mm}$ thick, designated as cobalt blue, copper green, carbon yellow, and selenium orange (disks will be supplied unless otherwise specified). Information provided to the user includes: values of transmittance at $25^{\circ} \mathrm{C}$ at $10 \mathrm{~nm}$ intervals from 380 to $770 \mathrm{~nm}$; the estimated uncertainty of each value; and data as to the effect of temperature change on transmittance at each wavelength.

Wavelength Standards (38050C)

Holmium oxide glass standards are also supplied for checking the ultraviolet and visible wavelength calibrations of recording spectrophotometers having a bandpass less than $2 \mathrm{~nm}$. These are made of polished Corning 3130 glass, $51 \times 51$ $\mathrm{mm}, 2.5 \mathrm{~mm}$ thick. A table of wavelengths of minimum transmittance is provided in the report to the user.

Special Tests of Spectral Transmittance and Reflectance (38060S)

Measurements of spectral transmittance can be made for the wavelength region 190 to $2500 \mathrm{~nm}$. Measurements of absolute spectral reflectance factors and of spectral specular reflectance can be made for the wavelength region 250 to $2500 \mathrm{~nm}$. However, arrangements for these measurements on submitted specimens 
must be made before shipment. The decision as to whether or not to perform the measurements and selection of the instruments to be used will rest with NBS. Specimens not accepted for measurement will be returned. Accuracy and precision estimates will be given. Estimates will be dependent upon the optical characteristics of the submitted specimens.

Measurement Assurance Programs for Retroreflectance (38070M-38074M)

These Measurement Assurance Programs (MAPs) verify, within certain limits, how well a laboratory can measure coefficient of luminous intensity. The verification is accomplished by means of a MAP package. The MAP package contains two white bead sheeting retroreflectors, one colorless prismatic retroreflector, and seven colored glass filters. The elements in this package are measured by NBS, then by the participating laboratory, and finally by NBS. Quality control procedures are maintained by using NBS master standards.

The use of three retroreflectors enable determination of how well the participant can measure coefficient of luminous intensity for white or colorless samples of three kinds of geometries. The luminous transmittance of the seven colored glass filters can be used as a diagnostic tool to check measurements of coefficient of luminous intensity of colored retroreflectors. This is accomplished by checking the conformance of the source-receiver combination to CIE Illuminant $\mathbf{A}$ and photopic response respectively.

The coefficient of luminous intensity of each of the bead sheeting standards is measured at six combinations of observation and entrance angles. The coefficient of luminous intensity of the prismatic retroreflector is measured at 18 combinations of entrance and observation angles. The luminous transmittance of the filters is provided only for the spectral conditions of source and receiver specified above.

A general testing laboratory will probably need the service utilizing the complete MAP package. However, some laboratories may be specialized. For this reason, we list five options that offer not only the complete package, but also some selected components. These options are:

A. Complete MAP package;

$B$. Sheeting standards or prismatic standard with colored filters;

$C$. Sheeting standards or prismatic standard without colored filters;

$D$. Sheeting standards and prismatic standard without colored filters; and

$E$. Colored filters only.

Measurement of even the complete MAP package achieves only part of the goal of a MAP service. To fully benefit from the MAP procedure, we suggest that the participant have on hand several check standards to be measured while also measuring the MAP package. These check standards can then be measured periodically to determine any gross error in measurement procedure, and a control chart can be constructed. A control chart is a plot of measurement result versus time, and normally the measurement process is considered to be under control if measurements fall within \pm 3 standard deviations from the mean. For retroreflectance measurements where geometric errors are large, the standard deviation obtained after changing geometrical parameters may be large compared with that 
obtained from repeated measurements without changing the apparatus. Thus, the total variation for a given instrument can be obtained only by repetition over a period of time and realignment of the experimental apparatus.

The uncertainties of retroreflectometer measurements have three sources: uncertainties associated with values assigned by NBS to the MAP package, participant uncertainties, and uncertainties due to environment and sample interaction. Repeated measurements without changing the apparatus show that the NBS random error is small relative to the systematic errors. A large fraction of the latter arise when the retroreflector is rearranged and realigned for making measurements with different measurement parameters.

Measurement Assurance Program for Transmittance (38080M)

The Transmittance Measurement Assurance Program (MAP) provides a means for a laboratory to assess the accuracy of its spectral transmittance measurement capabilities. A laboratory which participates in this program will be sent a package of transmittance filters, which have been measured at NBS. These are to be measured by the laboratory on its spectrophotometer(s) and returned, together with the measurement results, to NBS. NBS will then remeasure the filters and send a final analysis of the result to the participating laboratory. The range of filter measurements provided in the MAP package permits an evaluation of the accuracy of a laboratory's spectral transmission measurements and will often reveal the cause of any systematic errors that exist.

The contents of the MAP package include seven neutral density filters with nominal transmittances ranging from 0.2 to 0.001 . The filters are available in three sizes. The filter holders are $51 \times 51 \mathrm{~mm}, 51 \times 38 \mathrm{~mm}$, or standard cuvette. In addition, the package contains one didymium glass filter that is to be used for wavelength scale calibration: several wavelengths of transmittance minima and points of inflection have been measured by NBS for this filter. These wavelengths have been shown to be stable over long periods of time; therefore, these didymium filters are not normally measured by NBS with every use of the MAP package. The didymium filter is useful for triangular bandpasses between 1.5 and $10.5 \mathrm{~nm}$.

It is strongly suggested that the participating laboratory acquire a set of check standards similar to the NBS filters for maintaining a control chart and measurement assurance.

Special Tests of Photographic Step Tablets (38090S)

Special tests for transmission or reflection optical density can be performed by prior arrangement. Tablets submitted must be free of scratches, fingerprints, abrasions, and foreign matter and must have steps of uniform density. $45^{\circ} / 0^{\circ}$ absolute visual reflection density is measured in accordance with ANSI Standard PH2.17-1977.

Special Tests of Microcopy Resolution Test Charts (38100S)

Tests charts conforming to ISO Standard 3334, NMA Standard

MS104-1972, and MIL-M-9868D, can be tested by special arrangement.

References-Spectrophotometric Measurements

White Opal Glass Diffuse Spectral Reflectance Standards for the Visible 
Spectrum (SRMs 2015 and 2016), V. R. Weidner, Natl. Bur. Stand. (U.S.), Spec. Publ. 260-82 (1983).

Extension of a Reference Spectrophotometer into the Near Infrared, K. L. Eckerle, V. R. Weidner, J. J. Hsia, and Z. W. Chao, Natl. Bur. Stand. (U.S.), Tech. Note 1175 (Apr. 1983).

Measurement Assurance ProgramTransmittance Standards for Spectrophotometric Linearity Testing: Preparation and Calibration, K. L. Eckerle, V. R. Weidner, J. J. Hsia, and K. Kafadar, J. Res. Natl. Bur. Stand. (U.S.), 88(1), 25 (1983).

Second-Surface Mirror Standards of Spectral Specular Reflectance (SRMs 2023, 2024, 2025), J. C. Richmoind, J. J. Hsia, V. R. Weidner, and D. B. Wilmering, Natl. Bur. Stand. (U.S.), Spec. Publ. 260-79 (Oct. 1982).

Proposed Standards for the NBS Retroreflectance MAP, K. L. Eckerle and J. J. Hsia, Color Res. and Appl., 7(3), 235 (1982).

NBS $45^{\circ}$ /Normal Reflectometer for Absolute Reflectance Factors, J. J. Hsia and V. R. Weidner, Metrologia, 17, 97 (1981).

NBS Specular ReflectometerSpectrophotometer, V. R. Weidner and J. J. Hsia, Appl. Opt., 19, 1268 (Apr. 1980).

New Reference Retroreflectometer, K. L. Eckerle, J. J. Hsia, V. R.
Weidner, and W. H. Venable, Jr., Appl. Opt., 19(8), 1253 (1980).

Photometry and Colorimetry of Retroreflection: State-of-Measurement Accuracy Report, K. L. Eckerle, Natl. Bur. Stand. (U.S.), Tech. Note 1125 (July 1980).

Inverse-Fourth Apparatus for Photometric Calibrations, D. A. Swyt and J. G. LaRock, Rev. Sci. Instrum., 49(8), 1083 (Aug. 1978).

Establishing a Scale of DirectionalHemispherical Reflectance Factor 1: The Van den Akker Method, W. H. Venable, Jr., J. J. Hsia, and V. R. Weidner, J. Res. Natl. Bur. Stand. (U.S.), 82, 1, 29 (July-Aug. 1977). New Reference Spectrophotometer, K. D. Mielenz, K. L. Eckerle, R. P. Madden, and J. Reader, Appl. Opt., 12, 7, 1630 (July 1973).

Permanence of Glass Standards of Spectral Transmittance, K. S. Gibson and M. A. Belknap, J. Res. Natl. Bur. Stand. (U.S.), 44, 463 (May 1950).

Basic Considerations of Densitometer Adjustment and Calibration, R. E. Swing, Natl. Bur. Stand. (U.S.), NBSIR 75-682 (Feb. 1975).

The Optics of Densitometry, R. E. Swing, Opt. Eng., 12, 6, 185 (Nov./Dec. 1973).

Basic Considerations of Densitometer Adjustment and Calibration, R. E. Swing, Natl. Bur. Stand. (U.S.), Report 10970 (Dec. 1972). 
Radiometric Measurements

Radiometric Physics Division

Center for Radiation Research

Technical Contact:

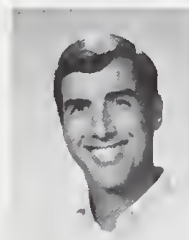

John K. Jackson

Tel: 301/921-3613

Mailing Address: A221 Physics, National Bureau of Standards, Gaithersburg, MD 20899

Test No. Items

39010C Spectral Radiance Ribbon Filament Lamps (225 to $2400 \mathrm{~nm}$ )

39020C Spectral Radiance Ribbon Filament Lamps (225 to $800 \mathrm{~nm}$ )

39030C Spectral Radiance Ribbon Filament Lamps (650 to $2400 \mathrm{~nm}$ )

39040C Spectral Irradiance Quartz-Halogen Lamps (250 to $1600 \mathrm{~nm}$ )

39050C Spectral Irradiance Deuterium Lamps (200-350 nm)

39060C Photodiode Spectral Response Rental Package (DRIP)

39070S Special Tests of Radiometric Sources

Spectral Radiance Ribbon Filament Lamps (39010C-39030C)

These spectral radiance standards are supplied by NBS. Tungsten, ribbon filament lamps (30A/T24/13) are provided as lamp standards of spectral radiance. The lamps are calibrated at 34 wavelengths from 225 to $2400 \mathrm{~nm}$, with a target area $0.6 \mathrm{~mm}$ wide by 0.8 $\mathrm{mm}$ high. Radiance temperature ranges from $2650 \mathrm{~K}$ at $225 \mathrm{~nm}$, and $2475 \mathrm{~K}$ at $650 \mathrm{~nm}$ to $1610 \mathrm{~K}$ at 2400 $\mathrm{nm}$, with corresponding uncertainties of 3,1 , and $0.5 \%$. See also related tests $40010 \mathrm{~S}-40040 \mathrm{~S}$, next section.

Figure 11 summarizes the measurement uncertainty for NBS spectral radiance calibrations.

Spectral Irradiance Lamps (39040C and $39050 \mathrm{C}$ )

These spectral irradiance standards are supplied by NBS. Lamp standards of spectral irradiance are provided in two forms. Tungsten filament, 1000-watt quartz halogen type FEL lamps are calibrated at 26 wave-

Figure 11. Uncertainties for NBS Spectral Radiance Calibrations

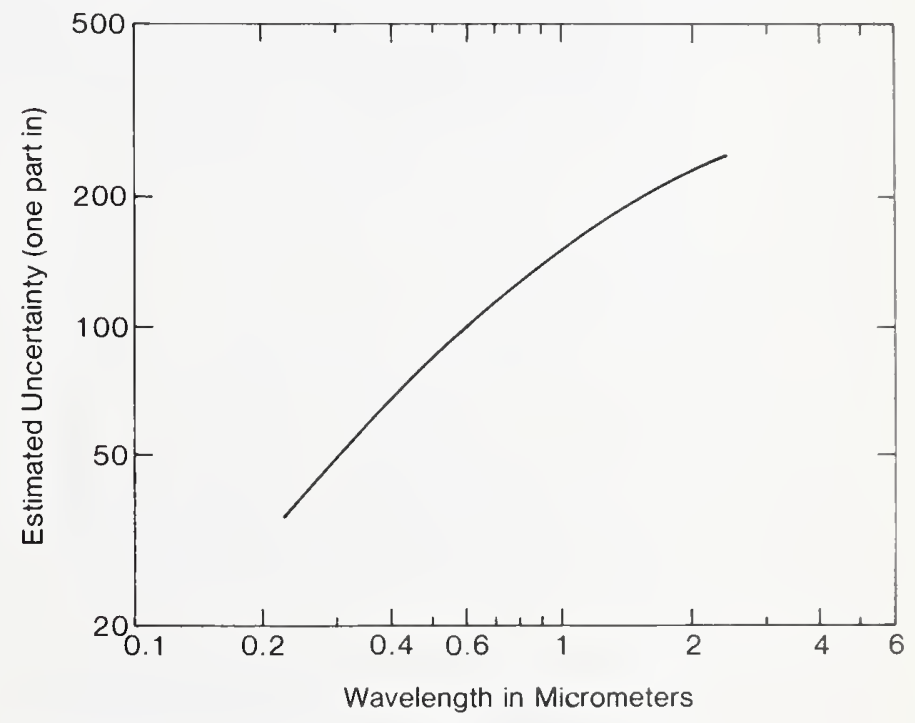

lengths in the range 250 to $1600 \mathrm{~nm}$. This will be extended shortly to 2400 $\mathrm{nm}$. At the working distance of 50 $\mathrm{cm}$, the lamps produce $0.2 \mathrm{~W} / \mathrm{cm}^{3}$ at $250 \mathrm{~nm}, 220 \mathrm{~W} / \mathrm{cm}^{3}$ at $900 \mathrm{~nm}$, and $115 \mathrm{~W} / \mathrm{cm}^{3}$ at $1600 \mathrm{~nm}$, with corresponding uncertainties ranging from 2.5 to 1 percent. Deuterium lamp 
standards of spectral irradiance are also provided and are calibrated at 16 wavelengths from 200 to $350 \mathrm{~nm}$. At the working distance of $50 \mathrm{~cm}$, the spectral irradiance produced by the lamp ranges from about $0.4 \mathrm{~W} / \mathrm{cm}^{3}$ at $200 \mathrm{~nm}$ and $0.3 \mathrm{~W} / \mathrm{cm}^{3}$ at $250 \mathrm{~nm}$ to $0.07 \mathrm{~W} / \mathrm{cm}^{3}$ at $350 \mathrm{~nm}$. The deuterium lamps are intended primarily for the spectral region 200 to $250 \mathrm{~nm}$. The approximate uncertainty relative to SI units is $6 \%$ at $200 \mathrm{~nm}$ and $3 \%$ at $250 \mathrm{~nm}$. The approximate uncertainty in relative spectral distribution is $3 \%$. It is strongly recommended that the deuterium standards be compared to an FEL tungsten standard over the range 250 to $300 \mathrm{~nm}$ each time the deuterium lamp is lighted to take advantage of the accuracy of the relative spectral distribution.

Figure 12 summarizes the measurement uncertainty for NBS spectral irradiance calibrations.

\section{Photodiode Spectral Response Package (39060C)}

Photodiode response packages can be rented from NBS. Absolute spectral responsivity calibrations can be obtained by leasing one of the NBS Detector Response Transfer and Intercomparison Packages (DRIPs). This is a well-characterized radiometer that utilizes a silicon photodiode as the detector element. Its calibration is reported in units of $\mathrm{A} / \mathrm{W}$ at a number of wavelengths in the 250 to $1064 \mathrm{~nm}$ range. A precision aperture is provided for calibrations in units of $A$ $\mathrm{cm}^{2} / \mathrm{W}$. The duration of the lease is sufficient to enable the transfer of the calibration to a laboratory's own in-house standards, and the performance of specific diagnostic tests to check the laboratory's capability to perform spectral response transfer measurements. At present, the DRIP calibration is based on the selfcalibrated silicon photodiode technique and electrical substitution radiometry using $\mathrm{cw}$ laser lines and several atomic emission lines as monochromatic radiation sources for the characterization measurements. The absolute spectral response is reported at $10 \mathrm{~nm}$ intervals from 250 to $960 \mathrm{~nm}$, and at two discrete wavelengths outside this range (1014 and $1064 \mathrm{~nm}$ ). The estimated uncertainty ranges from 1 to $6 \%$, depending on the wavelength and the particular radiometers. The radiometers cover a range of detector current from $10^{-7}$

\section{Figure 12. Uncertainties for NBS Spectral Irradiance Calibrations}

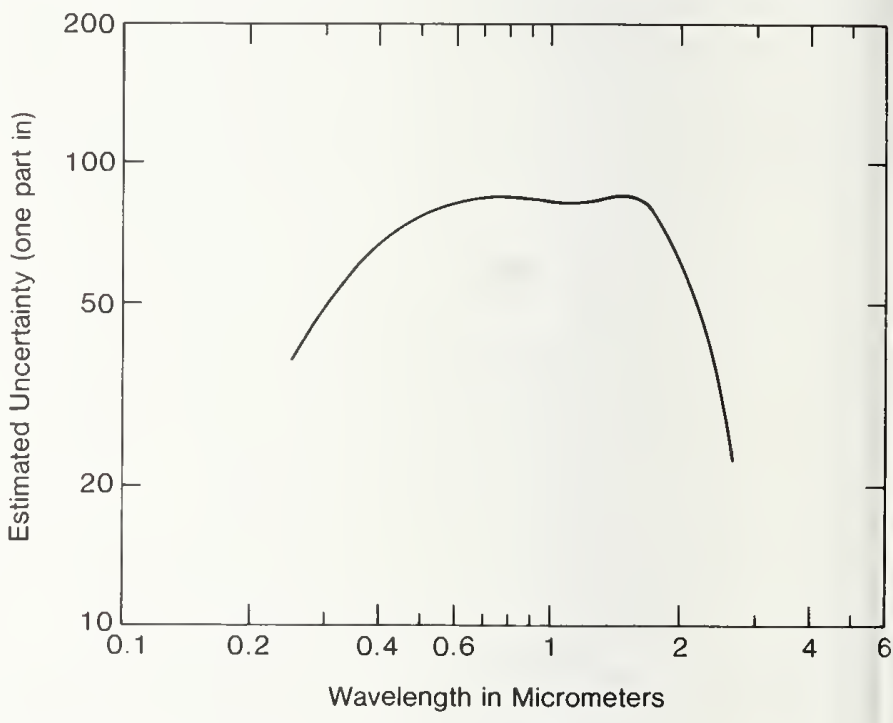

to $10^{-4} \mathrm{~A}$. This corresponds to a radiant power range of about $1 \mathrm{nw}$ to 1 mw.

\section{Special Tests of Radiometric Sources (39070S)}

Spectroradiometric source calibrations are performed on the Facility for Automatic Spectral Calibrations (FASCAL). This instrument has the capability of performing spectral radiance measurements from 200 to 2500 $\mathrm{nm}$, radiance temperatures from 1050 $\mathrm{K}$ to $2700 \mathrm{~K}$, and adjustable spectral bandpass down to $0.1 \mathrm{~nm}$. Spectral irradiance measurement capability from 200 to $2400 \mathrm{~nm}$ at flux levels down to $0.1 \mathrm{~W} / \mathrm{cm}^{3}$ is also available. For both spectral radiance and irradiance measurements a wide variety of sources 


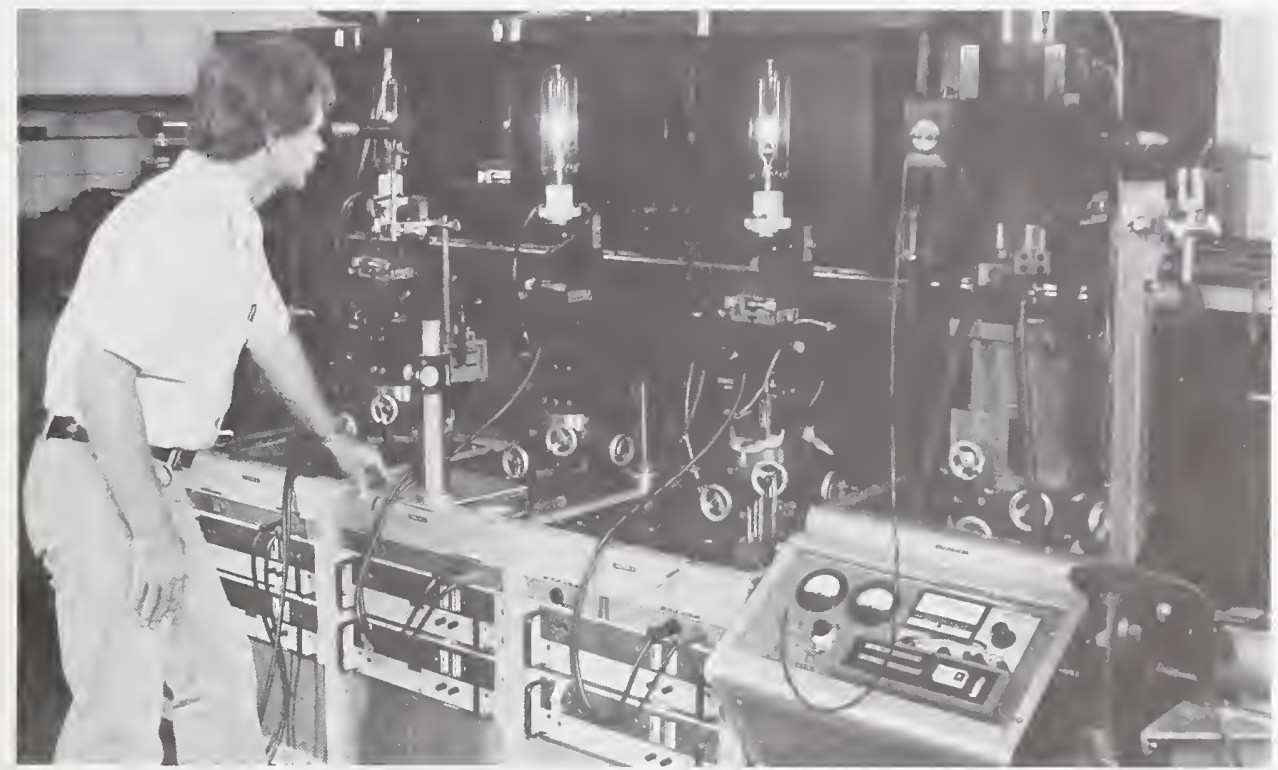

Jim Walker, aligning a lamp in the Facility for Automated Spectrometric Calibrations.

and measurement geometries are possible. Special tests utilizing the capabilities of FASCAL are occasionally performed depending on the availability of the equipment and associated personnel.

\section{References-Radiometric Measurements}

High-Accuracy Spectral Radiance Calibration of Tungsten-Strip Lamps, H. J. Kostkowski, D. E. Erminy, and A. T. Hattenburg, Adv. Geophys., 14, 111 (1970).

The 1973 NBS Scale of Spectral Irradiance, R. D. Saunders and J. B. Shumaker, Natl. Bur. Stand. (U.S.), Tech. Note 594-13 (1977).

Spectral Irradiance Standard for the Ultraviolet: The Deuterium Lamp, R. D. Saunders, W. R. Ott, and J. M. Bridges, Appl. Opt. 17, 593 (1978). Silicon Photodiode Device with $100 \%$ External Quantum Efficiency, E. F. Zalewski and C. R. Duda, Appl. Opt., 22, 2867 (1983).

Silicon Photodiode Absolute Spectral Response-Self-Calibration Using a Filtered Tungsten Source, C. G.
Hughes, III, Appl. Opt., 21, 2129 (1982).

Silicon Photodiode Absolute Spectral Response Self-Calibration, E. F.

Zalewski and J. Geist, Appl. Opt., 19, 1214 (1980).

Spectral Response Self-Calibration and Interpolation of Silicon Photodiodes, J. Geist, E. F. Zalewski, and A. R. Schaefer, Appl. Opt. 20, 3795 (1980).

The NBS Detector Response Transfer and Intercomparison Package: The Instrumentation, M. A. Lind, E. F. Zalewski, and J. B. Fowler, Natl. Bur. Stand. (U.S.), Tech. Note 950 (1977).

Spectral Radiometry: A New Approach Based on Electro-Optics, J. Geist, M. A. Lind, A. R. Schaefer, and E. F. Zalewski, Natl. Bur. Stand. (U.S.), Tech. Note 954 (1977).

Fundamental Principles of Absolute Radiometry and the Philosophy of this NBS Program (1968 to 1971), J. Geist, Natl. Bur. Stand. (U.S.), Tech. Note 594-1 (1972). 


\section{Radiometric Standards in the Ultraviolet Atomic and Plasma Radiation Division Center for Radiation Research}

Technical Contacts:

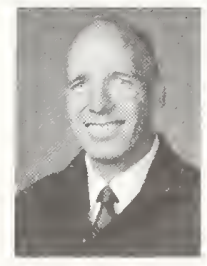

John M. Bridges Tel: $301 / 921-2356$

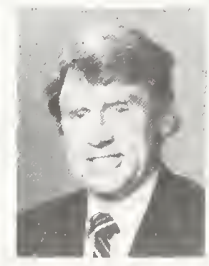

Jules Z, Klose Tel:301/921-2356

Mailing Address: A167 Physics, National Bureau of Standards, Gaithersburg, MD 20899

\begin{tabular}{ll} 
Test No. & Items \\
\hline $40010 \mathrm{~S}$ & $\begin{array}{l}\text { Special Test, Spectral Irradiance Standard, } \\
\text { Argon Mini-Arc (140 to 330 nm) }\end{array}$ \\
$40020 \mathrm{~S}$ & $\begin{array}{l}\text { Special Test, Spectral Radiance Standard, } \\
\text { Argon Mini-Arc (115 to 330 nm) }\end{array}$ \\
$40030 \mathrm{~S}$ & $\begin{array}{l}\text { Special Test, Spectral Irradiance Standard, } \\
\text { Deuterium Arc Lamp (165 to 200 nm) }\end{array}$ \\
$40040 \mathrm{~S}$ & $\begin{array}{l}\text { Special Tests of Radiometric Devices in the } \\
\text { Near and Vacuum Ultraviolet }\end{array}$
\end{tabular}

Special Tests of Radiometric Standards in the Ultraviolet (40010S-40040S)

NBS maintains a collection of secondary standard sources such as argon maxi-arcs, argon mini-arcs, and deuterium arc lamps in the near and vacuum ultraviolet radiometric standards program to provide calibrations for user-supplied sources. The calibrations of these sources are traceable to a hydrogen arc whose radiance is calculable and which NBS maintains as a primary standard. The collection also includes tungsten strip lamps and tungsten halogen lamps whose calibrations are based on a blackbody rather than a hydrogen arc.

Customer-supplied sources are calibrated in both radiance and irradiance by comparing them with NBS secondary standards.

Argon arcs are used to calibrate other sources in the wavelength range $115 \mathrm{~nm}$ to $330 \mathrm{~nm}$ for radiance and $140 \mathrm{~nm}$ to $330 \mathrm{~nm}$ for irradiance. The lower wavelength limit is determined in radiance by the cutoff of the magnesium fluoride windows used in the arcs and in irradiance by the decrease in signal produced by the addition of a diffuser. Deuterium arc lamps are used in the range $165 \mathrm{~nm}$ to $200 \mathrm{~nm}$, with the low wavelength cutoff due to the onset of blended molecular lines. The high wavelength limit is the starting point of the range of another calibration group at NBS. (See tests 39010C-39050C, previous section.) The tungsten lamps are used at $250 \mathrm{~nm}$ and above, since their signals are too weak at shorter wavelengths. It should be noted that the wavelength range of the NBS arcs partially overlaps the range of tungsten lamps, thus providing an independent check on calibrations.

An argon mini-arc lamp supplied by the customer is calibrated for spectral irradiance at $10 \mathrm{~nm}$ intervals in the wavelength region $140-300 \mathrm{~nm}$. 
Absolute values are obtained by comparison of the radiative output with laboratory standards of both spectral irradiance and spectral radiance. The spectral irradiance measurement is made at a distance of $50 \mathrm{~cm}$ from the field stop. Uncertainties are estimated to be less than \pm 10 percent in the wavelength region 140-200 $\mathrm{nm}$ and within \pm 5 percent in the wavelength region $200-330 \mathrm{~nm}$. A measurement of the spectral transmission of the lamp window is included in order that the calibration be independent of possible window deterioration or damage.

The spectral radiance of argon mini-arc radiation sources is determined to within an uncertainty of less than 7 percent over the wavelength range $140-330 \mathrm{~nm}$ and 20 percent over the wavelength range 115-140 $\mathrm{nm}$. The calibrated area of the $4 \mathrm{~mm}$ diameter radiation source is the central $0.3 \mathrm{~mm}$ diameter region. Typical values of the spectral radiance are: at $250 \mathrm{~nm}, \mathrm{~L}_{\lambda}=30 \mathrm{~mW} \mathrm{~cm}^{-2} \mathrm{~nm}^{-1} \mathrm{sr}^{-1}$; and at $150 \mathrm{~nm}, \mathrm{~L}_{\lambda}=3 \mathrm{~mW} \mathrm{~cm} \mathrm{~mm}^{-1}$ $\mathrm{sr}^{-1}$. The transmission of the demountable lamp window and that of an additional $\mathrm{MgF}_{2}$ window are determined individually so that the user may check periodically for possible long term variations.

The deuterium arc lamp is calibrated at 10 wavelengths from 165 to $200 \mathrm{~nm}$, at a distance of $50 \mathrm{~cm}$, at a spectral irradiance of about $0.5 \mathrm{~W} / \mathrm{cm}^{3}$ at $165 \mathrm{~nm}, 0.3 \mathrm{~W} / \mathrm{cm}^{3}$ at $170 \mathrm{~nm}$, and $0.5 \mathrm{~W} / \mathrm{cm}^{3}$ at $200 \mathrm{~nm}$. The approximate uncertainty relative to SI units is estimated to be less than
10 percent. The lamp is normally supplied by NBS and requires $300 \mathrm{~mA}$ at about $100 \mathrm{~V}$.

References-Vacuum Ultraviolet Radiometric Measurements

VUV Spectral Irradiance Calibrations: Method and Applications, W. R. Ott, J. M. Bridges and J. Z. Klose, Opt. Lett., 5, 225 (1980).

Spectral Irradiance Standard for the Ultraviolet: The Deuterium Lamp, $\mathbf{R}$. D. Saunders, W. R. Ott, and J. M. Bridges, Appl. Opt., 17, 593 (1978). Spectral Radiance Calibrations Between 165-300 nm: An Interlaboratory Comparison, J. M. Bridges, W. R. Ott, E. Pitz, A. Schultz, D. Einfield, and D. Stuck, Appl. Opt., 16, 1788 (1977).

VUV Radiometry. 3: The Argon Mini-Arc as a New Secondary Standard of Spectral Radiance, J. M. Bridges and W. R. Ott, Appl. Opt., 16, 367 (1977).

NBS UV Radiometric Standards, W. R. Ott, Natl. Bur. Stand. (U.S.), Spec. Publ. 456, 107 (1976). 


\section{Optical Fiber Attenuation and Bandwidth Electromagnetic Technology Division Center for Electronics and Electrical Engineering}

Technical Contacts:

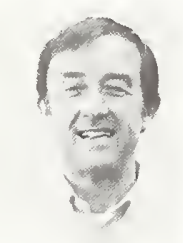

Robert L.

Gallawa

Tel: 303/497-3761

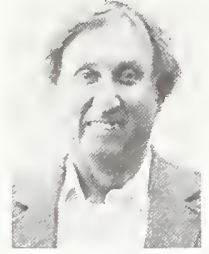

Aaron A. Sanders Tel: 303/497-5341

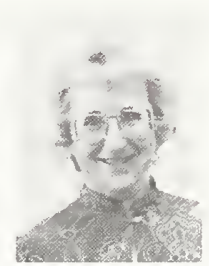

Edna M. Jones Administrative and Logistics Tel:303/497-3753
Mailing Address: 724.02, National Bureau of Standards, 325 Broadway, Boulder, CO 80303

Test No. Items

41010S Special Tests for Attenuation of TelecommunicationGrade Multimode Graded-Index Optical Fibers at 850 and $1300 \mathrm{~nm}$, by Prearrangement

41020S Special Tests for Bandwidth of TelecommunicationGrade Multimode Graded-Index Optical Fiber Having an Operating Wavelength of $1300 \mathrm{~nm}$, by Prearrangement

\section{Optical Fiber Attenuation and Bandwidth-General Information}

The National Bureau of Standards has been instrumental in the development of test methods that are now accepted by the U.S. optical fiber community. Attenuation and bandwidth are two of the most fundamental parameters of interest in system design and accordingly have been addressed first.
These special tests utilize a dedicated set of instruments and ancillary equipment. Transfer standards are maintained at NBS for the express purpose of serving industry in maintaining precision and capability. The references collectively provide detailed information on measurement procedures and NBS capabilities.

The optical fiber services are based on the use of transfer standards in the form of good-quality fibers of the appropriate type. The mode of operation is akin to that of a measurement assurance program. The standards are characterized in the laboratories of NBS and are available to the participant twice each year. The participant laboratory measures the loss or bandwidth, or both, in accordance with the established standard procedures provided or using its own normal procedures. The data are then sent to NBS, where they are analyzed and a report prepared. The report gives information on the precision of the intercomparison and relates the participant's data to data collected by other participants (anonymously) and by NBS. As appropriate, NBS may act as consultant to the participating laboratory to improve its precision. Note: NBS plans to continue to offer an annual three-day short course on optical fiber measurements, as long as there appears to be need for it.

\section{Special Test Measurements for Fiber Attenuation (41010S)}

The fiber attenuation measurement special test is a new service supporting the measurement of total loss in telecommunication-grade multimode graded-index optical fiber. Measurement procedures are based on recently established industry-approved methods. This special test covers fiber 
loss at wavelengths of 850 and 1300 $\mathrm{nm}$.

Special Test Measurements for Fiber Bandwidth (41020S)

The fiber bandwidth measurement special test is a new service supporting the measurement of informationcarrying capacity of telecommunication-grade multimode graded-index optical fiber. Measurement procedures are based on methods approved by the Electronic Industry Association. This special test covers the determination of bandwidth at the operating wavelength of $1300 \mathrm{~nm}$.

References-Optical Fiber Attenuation and Bandwidth

Measurement Assurance, J. M. Cameron, Natl. Bur. Stand. (U.S.), Int. Report, NBSIR 77-1240 (April 1977). An NBS Measurement Assurance Program, A. A. Sanders and A. R. Cook, Proc. 1976 Electro-Optics Laser Conf. (1976).

Optical Fiber Characterization, Volume I, B. L. Danielson, G. W. Day, D. L. Franzen, E. M. Kim, and M. Young, Natl. Bur. Stand. (U.S.), Spec. Publ. 637 (1982).

Optical Fiber Characterization, Volume II, G. E. Chamberlain, G. W. Day, D. L. Franzen, R. L. Gallawa, E. M. Kim, and M. Young, Natl. Bur. Stand. (U.S.), Spec. Publ. 637 (1983). Technical Digest-Symposium on Optical Fiber Measurements, G. W. Day, D. L. Franzen, Eds., Natl. Bur. Stand. (U.S.), Spec. Publ. 597 (1980). Technical Digest-Symposium on Optical Fiber Measurements, D. L. Franzen, G. W. Day, and R. L. Gallawa, Eds., Natl. Bur. Stand. (U.S.), Spec. Publ. 641 (1982).

Interlaboratory Measurement Comparison to Determine the Attenuation and Bandwidth of Graded-Index Optical Fibers, D. L. Franzen, G. W. Day, B. L. Danielson, G. E. Chamberlain, and E. M. Kim, Appl. Opt. 20, 2412 (1981).

Attenuation Measurements of Optical Fiber Waveguides: An Inter-

laboratory Comparison Among Manufacturers, G. W. Day and G. E.

Chamberlain, Natl. Bur. Stand. (U.S.), Int. Report, NBSIR 79-1608 (1979).

Standardizing Test Conditions for Characterizing Fibers, D. L. Franzen, G. W. Day and R. L. Gallawa, Laser Focus, 103 (Aug. 1982).

Optics and Lasers Including Fibers and Integrated Optics, M. Young, Springer-Verlag, New York (1984).

Measurement of Far-Field and NearField Radiation Patterns from Optical Fibers, E. M. Kim and D. L. Franzen, Natl. Bur. Stand. (U.S.), Tech. Note 1032 (1981).

On the Definition of Fiber Numerical Aperature, R. L. Gallawa, ElectroOptical System Design, 46 (April 1982).

Optical Waveguide Communications Glossary, A. G. Hanson, L. R.

Bloom, A. H. Cherin, G. W. Day, R. L. Gallawa, E. M. Gray, C. Kao, F. P. Kapron, B. S. Kawasaki, P. Reitz, and $M$. Young, Natl. Bur. Stand. (U.S.), Handb. 140 (1982).

Measurement of Optical Fiber Attenuation: An NBS Special Test Service, R. L. Gallawa, G. E. Chamberlain, G. W. Day, D. L. Franzen, and M. Young, Natl. Bur. Stand. (U.S.), Int. Report, NBSIR 83-1691 (1984).

Technical Digest-Symposium on Optical Fiber Measurements, G. W. Day and D. L. Franzen, Eds., Natl. Bur. Stand. (U.S.), Spec. Publ. 683 (1984). 


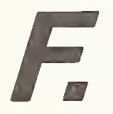

Laser Power and Energy

Electromagnetic Technology Division Center for Electronics and Electrical Engineering

\section{Technical Contacts:}
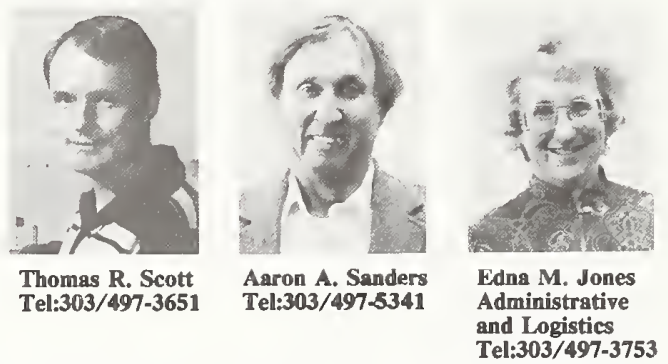

Mailing Address: 724.02, National Bureau of Standards, 325 Broadway, Boulder, CO 80303

\begin{tabular}{|c|c|}
\hline est No. & Items \\
\hline $42010 S$ & $\begin{array}{l}\text { Special Tests of Laser Power and Energy by } \\
\text { Prearrangement }\end{array}$ \\
\hline $42020 \mathrm{M}$ & $\begin{array}{l}\text { Measurement Assurance Program (MAP) for Laser } \\
\text { Power; Wavelength: } 514.5 \mathrm{~nm} \text {; Power: } \\
10 \mathrm{~mW}-600 \mathrm{~mW}\end{array}$ \\
\hline $42030 \mathrm{M}$ & MAP for Laser Power $(632.8 \mathrm{~nm} ; 1 \mathrm{~mW})$ \\
\hline $42040 \mathrm{M}$ & $\begin{array}{l}\text { MAP for Laser Power }(632.8 \mathrm{~nm} ; 1 \mu \mathrm{W}, 30 \\
\mu \mathrm{W}, 100 \mu \mathrm{W})\end{array}$ \\
\hline $42050 \mathrm{M}$ & $\begin{array}{l}\text { MAP for Laser Power }(632.8 \mathrm{~nm} \text {; For Any } \\
2 \text { Power Levels of } 1 \mathrm{~mW}, 1 \mu \mathrm{W}, 30 \mu \mathrm{W}, 100 \mu \mathrm{W} \text {, } \\
\text { where measurements are performed together })\end{array}$ \\
\hline 42060M & $\begin{array}{l}\text { MAP for Laser Power }(647.1 \mathrm{~nm} \text {; } \\
10 \mathrm{~mW}-200 \mathrm{~mW})\end{array}$ \\
\hline 42070M & $\begin{array}{l}\text { MAP for Laser Power }(1.06 \mu \mathrm{m} \\
10 \mathrm{~mW}-1 \mathrm{~W})\end{array}$ \\
\hline $42080 \mathrm{M}$ & $\begin{array}{l}\text { MAP for Laser Energy }(1.06 \mu \mathrm{m} ; \mathrm{Q}- \\
\text { switched, } 100 \mathrm{~mJ}-10 \mathrm{~J})\end{array}$ \\
\hline $42090 \mathrm{M}$ & MAP for Laser Power $(10.6 \mu \mathrm{m} ; 5-50 \mathrm{~W})$ \\
\hline
\end{tabular}

\section{Laser Power and Energy- General Information}

The National Bureau of Standards develops and maintains the U.S. national standards for measurement of laser power and energy. These standards are realized in the form of three types of isoperibol (constant temperature environment) calorimeters. The calorimeters compare absorbed laser radiation to an equivalent quantity of electrical energy. NBS maintains these calorimeters in three measurement systems so that other laser power or energy meters can be calibrated against the national standards. The calibration uncertainty ranges from about 1 to 5 percent at the 99 percent level of confidence, depending on the power (or energy) level and the wavelength at which the calibration is performed.

Special Tests of Laser Power and Energy Meters by Prearrangement (42010S)

Services include special calibrations by prearrangement of laser power and energy meters outside the formal Measurement Assurance Programs described below. Customer-owned instruments are sent to NBS for measurement using one or more of the NBS laser calibrating systems; the customer receives a Report of Test. These special tests include special Measurement Assurance Programs, special calibration of instruments by means of $1.064-\mu \mathrm{m}$ laser pulses from $10^{-8}$ to $10^{-4}$ watts peak power and $10^{-16}$ to $10^{-11}$ joules, and the special calibration of instruments by means of $10.6 \mu \mathrm{m}$ laser pulses at nanosecond time scales using a TEA laser in the energy range $10 \mathrm{~mJ}$ to $300 \mathrm{~mJ}$.

Measurement Assurance Programs for Laser Power (42020M-42090M)

The laser power and energy measurement services include several advertised Measurement Assurance Programs (MAPs). The laser MAPs are implemented by means of transfer standards which have been evaluated and characterized relative to the national standards. The characteristics of these transfer standards are well understood, and their associated accuracies do not differ significantly from those associated with direct comparisons to national standards. An NBS-characterized transfer standard, evaluated for the specific range of laser wavelength and power of interest (or energy, as appropriate to the situation), is forwarded to each MAP 


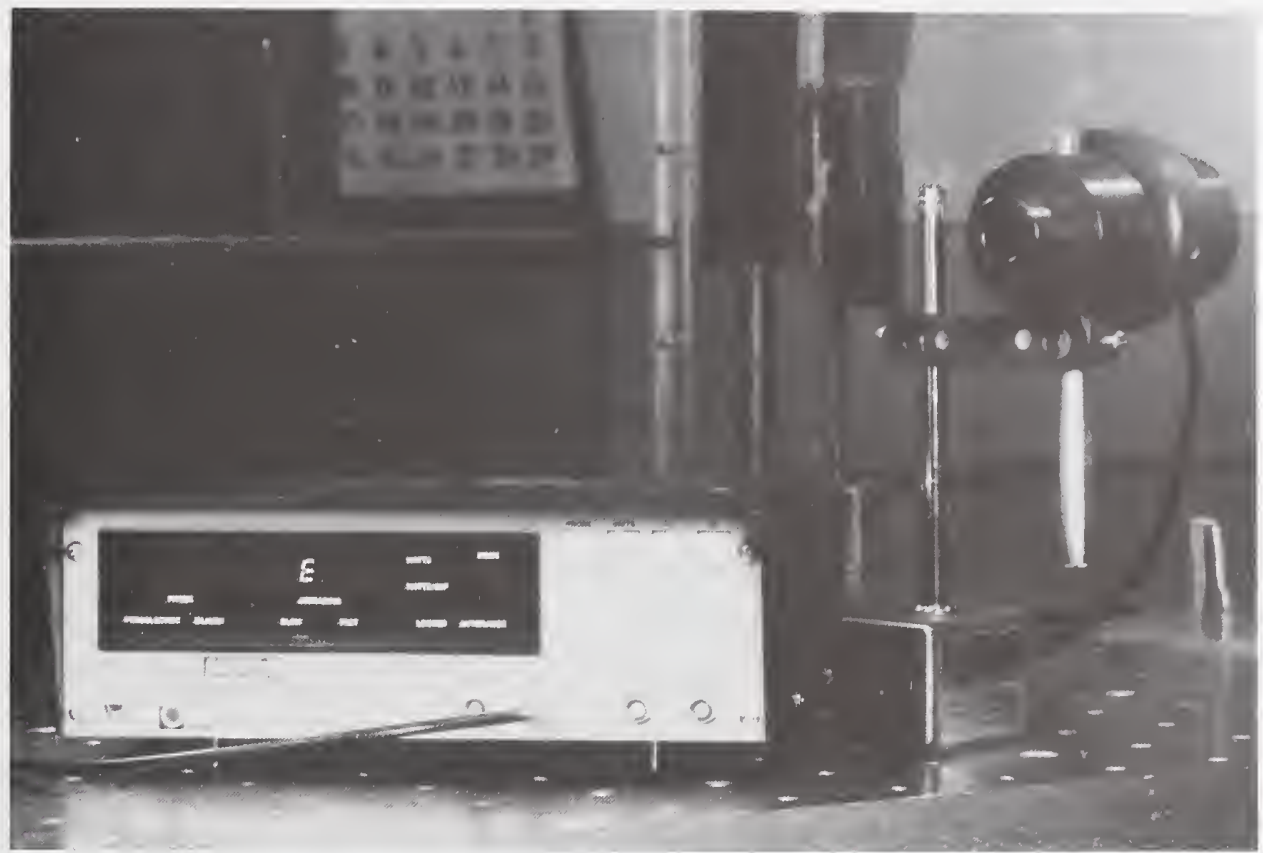

Commercial, electrically calibrated optical power meter based on NBS design.

participant twice per year. The participant is asked to calibrate the NBS transfer standard in accordance with the normal procedures in use at that laboratory, or in accordance with procedures supplied by NBS with the instrument.

NBS performs an analysis of the data to provide an assessment of the participant's measurement process for laser power and energy. The resulting report contains a scale factor that can be used to adjust values measured by the participant to be consistent with the national standards.

The participant is encouraged to make regular measurements on one or more in-house reference power meters or calorimeters (check standards) in order to establish the random error and to provide assurance that the process is stable.

Each of the three laser calibrating systems used to support the NBS laser MAP service employs the two calorimeter-beamsplitter configuration. All the significant parameters for each calorimeter, including the electrical calibration coefficient and the absorption and window transmission for each laser wavelength be- ing used, have been evaluated to relate laser energy to electrical energy. The application of theory to the voltage data (proportional to temperature) taken at equal time intervals is accomplished by using a special least squares computer program.

A properly designed and operated calorimeter can make a valid comparison of energies independent of the time (up to five minutes) required to put the energy into the calorimeter. For instance, it is valid to compare the energy in a pulse to continuous wave (cw) energy, applied over a five minute period, or to compare a laser pulse to an electrical input of 10 to 300 second duration.

Using a beamsplitter configuration, energy measuring calorimeters can be calibrated independently of laser stability, either with $\mathrm{cw}$ power or the energy of single or multiple pulses. In addition, if accurate timing and a stable laser are employed, laser power meters can also be calibrated.

Laser sources at NBS used with these calorimeters are carbon dioxide, argon, krypton, helium-neon and 
neodymium-doped YAG cw lasers, and a pulsed YAG laser with a pulse energy of about 0.1 joule and a pulse width of about 30 nanoseconds.

Since laser power and energy are highly-derived quantities, they are subject to more sources of error than are typically encountered in MAPs for measurements closer to the base SI units. Sources of error which must be considered in laser power and energy measurements include:

$A$. Beam size. The beam size should be small enough that the various instruments can capture the total beam, and large enough that the energy density of the beam does not damage the surface of the absorber.

$B$. Beam alignment. Proper alignment ensures total beam capture and avoids interference problems with reflections.

C. Window transmittance and beam splitter ratio. These wavelength-dependent ratio measurements must be determined for each laser wavelength of interest.

$D$. Electrical measurements. To relate the laser energy to base SI units, time intervals, voltages and currents of the heater circuitry must be measured accurately with respect to national standards.

$E$. Long term drifts in the parameters characterizing the measurement system. Examples of parameters that may change with time are: electrical calibration coefficients; absorbing surface of the calorimeters; and window transmittance.

Control charts for the beamsplitter measurements with the two calorimeter-beamsplitter configuration are used at NBS to verify the stability of the calibration systems.

References-Laser Power and Energy An NBS Measurement Assurance Program, A. A. Sanders and A. R.
Cook, Proc. Electro-Optics Laser Conference (1976).

Theory of Isoperibol Calorimetry for Laser Power and Energy Measurement, E. D. West and K. L. Churney, J. Appl. Phys. 41, No. 6, 2705 (May 1970).

A Reference Calorimeter for Laser Energy Measurement, E. D. West, W. E. Case, A. L. Rasmussen, and L. B. Schmidt, J. Res. Natl. Bur. Stand. (U.S.), 76A, No. 1, 13 (Jan.-Feb. 1972).

Data Analysis for Isoperibol Laser Calorimetry, E. D. West, Natl. Bur. Stand. (U.S.), Tech. Note 396 (Feb. 1971).

Quality Assurance Program for the NBS C, K and Q Laser Calibration Systems, W. Case, Natl. Bur. Stand. (U.S.), Int. Report, NBSIR 79-1619 (Aug. 1979).

Absolute Reference Calorimeter for Measuring High Power Laser Pulses, D. L. Franzen and L. B. Schmidt, Appl. Opt. 15, 3115 (Dec. 1976). A System for Calibrating Laser Power Meters for the Range 5-1000 W., E. D. West, and L. B. Schmidt, Natl. Bur. Stand. (U.S.), Tech. Note 685 (May 1977).

Documentation of the NBS C, K and Q Laser Calibration Systems, W. E. Case, Natl. Bur. Stand. (U.S.), Int. Report, NBSIR 82-1676 (Sept. 1982). A System for Measuring Energy and Peak Power of Low-Level 1.064- $\mu \mathrm{m}$ Laser Pulses, A. A. Sanders and A. L. Rasmussen, Natl. Bur. Stand. (U.S.), Tech. Note 1058 (Oct. 1982). A Calorimeter for Measuring HighEnergy Optical Pulses, P. A. Simpson, E. G. Johnson, Jr., and S. M. Etzel, Natl. Bur. Stand. (U.S.), Int. Report, NBSIR 84-3008 (Oct. 1984). 


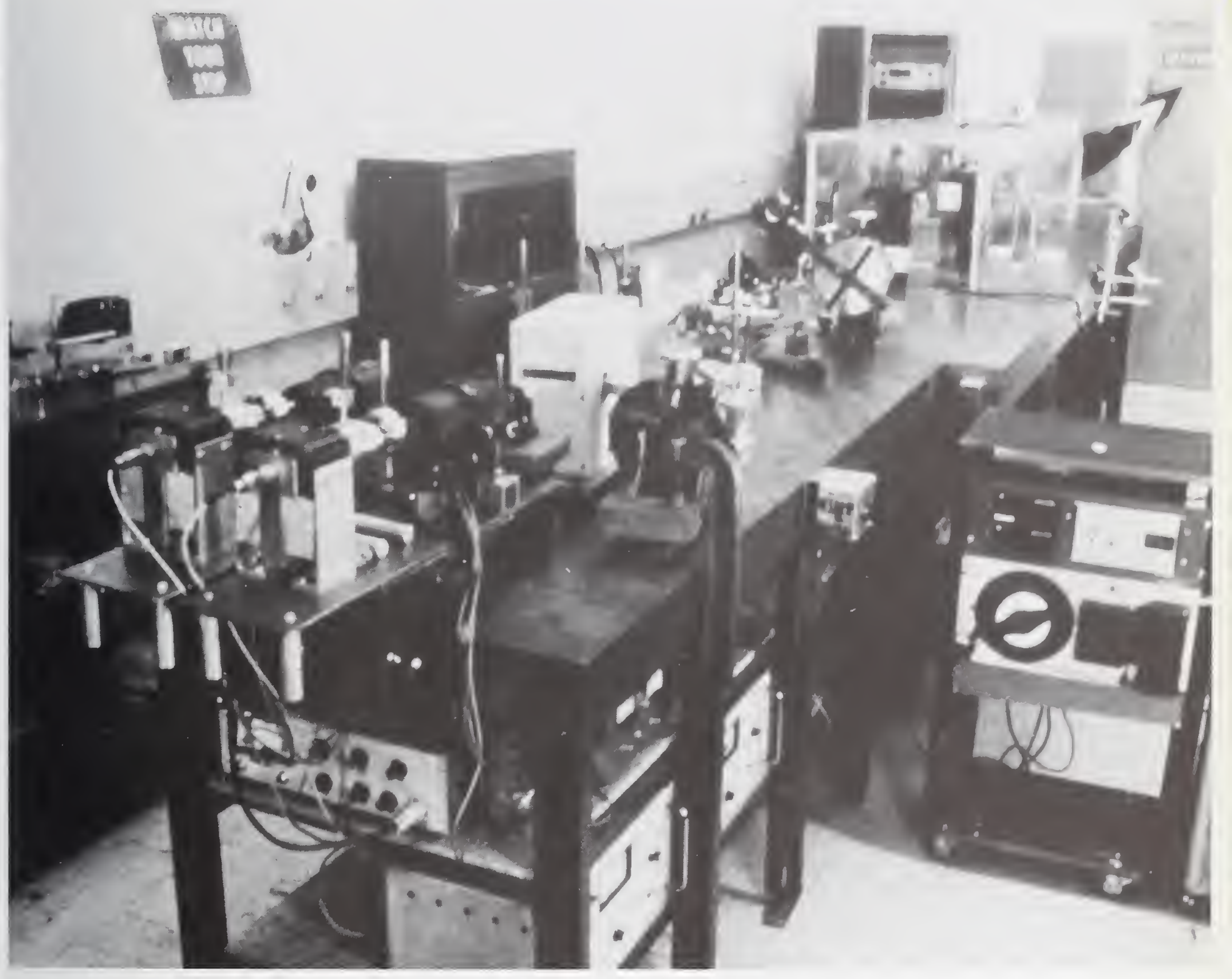

Apparatus for comparing customer's laser power meter (calorimeter) with NBS reference calorimeter.

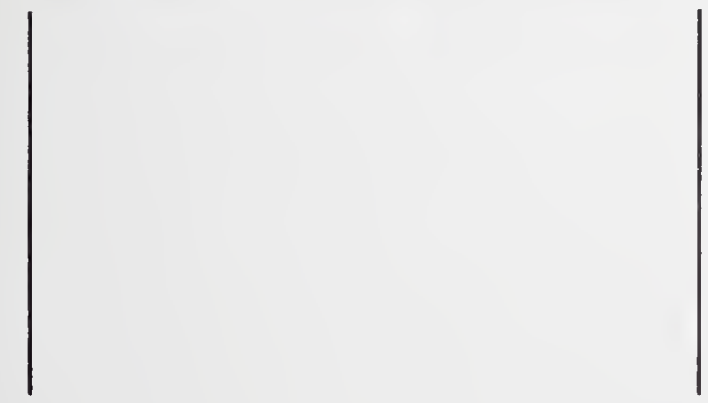

$$
\mid
$$


Chapter

A Radioactivity Sources
B Neutron Sources and Dosimeters
C Dosimetry of X Rays, Gamma Rays,
and Electrons
$D$ Dosimetry for High-Dose Applications 
Radioactivity Sources

Ionizing Radiation Division

Center for Radiation Research

Technical Contacts:

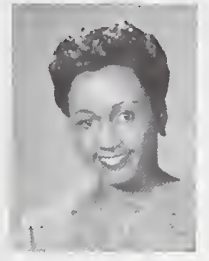

Jacqueline $\mathbf{M}$. Calhoun

Tel: 301/921-2665

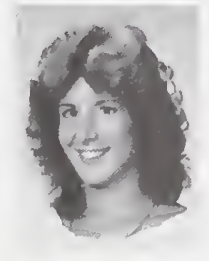

Pamela A. Hodge Administrative and Logistics Tel:301/921-2665
Mailing Address: C114 Radiation Physics, National Bureau of Standards, Gaithersburg, MD 20899

\begin{tabular}{cl} 
Test No. & Items \\
\hline $43010 \mathrm{C}$ & $\begin{array}{l}\text { Gamma-Ray-Emitting Radionuclides in Solution } \\
\text { (Half Lives Greater Than 15 Days) }\end{array}$ \\
43020C & $\begin{array}{l}\text { Gamma-Ray-Emitting Radionuclides in Solution } \\
\text { (Half Lives Less Than 15 Days) }\end{array}$ \\
43030C & $\begin{array}{l}\text { Alpha-Particle-Emitting Solid Sources, NBS 2 } \pi \alpha \\
\text { proportional counter }\end{array}$ \\
$43040 \mathrm{C}$ & $\begin{array}{l}\text { Alpha-Particle-Emitting Solid Sources, NBS 0.8 } \pi \alpha \\
\text { defined-solid-angle counter }\end{array}$ \\
$43050 \mathrm{C}$ & $\begin{array}{l}\text { Alpha-Particle-Emitting Solid Sources, using both } \\
\text { counting systems }\end{array}$ \\
$43060 \mathrm{~S}$ & $\begin{array}{l}\text { Special Test of Beta-Particle-Emitting Solution } \\
\text { Sources-Liquid Scintillation Counting }\end{array}$ \\
$43070 \mathrm{~S}$ & $\begin{array}{l}\text { Special Tests of Beta-Particle-Emitting Solution } \\
\text { Sources, Other Techniques }\end{array}$ \\
$43090 \mathrm{~S}$ & $\begin{array}{l}\text { Special Tests of Alpha-Particle-Emitting Solid } \\
\text { Sources }\end{array}$ \\
\hline
\end{tabular}

Radioactivity Sources-General Information (43010C-43090S)

The National Bureau of Standards offers calibration services for over 50 radionuclides. This service provides calibrations which meet requirements of industry, research, environmental monitoring, and the life sciences. Radioactivity calibration services are available for alpha-particle solid sources, beta-particle solutions, and gamma-ray solutions.

In order to offer such a broad range of services, NBS must place stringent limitations on the physical and chemical form and activity range of sources which can be accepted. To insure that these specifications are understood, it is essential that there be good communication between the technical user at the facility and those at NBS. When planning to have a source calibrated the user should discuss the following points with the technical contact at NBS:

A. Type of calibration: Often, more than one type of calibration is available for a given source. A cobalt- 60 source, for example, may be calibrated in terms of total activity or gamma-ray-emission rate. (Inquiries regarding the calibration of radioactive sources for exposure rate should be directed to the Dosimetry Group. See tests 47010 C to 47040 C.) The total uncertainty in the calibration should also be discussed.

B. General packaging and shipping requirements: Two general requirements apply to all sources submitted for calibration: (1) all shipments must conform to applicable Nuclear Regulatory Commission (NRC) and Department of Transportation (DOT) packaging and transport; and (2), source descriptions, including approximate activity, must be provided in advance. The NBS Health Physics Section must approve in advance all proposed calibrations, and sources may be refused if the necessary information is not available.

C. Reports of Calibration: A Report of Calibration is sent on completion of a radioactivity calibration service. If the user has particular requirements for documentation of the calibration, these should be discussed with the technical contact at NBS before the services are performed.

D. Sample Preparation, Packaging and Shipping: All samples submitted for calibration must be chemically and physically stable. The chemical form of solutions which are suggested for beta-particle emitters and gamma-ray emitters are described 
later in this document. A special lot of borosilicate-glass ampoules must be used for gamma-ray emitters. Empty ampoules are provided for this purpose. The volume of material in the ampoule should be $5.0 \pm 0.2 \mathrm{ml}$.

Packaging for all sources must be in compliance with DOT and NRC regulations. Copies of regulations may be obtained from Operations Division, Office of Hazardous Materials, Department of Transportation, Washington, DC 20590. Postal regulations prohibit mailing radioactive materials which require a caution label under DOT regulations.

Alpha-particle solid sources must be supplied in special source holders so designed that the active area is not touched by any material. For sources to be measured in the $2 \pi \alpha$ counter (calibration $43030 \mathrm{C}$ ), the diameter of the source must be less than $10 \mathrm{~cm}$ and that of the active surface less than $9 \mathrm{~cm}$. For the $0.8 \pi \alpha$ counter (calibration $43040 \mathrm{C}$ ), the maximum diameter is $1.6 \mathrm{~cm}$.

All sources arriving at NBS are checked by the Health Physics Section for radiation level and source integrity. Sources should be shipped to the attention of the technical contact at NBS, addressed as follows:

National Bureau of Standards

Attn: Jacqueline M. Calhoun

Health Physics (Radioactivity

Group)

Quince Orchard and Clopper

Roads

Gaithersburg, MD 20899

Gamma-Ray-Emitting Solution Sources (43010C-43020C)

Tables 3 and 4 list 39 radionuclides, solutions of which may be calibrated in the National Bureau of Standards " $4 \pi$ " $\gamma$ ionization chamber. The sources must be submitted flamesealed in the special ampoules provided by NBS. The operation of this type of chamber is described in
NCRP Report 58, A Handbook of Radioactivity Measurements Procedures, Section 4.4 "Ionization Chambers", National Council on Radiation Protection and Measurements Report, Mann, W.B. (Ed.), Washington (1985).

Table 3: Calibration Uncertainties for Radionuclides Having Half Lives Greater Than 15 Days (43010C)

Suggested Chemical Form ${ }^{(c)}$

\begin{tabular}{|c|c|c|c|c|}
\hline $\begin{array}{ll} & \text { Nomi } \\
& \text { Limit } \\
\text { Radio- } & \text { izatio } \\
\text { nuclide } & \text { Calib }\end{array}$ & $\begin{array}{l}\text { minal Uncer. } \\
\text { nits of Ion- } \\
\text { tion-Chamber } \\
\text { libration }\end{array}$ & $\begin{array}{l}\text { Activity } \\
\text { Range } \\
\text { (MBq) }\end{array}$ & Carrier & Solution \\
\hline${ }^{22} \mathrm{Na}$ & $1.6 \%$ & $0.4-40$ & $\mathrm{NaCl}$ & $1 \mathrm{M} \mathrm{HCl}$ \\
\hline${ }^{46} \mathrm{Sc}$ & $0.8 \%$ & $0.4-40$ & $\mathrm{ScCl}_{3}$ & $1 \mathrm{M} \mathrm{HCl}$ \\
\hline${ }^{51} \mathrm{Cr}$ & $1.0 \%$ & $2-60$ & $\mathrm{CrCl}_{3}$ & $0.5 \mathrm{M} \mathrm{HCl}$ \\
\hline${ }^{54} \mathrm{Mn}$ & $1.2 \%$ & $2-60$ & $\mathrm{MnCl}_{2}$ & $1 \mathrm{M} \mathrm{HCl}$ \\
\hline${ }^{57} \mathrm{Co}$ & $0.8 \%$ & $2-60$ & $\mathrm{CoCl}_{2}$ & $1 \mathrm{M} \mathrm{HCl}$ \\
\hline${ }^{59} \mathrm{Fe}$ & $1.4 \%$ & $0.4-40$ & $\mathrm{FeCl}_{3}$ & $1 \mathrm{M} \mathrm{HCl}$ \\
\hline${ }^{60} \mathrm{Co}$ & $0.8 \%$ & $0.4-40$ & $\mathrm{CoCl}_{2}$ & $1 \mathrm{M} \mathrm{HCl}$ \\
\hline${ }^{65} \mathrm{Zn}^{(\mathrm{d})}$ & $1.7 \%$ & $2-60$ & $\mathrm{ZnCl}_{2}$ & $1 \mathrm{M} \mathrm{HCl}$ \\
\hline${ }^{75} \mathrm{Se}$ & $2.4 \%$ & $2-60$ & $\mathrm{H}_{2} \mathrm{SeO}_{3}$ & $1 \mathrm{M} \mathrm{HNO}_{3}$ \\
\hline${ }^{85} \mathrm{Sr}$ & $2.0 \%$ & $2-60$ & $\mathrm{SrCl}_{2}$ & $1 \mathrm{M} \mathrm{HCl}$ \\
\hline${ }^{88} \mathrm{Y}$ & $0.7 \%$ & $0.4-40$ & $\mathrm{YCl}_{3}$ & $1 \mathrm{M} \mathrm{HCl}$ \\
\hline${ }^{109} \mathrm{Cd}-{ }^{109 \mathrm{~m}} \mathrm{Ag}^{(\mathrm{d})}$ & (d) $1.7 \%$ & $2-60$ & $\mathrm{CdCl}_{2}$ & 1. $3 \mathrm{M} \mathrm{HCl}^{*}$ \\
\hline${ }^{110 \mathrm{~m}} \mathrm{Ag}-{ }^{110} \mathrm{Ag}$ & $0.9 \%$ & $0.4-40$ & $\mathrm{AgNO}_{3}$ & $1 \mathrm{~N} \mathrm{HNO}_{3}$ \\
\hline${ }^{113} \mathrm{Sn}-{ }^{113 \mathrm{~m}} \mathrm{In}$ & $3.0 \%$ & $2-60$ & $\begin{array}{l}\mathrm{SnCl}_{2} \text { or } \\
\mathrm{SnCl}_{4}\end{array}$ & $4 \mathrm{M} \mathrm{HCl}$ \\
\hline${ }^{133} \mathrm{Ba}$ & $1.5 \%$ & $2-60$ & $\mathrm{BaCl}_{2}$ & $1 \mathrm{M} \mathrm{HCl}$ \\
\hline${ }^{134} \mathrm{Cs}$ & $1.0 \%$ & $2-60$ & $\mathrm{CsCl}$ & $1 \mathrm{M} \mathrm{HCl}$ \\
\hline${ }^{137} \mathrm{Cs}-{ }^{137 \mathrm{~m}} \mathrm{Ba}$ & $1.5 \%$ & $2-60$ & $\mathrm{CsCl}$ & $1 \mathrm{M} \mathrm{HCl}$ \\
\hline${ }^{139} \mathrm{Ce}$ & $1.0 \%$ & $2-60$ & $\mathrm{CeCl}_{3}$ & $1 \mathrm{M} \mathrm{HCl}$ \\
\hline${ }^{141} \mathrm{Ce}$ & $2.0 \%$ & $2-60$ & $\mathrm{CeCl}_{3}$ & $1 \mathrm{M} \mathrm{HCl}$ \\
\hline${ }_{152}^{15 u}$ & $1.6 \%$ & $0.4-40$ & $\mathrm{EuCl}_{3}$ & $1 \mathrm{M} \mathrm{HCl}$ \\
\hline${ }^{154} \mathrm{Eu}$ & $0.8 \%$ & $0.4-40$ & $\mathrm{EuCl}_{3}$ & $4 \mathrm{M} \mathrm{HCl}$ \\
\hline${ }^{155} \mathrm{Eu}$ & $1.5 \%$ & $2-60$ & $\mathrm{EuCl}_{3}$ & $4 \mathrm{M} \mathrm{HCl}$ \\
\hline${ }^{169} \mathrm{Yb}$ & $2.5 \%$ & $2-60$ & $\mathrm{YbCl}_{3}$ & $0.1 \mathrm{M} \mathrm{HCl}^{*}$ \\
\hline${ }^{195} \mathrm{Au}$ & $2.3 \%$ & $2-60$ & $\mathrm{KAu}(\mathrm{CN})_{4}$ & $\begin{array}{l}10 \mathrm{gL}^{-1} \mathrm{KCN}^{*} \\
10 \mathrm{gL}^{-1} \mathrm{KCl}^{*}\end{array}$ \\
\hline${ }^{203} \mathrm{Hg}$ & $1.4 \%$ & $2-60$ & $\mathrm{Hg}\left(\mathrm{NO}_{3}\right)_{2}$ & $0.1 \mathrm{M} \mathrm{HNO}_{3}$ \\
\hline${ }^{226} \mathrm{Ra}$ & $1.1 \%$ & $0.4-40$ & $\mathrm{RaCl}_{2}$ & $1.4 \mathrm{M} \mathrm{HCl}$ \\
\hline
\end{tabular}

a The total estimated uncertainty will depend upon the activity level and chemical form.

${ }^{b}$ The source activity should be in the indicated range when it arrives at NBS. The calibration scheduling must be coordinated with the NBS technical contact.

${ }^{c}$ This information is based in large part on the NBS Standard Reference Materials for these radionuclides. For those radionuclides marked with an asterisk, the carrier should be discussed with the NBS technical contact.

${ }^{d}$ The calibrations for ${ }^{65} \mathrm{Zn}$ and ${ }^{109} \mathrm{Cd}-{ }^{109 m} \mathrm{Ag}$ are in terms of gamma-rayemission rate rather than activity. 
Table 4: Calibration Uncertainties for Radionuclides Having Half Lives Less Than 15 Days (43020C)

Suggested Chemical Form ${ }^{(c)}$

\begin{tabular}{|c|c|c|c|c|}
\hline $\begin{array}{ll} & \text { N } \\
\text { Radio- } & \text { iz } \\
\text { nuclide } & \text { C }\end{array}$ & $\begin{array}{l}\text { Nominal Uncer. } \\
\text { Limits of Ion- } \\
\text { ization-Chamber } \\
\text { Calibration }^{(\mathbf{a})}\end{array}$ & $\begin{array}{l}\text { Activity } \\
\text { Range }{ }^{(b)} \\
\text { (MBq) }\end{array}$ & Carrier & Solution \\
\hline${ }^{24} \mathrm{Na}$ & $0.8 \%$ & $0.4-40$ & $\mathrm{NaCl}$ & $1 \mathrm{M} \mathrm{HCl}$ \\
\hline${ }^{42} \mathrm{~K}$ & $2.0 \%$ & $2-60$ & $\mathrm{KCl}$ & $1 \mathrm{M} \mathrm{HCl}$ \\
\hline${ }^{67} \mathrm{Ga}$ & $1.4 \%$ & $0.4-40$ & $\mathrm{GaCl}_{3}$ & $1 \mathrm{M} \mathrm{HCl}$ \\
\hline${ }^{99} \mathrm{Mo}-{ }^{99 \mathrm{~m}} \mathrm{~T}$ & $1.6 \%$ & $2-60$ & Molybdate & $4 \mathrm{M} \mathrm{HNO}_{3}$ \\
\hline${ }^{99 \mathrm{~m}} \mathrm{Tc}$ & $1.5 \%$ & $2-60$ & $\begin{array}{l}\text { No carrier } \\
\text { added/ } \\
\text { pertechnetate }\end{array}$ & Saline \\
\hline${ }^{111} \mathrm{In}$ & $1.3 \%$ & $2-60$ & $\mathrm{InCl}_{2}$ & $3 \mathrm{M} \mathrm{HCl}$ \\
\hline${ }^{123}$ I & $1.5 \%$ & $2-60$ & $\mathrm{KI}, \mathrm{Na}_{2} \mathrm{SO}_{3}$ & $0.01 \mathrm{M} \mathrm{LiOH}^{*}$ \\
\hline${ }^{131} \mathbf{I}$ & $1.3 \%$ & $2-60$ & $\mathrm{KI}, \mathrm{Na}_{2} \mathrm{SO}_{3}$ & $0.01 \mathrm{M} \mathrm{LiOH}^{*}$ \\
\hline${ }^{140} \mathrm{Ba}-{ }^{140} \mathrm{La}$ & $3.4 \%$ & $0.4-40$ & $\begin{array}{l}\mathrm{Ba}\left(\mathrm{NO}_{3}\right)_{2} \\
\mathrm{La}\left(\mathrm{NO}_{3}\right)_{3}\end{array}$ & $1 \mathrm{M} \mathrm{HCl}$ \\
\hline${ }^{197} \mathrm{Hg}$ & $2.4 \%$ & $2-60$ & $\mathrm{Hg}\left(\mathrm{NO}_{3}\right)_{2}$ & $0.1 \mathrm{M} \mathrm{HNO}_{3}$ \\
\hline${ }^{198} \mathrm{Au}$ & $1.3 \%$ & $2-60$ & $\mathrm{KAu}(\mathrm{CN})_{4}$ & $\begin{array}{l}10 \mathrm{gL}^{-1} \mathrm{KCN}^{*} \\
10 \mathrm{gL}^{-1} \mathrm{KCl}\end{array}$ \\
\hline${ }^{201} \mathrm{Tl}$ & $1.9 \%$ & $2-60$ & $\mathrm{~T}\left(\mathrm{NO}_{3}\right)_{3}$ & $0.9 \mathrm{M} \mathrm{HNO}_{3}$ \\
\hline${ }^{203} \mathrm{~Pb}$ & $1.7 \%$ & $2-60$ & $\mathrm{PbCl}_{2}$ & $0.5 \mathrm{M} \mathrm{HCl}$ \\
\hline
\end{tabular}

a The total estimated uncertainty will depend upon the activity level and chemical form.

' The source activity should be in the indicated range when it arrives at NBS. The calibration scheduling must be coordinated with the NBS technical contact.

c This information is based in large part on the NBS Standard Reference Materials for these radionuclides. For those radionuclides marked with an asterisk, the carrier should be discussed with the NBS technical contact. discussed in the references below. The source thickness must be such that more than 99.5 percent of the emitted alpha particles have an energy greater than $400 \mathrm{keV}$. Further specifications for these calibration services are given in Table 5 . Test $43050 \mathrm{C}$ includes calibration of the same source using both counting systems.

Table 5: Specifications for Calibration of Alpha-ParticleEmitting Samples

\begin{tabular}{|c|c|c|}
\hline & $\begin{array}{l}\text { Calibration } \\
43030 \mathrm{C}\end{array}$ & $\begin{array}{l}\text { Calibration } \\
43040 \mathrm{C}\end{array}$ \\
\hline Counting System & $\begin{array}{l}\text { NBS } 2 \pi \alpha \text { pro- } \\
\text { portional } \\
\text { counter }\end{array}$ & $\begin{array}{l}\text { NBS } 0.8 \pi a \text { de- } \\
\text { fined-solid-angle } \\
\text { counter }\end{array}$ \\
\hline Sources Calibrated For: & $\begin{array}{l}\text { Alpha-particle- } \\
\text { emission } \\
\text { rate into } 2 \pi \\
\text { steradians }\end{array}$ & Total activity \\
\hline Nominal Uncertainty ${ }^{(a)}$ & $1.5 \%$ & $1.0 \%$ \\
\hline Activity Range & $\begin{array}{l}1.5 \mathrm{~Bq} \text { to } \\
1.1 \times 10^{4} \mathrm{~Bq}\end{array}$ & $\begin{array}{l}1.9 \times 10^{2} \mathrm{~Bq} \text { to } \\
1.1 \times 10^{4} \mathrm{~Bq}\end{array}$ \\
\hline $\begin{array}{l}\text { Maximum Source } \\
\text { Diameter }\end{array}$ & $\begin{array}{l}10 \mathrm{~cm} \text { ( } 9 \mathrm{~cm} \text { for } \\
\text { active surface) }\end{array}$ & $1.6 \mathrm{~cm}$ \\
\hline
\end{tabular}

a The total estimated uncertainty will depend upon the activity level and source geometry.

Special Tests of Beta-Particle-Emitting Solution Sources (43060S and 43070S)

Beta-particle-emitting solutions that conform to the physical, chemical and activity specifications for measurement are assayed by liquidscintillation counting. The specifications are shown in Table 6. Solutions should be approximately $5 \mathrm{~mL}$ in vol- 
ume and flame-sealed in glass vials or ampoules. The suggested radioactivity concentration range is 20 to $2000 \mathrm{kBq} / \mathrm{g}$.

Table 6: Specifications for Special Tests of Beta-ParticleEmitting Solution Sources

\begin{tabular}{|c|c|c|c|}
\hline \multirow{2}{*}{$\begin{array}{l}\text { Radio- } \\
\text { nuclide }\end{array}$} & \multirow{2}{*}{$\begin{array}{c}\text { Nominal } \\
\text { Uncertainty }^{(\mathrm{b})}\end{array}$} & \multicolumn{2}{|c|}{$\begin{array}{l}\text { Suggested Chemical } \\
\text { Composition }^{(\mathrm{b})}\end{array}$} \\
\hline & & Carrier & Solution \\
\hline${ }^{3} \mathbf{H}$ & $1.0 \%$ & $\mathrm{H}_{2} \mathrm{O}$ & $\mathrm{H}_{2} \mathrm{O}$ \\
\hline${ }^{14} \mathrm{C}$ & $1.5 \%$ & $\mathrm{Na}_{2} \mathrm{CO}_{3}$ & $0.001 \mathrm{M} \mathrm{NaOH}$ \\
\hline${ }^{32} \mathrm{P}^{(\mathrm{c})}$ & $1.0 \%$ & $\mathrm{H}_{3} \mathrm{PO}_{4}$ & $0.0034 \mathrm{M} \mathrm{H}_{3} \mathrm{PO}_{4}$ \\
\hline${ }^{33} \mathrm{P}$ & $1.0 \%$ & $\mathrm{H}_{3} \mathrm{PO}_{4}$ & $0.0034 \mathrm{M} \mathrm{H}_{3} \mathrm{PO}_{4}$ \\
\hline${ }^{35} \mathrm{~S}$ & $1.0 \%$ & $\mathrm{Li}_{2} \mathrm{SO}_{4}$ & $0.1 \mathrm{M} \mathrm{HCL}$ \\
\hline${ }^{36} \mathrm{Cl}$ & $2.0 \%$ & $\mathrm{NaCl}$ & $\mathrm{H}_{2} \mathrm{O}$ \\
\hline${ }^{89} \mathrm{Sr}$ & $1.0 \%$ & $\mathrm{SrCl}_{2}$ & $1 \mathrm{M} \mathrm{HCl}$ \\
\hline${ }^{90} \mathrm{Sr}-{ }^{90} \mathrm{Y}$ & $1.0 \%$ & $\mathrm{SrCl}_{2} / \mathrm{YCl}_{3}$ & $1 \mathrm{M} \mathrm{HCl}$ \\
\hline${ }^{90} \mathrm{Y}$ & $1.0 \%$ & $\mathrm{YCl}_{3}$ & $1 \mathrm{M} \mathrm{HCl}$ \\
\hline${ }^{147} \mathrm{Pm}$ & $1.0 \%$ & $\mathrm{PmCl}_{3}$ & $1 \mathrm{M} \mathrm{HCl}$ \\
\hline${ }^{204} \mathrm{Tl}$ & $2.0 \%$ & $\mathrm{Tl}\left(\mathrm{NO}_{3}\right)_{3}$ & $1 \mathrm{M} \mathrm{HNO}_{3}$ \\
\hline
\end{tabular}

${ }^{a}$ The total estimated uncertainty will depend upon the activity level and chemical form.

${ }^{\mathrm{b}}$ The chemical composition is critical for these calibrations and should be discussed before sending the source.

${ }^{\mathrm{c}}$ This calibration includes a half-life fit to determine the ${ }^{33} \mathrm{P}$ impurity.

No examination is made for betaparticle-emitting impurities, except in the case of phosphorus- 32 where a half-life fit is made. The sources will be examined for gamma-ray emitting impurities.

Measurement of beta-particleemitting solutions by techniques other than liquid-scintillation may be made by special arrangement.

\section{Special Alpha-Particle-Emitting Solid} Sources (43090S)

Special arrangements may be made for measurements of solid alphaparticle-emitting sources with emission rates exceeding $1.1 \times 10^{4} \mathrm{~Bq}$.

\section{References-Radioactivity Sources} NCRP Report 58, A Handbook of Radioactivity Measurements Procedures, Section 3.7-Alpha-Particle
Counting, W. B. Mann, Ed., Natl. Council Rad. Protect. and Meas., Wash., DC (1985).

Study of the Scattering Correction for Thick Uranium-Oxide and Other a-Particle Sources-I: Theoretical, L. L. Lucas and J. M. R. Hutchinson, Int. J. Appl. Radiat. Isotopes, 27, 35 (1976).

Study of the Scattering Correction for Thick Uranium-Oxide and Other a-Particle Sources-II: Experimental, J. M. R. Hutchinson, L. L. Lucas, and P. A. Mullen, Int. J. Appl. Radiat. Isotopes, 27, 43 (1976). Backscattering of Alpha Particles from Thick Metal Backings as a Function of Atomic Weight, J. M. R. Hutchinson, C. R. Naas, D. H. Walker, and W. B. Mann, Int. J. Appl. Radiat. Isotopes, 19, 517 (1968). An Experimental Study of the Backscattering of $5.3 \mathrm{MeV}$-Alpha Particles from Platinum and Monel Metal, D. H. Walker, Int. J. Appl. Radiat. Isotopes, 16, 183 (1965). 
Neutron Sources and Dosimeters

Ionizing Radiation Division Center for Radiation Research

Technical Contacts:
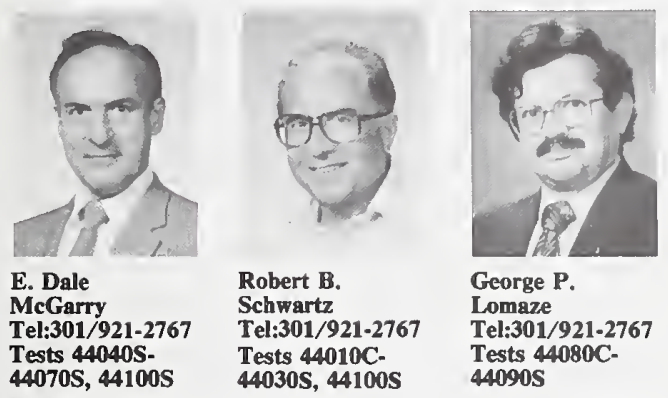

Mailing Address: A155 Reactor, National Bureau of Standards, Gaithersburg, MD 20899

Test No. Items

$44010 \mathrm{C}$ Natural Standard Neutron Sources $\left(10^{5}\right.$ to $\left.10^{8} \mathrm{n} / \mathrm{s}\right)$

$44020 \mathrm{C}$ Natural Standard Neutron Sources $\left(10^{8}\right.$ to $\left.10^{10} \mathrm{n} / \mathrm{s}\right)$

44030S Activated Foil Irradiation with Thermal Neutrons

44040S Special Tests of Neutron Dosimeters, Thermal Beam

44050 Special Tests of Neutron Dosimeters, Filtered Beam

44060C Calibrations of Neutron Dosimeters, Californium Sources

44070S Special Tests of Neutron Dosimeters, Van de Graaff

44080C Activated Foil Irradiation, Californium Fission Neutrons

44090C Activated Foil Irradiation, Cavity

Fission Source

44100S Special Tests of Neutron Sources and Dosimeters

Natural Standard Neutron Sources (44010C-44020C)

NBS provides calibration services for natural standard neutron sources and neutron measuring devices such as activation foils. Neutron sources in the range from $5 \times 10^{5}$ to $5 \times 10^{9}$ neutrons/second may be calibrated to an accuracy of about $\pm 1.2 \%$ (one sigma) depending upon the amount and knowledge of construction of their encapsulations. Emission rates (neutrons/second) of neutron sources of unknown source strength are determined by the Manganous Sulfate Bath Method. The neutron sources are calibrated by comparing their strengths to that of the NBS primary standard source, a Ra-Be photo neutron source known as NBS-1. The comparison of the source strengths is made by activating a manganese sulfate bath solution and continuously counting the induced, saturated manganese-56 radioactivity with a scintillation counter. The present emission rate of NBS-1, which is absolutely determined, is $1.246 \times 10^{6} \mathrm{n} / \mathrm{s}$ with an assigned uncertainty of $\pm 0.85 \%$ (one sigma).

Activated Foil Irradiation with Thermal Neutrons (44030S)

Materials dosimetry, such as that accomplished for surveillance of fast neutron fluence seen by the pressure vessel in an operating nuclear power plant, depends upon correct assay of the amount of isotopic radioactivity induced in radiometric dosimeters, such as foils or wires. For activation foil irradiations, the following thermal neutron sources are available:

A. External Beam (Fully moderated): $4 \times 10^{7} \mathrm{n} /\left(\mathrm{cm}^{2} \cdot \mathrm{s}\right)$

B. Cavity (Isotropic, Fully moderated): $2 \times 10^{11} \mathrm{n} /\left(\mathrm{cm}^{2} \cdot \mathrm{s}\right)$

C. Thermal Density Standard (Undermoderated): $4000 \mathrm{n} / \mathrm{cm}^{2} \cdot \mathrm{s}$ )

Special Tests and Calibrations of Neutron Dosimeters (44040S-44070S)

A wide variety of neutron radiation detection instrumentation exists for the protection of personnel. NBS maintains a correspondingly wide variety of neutron fields for both research and calibration in the area of personnel dosimetry. A thermal neutron beam is available at the thermal column of the NBS Research Reactor (NBSR) which can provide dose equivalent rates up to approximately $1 \mathrm{rem} /$ hour over a $30-\mathrm{cm}$ diameter circle. Three monoenergetic epithermal neutron beams are available 
at the NBSR to determine neutron response as a function of energy:
A. $2 \mathrm{KeV}$ beam Dose Equiv. rate $=8 \mathrm{mrem} /$ hour
B. $24 \mathrm{KeV}$ beam Dose Equiv. rate $=15 \mathrm{mrem} /$ hour
C. $144 \mathrm{KeV}$ beam Dose Equiv. rate $=120 \mathrm{mrem} /$ hour

These epithermal neutron beams give primarily neutron doses with the gamma contributions being approximately 2 to 4 percent. The neutron spectrum for a deuterium moderated Cf-252 neutron source is available for calibration of personnel dosimetry instruments. Available rates are $1.1 \mathrm{x}$ $10^{5} \mathrm{n} /\left(\mathrm{cm}^{2} \cdot \mathrm{s}\right)$ or equivalently $3.0 \mathrm{rem} /$ hour. Additionally, a pure Cf-252 fission neutron spectrum is available with rates of $1.3 \times 10^{4} \mathrm{n} /\left(\mathrm{cm}^{2} \cdot \mathrm{s}\right)$ or equivalently $1.6 \mathrm{rem} /$ hour. A Van de Graaff generator also provides neutrons in the energy range of $0.2-1.2$ $\mathrm{MeV}$ with rates of $1.5 \times 10^{3} \mathrm{n} / \mathrm{cm}^{2} \cdot \mathrm{s}$ $(170 \mathrm{~m} \mathrm{rem} / \mathrm{hr}$ ) and at $14 \mathrm{MeV}: 60 \mathrm{n} /$ $\mathrm{cm}^{2} \cdot \mathrm{s}(80 \mathrm{~m} \mathrm{rem} / \mathrm{hr})$.

\section{Calibrations of}

Activated Foil Irradiations (44080C-44090C)

NBS maintains Standard Fission Neutron Fields to supply calibration irradiations and Certified Fluence Standards. The NBS Cf-252 Fission Neutron Source (typical maximum fluence $1.0 \times 10^{13}$ neutrons $/ \mathrm{cm}^{2}$ in 24 hours) and the U-235 Cavity Fission Neutron Source (typical maximum fluence $3.3 \times 10^{15}$ neutrons $/ \mathrm{cm}^{2}$ in 24 hours) provide standard neutron field spectra. Known fluences are based upon known source strengths for the californium sources.

Special Tests of Neutron Sources and Dosimeters (44100S)

Other tests of neutron sources and dosimetry may be made by special arrangement with the Ionizing Radiation Division.

\section{References-Neutron Sources and Dosimeters}

Fission Cross-Section Measurements in Reactor Physics and Dosimetry Benchmarks, J. A. Grundl and D. M. Gilliam, ANS Trans., 44, 533 (June 1983).

Measurement of Neutrons Reflected from the Surfaces of a Calibration Room, C. M. Eisenhauer, R. B. Schwartz, and T. Johnson, Health Physics, 42, 489 (1982).

Integral Reaction Rate Measurements in ${ }^{252} \mathrm{Cf}$ and ${ }^{235} \mathrm{U}$ Fission Spectra, G. P. Lamaze, E. D. McGarry, Proc. Conf. on Nucl. Data for Sci. and Tech., Antwerp, Belgium (Sept. 1982).

Requirements for Reference Reactor Pressure Vessel Surveillance Dosimetry to Benchmark Neutron Fields, E. D. McGarry, Proc. IAEA Advisory Group Meeting on Nuclear Data for Radiation Damage Assessment and Reactor Safety Aspects (Oct. 1981). Measurements of the Average Activation Cross Section for the Reaction ${ }^{63} \mathrm{Cu}(\mathrm{n}, \alpha){ }^{60} \mathrm{Ca}$ in the Spontaneous Fission Neutron Field of Californium252, C. Winkler, V. Spiegel, C. M. Eisenhauer, D. L. Smith, Nucl. Sci. Eng., 78, 415 (Aug. 1981).

National Standards for Neutron Measurements, J. Grundl, Traceability for Ionizing Radiation Measurement Symposium, Natl. Bur. Stand. (U.S.) (May 1980).

${ }^{235}$ U Cavity Fission Neutron Field Calibration via the ${ }^{252} \mathrm{Cf}$ Spontaneous Fission Neutron Field, V. Spiegel, C. M. Eisenhauer, D. M. Gilliam, J. A. 
Grundl, E. D. McGarry, I. G. Schroder, W. E. Slater, and R. S. Schwartz, IAEA Consultant's Mtg. on Neutron Source Properties, Debrecen, Hungary (Mar. 1980).

The Design and Construction of a $\mathrm{D}_{2} \mathrm{O}$-Moderated ${ }^{252} \mathrm{Cf}$ Source for Calibrating Neutron Personnel Dosimeters Used at Nuclear Power Reactors, R. B. Schwartz and C. M. Eisenhauer, U.S. Nucl. Reg. Com. Doc., NUREG/CR-1204 (Jan. 1980).

Detailed Error Analysis of Average Fission Cross-Section Measurements in NBS Standard Neutron Fields, J. J. Wagschal, R. E. Maerker (ORNL), and D. M. Gilliam (NBS), Trans. Am. Nucl. Soc., 33, 823 (Nov. 1979). Dosimetry Results for BIG TEN and Related Benchmarks, D. M. Gilliam, J. A. Grundl, and C. E. Hansen, Third ASTM-EURATOM Symposium on Reactor Dosimetry, Ispra, Italy (Oct. 1979).

Benchmark Referencing of Neutron Dosimetry Measurements, C. M. Eisenhauer, J. A. Grundl, D. M. Gilliam, E. D. McGarry, and V. Speigel, Third ASTM-EURATOM Symposium on Reactor Dosimetry, Ispra, Italy (Oct. 1979).

User's Manual-Neutron Calibration Fields at NBS, J. E. Hoy and R. B. Schwartz, Dec. 8, 1976. Revised by R. B. Schwartz (Jan. 1979).

Covariance of Fission-Integral Measurements at the NBS ${ }^{252} \mathrm{Cf}$ and ISNF Facilities and at the ORNL-PCA Facility, J. J. Wagschal, R. E. Maerker, and D. M. Gilliam, Third ASTMEURATOM Symposium on Reactor Dosimetry, Ispra, Italy (Oct. 1979).

Neutronic Analysis of the NBS Intermediate-Energy Standard Neutron Field (ISNF), P. D. Soran, R. J. Labauve, and E. C. George (LASL) and C. M. Eisenhauer (NBS), Trans. Am. Nucl. Soc., 32 (June 1979). Compendium of Benchmark and Test Region Neutron Fields for Pressure
Vessel Irradiation Surveillance; Standard Neutron Spectra-Part I: ${ }^{252} \mathrm{Cf}$ Spontaneous Fission and Part II: ${ }^{235} \mathrm{U}$ Thermal-Neutron-Induced Fission, Light-Water-Reactor, PressureVessel-Surveillance Dosimetry Progress Report. U.S. Nucl. Reg. Com. Doc., NUREG/CR-0551 (Dec. 1978).

Reaction Rate Measurements and Integral Cross Sections Using the NBS ${ }^{252} \mathrm{Cf}$ Fission Neutron Indoor Irradiation Facility, V. Spiegel, C. M. Eisenhauer, and J. A. Grundl (NBS), and G. C. Martin, Jr. (GE). Second ASTM-EURATOM Symposium on Reactor Dosimetry, Palo Alto, CA (Oct. 1977). Also published as U.S. Nucl. Reg. Com. Doc., NUREG/ CP0004 (1978).

Utilization of Standard and Reference Neutron Fields at NBS, C. M. Eisenhauer, D. M. Gilliam, J. A. Grundl, and V. Spiegel. Second ASTM/ EURATOM Symp. on Reactor Dosimetry, Palo Alto, CA (Oct. 1977). See also NUREG/CP0004 (1978).

A Californium-252 Fission Spectrum Irradiation Facility for Neutron Reaction Rate Measurements, J. A. Grundl, V. Spiegel, C. M. Eisenhauer, H. T. Heaton, II, and D. M. Gilliam (NBS), and J. Bigelow (ORNL), Nucl. Tech., 32, 315 (Mar. 1977).

Fission Reaction Rate Standards and Applications, J. Grundl and C. Eisenhauer, Int. Symp. on Neut. Stand. and Applic., Gaithersburg, MD, Natl. Bur. Stand. (U.S.), Spec. Publ. 493 (Oct. 1977).

Integral Measurements Results in Standard Fields, D. M. Gilliam, Int. Symp. on Neut. Stand. and Applic., 
Gaithersburg, MD, Natl. Bur. Stand. (U.S.), Spec. Publ. 493 (Oct. 1977).

Neutron Transport Calculations for the Intermediate-Energy Standard Neutron Field (ISNF), C. M. Eisenhauer and J. A. Grundl, Int. Symp. on Neut. Stand. and Applic., Gaithersburg, MD, Natl. Bur. Stand. (U.S.), Spec. Publ. 493 (Oct. 1977). Calibration and Use of Filtered Beams, R. B. Schwartz, Proc. Intl. Specialists Symp. on Neut. Stand. and Applic., Gaithersburg, MD, Natl. Bur. Stand. (U.S.), Spec. Publ. 493, 250 (Oct. 1977).

Neutron Source Calibrations at NBS for Calibration Checks of Neutron Radiation Instruments, V. Spiegel, Proc. of Symp. on Meas. for the Safe Use of Radiation, Natl. Bur. Stand. (U.S.), Spec. Publ. 456, 87 (Nov. 1976).

Benchmark Neutron Fields for Reactor Dosimetry, J. A. Grundl and C. M. Eisenhauer, IAEA Consultants' Meeting on Integral Cross Section Measurements in Standard Neutron Fields for Reactor Neutron Dosimetry, Vienna (Nov. 1975-6).

The Effective Half-Life of Californium-252, V. Spiegel, Jr., Nucl. Sci. and Eng., 53, 326 (1974). Calibration of Thermal Neutron Absorption in Cylindrical and Spherical Neutron Sources, V. Spiegel, Jr. and W. M. Murphey, Metrologia, 7, 34 (Jan. 1971).

Review of Measurements of Absolute Neutron Emission Rates and Spectra from Neutron Sources, R. S. Caswell, Neutron Sources and Applications, Proc. ANS Natl. Topical Meeting, April 19-21, 1971, Augusta, GA, CONF-71042, Vol. I, 1 (1971).

The Correction Factor for Fast Neutron Reactions on Sulphur and Oxygen in the Manganous-Sulfate-Bath Calibration of Neutron Sources, W. M. Murphey, Nucl. Instrum. Methods, 37, 13 (1965).

Recent Developments in Neutron Source Standardization, R. S. Caswell, R. H. Noyce, S. B. Garfinkel and E. R. Mosburg, Jr., Neutron Dosimetry II, 547, Intl. At. Energy Agency, Vienna (1963).

Absolute Calibration of the National Bureau of Standards Photoneutron Source: III. Absorption in a Heavy Water Solution of Manganous Sulfate, R. H. Noyce, E. R. Mosburg, Jr., S. B. Garfinkel, and R. S. Caswell, J. Nucl. Eng., 17, No. 7, 313 (1963).

Absolute Calibration of the National Bureau of Standards Photoneutron Standard: II. Absorption in Manganese Sulfate, J. A. DeJuren and J. Chin, J. Res. Natl. Bur. Stand. (U.S.), 55, 311 (Dec. 1955).

Absolute Calibration of the National Bureau of Standards Photoneutron Standard: I., J. A. DeJuren, D. W. Padgett, and L. F. Curtiss, J. Res. Natl. Bur. Stand. (U.S.), 55, 63 (Aug. 1955).

Reproducibility of Photo-Neutron Standards, L. F. Curtiss and A. Carson, Phys. Rev., 76, 1412 (1949). 
Dosimetry of X Rays, Gamma Rays, and Electrons

Ionizing Radiation Division

Center for Radiation Research

Technical Contacts:

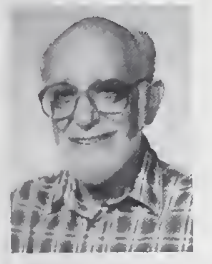

Robert Loevinger All Tests

Tel: 301/921-2364

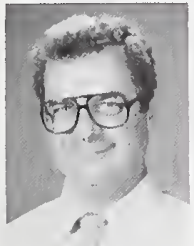

Paul J. Lamperti Tests 46010C$46050 \mathrm{~S}$ Tel: 301/921-2361

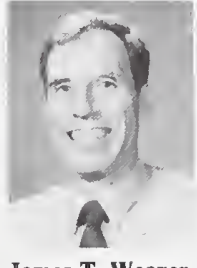

James T. Weaver Tests $47010 \mathrm{C}$. $47040 \mathrm{~S}$

Tel: 301/921-2361

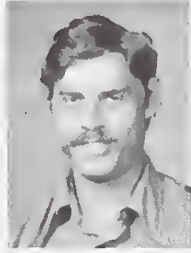

Christopher G. Soares Tests $48010 \mathrm{C}$. 480205 Tel:301/921-2366
Mailing Address: C214 Radiation Physics, Center for Radiation Research, National Bureau of Standards, Gaithersburg, MD 20899

Test No. Items

C.1 X-Ray and Gamma-Ray Measuring Instruments

46010C Radiation Detectors-Calibration/Correction Factor, One Beam Quality (See Table 7)

46011C Each Additional Beam Quality or Condition

46020C Passive Dosimeters-Irradiation of Up to Six, One Beam Quality at One Set-Up

46021C Up to Six Additional Dosimeters at Same Set-Up and Beam Quality

46030S Special Tests of High-Gain Electrometers-Charge Sensitivity, One Set of Switch Positions, with $46010 \mathrm{C} / 46011 \mathrm{C}$, by Previous Arrangement

46040S Special Tests of X-Ray Penetrameters, ArdranCrookes Type

46050S Special Tests of X-Ray and Gamma-Ray Measuring Instruments

C.2 Gamma-Ray and Beta-Particle Sources

47010C Gamma-Ray Sources- 0.5 to $250 \mathrm{mg} \mathrm{Ra}$; or ${ }^{60} \mathrm{Co}$, ${ }^{137} \mathrm{Cs},{ }^{125} \mathrm{I}$, or ${ }^{192} \mathrm{Ir}$, Having Exposure Rates 0.1 to 100 $(\mu \mathrm{R} / \mathrm{s}) \mathrm{m}^{2}$.

47011C Each Additional Gamma-Ray Source of Same Radionuclide

47030C Beta-Particle Sources Calibrated for Surface Dose Rate

47040S Special Tests of Gamma-Ray and Beta-Particle Sources

C.3 Dosimetry of High-Energy Electron Beams

48010C Irradiation of Ferrous-Ferric Dosimeters-Three Dosimeters (Two for Irradiation, One Control)

48011C Each Additional Dosimeter

48020S Special Tests of Electron-Beam Dosimeters
C.0 Special Instructions for Using

Electron and Photon Dosimetry Calibration and Test Services (46010C-48020S)

The NBS dosimetry calibration and test services for $\mathrm{x}$ rays, gamma rays, and electrons are performed in the Bureau's laboratories at Gaithersburg, Maryland. Inquiries should be addressed to the appropriate technical contacts listed at the beginning of this section. The name and telephone number of an individual who can answer technical questions that may arise must be given in any inquiry, order, or shipment.

Upon receipt of a purchase order, the Dosimetry Group assigns it a number. Calibrations are generally performed in the sequence established by those numbers, except when greater efficiency can be achieved by combining similar calibrations, or when work for a calibration laboratory is given a higher priority.

Arrangements for calibration must be made in advance by letter or telephone, so that the instrument or source to be calibrated will not be shipped to NBS until the time of its scheduled calibration approaches. Inquiry should be made as to scheduling and turn-around time.

Except for negligence by Bureau personnel, the Bureau assumes no responsibility for loss of or damage to the instruments or sources while in its possession. The risk should be covered by insurance.

The report of calibration or test will carry a Dosimetry Group number (e.g., DG 9876/85). Subsequent reference to that calibration or test should cite the DG number.

\section{C.1 X-Ray and Gamma-Ray Mea-} suring Instruments (46010C-46050S) $\mathrm{X}$-ray measuring instruments are calibrated in terms of exposure by a substitution method in an $\mathrm{x}$-ray beam at a point where the exposure rate has been determined by means of a standard free-air ionization chamber. In order to provide instrument calibrations over a wide range of $\mathrm{x}$-ray beam qualities, many combinations of 
generating potential and filtration are available. These are listed in Table 7 as lightly (L), moderately (M), and heavily $(\mathrm{H})$ filtered beams. Two beam qualities that do not fit into these categories are considered as special (S) qualitites, and two gamma-ray beams are also available. The beam qualities are identified by beam codes given in the first column. The calibration beam qualities requested should be appropriate to the instrument submitted.

Table 7: X-Ray Beam-Quality Parameters

\begin{tabular}{|c|c|c|c|c|c|c|c|c|c|c|c|c|c|}
\hline \multirow[t]{2}{*}{$\begin{array}{l}\text { Beam } \\
\text { Code }\end{array}$} & \multirow[t]{2}{*}{$\begin{array}{l}\text { Prev. } \\
\text { Code }\end{array}$} & \multicolumn{4}{|c|}{ Added Filter } & \multicolumn{2}{|c|}{$\begin{array}{c}\text { Half-Value } \\
\text { Layer }\end{array}$} & \multicolumn{2}{|c|}{$\begin{array}{l}\text { Homogeneity } \\
\text { Coefficient }\end{array}$} & \multirow{2}{*}{$\begin{array}{l}\text { Effective } \\
\text { Energy } \\
\text { (keV) }\end{array}$} & \multirow{2}{*}{$\begin{array}{l}\begin{array}{l}\text { Dis- } \\
\text { tance }\end{array} \\
\text { (cm) }\end{array}$} & \multirow{2}{*}{$\begin{array}{l}\text { Exposure } \\
\text { Min. } \\
(\mathrm{mR} / \mathrm{s})\end{array}$} & \multirow{2}{*}{$\begin{array}{l}\text { e Rate } \\
\text { Max. } \\
(\mathrm{R} / \mathrm{s})\end{array}$} \\
\hline & & $\begin{array}{c}\mathrm{Al} \\
(\mathrm{mm})\end{array}$ & $\begin{array}{c}\mathrm{Cu} \\
(\mathrm{mm})\end{array}$ & $\begin{array}{c}\mathrm{Sn} \\
(\mathrm{mm})\end{array}$ & $\begin{array}{c}\mathbf{P b} \\
(\mathrm{mm})\end{array}$ & $\underset{(\mathrm{mm})}{\mathrm{Al}}$ & $\underset{(\mathrm{mm})}{\mathrm{Cu}}$ & Al & $\mathrm{Cu}$ & & & & \\
\hline L10 & L-B & 0. & & & & 0.029 & & 79 & & & 25 & 0.001 & 1.7 \\
\hline L15 & L-C & 0. & & & & 0.050 & & 74 & & & 25 & 0.001 & 4.2 \\
\hline L20 & L-D & 0. & & & & 0.071 & & 76 & & & 50 & 0.001 & 3.3 \\
\hline L30 & & 0.265 & & & & 0.22 & & 60 & & & 50 & 0.001 & 0.4 \\
\hline L40 & & 0.50 & & & & 0.49 & & 57 & & & 50 & 0.001 & 0.4 \\
\hline L50 & & 0.639 & & & & 0.75 & & 58 & & & 50 & 0.001 & 0.4 \\
\hline L80 & & 1.284 & & & & 1.83 & & 58 & & & 50 & 0.001 & 0.4 \\
\hline $\mathrm{L} 100$ & L-M & 1.978 & & & & 2.8 & & 59 & & & 50 & 0.001 & 0.4 \\
\hline M20 & & 0.230 & & & & 0.152 & & 79 & & & 50 & 0.001 & 0.5 \\
\hline M30 & $\mathbf{L}-\mathrm{G}$ & 0.50 & & & & 0.36 & & 64 & & & 50 & 0.001 & 0.3 \\
\hline M40 & & 0.786 & & & & 0.73 & & 66 & & & 50 & 0.001 & 0.4 \\
\hline M50 & L-I & 1.021 & & & & 1.02 & 0.032 & 66 & 62 & & 50 & 0.001 & 0.4 \\
\hline M60 & MFB & 1.51 & & & & 1.68 & 0.052 & 68 & 64 & & & 0.8 & 0.2 \\
\hline M100 & MFG & 5.0 & & & & 5.0 & 0.20 & 72 & 55 & & & 1.0 & 0.3 \\
\hline M150 & MFI & 5.0 & 0.25 & & & 10.2 & 0.67 & 87 & 62 & & & 1.0 & 0.4 \\
\hline M200 & & 4.1 & 1.12 & & & 14.9 & 1.69 & 95 & 69 & & & 1.0 & 0.3 \\
\hline M250 & MFO & 5.0 & 3.2 & & & 18.5 & 3.2 & 98 & 86 & & & 1.0 & 0.2 \\
\hline M300 & & 4.0 & & 6.5 & & 22. & 5.3 & 100 & 97 & & & 0.5 & 0.08 \\
\hline H10 & & 0.105 & & & & 0.048 & & 89 & & & 25 & 0.001 & 0.003 \\
\hline H15 & & 0.500 & & & & 0.152 & & 87 & & & 25 & 0.001 & 0.003 \\
\hline $\mathrm{H} 20$ & & 1.021 & & & & 0.36 & & 88 & & & 50 & 0.001 & 0.003 \\
\hline Н30 & & 4.13 & & & & 1.23 & 0.038 & 93 & 94 & & 50 & 0.001 & 0.003 \\
\hline $\mathrm{H} 40$ & & 4.05 & 0.26 & & & 2.9 & 0.093 & 94 & 95 & & 50 & 0.001 & 0.003 \\
\hline H50 & $\mathrm{HFC}$ & 4.0 & & & 0.10 & 4.2 & 0.142 & 92 & 90 & 38 & & 0.3 & 0.065 \\
\hline $\mathrm{H} 60$ & & 4.0 & 0.61 & & & 6.0 & 0.24 & 94 & 89 & 46 & & 0.02 & 0.005 \\
\hline H100 & & 4.0 & 5.2 & & & 13.5 & 1.14 & 100 & 94 & 80 & & 0.005 & 0.002 \\
\hline H150 & HFG & 4.0 & 4.0 & 1.51 & & 17.0 & 2.5 & 100 & 95 & 120 & & 0.03 & 0.010 \\
\hline H200 & HFI & 4.0 & 0.60 & 4.16 & 0.77 & 19.8 & 4.1 & 100 & 99 & 166 & & 0.02 & 0.006 \\
\hline H250 & HFK & 4.0 & 0.60 & 1.04 & 2.72 & 22 & 5.2 & 100 & 98 & 211 & & 0.03 & 0.005 \\
\hline H300 & & 4.1 & & 3.0 & 5.0 & 23 & 6.2 & 99 & 98 & 252 & & 0.04 & 0.003 \\
\hline S75 & L-K & 1.504 & & & & 1.86 & & 63 & & & 50 & 0.001 & 0.4 \\
\hline S60 & MFC & 4.0 & & & & 2.8 & 0.089 & 75 & 70 & & & 0.3 & 0.06 \\
\hline $137 \mathrm{Cs}$ & Cs-137 & & & & & & 10.8 & & & 662 & & 1.5 & 0.1 \\
\hline $60 \mathrm{Co}$ & $\mathrm{Co}-60$ & & & & & & 14.9 & & & 1250 & & 1.5 & 2.5 \\
\hline
\end{tabular}

For the $\mathrm{x}$-ray beam codes, the letter indicates light, moderate, heavy, and special filtration and the number is the constant potential in kilovolts.

The inherent filtration is approximately

$1.0 \mathrm{~mm}$ Be for beam codes L10-L100, M20-M50, H10-H40, and S75; and

$3.0 \mathrm{~mm}$ Be for beam codes M60-M300, H50-H300, and S60.

The half-value layers for ${ }^{137} \mathrm{Cs}$ and ${ }^{60} \mathrm{Co}$ are calculated.

The homogeneity coefficient is taken as $100 \mathrm{x}(1 \mathrm{st} \mathrm{HVL}) /(2 \mathrm{nd}$ HVL $)$. 
Gamma-ray measuring instruments are calibrated in terms of exposure or absorbed dose at points in the collimated cobalt- 60 and cesium- 137 gamma-ray beams that have been standardized by means of graphite cavity chambers or a graphite calorimeter. Exposure rates and absorbed-dose rates at the time of calibration are computed from the original beam standardization data and appropriate decay corrections.

Ionization chambers submitted for an exposure calibration should have sufficient wall thickness to provide electron equilibrium for the gamma-ray energy selected. Ionization chambers submitted for an absorbed-dose calibration must be suitable for calibration in a phantom.

An ionization chamber and electrometer combination, with the electrometer marked in terms of exposure or absorbed dose, is calibrated by providing a dimensionless correction factor for the electrometer scale. An ionization chamber and electrometer combination with the electrometer marked in electrical units is calibrated as follows: (1) the chamber is calibrated in terms of exposure or absorbed dose per unit charge using an NBS electrometer, (2) the customer's electrometer is checked for linearity and charge measurement accuracy, and (3) the combination of chamber and electrometer is checked for consistency. An ionization chamber submitted without an electrometer is calibrated in terms of exposure or absorbed dose per unit charge. Calibration can be based on measurements for positive or negative polarizing potential, or on the mean of measurements for both potentials, as requested. The ratio of ionization currents for full and half polarizing potentials and the corresponding ionization current, will be stated in the calibration certificate.

Ionization chambers are tested, prior to calibration, for leakage, stabilization time, short-term stability, recombination loss, and connection to the atmosphere. Chambers found unsuitable for calibration will be returned with a statement of the reason for rejection. A charge may be made for time incurred in the tests.

Each instrument submitted to NBS for dosimetry calibration or test must be uniquely identified, usually by the manufacturer's name, model number, and instrument serial number. When the serial number is lacking, an alternative identifying mark should be provided. If none is found, NBS will mark the piece with an identification number. If the apparatus submitted has been calibrated previously by NBS, the serial number or identifying mark should be given on the new order so that a continuing record of stability can be maintained.

All shipments to NBS of instruments for dosimetry calibration must be in reusable containers. Even if properly packed, there can be no assurance that a calibrated instrument has maintained its calibration during shipment unless a method of verifying instrument stability has been established. Measurement should be made of the instrument response both be-

fore and after shipment, using a longlived radioactive source and a highly reproducible measurement procedure.

A long-term record of instrument stability using a suitable constancy check procedure is the most effective method for assuring the validity of the instrument calibration.

Irradiation of passive dosimeters, for readout by the customer, is available for the beam qualities listed in Table 7. These irradiations are generally in terms of exposure; for passive dosimeters suitable for insertion in a 
phantom, irradiation in terms of absorbed dose can be provided by in-phantom irradiation using cobalt- 60 gamma rays.

$\mathrm{X}$-ray penetrameters, of the Ardran-Crookes type, can be calibrated using constant $\mathrm{x}$-ray generating potentials up to $300 \mathrm{kV}$. These penetrameters are used for measurement of the generating potential of diagnostic X-ray units.

\section{C.2 Gamma-Ray and Beta-Particle Sources (47010C-47040S)}

Sources submitted to the Bureau for dosimetry calibration are subject to the following conditions:

A. Preparation: Sources submitted for calibration must be sealed so that there can be no escape of any radioactive material, including any gaseous decay products. The sources, shielding, and packaging must be free of contamination. Contaminated or leaking sources cannot be measured and may cause considerable loss of time and damage to laboratory facilities. Sources must have been sealed for a sufficient time to be substantially in radioactive equilibrium with their decay products when these contribute to the emitted radiation.

B. Packaging for shipment: Packages must be in compliance with the regulations of the Department of Transportation as specified in DOT 49CFR173.4-173.478. Radionuclides must be packaged as Limited Quantities (DOT 49CFR173.421) or in Type A packages (DOT 49CFR173.412 and 173.433). Type A packages must bear the appropriate radioactive-hazard labels (DOT 49CFR 172.403). If the source is considered by the shipper to be in DOT Special Form, a Special Form certificate must be furnished to NBS in strict compliance with DOT 49CFR 173.476. Copies of the codes are available at the Government Printing Office, Washington, DC 20402.

All shipments to NBS of gammaray and beta-particle sources must be in reusable containers. A drawing showing the source container and a description of the method of source removal must be provided before the shipment is received at NBS. Postal regulations preclude shipment of dosimetry sources via the Postal Service.

If the nature of the shipment requires a Type B container subject to an NRC quality assurance program, documentation must be supplied to NBS certifying that the use of the container by NBS is part of the program of the shipper.

C. Possession of licensed materials: In submitting a source for calibration, it is necessary for the submitter to certify that he is duly authorized to possess the source under license by the applicable authority. In the case of individuals residing in a State that has entered into agreement with the Nuclear Regulatory Commission, State regulations are applicable to all sources including radium. In the case of other individuals, NRC regulations are applicable (radium is not licensed by the NRC). This certification may be by letter, by a suitable statement on the purchase order covering the calibration fee, or by a clear copy of the submitter's Possession License for the source.

Calibration in terms of exposure rate at $1 \mathrm{~m}$ is provided for gamma-ray sources of cobalt- 60 , cesium-137, iridium-192, and iodine-125. Radium is calibrated in terms of mass of equivalent radium content measured relative to the National Radium Standard through comparison of the gamma radiation from the specimen and the standard; where the details of encapsulation of the specimen are known, corrections can be made to obtain milligrams of radium content. Calibration in terms of absorbed-dose rate is provided for suitable encapsulated beta-particle sources; the dose 
rate to a low-atomic-number material (graphite or plastic) is determined by measurement with an extrapolation chamber.

\section{C.3 Dosimetry of High-Energy Elec- tron Beams (48010C-48020S)}

Dosimeters are provided twice a year to users requesting assistance with absorbed-dose measurements in highenergy electron beams. The dosimeters consist of ferrous sulfate (Fricke) solution in radiation-resistant silica-glass spectrophotometer cells. The user irradiates all but one of the three furnished dosimeters to between 50 and $80 \mathrm{~Gy}$ (5000 and $8000 \mathrm{rad})$ to water at electron energies between 5 and $50 \mathrm{MeV}$, employing the irradiation geometry (field size, phantom, position of dosimeter in phantom) given in the "Protocol for Dosimetry of High-Energy Electrons," Physics in Medicine and Biology 11, 505 (1966).

After irradiation, the dosimeters are returned to the Bureau for spectrophotometric evaluation of the ferric-ion concentration in terms of absorbed dose in the phantom, using the G-value given in the Protocol.

\section{References-Dosimetry of X Rays, Gamma Rays, and Electrons}

\section{C.1 $X$-and Gamma-Ray Measuring Instruments}

The Photon-Fluence Scaling Theorem for Compton-Scattered Radiation, J. S. Pruitt and R. Loevinger, Med. Phys., 9, 176 (1982).

The Graphite Calorimeter as a Standard of Absorbed Dose for Cobalt- 60 Gamma Radiation, J. S. Pruitt, S. R. Domen, and R. Loevinger, J. Res. Natl. Bur. Stand. (U.S.), 86, 495 (1981).

Uncertainty in the Delivery of Absorbed Dose, R. Loevinger and T. P. Loftus, Ionizing Radiation Metrology, International Course at Varenna, Italy, 1974, E. Casnati, Ed., G-6, 459, Editrice Compositori, Bologna (1977). Medical Dosimetry Standards Program of the National Bureau of Stan- dards, R. Loevinger. Proc. Symp. on Natl. and Intl. Standardization in Rad. Dosimetry, Atlanta, GA, Dec. 5-9, 1977, Intl. Atomic Energy Agency, Vienna (1978). (This article provides references for earlier publications on NBS exposure and absorbed-dose standards.)

Exposure Spectra from the NBS Vertical-Beam ${ }^{60} \mathrm{Co}$ Gamma-Ray Source, M. Ehrlich and C. G. Soares, Natl. Bur. Stand. (U.S.), Int. Report, NBSIR 76-1117 (1976).

Spectrometry of a ${ }^{60} \mathrm{Co}$ Gamma-Ray Beam Used for Instrument Calibration, M. Ehrlich, S. M. Seltzer, M. J. Bielefeld, and J. I. Trombka, Metrologia, 12, 169 (1976).

\section{C.2 Gamma-Ray and Beta-Particle Sources}

Standardization of Iridium-192 Gamma-Ray Sources in Terms of Exposure, T. P. Loftus, J. Res. Natl. Bur. Stand. (U.S.), 85, 19 (1980). Medical Dosimetry Standards Program of the National Bureau of Standards, R. Loevinger. Proc. Symp. on Natl. and Intl. Standardization in Rad. Dosimetry, Atlanta, GA, Dec. 5-9, 1977, Intl. Atomic Energy Agency, Vienna, 1978. (This article provides references for earlier publications on NBS exposure and absorbed-dose standards.)

Exposure Standardization of Iodine-125 Seeds Used for Brachytherapy, T. P. Loftus, J. Res. Natl. Bur. Stand. (U.S.), 89, 295 (1984).

\section{C.3 Dosimetry of High-Energy Electron Beams}

Uniformity of High-Energy ElectronBeam Calibrations, M. Ehrlich and P. J. Lamperti, Phys. Med. Biol. 14, 305 (1969).

Proposed National Bureau of Standards Program for the Calibration of Instruments Used in High-Energy Electron and X-Ray Beams, M. Ehrlich, Ann. N.Y. Acad. Sci. 161, 139 (1969). 
Dosimetry for High-Dose Applications

Ionizing Radiation Division Center for Radiation Research

\section{Technical Contacts:}

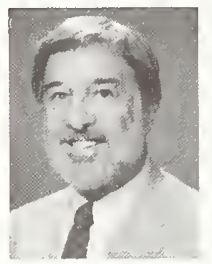

William L. McLaughlin

Tel: 301/921-2201

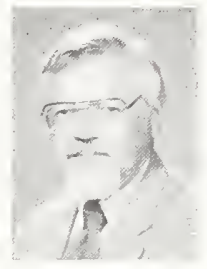

Jimmy C.

Humphreys

Tel: 301/921-2201
Mailing Address: C216 Radiation Physics, National Bureau of Standards, Gaithersburg, MD 20899

\begin{tabular}{ll} 
Test No. & Items \\
\hline $49010 \mathrm{~S}$ & $\begin{array}{l}\text { Special Tests of Customer-Supplied Dosimeters } \\
\text { Irradiated with }{ }^{60} \text { Co Gamma Rays }\end{array}$ \\
$49020 \mathrm{~S}$ & $\begin{array}{l}\text { Dose Interpretation of NBS-Packaged Dosimeters } \\
\text { Irradiated by Customer }\end{array}$ \\
$49030 \mathrm{~S}$ & $\begin{array}{l}\text { Dose Interpretation of Each NBS-Supplied } \\
\text { Dosimeter Package in Addition to those Supplied }\end{array}$ \\
$49040 \mathrm{~S}$ & $\begin{array}{l}\text { Under } 49020 \mathrm{~S} \\
\text { Special Tests of Dosimeters by Reading with } \\
\text { Spectrophotometer, Optical Density at One to Five } \\
\text { Wavelengths (Each Dosimeter) }\end{array}$ \\
$49041 \mathrm{~S} \quad \begin{array}{l}\text { Spectrophotometric Readings of Dosimeters, } \\
\text { Ultra-Violet and Visible Spectrum Scan (Each } \\
\text { Dosimeter) } \\
\text { Special Measurement Services for Dosimeter } \\
\text { Response }\end{array}$ \\
\hline
\end{tabular}

Special Tests of Dosimeters (49010S-49050S)

The following dosimetry services are for individual users of intense radiation fields, in particular, large gamma-ray sources and electron accelerators up to approximately $10 \mathrm{MeV}$. These services include the administering of known doses of photons to customer-supplied dosimeters; supplying calibrated secondary-standard transfer dosimeters to customers for irradiation and subsequent readout and dose interpretation; and special measurement services such as the determination of temperature dependence, dose-rate dependency or reproducibility of dosimeter response, and measurement of detailed dose distributions in specific irradiation geometries and in selected absorbing materials. These dose distribution measurements can include dose profiles in heterogenous absorbers and at surfaces and interfaces of different substances. Such information is important in research leading to the commissioning of a radiation process, and in measurement assurance that provides quality control of a given radiation treatment.

\section{Special Tests of Dosimeters Irradiated} with ${ }^{60}$ Co Gamma Rays (49010S)

Irradiation tests are available for customer-supplied dosimeters (such as solid radiochromic or liquid chemical types) or test samples that are sent to NBS, where they are packaged in appropriate conditions of electron equilibrium. They are then irradiated in the NBS standard cobalt-60 calibration facility to specific agreedupon absorbed dose values in the 
nominal "high-dose" ranges of 10-10 grays $\left(10^{3}-10^{8}\right.$ rads). The dosimeters may either be read and evaluated by NBS or sent back to the customer for analysis and evaluation. Dosimeters should not exceed dimensions of $1 \mathrm{~cm}$ x $2 \mathrm{~cm} \times 5 \mathrm{~cm}$.

Special Tests of Radiochromic Dosimeters (49020S and 49030S)

NBS can provide sets of calibrated radiochromic dosimeters packaged in appropriate equilibrium material, such as polystyrene or aluminum. The sealed, packaged dosimeters are sent to the customer for irradiation to nominal agreed-upon absorbed dose levels in a prescribed geometrical arrangement. The unopened packaged dosimeters are then returned to NBS to be read and evaluated. The absorbed dose range that is suitable for use with the radiochromic dosimeters is 1 to $50 \mathrm{kGy}(0.1$ to $5 \mathrm{Mrad}$ ) in water, silicon, aluminum, graphite, or certain plastics.

Special Tests of Dosimeters: Spectrophotometric Reading (49040S-49041S)

Dosimeters may be read at several specific ultraviolet or visible optical wavelengths or as a spectral scan over an appropriate wavelength region of interest.

Special Measurement Services for Dosimeter Response (49050S)

Tests of dosimeter response, such as temperature dependence, dose rate dependence, and dose distributions in specific irradiation geometries, can be provided as special measurement services.

References-High Dose Dosimetry A National Standardization Programme for High-Dose Measurements, W. L. McLaughlin, Technical Report No. 205, 17, Intl.

Atomic Energy Agency, Vienna (1981).

Dosimetry for Industrial Radiation Processing, W. L. McLaughlin, J. C. Humphreys, and A. Miller, Natl. Bur. Stand. (U.S.), Spec. Publ. 609 (1981).

Dye Film Dosimetry for Radiation Processing, J. C. Humphreys and W. L. McLaughlin, IEEE Trans. Nucl. Sci., NS-28, 2, 1797 (Apr. 1981).

The Measurement of Absorbed Dose and Dose Gradients, W. L.

McLaughlin, Radiat. Phys. Chem., 15, 9 (1980).

Dosimetry Standards for Industrial Radiation Processing, W. L.

McLaughlin, National and International Standardization of Radiation Dosimetry, 1, Intl. At. Energy Agency, Vienna (1978). 


\title{
Chapter
}

\author{
A Resistance Measurements \\ $B$ Impedance Measurements \\ C Voltage Measurements \\ $D$ Precision Ratio Measurements \\ $E$ Phase Angle Measurements \\ $F$ Power and Energy Measurements \\ $G$ Microwave Measurements \\ $H$ Noise Temperature Measurements \\ I Electromagnetic Field-Strength and \\ Antenna Measurements \\ $J$ Pulse Waveform Measurements
}


Resistance Measurements

- A.1 DC Resistance Standards and

Measurements

Electricity Division

Center for Basic Standards

Technical Contacts:

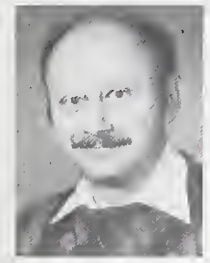

Ronald F.

Dziuba

Tel: 301/921-2715

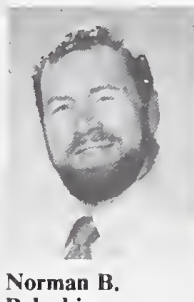

Belecki

Tel: 301/921-2715

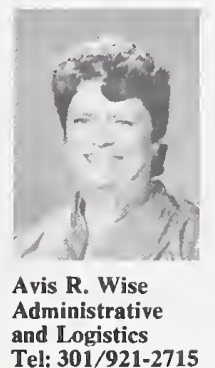

Mailing Address: B146 Metrology, National Bureau of Standards, Gaithersburg, MD 20899

\begin{tabular}{|c|c|}
\hline Test No. & Items \\
\hline $51100 \mathrm{~S}$ & $\begin{array}{l}\text { Special Resistance Measurement Services by } \\
\text { Prearrangement }\end{array}$ \\
\hline $51110 \mathrm{M}$ & $\begin{array}{l}\text { Measurement Assurance Program Services for } \\
\text { Resistance }\end{array}$ \\
\hline $51130 \mathrm{C}$ & Standard Resistor, Thomas-Type $1 \Omega$ \\
\hline $51131 \mathrm{C}$ & $\begin{array}{l}\text { Standard Resistor, Evanohm Wirewound High } \\
\text { Precision, } 10 \mathrm{k} \Omega\end{array}$ \\
\hline $51132 \mathrm{C}$ & Standard Resistor, Four-Terminal $0.0001 \Omega$ \\
\hline $51133 \mathrm{C}$ & Standard Resistor, Four-Terminal $0.001 \Omega$ \\
\hline $51134 \mathrm{C}$ & Standard Resistor, Four-Terminal $0.01 \Omega$ \\
\hline $51135 \mathrm{C}$ & Standard Resistor, Four-Terminal $0.1 \Omega$ \\
\hline $51136 \mathrm{C}$ & Standard Resistor, Four-Terminal $1 \Omega$ \\
\hline $51137 \mathrm{C}$ & Standard Resistor, Four-Terminal, $10 \Omega$ \\
\hline $51138 \mathrm{C}$ & Standard Resistor, Four-Terminal, $100 \Omega$ \\
\hline $51139 \mathrm{C}$ & Standard Resistor, $1 \mathrm{k} \Omega$ \\
\hline $51140 \mathrm{C}$ & Standard Resistor, $10 \mathrm{k} \Omega$ \\
\hline $51141 \mathrm{C}$ & Standard Resistor, $100 \mathrm{k} \Omega$ \\
\hline $51142 \mathrm{C}$ & Standard Resistor, $1 \mathrm{M} \Omega$ \\
\hline $51143 \mathrm{C}$ & Standard Resistor, $10 \mathrm{M} \Omega$ \\
\hline $51144 \mathrm{C}$ & Additional Voltage \\
\hline $51145 \mathrm{C}$ & Standard Resistor, $100 \mathrm{M} \Omega$ \\
\hline
\end{tabular}

Special DC Resistance Measurements by Prearrangement (51100S)

Testing or evaluation of prototype resistance standards or measuring instruments; unique resistance measurements; and other calibration services not specified below, such as the determination of the pressure co-

\begin{tabular}{|c|c|}
\hline Test No. & Items \\
\hline $51146 \mathrm{C}$ & Additional Voltage \\
\hline $51147 \mathrm{C}$ & Standard Resistor, $1 \mathrm{G} \Omega$ \\
\hline $51148 \mathrm{C}$ & Additional Voltage \\
\hline $51149 \mathrm{C}$ & Standard Resistor, $10 \mathrm{G} \Omega$ \\
\hline $51150 \mathrm{C}$ & Additional Voltage \\
\hline $51151 \mathrm{C}$ & Standard Resistor, $100 \mathrm{G} \Omega$ \\
\hline $51152 \mathrm{C}$ & Additional Voltage \\
\hline $51153 \mathrm{C}$ & Standard Resistor, $1 \mathrm{~T} \Omega$ \\
\hline $51154 \mathrm{C}$ & Additional Voltage \\
\hline \multirow[t]{2}{*}{$51160 \mathrm{C}$} & $\begin{array}{l}\text { Standard Resistor for Current Measurements } \\
\text { (Shunts), One Range, One Current Not to Exceed } 300\end{array}$ \\
\hline & A (May \& Nov.) \\
\hline $51161 \mathrm{C}$ & $\begin{array}{l}\text { Standard Resistor for Current Measurements } \\
\text { (Shunts), One Range, One Current Between } 300 \text { A } \\
\text { and } 1000 \text { A (May \& Nov.) }\end{array}$ \\
\hline $51162 \mathrm{C}$ & $\begin{array}{l}\text { Standard Resistor for Current Measurements } \\
\text { (Shunts), Additional Range of a Multi-Range Resistor } \\
\text { (May \& Nov.) }\end{array}$ \\
\hline $51163 \mathrm{C}$ & $\begin{array}{l}\text { Standard Resistor for Current Measurements } \\
\text { (Shunts), Additional Determination at Another } \\
\text { Current Level (May and Nov.) }\end{array}$ \\
\hline
\end{tabular}

efficient of Thomas-type resistors, the determination of the temperature coefficient of standard resistors, and the calibration of resistance standards in oil at temperatures other than $25^{\circ} \mathrm{C}$, are carried out under this test number. Such measurements are made at the discretion of the NBS technical 
staff in a manner specifically agreed upon by the customer and the expert involved. Testing of component resistors will only be considered under the rare circumstance that the behavior of the resistors has been observed to approximate that of state-of-the-art standards under the same conditions.

\section{Measurement Assurance Program} Services for Resistance (51110M)

Resistance MAP transfers are generally carried out at the $1 \mathrm{ohm}$ and 10 kilohm levels. Four wellcharacterized commerical standard resistors are used as transport standards. The suggested measurement schedule at the client laboratory consists of measurements on each transport resistor 3 times a weel for a period of 4-6 weeks, depending upon the settling time of the resistors due to transportation effects.

Participation in this program is generally not advisable unless one is required to support resistance measurements at or near state-of-the-art accuracies and is willing to adopt a system for the continuous surveillance of standards during the intervals between NBS MAP transfers. A successful transfer requires a considerable amount of data collection and a willingness to become involved in the data analysis process. Data supplied in the course of routine NBS calibrations suffice for normal measurement requirements of standards laboratories if proper methods are used by the laboratory to quantify the additional uncertainties caused by transportation and the laboratory's own measurement process.

Special Standard Resistors $1 \Omega$ and $10 \mathrm{k} \Omega(51130 \mathrm{C}$ and $51131 \mathrm{C})$

Thomas-type $1 \mathrm{ohm}$ resistors or their equivalent are calibrated directly against the NBS $1 \mathrm{ohm}$ reference group that is used to maintain the U.S. legal ohm. Special 10 kilohm standard resistors designed for air or oil use are calibrated directly against the NBS 10 kilohm working standards. The special 10 kilohm standard resistors (Evanohm wirewound highprecision or equivalent) are characterized by resistance corrections within $10 \mathrm{ppm}$ of nominal value, temperature coefficients of $0 \pm 1 \mathrm{ppm} /{ }^{\circ} \mathrm{C}$ at the operating temperature, and drift rates of $\leq 1 \mathrm{ppm} /$ year.

The customer resistors are acclimatized in their respective test environments for approximately one week prior to their calibration. Measurement parameters of temperature and current level are as follows:

$\begin{array}{cccr}\text { Resistor } & \text { Medium } & \text { Temperature } & \text { Current } \\ 1 \Omega & \text { oil } & 25.00 \pm 0.003^{\circ} \mathrm{C} & 100 \mathrm{~mA} \\ 10 \mathrm{k} \Omega & \text { oil } & 25.00 \pm 0.01^{\circ} \mathrm{C} & 1 \mathrm{~mA} \\ 10 \mathrm{k} \Omega & \text { air } & 23.0 \pm 1.0^{\circ} \mathrm{C} & 1 \mathrm{~mA}\end{array}$

The temperature of the customer resistor at the time of the measurement 
is given in the report of calibration. Since the Thomas-type resistor exhibits a significant pressure coefficient, the barometric pressure at the time of the measurement is also reported for the $1 \mathrm{ohm}$ standards. Uncertainties are based upon (1) the random behavior of the measurement process as characterized by data from a large population of individual calibrations, and (2) an estimate of the systematic errors. Uncertainties are listed in Table 8 at the end of this section.

\section{Standard Resistors $10^{-4}-10^{6} \Omega$ (51132C-51142C)}

Standard resistors with nominal decade values in the range between $10^{-4}$ and $10^{6} \mathrm{ohm}$ are calibrated by comparison with NBS working standards. In general, these standards are characterized by (1) resistance corrections within $500 \mathrm{ppm}$ of nominal value, (2) temperature coefficients of $\leq 10 \mathrm{ppm} /$ ${ }^{\circ} \mathrm{C}$ at the temperature of use, and (3) drift rates of $\leq 5 \mathrm{ppm} /$ year. Normally, standard resistors are measured in an oil bath maintained at $25.0 \pm 0.05^{\circ} \mathrm{C}$, and at a power level of $\leq 0.1 \mathrm{~W}$. Resistors in temperature-controlled enclosures with fixed terminations are also accepted for calibration. At the levels of accuracy involved, fourterminal measurements are required for resistors whose nominal value is $100 \mathrm{ohms}$ or less. Uncertainties are based upon (1) the random behavior of the measurement process as characterized by data from a large population of individual calibrations, and
(2) an estimate of the systematic errors. Uncertainties are given in Table 8 at the end of this section.

High-Valued Standard Resistors: $10^{7}-10^{12} \Omega(51143 C-51154 C)$

High-value standard resistors in the range between $10^{7}$ and $10^{12} \mathrm{ohms}$ are calibrated in an air bath maintained at a temperature of $23.0 \pm 0.5^{\circ} \mathrm{C}$ and at a relative humidity of $35 \pm 5 \%$. Customer resistors are compared 1:1 with NBS working standards of the same nominal value up to and including the $10^{10} \mathrm{ohms}$ level. Above $10^{10} \mathrm{ohms}$, 10:1 and 100:1 ratio techniques are employed. The maximum test voltage is 500 volts for resistors $<10^{10} \mathrm{ohms}$ and 1000 volts for resistors $\geq 10^{10}$ ohms. Uncertainties depend upon the stability and performance of the specific resistor involved, and are given at the end of this section. Only resistors that are mounted in a shielded enclosure with a permanent identifying number and have suitable terminations are accepted for calibration.

The resistance of thin-film, highvalued resistance standards is frequently highly voltage dependent. Hence, the magnitude of the test voltage should be specified by the customer when a resistor is submitted for calibration. The temperature, relative 
humidity, and test voltage of the resistor are given in the report of calibration.

\section{High-Current Standard Resistors- Shunts (51160C-51163C)}

Four-terminal standard resistors for use in the precise measurement of high direct currents (shunts) are calibrated by NBS only during May and November of the calendar year. Arrangements should be made with NBS prior to submitting a resistor for calibration. Normally only resistors of $0.04 \%$ accuracy or better are calibrated. The maximum test current available is 1000 amperes. The uncertainty of measurement depends largely upon the performance of the customer resistor involved.

Table 8: Calibration Uncertainties for DC Resistance Standards

\begin{tabular}{ccccc}
\hline $\begin{array}{c}\text { Test } \\
\text { Number Resistance (ohms) }\end{array}$ & Nominal & Terminal & \multicolumn{3}{c}{ Maximum Uncertainty } \\
Connection & Power (mw) & ppm \\
\hline $51130 \mathrm{C}$ & 1 (Thomas) & 4 & 10 & 0.08 \\
$51131 \mathrm{C}$ & $10^{4}$ (Special) & 5 & 50 & 1 \\
$51132 \mathrm{C}$ & $10^{-4}$ & 4 & 100 & 20 \\
$51133 \mathrm{C}$ & $10^{-3}$ & 4 & 100 & 12 \\
$51134 \mathrm{C}$ & $10^{-2}$ & 4 & 100 & 7 \\
$51135 \mathrm{C}$ & $10^{-1}$ & 4 & 100 & 5 \\
$51136 \mathrm{C}$ & 1 & 4 & 100 & 3 \\
$51137 \mathrm{C}$ & 10 & 4 & 100 & 4 \\
$51138 \mathrm{C}$ & $10^{2}$ & 2 & 100 & 4 \\
$51139 \mathrm{C}$ & $10^{3}$ & 2 & 100 & 5 \\
$51140 \mathrm{C}$ & $10^{4}$ & 2 & 100 & 7 \\
$51141 \mathrm{C}$ & $10^{5}$ & 2 & 100 & 10 \\
$51142 \mathrm{C}$ & $10^{6}$ & 2 & 100 & 15 \\
$51143 \mathrm{C}$ & $10^{7}$ & 3 & $*$ & $50-2000$ \\
$51145 \mathrm{C}$ & $10^{8}$ & 3 & $*$ & $100-2000$ \\
$51147 \mathrm{C}$ & $10^{9}$ & 3 & $*$ & 2000 \\
$51149 \mathrm{C}$ & $10^{10}$ & 3 & $*$ & 2000 \\
$51151 \mathrm{C}$ & $10^{11}$ & 3 & $*$ & 2000 \\
$51153 \mathrm{C}$ & $10^{12}$ & 3 & $*$ & 2000 \\
\hline
\end{tabular}

- Resistors at this level are tested at customer-specified voltages up to $1 \mathrm{k} \mathrm{V}$.
References-DC Resistance

A Test of the Quantum Hall Effect as a Resistance Standard, M. E. Cage, R. F. Dziuba, and B. F. Field, IEEE Trans. Instrum. Meas., IM-34, 301 (1985).

Automated NBS 1-Ohm Measurement System, K. R. Baker and R. F.

Dziuba, IEEE Trans. Instrum. Meas., IM-32, 154 (1982).

Determination of the Fine-Structure Constant Using $\mathrm{GaAs}-\mathrm{Al}_{\mathrm{x}} \mathrm{Ga}_{(1-\mathrm{x})}$ as Heterostructures, D. C. Tusui, A. C. Gossard, B. F. Field, M. E. Cage, and R. F. Dziuba, Phys. Rev. Lett., 48, 3 (1982).

Measurement of the Quantized Hall Steps in Silicon at the PPM Level, R. J. Wagner, C. F. Lavin, M. E. Cage, R. F. Dziuba, and B. F. Field, Surf. Sci., 113, 10 (1982).

An Integrated System for the Precision Calibration of Four-Terminal Standard Resistors, T. E. Wells and E. F. Gard, IEEE Trans. Instrum. Meas., IM-20, 253 (Nov. 1971). Calibration Procedures for Direct Current Apparatus, P. Brooks, Natl. Bur. Stand. (U.S.), Monogr. 39 (Mar. 1962).

Measurement of Multimegohm Resistors, A. H. Scott, J. Res. Natl. Bur. Stand. (U.S.), 50, No. 3 (Mar. 1953).

Precision Resistors and Their Measurement, J. L. Thomas, Natl. Bur. Stand. (U.S.), Circular 470 (Oct. 1948).

Methods, Apparatus, and Procedures for the Comparison of Precision Standard Resistors, F. Wenner, J. Res. Natl. Bur. Stand. (U.S.), 25, Res. Paper RP1323 (Aug. 1940). 


\section{Resistance Measurements}

- A.2 High-Voltage Standard Resistors Electrosystems Division

Center for Electronics and Electrical Engineering

\section{Technical Contacts:}

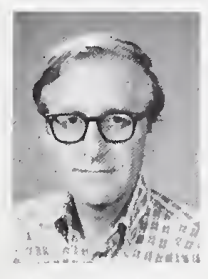

Martin Misakian Tel: 301/921-3121

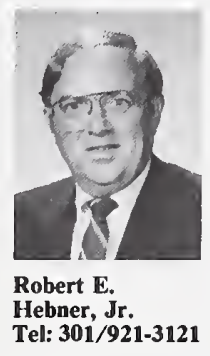

Tel: $301 / 921-3121$
Mailing Address: B344 Metrology, National Bureau of Standards, Gaithersburg, MD 20899

Shipping Address: National Bureau of Standards I-270 at Quince Orchard Road, Gaithersburg, MD 20899

[Attn: M. Misakian, Bld. 220, Room B344]

Test No. Items

51210C High-Voltage Standard Resistors

High-Voltage Resistors (51210C)

A routine calibration service is maintained for resistors designed for dc high-voltage applications. This service is for nearly corona-free resistors designed for dc operation between 10 $\mathrm{kV}$ and $150 \mathrm{kV}$.

Resistors can be hand-carried or shipped to NBS. If they are shipped, they should be packaged in sturdy reusable containers. The design of many high voltage resistors makes them vulnerable to shear-type forces, so provisions should be made to minimize the likelihood of damage due to such forces when the device is in the shipping container.

\section{References-High-Voltage Standard} Resistors

Special Shielded Resistor for HighVoltage Measurements, J. H. Park, J. Res., Natl. Bur. Stand., 66C, No. 1, 1924 (Jan.-Mar. 1962).

High Voltage Divider and Resistor Calibrations, M. Misakian, NBS Tech. Note 1215 (July 1985).

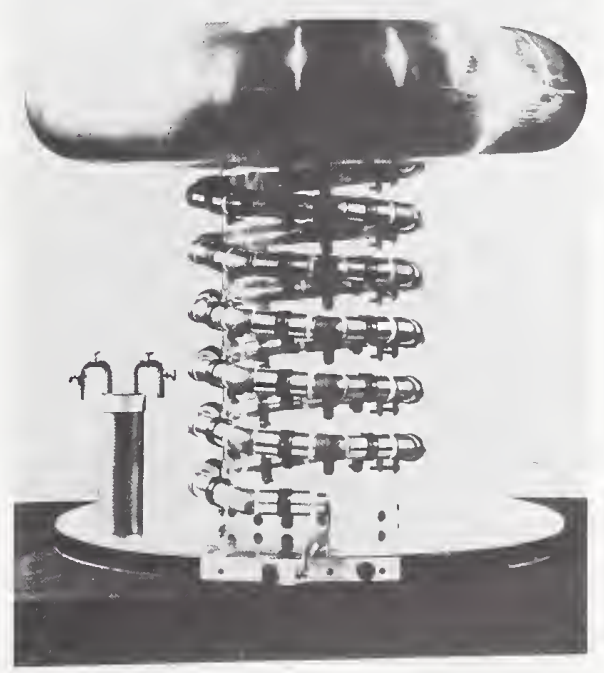

NBS reference high-voltage resistor (large object; for size comparison, low-voltage resistor at left). 


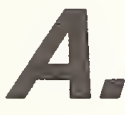

Resistance Measurements

A.3 High-Frequency Standard Resistors Electromagnetic Fields Division Center for Electronics and Electrical Engineering

\section{Technical Contacts:}

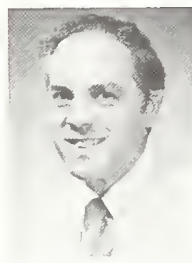
Tel: 303/497-3705
Cletus A Hoer

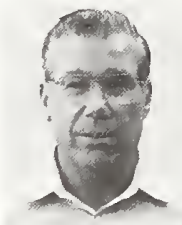

Raymond N. Jones Tel: $303 / 497-3609$

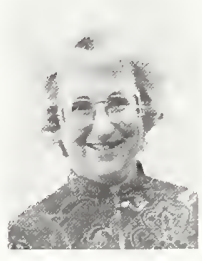

Edna M. Jones Administrative and Logistics Tel: $303 / 497-3753$
Mailing Address: M.C. 723.10, National Bureau of Standards, 325 Broadway, Boulder, CO 80303

\section{Test No. Items}

51310C High-Frequency Standard Resistors; Two-Terminal

High-Frequency Standard Resistors (51310C)

The overall frequency range covered is $10 \mathrm{kHz}$ to $250 \mathrm{MHz}$. The range of resistance that can be calibrated de- pends on the measurement frequency, as follows:

Frequency Range Resistance Range

$10 \mathrm{kHz}-2 \mathrm{MHz}$

$0.1 \Omega$ to $1 \mathrm{M} \Omega$

$2 \mathrm{MHz}-10 \mathrm{MHz}$

$50 \Omega$ to $1 \mathrm{M} \Omega$

$10 \mathrm{MHz}-100 \mathrm{MHz} \quad 20 \Omega$ to $50 \mathrm{k} \Omega$

$100 \mathrm{MHz}-250 \mathrm{MHz} \quad 20 \Omega$ to $20 \mathrm{k} \Omega$

Measurement uncertainties are given in the reference; the minimum uncertainty provided is \pm 0.1 percent.

Reports of Calibration or Tests for resistors will include the inductance or capacitance associated with the resistor. Equivalent series values are normally given for inductive resistors and equivalent parallel values for capacitive resistors.

References-High-Frequency Standard Resistors

The Measurement of Lumped Parameter Impedance: A Metrology Guide, R. N. Jones, Nat. Bur. Stand. (U.S.), Monogr. 141, (June 1974).

Impedance of Lumped Circuits, L. E. Huntley, and R. N. Jones, Proc.

IEEE, 55(6), 900 (June 1967). 


\section{Resistance Measurements}

\section{A.4 AC Resistors}

Electrosystems Division

Center for Electronics and Electrical Engineering

\section{Technical Contacts:}
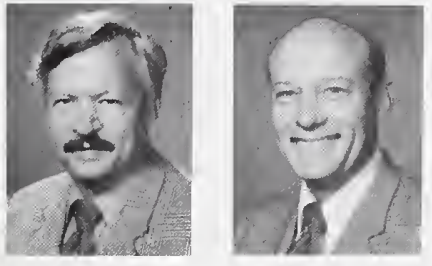

T. Michael

Souders

Barry A. Bell

Tel: 301/921-2727

Mailing Address: B162 Metrology, National Bureau of Standards, Gaithersburg, MD 20899

Test No. Items

Special Tests of AC Resistors (51410S)

Properly designed four-terminal ac resistors in the range of $0.1 \mathrm{ohm}$ to $0.001 \mathrm{ohm}$ can be measured at current ratings not to exceed $50 \mathrm{~A}$. The values for the ac resistance and phase angle (or time constant) can be reported for frequencies between $50 \mathrm{~Hz}$ and 10 $\mathrm{kHz}$. To be accepted for test, resistors must have phase angles no greater than 0.01 radian at all requested test frequencies.

The service is being offered on a trial basis under Special Test Procedures. The fee for this service will be based on the actual cost. Prior arrangements are essential.

\section{References-AC Resistors}

An Audio Frequency Four-Terminal Resistance Bridge, T. M. Souders, IEEE Trans. Instrum. Meas., IM-23, No. 4, 342 (Dec. 1974). 


\section{IImpedance Measurements (Except Resistors) B.1 Low-Frequency Capacitance and Inductance \\ Measurements and Standards \\ Electricity Division \\ Center for Basic Standards}

\section{Technical Contacts:}

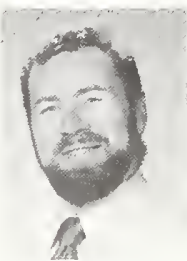

Norman B. Belecki Tel: 301/921-2715

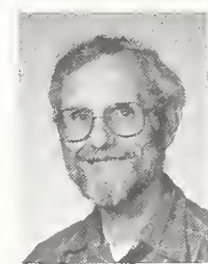

George M. Free Tel: 301/921-2715

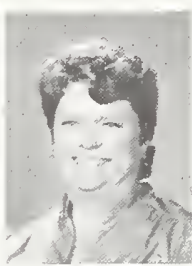

Avis R. Wise Administrative and Logisties Tel: 301/921-2715
Mailing Address: B146 Metrology, National Bureau of Standards, Gaithersburg, MD 20899

Test No. Items

$52110 \mathrm{~S}$ Special LF Impedance Measurements by Prearrangement

52130C Standard Fixed, Fused-Silica Dielectric Capacitor $(10$ and $100 \mathrm{pF}$ at 100,400 , or $1000 \mathrm{~Hz}$ )

52131C Additional Frequency Points

52140C Fixed Three-Terminal, High-Precision Standard Capacitor With Coaxial Connectors (1 frequency, high accuracy under controlled conditions, 100, 400, or $1000 \mathrm{~Hz}$ )

52141C Additional Frequency Points

52150C Physical Tests to Qualify Three-Terminal Air Capacitor for Measurement under 52140C

52160C Fixed Three-Terminal Standard Capacitor with Coaxial Connectors ( 1 frequency, laboratory conditions, 100,400 , or $1000 \mathrm{~Hz}$ )

52161C Additional Frequencies

52170C Two or Three-Terminal Solid Dielectric Standard Capacitor $(66-2 / 3,100,400,1000$, or $10,000 \mathrm{~Hz})$

$52171 \mathrm{C}$ Additional Frequencies

$52180 \mathrm{C}$ Fixed Inductor, Self or Mutual $(100,400,1000$, or $10,000 \mathrm{~Hz})$

52181C Additional Points

Low-Frequency Capacitance and Inductance Measurements and Standards (52110S-52181C)

These services cover the calibration of standard capacitors and inductors in the audio-frequency range. Standard capacitors having fused-silica (10 and $100 \mathrm{pF})$, air $(0.001$ to $1000 \mu \mathrm{F})$, and silvered-mica ( 1 to $1000 \mathrm{HF}$ ) dielectrics can be measured at frequencies between $66-2 / 3$ and 10,000 $\mathrm{Hz}$. Air-core standard inductors having nominal values between $0.01 \mathrm{mH}$ and $10 \mathrm{H}$ can be measured at the same frequencies.

Calibration services for some types of capacitance standards at frequencies as low as $1 \mathrm{kHz}$ can be provided by the NBS Boulder Laboratory provided the accuracy requirement does not exceed \pm 0.01 percent. In some circumstances, this can eliminate the necessity of sending a standard to both Gaithersburg and Boulder Laboratories for a complete calibration. See also tests 52210C-52310C for calibration services for capacitors at higher frequencies. For additional details please inquire at NBS/Boulder: Telephone (303) 497-3609.

\section{Special LF Impedance Measurements} by Prearrangement (52110S)

This service provides for the testing or evaluation of prototype impedance standards or measurement instrumentation at the state-of-the-art, and other impedance measurements (such as the calibration of decade or variable capacitance standards), at the discretion of NBS technical experts. Component capacitors, inductors, and resistors are not considered for test by the NBS unless their performance approximates that of the best available standards. Even under those conditions, only limited testing will be done to ascertain the possible use of the components in precision measurement applications.

\section{Standard Fixed, Fused-Silica Dielectric Capacitors (52130C-52131C)}

Fused-silica dielectric standard capacitors are generally submitted in temperature-controlled ovens due to their 10-ppm/degree temperature coefficient. Because of the magnitude of the temperature coefficient, it is rec- 
ommended that a calibrated temperature sensor be permanently mounted in the oven and thus included for the calibration. For baths not so equipped, the temperature is measured in terms of the International Practical Temperature Scale of 1968 as amended in 1975 [Metrologia 12, 7 (1976)] using a standard platinum resistance thermometer.

Calibrations are carried out at 100 , 400 , or $1000 \mathrm{Hertz}$, or any combination of these chosen by the client. A minimum of eight measurements are made over a two-week or longer period, comparing the test capacitor directly with an NBS fused-silica standard at $10 \mathrm{pF}$. The number of readings taken depends on the stability of the temperature controller in the oven containing the test capacitors and can be as high as fourteen. The averages of the measured values of capacitance and temperature are reported. The uncertainty of the reported capacitance value depends on the stability of the temperature as well as on the performance of the capacitance standard itself. Because the temperature coefficients of individual standards are not known quantitatively, the results are not temperature corrected. Despite these factors, the uncertainty can be as low as $0.1 \mathrm{ppm}$.

Fused-silica dielectric standards not submitted in their own temperaturecontrolled oven are calibrated in stirred oil at a temperature of $25^{\circ} \mathrm{C}$. If they are supplied with built-in sensors, the sensors and the bath temperature are both measured.

Standard Capacitors (52140C-52171C)

The following guidelines apply to the calibration of standard capacitors at NBS.

Calibrations are ordinarily performed at a normal laboratory ambient temperature of $23 \pm 1^{\circ} \mathrm{C}$ except for high stability gas dielectric capacitors. These are placed in a highly insulated chamber for 48 hours to achieve temperature stability during calibration. The calibration temperature of about $23^{\circ} \mathrm{C}$ is reported to within $\pm 0.1^{\circ} \mathrm{C}$. Relative humidity is maintained at 50 percent or less in all cases.

Precision three-terminal gas dielectric capacitors, such as ESI Model SC1000 and GENRAD Model 1404 , have been found to be variously affected by mechanical shock and orientation. Accordingly, two types of calibrations are offered. The higher accuracy calibration (52140C) requires a qualification test $(52150 \mathrm{C})$ to determine the effect on capacitance of various impacts and changes in orientation. Results of this test are coupled with the random error of the precision calibration which follows to provide a definitive accuracy for the process. For the lower accuracy test $(52160 \mathrm{C})$, a similar calibration, albeit with reduced resolution, is per-

formed, but no physical testing is performed. The assigned uncertainty is fixed and has been deduced from an analysis of data taken from tests on a large population of standard capacitors.

The frequencies available for capacitance calibrations depend upon the type of capacitor and its connectors. In general, capacitors with coaxial connectors can be calibrated at 100,400 , and $1000 \mathrm{~Hz}$. Capacitors with binding posts or banana plugs can be calibrated at $66-2 / 3,100,400$, 1000 and $10,000 \mathrm{~Hz}$.

The capacitance value given is the equivalent parallel capacitance. In general, an accurate determination of the equivalent parallel conductance with high accuracy is not feasible. However, for solid dielectric capacitors an approximate value is given without charge.

The uncertainty stated in the report of calibration is determined in part by the accuracy of the Bureau's measurements and in part by the characteristics of the capacitor itself. The uncertainty is sufficiently broad to allow for variations in the stray capacitance at the connectors, variations in temperature of a few degrees Celsius, considerable variation in relative humidity and atmospheric pressure, and 
frequency deviations of a few percent from the stated test conditions. Over the above frequency range, and in the capacitance range from 0.001 to $100 \mu \mathrm{F}$, the uncertainty usually lies in the range 0.002 to 0.5 percent.

Capacitors requiring terminal plugs (banana plugs) for parallel connection should be sent to NBS, together with the plugs that will be used with the capacitor after calibration. If such a capacitor arrives without plugs, the NBS must attach plugs temporarily in order to calibrate the capacitor. The plugs used by the Bureau are GENRAD Type 274-P. If, after calibration with these plugs, the capacitor is used with plugs of even slightly different length and base, the capacitance can differ significantly from that reported. Unless otherwise requested, the measured value reported by NBS is the capacitance added when the standard is plugged directly into the binding posts of the NBS bridge. For twoterminal GENRAD capacitors Type 1401, Type 509, and Type 1409 (when used as a two-terminal capacitor), a capacitance increase ranging from 0.01 to $0.04 \mathrm{pF}$ has been found for different plugs. No significant change in conductance has been found in either the two-terminal or three-terminal value. The importance of terminal connection methods becomes extremely critical when capacitance values of $0.01 \mu \mathrm{F}$ or less are being measured. Improved accuracy in two-terminal measurement can be realized if standards are provided with precision coaxial connectors.

In the case of direct or threeterminal capacitance standards, the connectors are assumed to be coaxial. While the connectors available for this purpose are adequate, it should be noted that changes or instabilities in the impedance of the shield or guard connection of a three-terminal capacitor can change the capacitance significantly.

Unless otherwise specified in the customer's purchase order, capacitors with solid dielectric-except fusedsilica capacitors,- - will be calibrated as two-terminal capacitors (measurement of "grounded" capacitance, case connected to low terminal).

\section{Standard Inductors, Self or Mutual (52180C-52181C)}

Standard inductors for use in ac bridges are tested at a room temperature of $23^{\circ} \mathrm{C}$ and a relative humidity of 50 percent or less. Measurements at $10,000 \mathrm{~Hz}$ are limited to standard inductors of $0.1 \mathrm{H}$ or less. Most inductors used at $60 \mathrm{~Hz}$ can be tested at $100 \mathrm{~Hz}$ since the variation of inductance with frequency in this range is usually negligible. A metalencased standard is calibrated with the case connected to the "low" terminal of the inductor unless other conditions are specified.

\section{References-Low-Frequency Capaci- tance and Inductance Standards}

Testing to Quantify the Effects of Handling of Gas Dielectric Standard Capacitors, C. R. Levy, Natl. Bur. Stand. (U.S.), Tech. Note 1161 (1982).

Transportable $1000 \mathrm{pF}$ Standard, G. M. Free and J. J. Morrow, Natl. Bur. Stand. (U.S.), Tech. Note 1162 (1982).

New Measurements of the Absolute Farad and Ohm, R. D. Cutkosky, IEEE Trans. Instrum. Meas., IM-23, No. 4, 305 (Dec. 1974).

Applications of Coaxial Chokes to AC Bridge Circuits, D. N. Homan, J. Res. Natl. Bur. Stand. (U.S.), 72C, No. 2 (June 1968).

Improved Ten-Picofarad Fused Silica Dielectric Capacitor, R. D. Cutkosky and H. L. Lee, J. Res. Natl. Bur. Stand. (U.S.), 69C, No. 3, 173 (Sept. 1965).

Calibration of Inductance Standards in the Maxwell-Wein Bridge Circuit, T. L. Zapf, J. Res. Natl. Bur. Stand. (U.S.), 65C, No. 3 (Sept. 1961).

Capacitance Bridge-NBS Type 2, R. D. Cutkosky, Natl. Bur. Stand. (U.S.), Report 7103 (Mar. 1961). 
Impedance Measurements (Except Resistors)

B.2 High-Frequency Standard Capacitors and Inductors

Electromagnetic Fields Division

Center for Electronics and Electrical Engineering

Technical Contacts:

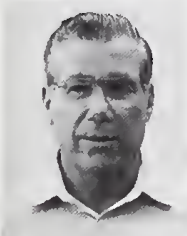

Raymond N. Jones

Tel: 303/497-3609

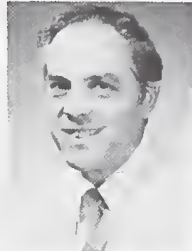

Cletus A. Hoer Tel: 303/497-3705 Administrative and Logistics Tel: 303/497-3753
Mailing Address: M.C. 723.10, National Bureau of Standards, 325 Broadway, Boulder, CO 80303

Test No. Items

52210S Two-Terminal, Low-Loss Standard Capacitors$10 \mathrm{kHz}$ to $250 \mathrm{MHz} ; 1 \mathrm{pF}$ to $1 \mu \mathrm{F}$

52211C Two-Terminal, Low-Loss Standard Capacitors, (High Accuracy)-1 MHz; 50, 100, 200, 500 and $1000 \mathrm{pF}$

52220C Three-Terminal, Low-Loss Standard Capacitors$100 \mathrm{kHz}, 465 \mathrm{kHz}, 1 \mathrm{MHz} ; 10^{-2} \mathrm{pF}$ to $10^{3} \mathrm{pF}$

52221C Three-Terminal, Low-Loss Standard Capacitors (High Accuracy) $-100 \mathrm{kHz}, 465 \mathrm{kHz}, 1 \mathrm{MHz} ; 10^{-2}$, $10^{-1}, 1,10,10^{2}$ and $10^{3} \mathrm{pF}$

52222C Three-Terminal (MacLeod and Hanopol) Capacitors$465 \mathrm{kHz} ; 0.001$ to $10 \mathrm{pF}$

52223C Auxiliary Unit for 52222C

52310S Two-Terminal, High-Q Standard Inductors $\left(10^{-2} \mu \mathbf{H}\right.$ to $\left.1 \mathbf{H}\right)$

High-Frequency Standard Capacitors and Inductors (52210S-52310S)

Services provided in this category (and also test nos. 51310C and $52700 \mathrm{C}$ ) are for passive devices over the frequency range from $10 \mathrm{kHz}$ to $250 \mathrm{MHz}$. Highest accuracy is obtained only for standards equipped with precision coaxial connectors. Standards submitted for calibration should be in good repair and, except for very minor cleaning of connector surfaces, should require no precalibration maintenance. NBS does not provide repair services so that items received that require maintenance will be returned to the sender and a handling fee will be charged.

Calibration services for some types of capacitance standards at frequencies as low as $1 \mathrm{kHz}$ can be provided by the NBS Boulder Laboratory provided the accuracy requirement does not exceed \pm 0.01 percent. In some circumstances this can eliminate the necessity of sending a standard to both the Gaithersburg and Boulder Laboratories for a complete calibration. For additional details please consult with the technical contact listed at the beginning of this section.

Calibration service for measuring instruments such as bridges or meters is not provided. The accuracy of these instruments should be verified by the owner through the use of stable standards especially selected for particular values and frequencies appropriate to the instrument in question.

All calibrations are performed under typical ambient laboratory conditions of $23^{\circ} \mathrm{C}$, and an atmospheric pressure of approximately $8.4 \pm 0.2 \times 10^{4} \mathrm{~Pa}$ at Boulder, Colorado. Services at ambient conditions outside these limits are not provided. Also, the power applied to any device being calibrated does not exceed $1 \mathrm{~W}$. Additional information pertaining to immittance (impedance and admittance) measurement and standards is contained in the references.

Two-Terminal, Low-Loss, Standard Capacitors (52210C-52211C)

In the frequency range from $10 \mathrm{kHz}$ to $250 \mathrm{MHz}$, capacitance calibrations to a minimum uncertainty of \pm 0.1 
percent are available from $1 \mathrm{pF}$ to 1 $\mu F$ depending upon frequency. The upper capacitance limit for calibration decreases as the frequency increases and is $50 \mathrm{pF}$ at $5 \mathrm{MHz}$ and above.

At $1 \mathrm{MHz}$ a special high accuracy service is available for capacitors with nominal values of $50,100,200$, 500 , and $1000 \mathrm{pF}$ provided they are equipped with $14 \mathrm{~mm}$ coaxial connectors.

Reports of calibration for capacitors normally do not give conductance values. This is because capacitors of standard quality, especially those with air-dielectric, have conductance values too small to be measured accurately at the present stateof-the-art.

A technique for extrapolating the 1 $\mathrm{kHz}$ values of capacitance standards to high frequencies is described by $\mathbf{R}$. $\mathrm{N}$. Jones (see references). This reference describes a technique for obtaining a high frequency value of a capacitor equipped with an unshielded (banana plug) connector. The measurement technique yields effective capacitance values at high frequencies using the capacitance value at $1 \mathrm{kHz}$ and the residual series inductance. The same technique, with some modifications, is usable for three-terminal and four-terminal pair capacitors. It is emphasized that these extrapolation procedures are only usable for air dielectric capacitors or capacitors with insulating materials whose dielectric constant does not change with frequency.

Three-Terminal, Low-Loss, Standard Capacitors (52220C-52221C)

Fixed value reference standards are maintained by NBS for values of 10 , 100 , and $1000 \mathrm{pF}$. High quality three- terminal air dielectric capacitance standards should have low residual series inductance $(<0.1 \mu \mathrm{H})$. This being the case, it may be assumed that to an accuracy of \pm 0.10 percent, the capacitances of standards of $1 \mathrm{pF}$ or less with air dielectric is the same at 1 $\mathrm{MHz}$ as it is at $1 \mathrm{kHz}$. Thus, it is unnecessary to have capacitors smaller than $10 \mathrm{pF}$ calibrated at $1 \mathrm{MHz}$.

\section{Two-Terminal, High-Q, Standard Inductors (52310S)}

In the frequency range from $10 \mathrm{kHz}$ to $250 \mathrm{MHz}$, inductance calibrations to a minimum uncertainty of \pm 0.1 percent are available from $0.01 \mu \mathrm{H}$ to $1 \mathrm{H}$. The upper inductance limit for calibration decreases as the frequency increases and is $1 \mu \mathrm{H}$ at $250 \mathrm{MHz}$. In the Report of Calibration, the resistance of the inductor is also given. Service is available only for aircore inductors or inductors whose value is independent of current.

\section{References-High Frequency Standard Capacitors and Inductors}

The Measurements of Lumped Parameter Impedance: A Metrology Guide, $\mathbb{R}$. N. Jones, Natl. Bur. Stand. (U.S.), Monogr. 141 (June 1974).

Impedance of Lumped Circuits, L. E. Huntley, R. N. Jones, Proc. IEEE 55(6), 900 (June 1967).

A Technique for Extrapolating the 1 kc Values of Secondary Capacitance Standards to Higher Frequencies, $R$. N. Jones, Natl. Bur. Stand. (U.S.), Tech. Note 201 (Nov. 1963).

A Precision High Frequency Calibration Facility for Coaxial Capacitance Standards, R. N. Jones and L. E. Huntley, Natl. Bur. Stand. (U.S.), Tech. Note 386 (Mar. 1970). Evaluation of Three-Terminal and Four-Terminal Pair Capacitors at High Frequencies, R. N. Jones, Natl. Bur. Stand. (U.S.), Tech. Note 1024 (Sept. 1980). 
D Impedance Measurements (Except Resistors) - B.3 Power-Frequency Capacitors Electrosystems Division Center for Electronics and Electrical Engineering

Technical Contacts:

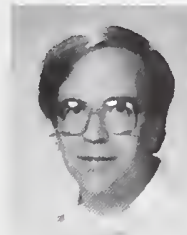

William E. Anderson Tel: 301/921-3121

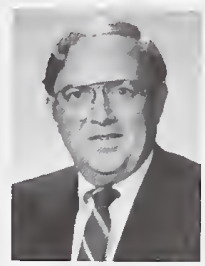

Robert E. Hebner, Jr. Tel: 301/921-3121
Mailing Address: B344 Metrology, National Bureau of Standards, Gaithersburg, MD 20899

Shipping Address: National Bureau of Standards I-270 at Quince Orchard Road, Gaithersburg, MD 20899

[Attn: W. E. Anderson, Bld. 202, Room 167]

Test No. Items

52400C Power-Frequency Capacitors

Power-Frequency Capacitors (52400C)

A calibration service is maintained for capacitors designed for $60-\mathrm{Hz}$ operation, especially at voltages above 100
V. Typical uncertainties for a calibration are $\pm 100 \mathrm{ppm}$ of the capacitance, and $\pm 1 \%$ of the dissipation factor $\pm 1 \times 10^{-5}$. Routine calibrations are limited to devices with a dissipation factor of 0.011 or smaller and which are operated at sufficient voltage that at least $40 \mu \mathrm{A}$ pass through the device under test.

The high power limit for routine tests is $10 \mathrm{kVA}$. Some capability to perform tests outside of these limits exists and NBS should be contacted to discuss special arrangements for such tests.

\section{References-Power-Frequency Capacitors}

A Wide Range High-Voltage Capacitance Bridge With One ppm Accuracy, O. Petersons, and W. E. Anderson, IEEE Trans. Instrum. Meas. 24, 4, 336 (Dec. 1975).

An International Comparison of High-Voltage Capacitor Calibrations, W. E. Anderson, R. S. Davis, O. Petersons, and W. J. M. Moore, IEEE Trans. Power Appar. Syst., 97, 4, 1217 (July 1978). 
Impedance Measurements (Except Resistors) B.4 Eddy-Current Conductivity Standards Electricity Division Center for Basic Standards

Technical Contacts:

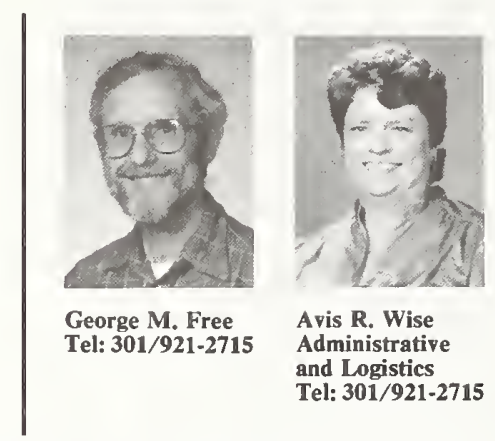

Mailing Address: B146 Metrology, National Bureau of Standards, Gaithersburg, MD 20899

Test No. Items

52610C Eddy-Current Conductivity Standards; $15-100 \%$ IACS

Eddy-Current Conductivity Standards; $15 \%$ to $100 \%$ IACS (52610C)

Electrical conductivity standards for calibrating eddy-current conductivity instruments in the range $15-100 \%$ IACS (International Annealed Copper Standard) are calibrated in the Electricity Division. Customer standards are calibrated on a variable frequency eddy-current bridge using a coil with a mean diameter of $0.4 \mathrm{~cm}$. Standards are measured in a frequency range of $10 \mathrm{kHz}$ to $100 \mathrm{kHz}$, depending on the electrical conductivity value of the standards. Customer standards are compared with NBS standards while submerged in an oil bath which maintains a nominal temperature of $20.00^{\circ} \mathrm{C}$. The electrical conductivity of the NBS standards is based on a dc measurement of electrical conductivity. Customer standards are checked for uniformity of electrical conductivity over the surface to be calibrated. The conductivity reported is that measured at the center of this surface.

Standards to be tested must be of non-magnetic materials and must have a surface geometry such that the distance from the center of the standards to the closest edge is at least $2.2 \mathrm{~cm}$ and no greater than $3.8 \mathrm{~cm}$. The sample must be free of scratches, grooves, etc. Special arrangements can be made for calibrating standards at user-specified frequencies for those eddy-current systems that function at a fixed frequency. The user-specified frequency should be less than 100 $\mathrm{kHz}$.

The minimum uncertainty of the calibrated value is $\pm 0.15 \%$ of the stated value. This uncertainty consists of components from the dc determination of the NBS standards, errors in the transfer of value from the NBS standards to customer standards, and errors due to offset from the nominal temperature of $20.00^{\circ} \mathrm{C}$.

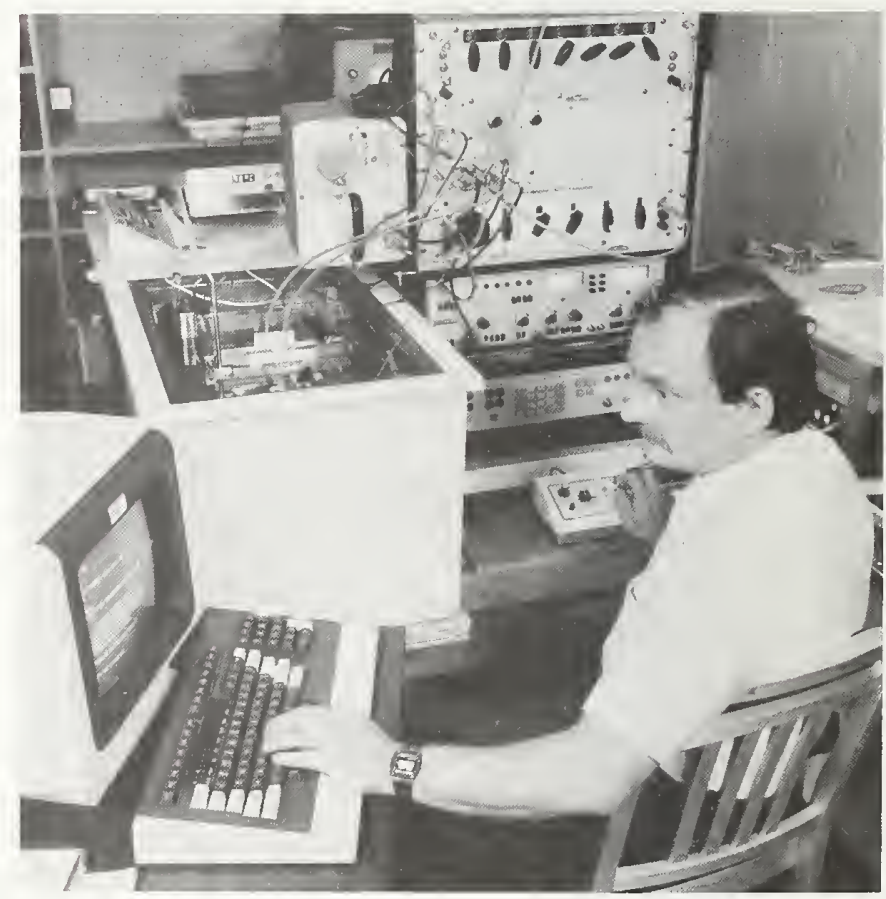

Charles Levy, conducting electrical conductivity measurements of non-ferrous standards. 
Impedance Measurements (Except Resistors) B.5 Q-Standards

\section{Electromagnetic Fields Division Center for Electronics and Electrical Engineering}

Technical Contacts:

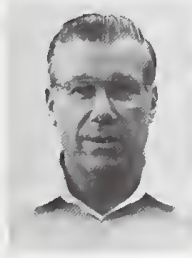

Raymond $\mathbf{N}$. Jones

Tel:303/497-3609

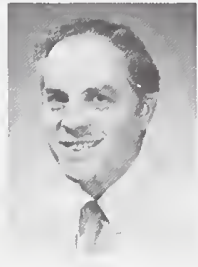

Cletus A. Hoer Tel: 303/497-3705

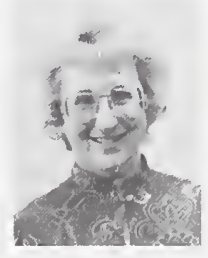

Edna M. Jones Administrative and Logistics Tel: $303 / 497-3753$

Mailing Address: M.C. 723.10, National Bureau of Standards, 325 Broadway, Boulder, CO 80303

\section{Test No. Items}

52710C Inductive Q-Standards; $50 \mathrm{kHz}-45 \mathrm{MHz}, 0.25 \mu \mathrm{H}$ to $25 \mathrm{mH}$

52711C Each Additional Frequency for 52710S

Q-Standards (52710C-52711C)

Standards for Q-measurements are maintained at NBS. These are high-Q inductors equipped with banana plug connectors at a spacing of 1 inch on

centers. These standards have inductance values of $0.25,2.5,25,250$, 2500 , and $25,000 \mu \mathrm{H}$, and effective Qvalues from 100 to approximately 600 . These serve as working standards for calibration of Q-standards of a similar type. Calibration frequencies range from $50 \mathrm{kHz}$ to $45 \mathrm{MHz}$. The calibration report includes effective resonating capacitance and effective $Q$. Uncertainties are of the order of \pm 0.2 percent for capacitance and 2 percent for Q. Provisions are made for calibrating each Q-standard at three frequencies; however, adequate assurance of stability is usually provided by recalibrating only at the center frequency.

Estimated limits of uncertainty are based upon a statistical analysis of previously obtained calibration data. These uncertainties are believed to result solely from sources of random error as opposed to known systematic errors.

\section{References-Q Standards}

Standards for the Calibration of QMeters, $50 \mathrm{kHz}$ to $45 \mathrm{MHz}, \mathrm{R}$. N. Jones, J. Res. Natl. Bur. Stand. (U.S.), 58C No. 4, 243 (Oct.-Dec. 1964). 


\section{Voltage Measurements - C. 1 DC Voltage Measurements and Standards Electricity Division Center for Basic Standards}

\section{Technical Contacts:}

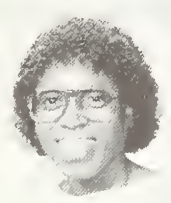

June $\mathbb{E}$. Sims Tel:301/921-3806

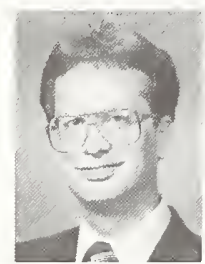

Bruce F. Field Tel:301/921-3806

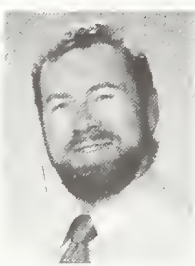

Norman B. Belecki Tel: $301 / 921-2715$

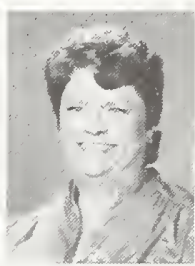

Avis R. Wise Administrative and Logistics Tel: 301/921-2715
Mailing Address: B146 Metrology, National Bureau of Standards, Gaithersburg, MD 20899

Test No. Items

53110S Special DC Voltage Measurements by

Prearrangement

53120M Measurement Assurance Program for DC Voltage

53130C First Saturated Standard Cell in a Group

53131C Each Additional Cell

53140C Platinum Resistance Thermometer Temperature Determination for Standard Cell Calibration

53150C Unsaturated Standard Cells

53160C Tests of Solid State Voltage Reference Standard (1 Output, 1-10 V)

53161C Each Additional Output

53180S Special Handling (Equipment Pickup or Delivery)

53190S Special Handling (Cleaning, Minor Repair, Return Service Charge)

\section{General Information-DC Voltage} Measurement Standards

The service described in this section provides for the calibration of standards of direct voltage, saturated and unsaturated standard cells, and solid state standards, and for dc voltage MAP services at the 1.02 volt level. The U.S. Legal Volt is maintained by monitoring the emf's of a group of saturated standard cells in an oven on a monthly basis using the ac Josephson effect and a specialized mea- suring system to perform the required scaling (from about $10 \mathrm{mV}$ to 1.02 V). Customer cells are calibrated by measuring the difference between their emf's and those of working groups of standard cells using lowlevel potentiometers and nanovoltmeters or precision digital voltmeters.

Figure 13 summarizes the uncertainty of NBS dc voltage measurements for the primary standards, standard cells, and Zener diodes.

Special DC Voltage Measurements by Prearrangement (53110S)

The evaluation, testing, or calibration of prototype dc voltage standards and measuring apparatus or unique voltage measurements are provided for in this service. These measurements are performed only when deemed reasonable by the appropriate technical staff and serving the best long-term interests of the client, the measurement community, and NBS.

\section{Measurement Assurance Program Service (53120M)}

This MAP service provides a measurement of the error of dc voltage measurements in the customer laboratory at the 1.02-volt level, the uncertainty of the results, and an updated assigned value for the client's reference standards. A transport standard, which consists of a standard cell enclosure containing four saturated standard cells, maintaining constant temperature via line and battery power, and packaged for shipment by air, is used. It is calibrated by NBS, the customer laboratory, and again by NBS to obtain the required data. The transport standards are capable of performing at the 0.2 to $0.3 \mathrm{ppm}$ level of reproducibility under these conditions.

The measurement uncertainty achieved in this service contains primarily random errors. The major components of random error can be attributed to:

A. Day-to-day fluctuations in temperature-corrected cell emf's 
caused by temperature-hysteresis effects;

B. The finite resolution of the measurement apparatus at both the client laboratory and at NBS;

C. Thermal emf's, unstable with time, which occur in the measuring circuit due to room temperature changes and drafts;

D. Temperature coefficients of the enclosures as a whole, not compensated for by temperature corrections;

E. Lack of resolution or instability of the apparatus used to monitor the cell temperatures;

F. Slow changes in temperature gradients or enclosure temperatures possibly due to atmospheric "pumping" of cool air into the enclosures, or vibration effects on the control circuitry;

G. Controller instability caused by power-line noise;

H. Effects of electrostatic or electromagnetic pick-up on the measuring system;

I. Detector drift; and

J. Momentary upsets in cell emf's caused by small electrical currents passing through the cells.

The experimental design described for making the intercomparison measurements removes the effects of average "left-right" or offset errors. One potentially significant source of error not corrected for or quantified in the MAP service is that caused by scale-factor errors in the instrumentation used to measure the differences between cell emf's. An error from this source can be eliminated by using calibrated instruments and applying the appropriate calibration corrections to the results. A method for quantifying scale-factor errors can be provided to MAP service users by NBS on request.

The transport standard is normally kept in the client's laboratory for about four weeks, as eight to twelve measurement sets are generally required. Data analysis and issuance of the test report by the NBS takes four to five weeks following the return of the transfer standards.

If the participating laboratory has a quality instrument that has been accurately calibrated and also has quality standards, the uncertainty of a single transfer of the unit of voltage using NBS transport standards is generally of the order of $0.5 \mathrm{ppm}$ or better. The best achievable long-term uncertainty,

Figure 13. Uncertainties of NBS DC Voltage Measurements

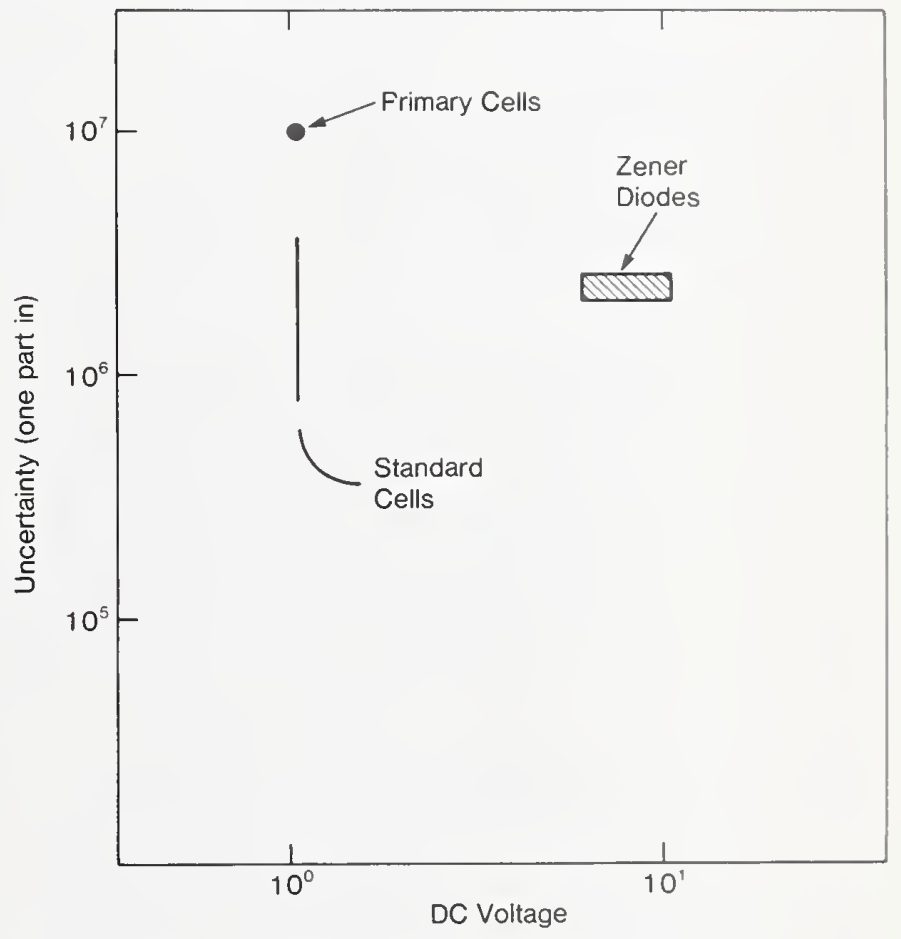

resulting from five or more transfers over an extended time, is of the order of $0.2-0.3 \mathrm{ppm}$.

In this service, the NBS provides detailed instructions for carrying out the transfer and making the required measurements. The participant must have in-house standards and instrumentation capable of sustained performance at the $0.1 \mathrm{ppm}$ level. When a new participant (or group of participants) expresses a desire to use the 
voltage MAP service, NBS requests that a complete description of the participant's measurement system, including instruments, standards, wires, switches, and their use, be sent to the NBS technical staff. This description enables NBS personnel to assist in resolving measurement problems by telephone.

NBS now requires evidence, in the form of control charts, of the existance of a formal quality-control program in the laboratory as a prerequisite to participation in the service. This requirement has been established to enable problems to be addressed in advance of the transfer and to reduce delays in returning the standards to NBS.

\section{Saturated Standard Cells (53130C-53140C)}

Routine calibrations of saturated standard cells involve the following considerations:

A. Saturated standard cells of the unshippable type should always be transported by messenger because such cells should never be tipped from an upright position by more than $45^{\circ}$ in any direction. Unshippable saturated cells contained in portable, temperature-regulated enclosures should also be transported by messenger and with the enclosure activated or under power, if possible.

B. Saturated standard cells of the shippable type housed in portable thermoregulated enclosures should be packed carefully and shipped under power if possible. Any liquid-in-glass thermometer mounted in such a device should be removed and provided with additional rigid packing for protection against breakage. Enclosures having a nominal cell temperature of $28^{\circ} \mathrm{C}$ or lower should not be transported during the summer due to the danger of overheating. Enclosures should not be energized by using the ac power mains while they are in shipping containers as heat from the transformer will cause them to go over-temperature.

C. Saturated standard cells, which are maintained continuously at their nominal temperature of use during shipment, will (workload permitting) undergo test starting one week after receipt for a period not to exceed four weeks, unless other arrangements are made. If such cells perform abnormally, the owner will be notified. Arrangements for further testing may be made at that time if desired. Cells will be returned as soon as possible after calibration.

D. Saturated cells arriving at a temperature other than their nominal temperature of use will be brought to their use temperature as soon as possible after receipt. Starting one month after they are initially brought to use temperature, weekly readings will be taken to observe the stability of the cells. When the cells stabilize, 10 daily readings will be taken and averaged to assign values to them. This process will not exceed 90 days without special arrangements being made.

E. For an additional fee, the temperature of air bath enclosures for saturated standard cells will be determined using a calibrated NBS platinum resistance thermomenter (test $53140 \mathrm{C})$. Daily readings are taken and reported. The reported cell emf's are assumed to correspond to the mean of the temperatures measured on the same days as the emf readings were taken. The client must understand that, when this is done, the uncertainties of the reported emfs include the emf equivalent of the uncertainty of the measured temperatures in terms of the International Practical Temperature Scale of 1968 as amended in 1975 [Metrologia 12,7 (1976)]. Moreover, estimates of the uncertainties of any voltage measurements made by the client using these cells as a reference must include corresponding uncertainties of his own temperature measurements.

F. NBS accepts cells used in oil baths for calibration in NBS oil baths maintained at 28 and $30^{\circ} \mathrm{C}$. Cells used in oil baths operating at other nominal temperatures can best be calibrated using transport standards as in 
the MAP service. (See 53120M above.)

Calibration uncertainties generally range from 0.3 to $0.75 \mathrm{ppm}$. The stated uncertainties are those of the NBS measured average values, i.e., they do not reflect long-term behavior of the cells, transporation effects, etc.

Unsaturated Standard Cells (53150C) Unsaturated cells require approximately three weeks for a complete calibration. The emf's of such cells are read daily for a minimum period of ten days. These cells are compared with NBS saturated cells using a precision digital voltmeter to measure the difference emf directly. The calibration uncertainty is $0.005 \%$ of the measured voltage unless the cell is abnormal. If the measured emf fluctuates unduly or is unusually low, or if the cell behaves abnormally, the report of calibration will reflect these circumstances. Unsaturated cells are not likely to be injured by normal transportation (mail or express) if they are packed carefully. Because of the possible hazard from freezing, shipment during extremely cold weather should be avoided.

Solid-State Voltage Reference Standards (53160 C and 53161C)

Solid-state voltage standards with outputs in the range from one to ten volts are calibrated using a selfcalibrating automated system which scales to any multiple up to ten of 1.018 volts from the emf of a working group of NBS saturated standard cells. It then measures the difference between the emf of the standard under test and the emf of its own output closest to that being measured and computes the emf of the test unit. Measurements are taken daily for twelve to fifteen working days and the mean value of the results reported. If the standard being calibrated has internal batteries, the measurements are generally taken with it disconnected from the mains to avoid possible ground loop, common mode, or mains noise problems. Sufficient time is allowed for stabilization after disconnection from the mains.

Because of the limited battery life of many commercial standards, special shipping arrangements are advisable and can be made by contacting the Electricity Division.

Many solid-state standards have multiple outputs; the outputs to be calibrated should be specified on the shipping papers as well as on the purchase order to facilitate testing.

Voltmeter calibrators, multirange instruments with up to eight decimal digits of adjustability, are not considered by the NBS to be standards and are not to be submitted for calibration under this test category. Likewise, NBS will not accept component solid-state devices for routine calibration. New, state-of-the-art devices and instruments may be accepted for test under special circumstances (see test 53110S) at the discretion of NBS technical staff.

\section{References-Voltage Measurements and Standards}

Volt Transfer Program Instructions, NBS Internal Document, Unpublished, Revised (1983).

A High-Resolution Prototype System for Automatic Measurement of Standard Cell Voltages, D. W. Braudaway and R. E. Kleinmann, IEEE Trans. Instrum. Meas., IM-23, 282 (1974).

Volt Maintenance at NBS via $2 \mathrm{e} / \mathrm{h}$ : A New Definition of the NBS Volt, B. F. Field, T. F. Finnegan, and J. Toots, Metrolgia, 9, 155 (1973). Designs for Surveillance of the Volt Maintained by a Small Group of Saturated Standard Cells, W. G. Eicke and J. M. Cameron, Natl. Bur. Stand. (U.S.), Tech. Note 430 (Oct. 1967).

Standard Cells-Their Construction, Maintenance and Characteristics, W. J. Hamer, Natl. Bur. Stand. (U.S.), Monogr. 84 (Jan. 1965).

A Sub-PPM Automated One-To-Ten Volt Measuring System, B. F. Field, IEEE Trans. Instrum. Meas., IM-34, 327 (1985). 
Voltage Measurements

C.2 Low-Frequency AC Voltmeters and Sources

Electrosystems Division

Center for Electronics and Electrical Engineering

Technical Contacts:

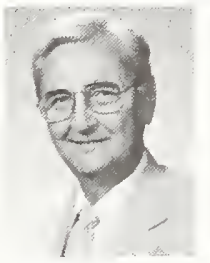

Howard K.

Schoenwetter

Tel: 301/921-2727

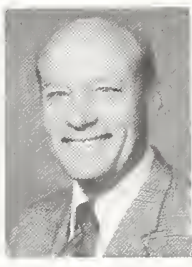

Barry A. Bell Tel: 301/921-2727
Mailing Address: B162 Metrology, National Bureau of Standards, Gaithersburg, MD 20899

Test No. Items

$53200 S$ Special Tests of Low-Frequency AC Voltmeters and Sources- $0.1 \mathrm{~Hz}$ to $10 \mathrm{~Hz}, 0.5 \mathrm{mV}$ to $7 \mathrm{~V}$, by Prearrangement

Special Tests of Low-Frequency AC

Voltmeters and Sources by

Prearrangement (53200S)

NBS offers a calibration service for ac voltage standards and rms voltmeters in the $0.1 \mathrm{~Hz}$ to $10 \mathrm{~Hz}$ range. This service is provided by means of an "AC Voltmeter/Calibrator," which is an NBS-developed instrument containing a high resolution rms digital voltmeter and both ac (sinewave) and dc voltage calibrators.

Calibrations are performed on rmsresponding ac voltmeters using the ac voltage calibrator of the AC

Voltmeter/Calibrator. AC voltmeters can be calibrated at frequencies of 10 , $5,2,1,0.5,0.2$, and $0.1 \mathrm{~Hz}$ at any voltage level between $0.5 \mathrm{mV}$ and 7
$\mathrm{V}$. The total uncertainty of a calibration is $\pm\left(\epsilon_{\mathrm{c}}+\epsilon_{\mathrm{r}}\right)$, where $\epsilon_{\mathrm{c}}$ is the uncertainty of the ac voltage calibrator voltage and $\epsilon_{\mathrm{r}}$ is the imprecision of the calibration process. The estimated uncertainty of the ac voltage calibrator is \pm 0.020 percent. The imprecision for a given calibration point is $t s / \sqrt{N}$, where $t$ is Student's $t$ for the selected confidence level, $\mathrm{s}$ is the standard deviation for a measurement, and $\mathrm{N}$ is the number of measurements (test runs) used to obtain the mean values of the measured quantities (voltmeter readings).

Unless otherwise requested by the customer, a single uncertainty of calibration will be given for the corrections to the calibration points, based on a confidence level of 0.98 and the largest standard deviation encountered. It is expected that the value of $\mathrm{N}$, requested by the customer, will generally be 3,4 , or 5 . Assuming a selected confidence level of 0.98 , values of $t$ corresponding to $\mathrm{N}$ equal 3,4 , and 5 are approximately $7.0,4.5$, and 3.7 , respectively.

Typical NBS uncertainties of ac voltage measurements for calibration of ac voltmeters $(0.1-10 \mathrm{~Hz})$ and ac/dc difference $(20 \mathrm{kHz}-1 \mathrm{MHz})$ are shown in Figure 14.

Voltage calibrations are performed on precision ac sources using the ac voltage calibrator and rms voltmeter of the AC Voltmeter/Calibrator. The rms voltmeter is used as a transfer voltmeter to compare the voltages (of the same nominal level) from the test unit and the ac calibrator. Voltage calibrations can be made at any frequency in the $10 \mathrm{~Hz}$ to $0.1 \mathrm{~Hz}$ range and are usually made near the fullscale level of the voltmeter ranges ( 2 , $5,10,20,50 \mathrm{mV}$, and $0.1,0.2,0.5,1$, $2,5 \mathrm{~V})$. For each calibration point, the rms voltmeter (DVM) is used to compare the voltage $\mathrm{V}_{\mathrm{T}}$ from the standard under test with the voltage $\mathrm{V}_{\mathrm{C}}$ of the same nominal level from the ac voltage calibrator, choosing the calibrator frequency closest to 
that of the voltage being measured. After the test runs are made, the average $\left(V_{C}-V_{T}\right)$ is calculated for each calibration point, yielding corrections to the nominal voltage values of the test unit.

If the uncertainty of the calibrator voltage and the uncertainty caused by the DVM frequency response are denoted by $\epsilon_{\mathrm{c}}$ and $\epsilon_{\mathrm{m}}$, respectively, the total uncertainty of a calibration point is given by $\pm\left(\epsilon_{\mathrm{c}}+\epsilon_{\mathrm{m}}+\right.$ ts $\left./ \sqrt{\mathrm{N}}\right)$, where $\mathrm{s}$ is the standard deviation of $\mathrm{a}$ $\left(\mathrm{V}_{\mathrm{c}}-\mathrm{V}_{\mathrm{T}}\right)$ comparison and $\mathrm{N}$ is the number of comparisons (test runs). If the frequencies of the voltages being compared are within 5 percent of

\section{Figure 14. NBS Uncertainties for AC Voltage} Measurements

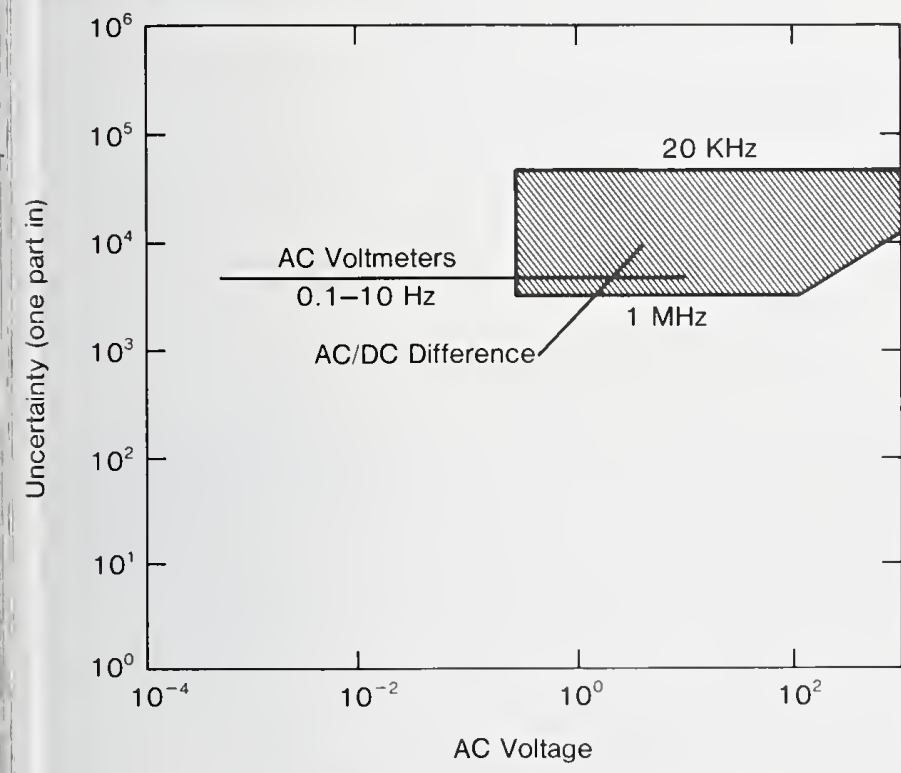

each other, $\epsilon_{\mathrm{m}}$ is $7 \mathrm{ppm}$. If the frequency difference is larger, the worst case value of $\epsilon_{\mathrm{m}}, 40 \mathrm{ppm}$, is used. The value assigned to $\epsilon_{\mathrm{c}}$ is $200 \mathrm{ppm}$ $(0.02 \%)$. However, if the highest calibration accuracy is required by the customer, $\epsilon_{\mathrm{c}}$ can be decreased to 125 ppm by a special calibration of the NBS instrument.

If the voltage standard has inherently stable voltage with respect to frequency, a frequency response (relative voltage) calibration may be preferable to a conventional voltage calibration. The user then establishes the voltage levels by calibrating the voltage at $10 \mathrm{~Hz}$. Since the rms voltmeter has a frequency response that is flat to within $\pm 40 \mathrm{ppm}$, it is used to determine the frequency response of voltage sources. Frequency response calibrations can be made at any frequency in the $10 \mathrm{~Hz}$ to $0.1 \mathrm{~Hz}$ range and are usually made near the fullscale level of the DVM ranges $(2,5$, $10,20,50 \mathrm{mV}$, and $0.1,0.2,0.5,1,2$, $5,10 \mathrm{~V}$ ). These calibrations are made using the DVM to compare test unit voltages of frequency $f$ with the 10 $\mathrm{Hz}$ value. After $\mathrm{N}$ comparisons, the average quantities $\left(\mathrm{V}_{\mathrm{r}}-\mathrm{V}_{10}\right)$ are computed for each test frequency, yielding the frequency response. The uncertainty of these calibration points is $\pm\left(\epsilon_{\mathrm{m}}+\mathrm{ts} / \sqrt{\mathrm{N}}\right)$, where $\epsilon_{\mathrm{m}}$ is $40 \mathrm{ppm}$, and $s$ is the standard deviation of a comparison.

For test requirements not covered by the above, contact the Electrosystems Division to make special arrangements.

\section{References-Low-Frequency AC Voltmeters and Sources}

An RMS Digital Voltmeter/ Calibrator for Very Low Frequencies, H. K. Schoenwetter, IEEE Trans. Instrum. Meas., IM-27, No. 3, 259 (Sept. 1978).

AC Voltage Calibrations for the 0.1 $\mathrm{Hz}$ to $10 \mathrm{~Hz}$ Frequency Range, H. K. Schoenwetter, Natl. Bur. Stand. (U.S.), Tech. Note 1182 (Sept. 83). (This reference provides a complete description of this calibration service.) 


\section{Voltage Measurements \\ C.3 AC-DC Thermal Voltage and Current \\ Converters (To $1 \mathrm{MHz}$ ) \\ Electricity Division \\ Center for Basic Standards}

Technical Contacts:

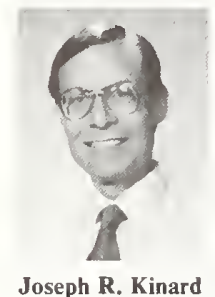

Tel: 301/921-2715

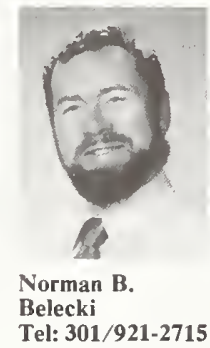

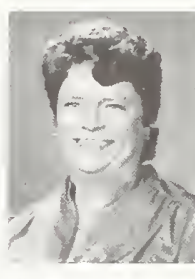

Avis R. Wise Administrative and Logistics Tel: 301/921-2715
Mailing Address: B146 Metrology, National Bureau of Standards, Gaithersburg, MD 20899

\begin{tabular}{ll} 
Test No. & Items \\
\hline $53310 \mathrm{~S}$ & $\begin{array}{l}\text { Special AC-DC Measurement Services by } \\
\text { Prearrangement }\end{array}$ \\
53340C & $\begin{array}{l}\text { AC-DC Thermal Voltage and Current Converters } \\
\text { (1 voltage, 1 frequency up to 50 kHz) }\end{array}$ \\
53341C & $\begin{array}{l}\text { AC-DC Thermal Voltage and Current Converters } \\
\text { (1 voltage, 1 frequency-50 kHz to 1 MHz) }\end{array}$ \\
$53342 \mathrm{C}$ & $\begin{array}{l}\text { Additional Determination at } 1 \text { Frequency }(20-50 \mathrm{kHz}) \\
\text { 53343C }\end{array}$ \\
& $\begin{array}{l}\text { Additional Determination at } 1 \text { Frequency } \\
\text { (from 50 kHz-1 MHz and from } 10 \mathrm{kHz}-50 \mathrm{kHz} \text { for } \\
1000 \text { Volt Range) }\end{array}$ \\
\hline
\end{tabular}

\section{General Information-Thermal Voltage and Current Converters}

Thermal voltage and current converters are now being calibrated on a scheduled basis. To arrange scheduling, contact A. R. Wise at the telephone no./address cited above. Send in the equipment only as scheduled to avoid a long turnaround time at NBS.

Calibration services for wide frequency range thermal voltage converters, such as John Fluke Model A55 or HP 11000 series, have been extended in the NBS Boulder Laboratory to cover frequencies down to
$100 \mathrm{~Hz}$ with uncertainties as low as $0.05 \%$ (see tests 53405S-53420C). This means thermal generators of this type can be completely calibrated at NBS Boulder if the $0.05 \%$ uncertainty is acceptable. Calibration requiring uncertainties less than $0.05 \%$ in the range below $1 \mathrm{MHz}$ continue to be done in NBS Gaithersburg (53310S-53343C).

\section{Special AC-DC Measurement Services} by Prearrangement (53310S)

This service provides for the measurement or evaluation of prototype ac voltage or current standards, sources, or measurement instrumentation, and for other measurements of alternating voltage, alternating current, or ac-dc difference not provided for below, at the discretion of NBS technical experts. Components used for ac-dc conversions will generally not be tested unless they show promise of standards-like behavior. Even then, such components will only be tested in very limited numbers to explore their possible use for precision measurements.

\section{AC-DC Thermal Voltage and Current Converters (Up to $1 \mathrm{MHz}$ ) (53340C-53343C)}

This service covers the calibration of thermal voltage and current converters, ac shunts, and primary thermoelements covering the ranges $2 \mathrm{~Hz}$ to $1 \mathrm{MHz}, 1 \mathrm{~mA}$ to $20 \mathrm{~A}$, and 0.5 to $1000 \mathrm{~V}$. These are used to make measurements of alternating current and voltage in terms of direct current standards of voltage and resistance and are calibrated at NBS by comparison with similar NBS devices. Ordinarily only ac-dc transfer standards and thermal converters of 0.05 percent or better rated accuracy are accepted for test. AC-DC difference tests consist of determinations of the differences between the current or voltage, required to give the same response (output) of the transfer standard for alternating current and for the average of the two directions of 
direct current. Tests are recommended at rated voltage or current on each range up to the highest frequency of interest. For $1000 \mathrm{~V}$ ranges, a second test at $600 \mathrm{~V}$ is recommended because these ranges may be affected by self-heating. In addition to the high-frequency tests, an ac-dc difference test (ordinarily at 20 $\mathrm{Hz}$ ) is recommended for one range, to verify the low-frequency accuracy. Thermoelements have a lowfrequency limit, below which they fail to integrate properly. The ac-dc difference may approach 0.02 percent at frequencies ranging from about 5 $\mathrm{Hz}$ for most low-range thermoelements to about $60 \mathrm{~Hz}$ for some thermoelements with ratings above 1 A. This low-frequency ac-dc difference is the same for all ranges of a multirange converter in which a single thermoelement is used with shunts or multipliers. For convenience, usually a low-voltage or current range is chosen for the test. Unless the test points have been firmly established in prior practice, the user is strongly advised to contact the appropriate NBS

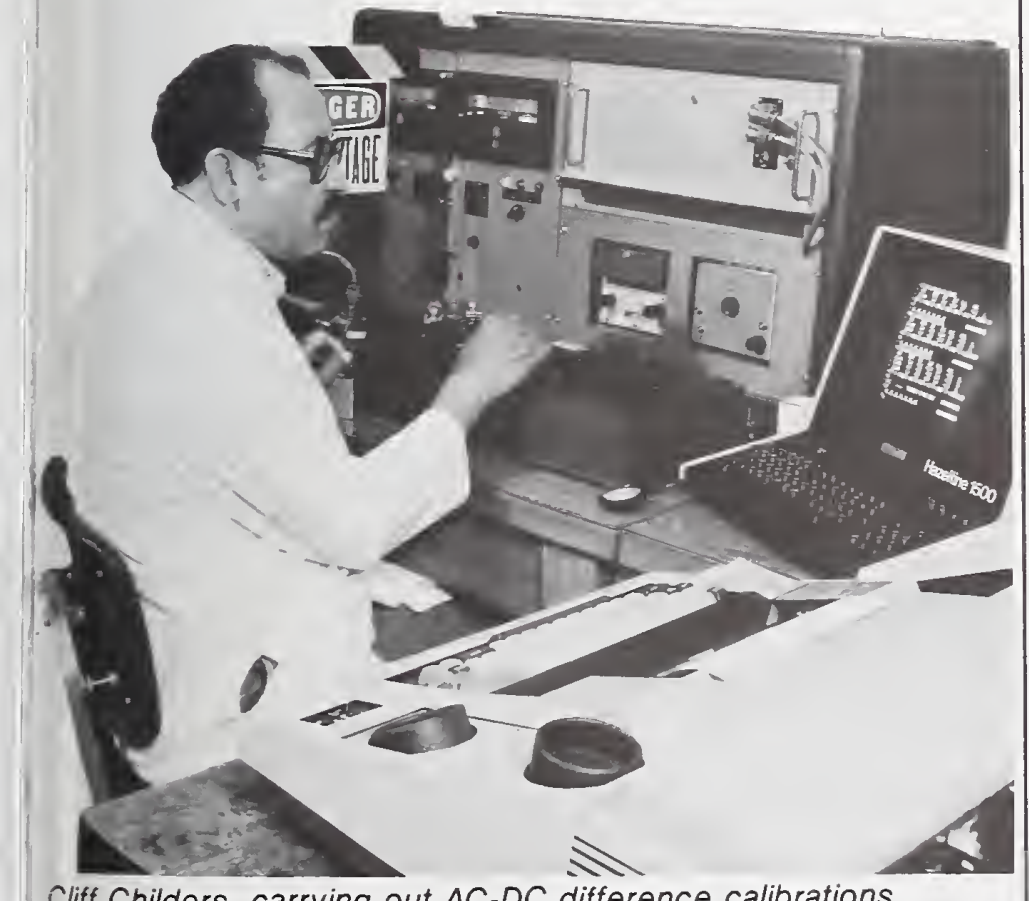

Cliff Childers, carrying out AC-DC difference calibrations. technical staff prior to submission of the standards to NBS for calibration.

\section{References-AC-DC Thermal Con- verters (To $1 \mathrm{MHz}$ )}

A Dual-Channel Automated Comparator for AC-DC Difference Measurements, E. S. Williams and J. R. Kinard, IEEE Trans. Instrum. Meas., IM-34, No. 2, 290 (June 1985).

An Investigation of the Uncertainty of the NBS Thermal Voltage and Current Converters, F. L. Hermach, Natl. Bur. Stand. (U.S.), Int. Report, NBSIR 84-2903 (April 1985).

The Practical Uses of AC-DC Transfer Instruments, E. S. Williams, Natl. Bur. Stand. (U.S.), Tech. Note 1166 (Nov. 1982).

A Thermoelement Comparator for Automatic AC-DC Difference Measurements, E. S. Williams, IEEE Trans. Instrum. Meas. IM-29, No. 4, 405 (Dec. 1980).

An Investigation of Multijunction Thermal Converters, F. L. Hermach and D. R. Flach, IEEE Trans. Instrum. Meas., IM-25, No. 4, 524 (Dec. 1976).

Thermal Voltage Converters and Comparators for Accurate AC Voltage Measurements, E. S. Williams, J. Res. Natl. Bur. Stand. (U.S.), 75C (Dec. 1971).

Thermal Voltage Converters for Accurate Voltage Measurements to 30 Megacycles Per Second, F. L. Hermach and E. S. Williams, Trans. AIEE (Communica. Elect.) 79, 1, 200 (July 1960).

Thermal Converters on AC-DC Transfer Standards for Current and Voltage Measurements at Audio Frequencies, F. L. Hermach, J. Res. Natl. Bur. Stand. (U.S.), 48, 121 (1952). 
Voltage Measurements

\section{C.4 RF-DC Thermal Voltage and Current Converters (100 Hz-1 GHz) Electromagnetic Fields Division Center for Electronics and Electrical Engineering}

Technical Contacts:

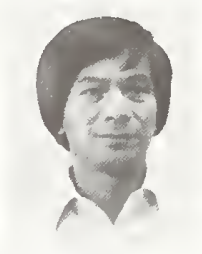

$$
\begin{aligned}
& \text { Gregorio } \\
& \text { Rebuldela } \\
& \text { Tel: } 303 / 497-3561
\end{aligned}
$$

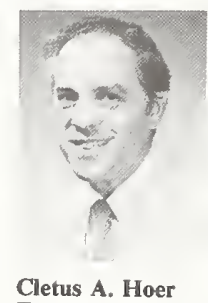

Tel: 303/497-3705

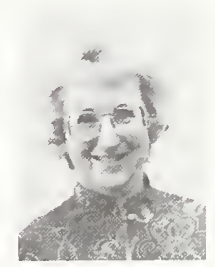

Edna M. Jones Administrative and Logistics Tel: $303 / 497-3753$

Mailing Address: M.C. 723.10, National Bureau of Standards, 325 Broadway, Boulder CO 80303

Test No. Items

53405S Special Tests of AC Thermal Current and Voltage Converters by Prearrangement

53410C Low Frequency TVC Calibration at One Frequency Selected from Those Given in Table 9 at Rated Voltage in the Range $0.1-50 \mathrm{~V}$.

53411C Additional Frequency Selected from Table 9 for Same TVC as in $53410 \mathrm{C}$

53412C Same as 53410C, Except Customer Designates a Single Frequency (in Same Frequency Range) other than those given in Table 9

53413C Low Frequency TVC Calibration at One Frequency Selected From Those Given in Table 9 at Rated Voltage in the Range $50-200 \mathrm{~V}$

53414C Additional Frequency Selected from Table 9 for Same TVC as in 53413C

53415C Same as 53413C, Except Customer Designates a Single Frequency (in Same Frequency Range) other than those given in Table 9

General Information-RF-DC Thermal Voltage and Current Converters, 100 $\mathrm{Hz}$ to $1 \mathrm{GHz}$ (53405S-53455S)

Services are available for four types of electromagnetic voltage measuring devices: (1) Thermal Voltage Converters (TVCs), (2) Peak-to-Peak Detectors, (3) Voltage Comparators, and (4) If Micropotentiometers.

\begin{tabular}{|c|c|}
\hline & \\
\hline $53420 \mathrm{C}$ & $\begin{array}{l}\text { High Frequency TVC Calibration at One Frequency } \\
\text { Selected from Those Given in Table } 10 \text { at Rated } \\
\text { Voltage in the Range } 0.1-7.5 \mathrm{~V}\end{array}$ \\
\hline $53421 \mathrm{C}$ & $\begin{array}{l}\text { Additional Frequency Selected from Table } 10 \text { for } \\
\text { Same TVC as in } 53420 \mathrm{C}\end{array}$ \\
\hline $53430 \mathrm{~S}$ & $\begin{array}{l}\text { Peak-to-Peak Detector Calibration at One Frequency } \\
\text { Selected from Those Given in Table } 11 \text { at } 1.2 \mathrm{~V} \\
\text { Applied RF Voltage }\end{array}$ \\
\hline $53431 \mathrm{~S}$ & $\begin{array}{l}\text { Additional Frequency for Peak-to-Peak Detector in } \\
\text { Test } 53430 \text { S }\end{array}$ \\
\hline $53440 \mathrm{C}$ & $\begin{array}{l}\text { RF Micropotentiometer Calibration for Percent } \\
\text { RF-DC Difference, at any Single Frequency Within } \\
0.05-900 \mathrm{MHz} \text { and at Rated Voltage (Range } \\
1-100,000 \mu \mathrm{V})\end{array}$ \\
\hline $53441 \mathrm{C}$ & $\begin{array}{l}\text { Frequency Selected for RF } \\
\text { ntiometer Calibrated in } 53430 \mathrm{C}\end{array}$ \\
\hline $53445 \mathrm{~S}$ & $\begin{array}{l}\text { Special Calibration of RF Micropotentiometer } \\
\text { (Output Voltage Range, } 200 \text { to } 200,000 \mu \mathrm{V} \text { at } \\
\text { Frequency Range, } 0.05 \text { to } 1000 \mathrm{MHz} \text { ) with Reduced } \\
\text { Limits of Uncertainty }\end{array}$ \\
\hline
\end{tabular}

Many years of experience in cali- bration of micropots and TVCs have shown that these are very stable devices even for periods of up to 10 years. Thus, in most cases, a 2-year or longer recalibration cycle is recommended. An exception might be the micropots which operate below $100 \mu \mathrm{V}$.

Assurance of device stability can be obtained by intercomparison of mi- 
cropots or TVCs with others which are adjacent in voltage. For example, a 0.3 to $1 \mathrm{~V}$ TVC can be compared with a 1 to $3 \mathrm{~V} \mathrm{TVC}$ at $1 \mathrm{~V}$, etc.

Calibrations requiring uncertainties less than $0.05 \%$ below $1 \mathrm{MHz}$ are performed in NBS Gaithersburg. See tests $53310 \mathrm{~S}-53343 \mathrm{C}$.

\section{Rf Voltage Comparators (53405S)}

Special tests are performed on rf voltage comparators using TVCs and micropotentiometers from $100 \mathrm{kHz}$ to 1 $\mathrm{GHz}$ at voltages ranging from $10 \mathrm{mV}$ to $20 \mathrm{~V}$. Several calibration options are available to the customer. Therefore, consultation by telephone or written correspondence is suggested before the comparator is submitted for calibration.

\section{Thermal Voltage Converters (53410C-53421C)}

The thermal voltage converter (TVC) category also includes other devices using thermal detectors such as Rawson rf voltmeters, thermal transfer standards, rf voltage standards, and ac-dc transfer standards.

Most converters have rf-dc differences within \pm 0.01 percent of zero at $1 \mathrm{MHz}$ and below. All converters having previous calibration history that are submitted for recalibration should be evaluated at $1 \mathrm{MHz}$ and results compared to prior data. If the difference is negligible, no further calibrations are usually necessary below $1 \mathrm{MHz}$.

The quantity measured by this calibration service is the $\mathrm{rf}$-dc difference, defined as the percentage difference between the rf and dc voltages required to produce the same thermocouple output, e.g.,

rf-dcdifference $(\%)=\left(\frac{V_{r f}-V_{d c}}{V_{d c}}\right) \times 100$.

Services available for low-frequency TVCs without a built-in " $T$ " connector are given in Table 9. For highfrequency TVCs with a built-in " $T$ " connector, the services available are given in Table 10. Calibrations above $100 \mathrm{MHz}$ are performed only on the new high frequency thermal voltage converters with a " $T$ " connector incorporated in the converter housing. The measurement reference plane is at the Type "N" male output connector.

Table 9: Specifications and Estimated Uncertainties for Low-Frequency TVC Services

\begin{tabular}{llc}
$\begin{array}{l}\text { Recommended } \\
\text { Frequencies }\end{array}$ & $\begin{array}{c}\text { RF Voltage } \\
\text { Range } \\
\text { (V) }\end{array}$ & $\begin{array}{c}\text { Limits of Uncertainty* } \\
( \pm \%)\end{array}$ \\
\hline $0.1,0.3,1$, & 0.1 to 200 & 0.05 \\
$3,10,30$, & & \\
100, and 300 & & 0.1 \\
kHz; $1 \mathrm{MHz}$ & 0.1 to 200 & 0.2 \\
3 and $10 \mathrm{MHz}$ & 0.1 to 200 & 1.0 \\
$\quad 30 \mathrm{MHz}$ & 0.1 to 200 & $\begin{array}{c}\text { Estimated } \\
100 \mathrm{MHz}\end{array}$ \\
\hline
\end{tabular}

*No rf-dc differences greater than \pm 20 percent will be reported. This normally limits the calibrations to $100 \mathrm{MHz}$ and below.

Table 10: Specifications and Estimated Uncertainties for High-Frequency TVC Services

\begin{tabular}{lcc}
$\begin{array}{l}\text { Frequency } \\
\text { (MHz) }\end{array}$ & $\begin{array}{c}\text { RF Voltage } \\
\text { Range } \\
\text { (V) }\end{array}$ & $\begin{array}{c}\text { Estimated } \\
\text { Limits of Uncertainty* } \\
\text { ( } \pm \%)\end{array}$ \\
\hline 10 & 0.1 to 7.5 & 0.1 \\
30 & 0.1 to 7.5 & 0.2 \\
$100,200,300,400$ & 0.1 to 7.5 & 1 \\
$500,600,700$ & 0.1 to 7.5 & 1 \\
$800,900,1000$ & 0.1 to 7.5 & 1 \\
\hline
\end{tabular}

*No rf-dc differences greater than \pm 20 percent will be reported.

Peak-to-Peak Detectors (53430S)

Measurements on peak-to-peak detectors are performed from $100 \mathrm{kHz}$ to $500 \mathrm{MHz}$ and are referenced to the center of a GR 874 " $T$ " connector. A $50 \mathrm{kHz}$ ac signal is applied instead of dc. The services available are specified in Table 11.

\section{RF Micropotentiometers (53440C-53445S)}

Radio frequency micropotentiometers are usually calibrated at their nominal rated output voltages. Frequencies 
Table 11: Specifications and Estimated Uncertainties for Peak-to-Peak Detector Services

\begin{tabular}{lcc}
$\begin{array}{c}\text { Frequency } \\
\text { (MHz) }\end{array}$ & $\begin{array}{c}\text { Applied RF Voltage } \\
\text { for "0" Detector Output } \\
\left(\mathbf{V}_{\mathrm{p}-\mathrm{p}}\right)\end{array}$ & $\begin{array}{c}\text { Estimated Limits } \\
\text { of Uncertainty } \\
(\%)\end{array}$ \\
\hline $0.1,0.3,1.0$ & 1.2 & 0.15 \\
3,10 & 1.2 & 0.20 \\
30 & 1.2 & 0.30 \\
50 & 1.2 & 0.60 \\
$100,200,300,400,500$ & 1.2 & 1.10 \\
\hline
\end{tabular}

suggested for a normal calibration are $5,100,300,400,500,700$, and 900 $\mathrm{MHz}$. Special arrangements may be made for calibrations up to $1000 \mathrm{MHz}$ with reduced limits of uncertainty.

Radio frequency micropotentiometers having resistive elements greater than 10 milliohms in combination with thermoelement housings between 5 and $100 \mathrm{~mA}$, usually have rf-dc differences within \pm 1 percent at $5 \mathrm{MHz}$. Since the rf-dc difference approaches zero below 5 $\mathrm{MHz}$, calibrations at $50 \mathrm{kHz}$ and 5 $\mathrm{MHz}$ would suffice to determine interpolated points of interest between $50 \mathrm{kHz}$ and $5 \mathrm{MHz}$, with no appreciable loss of accuracy. Estimated uncertainties are shown in Table 12.

An rf-dc difference of about \pm 5 percent at $1 \mathrm{MHz}$ usually results from a combination using a 1 milliohm element with thermoelement housings between 5 and $100 \mathrm{~mA}$. Interpolation below $1 \mathrm{MHz}$ is not recommended in this case.

The rf-dc difference is defined as the percentage difference between the rf and dc voltages required to produce the same thermocouple output, with the resistive elements terminated in $50 \mathrm{ohms}$, e.g.,

$$
\text { rf-dc difference }(\%)=\left(\frac{V_{\mathrm{rf}}-V_{\mathrm{dc}}}{V_{\mathrm{dc}}}\right) \times 100 \text {. }
$$

As a special service, rf micropotentiometers with output voltage greater than $200 \mu \mathrm{V}$ can be calibrated from 0.05 to $1000 \mathrm{MHz}$, with reduced limits of uncertainty varying from $\pm 0.2 \%$ to $\pm 2 \%$. This uncertainty is dependent on frequency, output level and the rf-dc difference vs frequency response. For further details, consult with the technical contact cited at the beginning of this section.

Table 12: Specifications and Estimated Uncertainties for RF Micropotentiometer Calibrations

\begin{tabular}{ccc}
$\begin{array}{c}\text { Any Frequency } \\
\text { Within Band } \\
(\mathbf{M H z})\end{array}$ & $\begin{array}{c}\text { RF Voltage } \\
\text { Range } \\
(\mu \mathrm{V})\end{array}$ & $\begin{array}{c}\text { Limits of Uncertainty* } \\
( \pm \%)\end{array}$ \\
\hline 0.05 to 100 & 1 to 100,000 & 2 \\
100 to 500 & 1 to 100,000 & 3 \\
500 to 900 & 1 to 100,000 & 5 \\
\hline
\end{tabular}

*For rf-dc differences greater than \pm 20 percent, estimated limits of uncertainty are larger than those listed.

References-RF-DC Voltage and Current Converters (100 Hz-1 GHz) NBS RF Voltage Comparator, L. D. Driver, F. X. Ries, G. Rebuldela, Natl. Bur. Stand. (U.S.), Int. Report, NBSIR 78-871, (Dec. 1978).

Thermal Voltage Converters for Accurate Voltage Measurements to 30 Megacycles Per Second, F. L. Hermach and E. S. Williams, Trans.

AIEE, Pt. 1, Commun. Elect., 72, 200 (July 1960).

Thermal Converters as AC-DC Transfer Standards for Current and Voltage Measurements at Audio Frequencies, F. L. Hermach, J. Res. Natl. Bur. Stand. (U.S.), 48, 121 (1952).

Accurate Radio Frequency Microvoltages, M. C. Selby, Trans. AIEE, Pt. 1, Commun. Elect., 72, 158 (May 1953).

High Frequency Microvolt Measurements, F. X. Ries, G. Rubuldela, ISA Proc., 18, 1, 37.2.63, Instrum. Soc. of America, Res. Triangle, NC (Sept. 1963). 
Voltage Measurements

C.5 Data Converters

\section{Electrosystems Division \\ Center for Electronics and Electrical Engineering}

Technical Contacts:

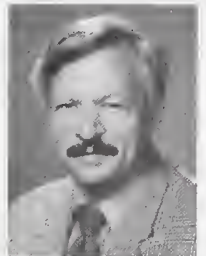

T. Michael

Souders

Tel: 301/921-2727

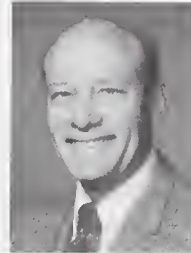

Barry A. Bell

Tel: 301/921-2727
Mailing Address: B162 Metrology, National Bureau of Standards, Gaithersburg, MD 20899

Test No. Items

53500S Special Data Converter Services by Prearrangement

53510C A/D or D/A Converter, Linearity Errors at 1024 Points, 10-Bit Correction Coefficients, and Superposition Errors

53520C A/D or D/A Converter, Differential Linearity Errors at 2(N-1) Points $(\mathrm{N}=$ No. of Bits)

53530C A/D Converter, Equivalent RMS Input Noise

53540S A/D or D/A Converter, Offset and Gain Errors Relative to U.S. Legal Volt

Data Converters (53500S-53540S)

NBS maintains a calibration service for static testing of high resolution (12-18 bit) analog-to-digital (ADC) and digital-to-analog (DAC) converters. Routine measurements, for which calibration reports are issued, are made of the static parameters listed below. However, NBS has recently developed the capability to measure the dynamic response of ADCs to well-defined, programmable input voltage steps characteristic of typical input signals. These dynamic measurements can be made as a special test. Until further analysis of systematic and random errors of the test procedure is completed and until additional operating experience is ob- tained, the customer will receive the test results with appropriate error analysis, but no calibration report will be issued.

There is no standard data-converter terminology, but NBS uses the following definitions of parameters to describe its calibration service:

A. Linearity Error: The difference between the actual and ideal levels of the static input/output characteristic after corrections have been made for offset and gain errors.

B. Differential Linearity Error: The difference between the actual and the ideal separation between adjacent levels.

C. Offset Error: The difference between the actual and the ideal levels, measured at the most negative level of the input/output characteristic. Due to practical considerations, this definition is modified to the 2nd most negative level, (i.e., with the least significant bit (LSB) on).

D. Gain Error: The difference between actual and ideal levels, measured at the most positive level of the input/output characteristic, after correction for offset error. Again, in practice, a defining level is chosen slightly below the one stated here.

E. Equivalent RMS Input Noise: The rms value of the effective internal noise of an ADC, referred to its input terminals.

In these definitions, the specified levels for DACs are taken to be the discrete output levels, and for ADCs the analog input levels at which the digital output transitions between adjacent codes occur. In this latter case, the transition levels are defined by the upper digital code of the transition in question.

The principal error parameters are usually those of linearity and differential linearity. Nevertheless, gain and offset errors may also be measured when appropriate, and the equivalent 
rms input noise of ADCs can be measured as well, provided it has approximately a Gaussian distribution. Determination of monotonicity in DACs and missing codes in ADCs is not generally performed since these tests require excessive measurement time for high-resolution converters. These characteristics can often be inferred, however, from the available linearity data. Sensitivity of the various parameters to changes in temperature and power supply voltage, for example, is also not generally determined.

\section{Description of Static Tests:}

A. Linearity: For the linearity test, all 1024 digital codeword combinations of the 10 most significant bits are measured. Errors contributed by the remaining, less significant bits are generally insignificant, a premise which is tested during the calibration process. The data are numerically processed to determine the maximum, minimum, and rms errors of the 1024 tested codes, and to determine, on a least-squares basis, individual correction coefficients for the ten most significant bits. The residuals from the computation of correction coefficients are a direct measure of the converter's superposition errors. These are computed as well.

B. Differential Linearity: Differential linearity errors are measured at 2(N-1) major codeword transitions, for an N-bit converter.

C. Offset \& Gain: In general, converter offset and gain measurements are not required, since it is common practice to provide adjustable trimmer circuits, which are periodically set to suit individual system requirements. However, accurate voltage measurements directly traceable to legal standards can be provided if required. Offset and gain errors are measured directly by setting the test converter to the designated code and measuring the input (or output) voltage by direct comparison with a transfer standard calibrated by NBS.

D. RMS Input Noise: The equivalent rms input noise of ADCs can be measured either as an average value over the entire full-scale range of the converter, or as a function of codeword, at 64 randomly selected points. The measurement technique relies upon the assumptions that the noise has a Gaussian distribution, and that at a given sampling rate, successive values are uncorrelated. The validity of these assumptions is tested prior to performing the measurements.

E. Specification for Test Converters: To be compatible with the NBS data converter test set, test units must conform to the following general specifications:

1. Nominal resolution from 12 to 18 bits,

2. Conversion rate of at least 10 $\mathrm{kHz}$,

3. Binary coding format, including binary sign-magnitude, offset binary, 2's complement, 1's complement, and complemented versions of these,

4. TTL compatibility,

5. Voltage ranges of $0-5 \mathrm{~V}, \pm 5 \mathrm{~V}$; 0-10 V, $\pm 10 \mathrm{~V}$,

6. Maximum error, including offset and gain, not to exceed $500 \mathrm{ppm}$.

\section{Systematic Uncertainties:}

The estimated limits of the systematic uncertainties in measuring the various converter error parameters are summarized in Table 13 for a $\pm 10 \mathrm{~V}$ range. Random errors of the measurement process necessarily include random variations in the test converter and are, therefore, individually evaluated for each test. Nevertheless, measurements on very stable (check standard) converters indicate the random errors contributed by the test set itself are substantially less than the respective systematic uncertainties listed in the table. Figure 15 shows 
the estimated systematic uncertainty of the NBS data converter test system for resolutions from 12 to 18 bits.

\section{Dynamic Tests of ADCs:}

Dynamic errors in ADCs are defined as any deviations from the static transfer characteristic resulting from

Figure 15. Uncertainty for NBS Data Converter Test System for Resolutions from 12-18 Bits

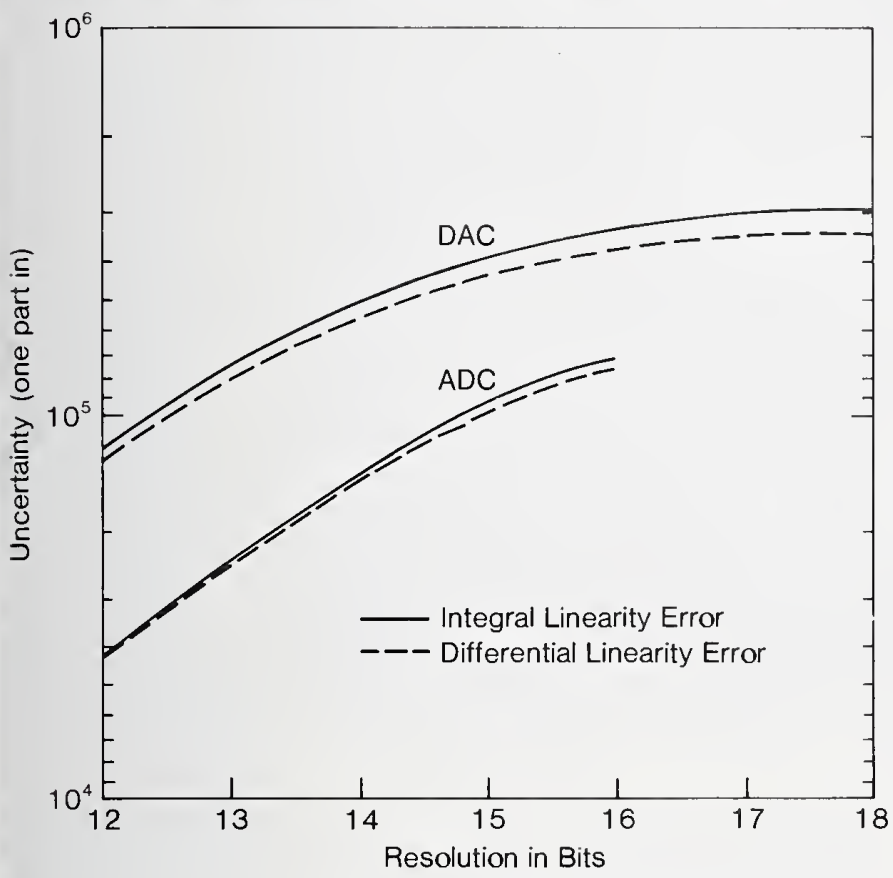

prior exercise, (i.e., previous changes in input). The test converter is exercised with stepped input changes typical of the conditions of actual use. The dynamic errors are measured in terms of the changes in the test converter's code transition levels resulting from prior exercise. A more complete description of the dynamic testing now provided for ADCs on a Special Test basis is provided in Souders et al., "An Automated Test Set for the Dynamic Characterization of A/D Converters" (see references).

\section{Preparation of Test Boards:}

In general, the customer is responsibile for mounting the integrated circuit, hybrid, or modular test converters on suitable test boards, and for providing all required trimmer circuits, voltage references, input or output amplifiers, recommended power supply decoupling capacitors, and connectors for interfacing to the input/output lines. Fully selfcontained converters need only be fitted with the necessary interfacing connectors. In so doing, the customer gains significant performance advantages while at the same time saving the additional fee that would otherwise be charged by NBS for performing this service. Highperformance converters are often susceptible to small changes in grounding, routing of dynamic signal lines, capacitive loading, etc. Particularly with ADCs, signal dynamics are

Table 13: Specifications and Estimated Uncertainties for Data Converter Calibrations

\begin{tabular}{|c|c|c|c|c|}
\hline \multirow{3}{*}{$\frac{\text { Parameter }}{\text { Linearity Error }}$} & \multicolumn{4}{|c|}{ Estimated Systematic Uncertainty } \\
\hline & \multicolumn{2}{|c|}{$\mathrm{DACs}$} & \multicolumn{2}{|c|}{$\mathrm{ADCs}$} \\
\hline & $2.7 \mathrm{ppm}$ & +0.04 LSB & $4.7 \mathrm{ppm}$ & +0.16 LSB \\
\hline $\begin{array}{l}\text { Differential } \\
\text { Linearity Error }\end{array}$ & $3.2 \mathrm{ppm}$ & +0.04 LSB & $5.2 \mathrm{ppm}$ & +0.16 LSB \\
\hline Offset Error ${ }^{(a)}$ & $3 \mathrm{ppm}$ & & $3 \mathrm{ppm}$ & $+0.07 \mathrm{LSB}$ \\
\hline Gain Error ${ }^{(a)}$ & $6 \mathrm{ppm}$ & & $6 \mathrm{ppm}$ & $+0.13 \mathrm{LSB}$ \\
\hline $\begin{array}{l}\text { RMS Input } \\
\text { Noise }^{(\mathrm{b})}\end{array}$ & & & $\begin{array}{l}-100 \% ; \\
\mu \mathrm{V}) \mathrm{Noi} \\
\text { by the } \mathrm{T} \\
\text { approxim } \\
30 \mathrm{nV} /(\mathrm{H} \\
1 \mathrm{MHz} b\end{array}$ & $\begin{array}{l}(20 \%+10 \\
\text { e introduced } \\
\text { st Set is } \\
\text { ately } \\
z)^{1 / 2} \text { in a } \\
\text { ndwidth }\end{array}$ \\
\hline
\end{tabular}

(a) Measured upon special request only, if no adjustable trimmers are provided for these parameters.

(b) Since the effective bandwidth of the test converter is generally unknown, the noise contribution from the test set cannot be determined. Therefore, only an upper limit can be accurately placed on the noise measurements.

quite important, even for static testing, because the converter itself always operates at high speeds. When mounted by the customer, the test converter and its support circuitry can be laid out to simulate more closely the way it will be used, according to the specific manufacturer's recommendations. Therefore, the test results should more closely describe the converter's in situ performance. Detailed type and wiring requirements for the interfacing connectors are available upon request. 


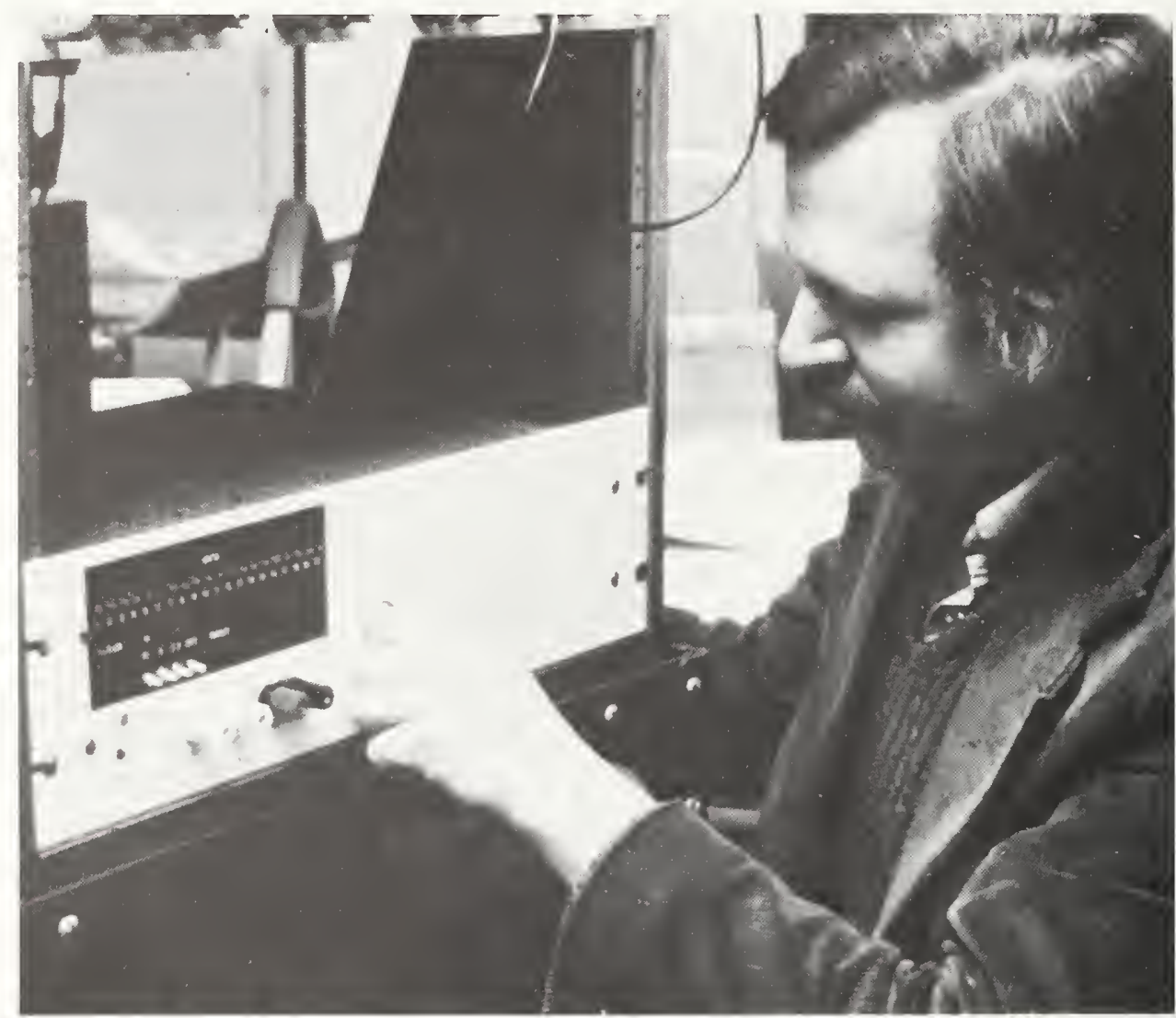

Michael Souders, working on development of NBS system for characterizing analog-to-digital and digital-to-analog data converters.

\section{References-Data Converters}

A Calibration Service for Analog-toDigital and Digital-to-Analog Converters, T. M. Souders, D. R. Flach, and B. A. Bell, Natl. Bur. Stand. (U.S.), Tech. Note 1145, (July 1981). (Provides a complete description of the calibration service.)

A 20-Bit + Sign Relay Switched D/ A Converter, T. M. Souders and D. R. Flach, Natl. Bur. Stand. (U.S.), Tech. Note 1105, (Oct. 1979). (De- scribes the reference standard used in the calibration service.)

A Technique for Measuring the Equivalent RMS Input Noise of A/D Converters, T. M. Souders and J. A. Lechner, IEEE Trans. Instrum. Meas., IM-29, No. 4, 251 (Dec. 1980). A High-Speed Low-Noise 18-Bit Digital-to-Analog Converter, H. K. Schoenwetter, IEEE Trans. Instrum. Meas., IM-27, No. 4, 413 (Dec. 1978). An Automated Test Set for the Dynamic Characterization of A/D Converters, T. M. Souders, D. R. Flach, and T. C. Wong, IEEE Trans. Instrum. Meas., IM-32, No. 1, 180 (Mar. 1983). 
Precision Ratio Measurements

\section{1 Inductive Dividers}

Electricity Division

Center for Basic Standards

\section{Technical Contacts:}

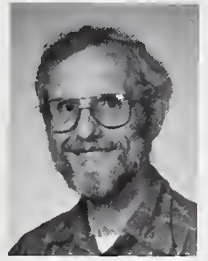

George M. Free Tel: $301 / 921-2715$

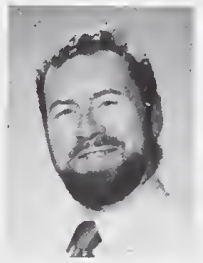

Norman B. Belecki Tel: 301/921-2715

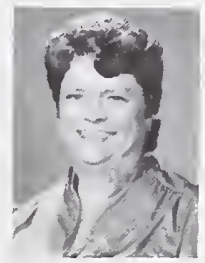

Avis R. Wise Administrative Logistics

Tel: 301/921-2715
Mailing Address: B146 Metrology, National Bureau of Standards, Gaithersburg, MD 20899

Test No. Items

54110 Special Ratio Measurements and Tests of Inductive Voltage Dividers by Prearrangement

54120C Inductive Voltage Dividers-(Single Frequency, Voltage to be Specified, Each Setting of 3 Most Significant Dials)

54121C Additional Frequency Points

54130C Inductive Voltage Dividers-(Single Frequency, Voltage to be Specified, Each Setting of Most Significant Dial Only)

54131C Additional Frequency Points

Special Ratio Measurements and Tests of Inductive Voltage Dividers by Prearrangement (54110S)

This service category provides for the measurement and/or evaluation of prototype ratio devices and inductive voltage dividers based on new principles, and for unique ratio measurements at the highest accuracy levels, such as the determination of the ratios of Hamon resistance transfer devices or Silsbee-type voltage ratio standards. Such measurements are undertaken at the discretion of NBS technical staff and oniy when the need for them can be clearly demonstrated.

\section{Inductive Voltage Dividers (54120C-54131C)}

Inductive voltage dividers (decade transformer dividers) are accepted for calibration only at 400,1000 , and $10,000 \mathrm{~Hz}$. The largest contribution to instability in undamaged inductive voltage dividers is wear or dirt in the decade switches. Variable contact resistance in these switches sometimes affects the stability of voltage-ratio measurements to a significant extent but is most evident by its effect on the phase angle. When a decade inductive voltage divider exhibits large changes in phase angle for repeated measurements after the switches have been disturbed, the divider should no longer be considered satisfactory for use as a voltage-ratio reference standard. Inductive voltage dividers that use pushbutton switching or incorporate a resistive divider as a fine adjustment usually are not accepted for calibration. Corrections to the separate decades of an inductive divider, in general, cannot be simply combined. However, the correction to a step setting of one of the higher decades usually is independent of the settings of the lower decades. The effects of stray impedances must be corrected by connecting the case to the divider at one point, and unless otherwise specified, the case will be connected to one of the common terminals. Decade inductive voltage dividers are calibrated at NBS at room temperature $\left(22\right.$ to $24^{\circ} \mathrm{C}$ ) by a comparison method, using a two-stage, three-decade transformer of known ratios.

\section{References-Inductive Dividers}

American National Standard for Decade Transformer Dividers (Voltage Type), ANSI C100, 1-1972 Amer. Natl. Stand. Inst., New York (Jan. 1972).

Instructions for the Use of the NBS

Reference Inductive Divider, Wilbur C. Sze, Nat1. Bur. Stand. Int. Report, Unpublished (1970). (Available from NBS).

Two-Stage, Guarded Inductive Voltage Divider for Use at $100 \mathrm{kHz}, \mathrm{D}$. H. Hamon and T. L. Zaf, ISA Transactions, 9, 3 Instrum. Soc. of America, Res. Triangle Park, NC (1970). Comparator for Calibration of Inductive Voltage Dividers from 1 to $10 \mathrm{kHz}$, W. C. Sze, ISA Transactions, 6, 4 Instrum. Soc. of America, Res. 


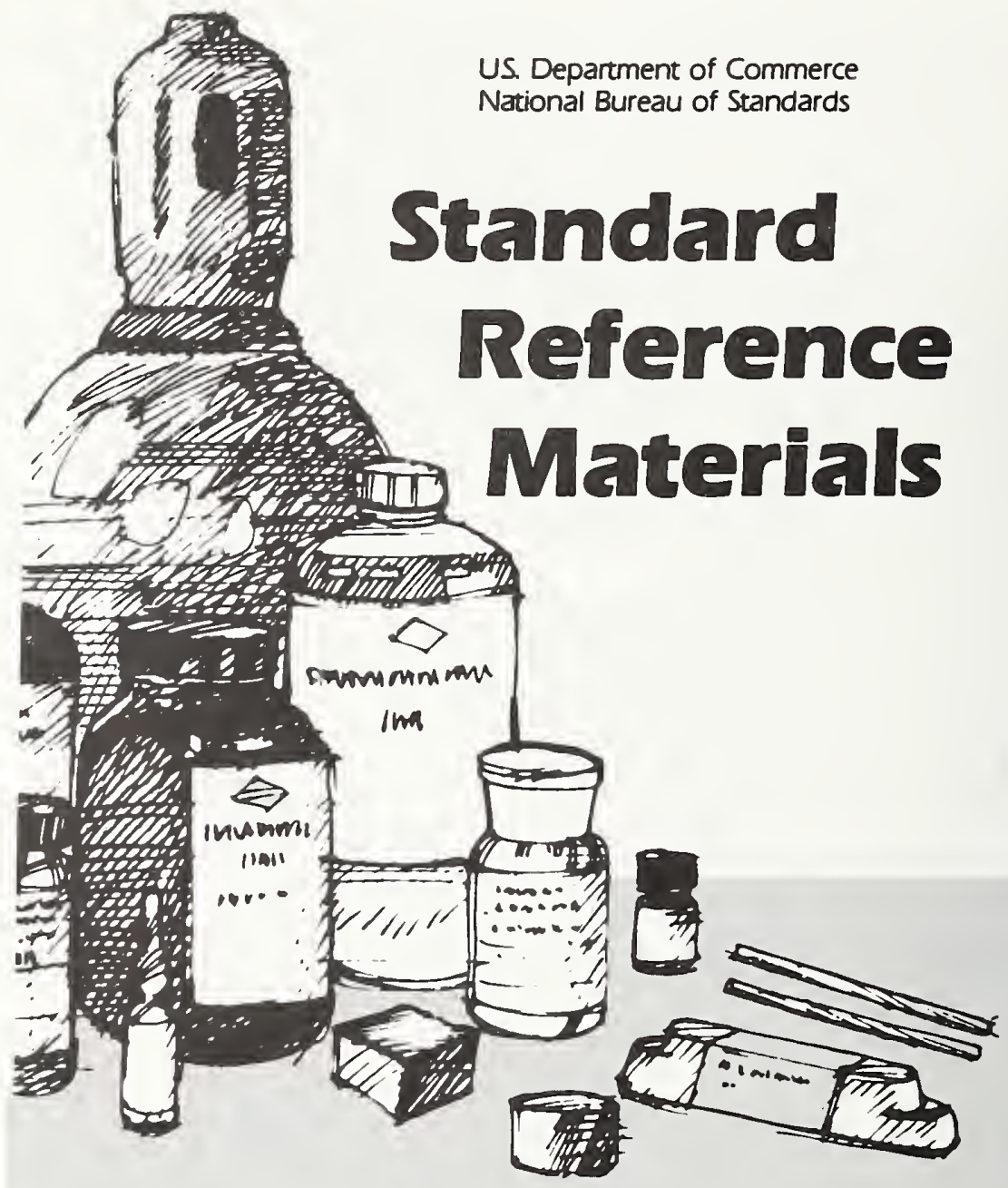

For Use In Calibrating or Checking Instruments Used in the Determination of:

- Chemical Composition

- Crystal Structure

- Electrical Properties

- Metallurgical Properties

- Optical Properties

- Partical Size

- $\mathrm{pH}$

- Temperature

- Thermal Properties

- And Others

Office of Standard Reference Materials

National Bureau of Standards Room B311 Chemistry Bldg Gaithersburg. MD 20899

301-921-2045 
Precision Ratio Measurements

D.2 Resistive Dividers

\section{Electrosystems Division \\ Center for Electronics and Electrical Engineering}

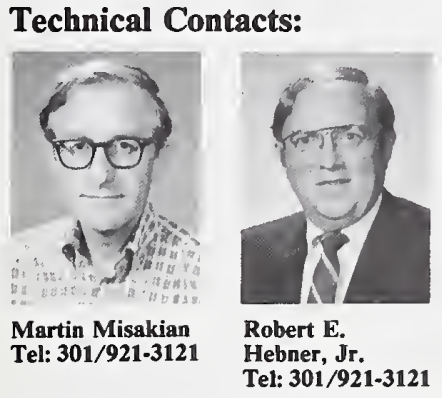

Mailing Address: B344 Metrology, National Bureau of Standards, Gaithersburg, MD 20899

Shipping Address: National Bureau of Standards, I-270 at Quince Orchard Road, Gaithersburg, MD 20899

[Attn: M. Misakian, Bld. 220, Room B351]

Test No. Items

54210C Resistor and Resistive Dividers, Total Resistance or Voltage Ratio, Two Direct Voltage Levels Between $10 \mathrm{kV}$ and $150 \mathrm{kV}$

\section{Resistor and Resistive Dividers} (54210C)

A calibration service is maintained at NBS to specify the dc voltage ratio of resistive dividers. The routine calibration service is available for applied voltages from $10 \mathrm{kV}$ to $150 \mathrm{kV}$. The calibrations are performed with a measurement system which has an uncertainty of $\pm 0.01 \%$ of the voltage ratio. To assure adequate sensitivity at the lowest applied voltage levels, calibrations are performed routinely only on dividers with ratios of 100,000:1 or smaller. The routine calibration service is also restricted to dividers with a low-resistance element of $10,000 \mathrm{ohms}$ or less.

Resistive dividers are acceptable for calibration only if they are nearly corona free at the rated operating voltage and are designed to have small temperature and voltage coefficients. Specifically, a device is not generally suitable for calibration by NBS if these coefficients produce a change in the ratio of $\pm 0.1 \%$ over the normal range of operating voltages. At a given voltage, dividers should not exhibit instabilities in their ratio value in excess of 0.005 percent. NBS staff can provide some assistance in the identification of other calibration laboratories capable of certifying the response of less accurate dividers.

Resistive dividers of sufficient quality to be considered as transfer standards are calibrated at $60 \mathrm{~Hz}$ for applied voltages between $10 \mathrm{kV}$ and 100 $\mathrm{kV}$ rms. High voltage dividers may perform satisfactorily as standards under dc voltages but do not perform well enough to be considered as standards when excited by $60-\mathrm{Hz}$ voltages. The design of an ac divider requires special features, beyond those of a dc divider. In particular, ac dividers designed to be used as transfer standards may have to be equipped with external shielding to minimize the effects of capacitive coupling to surrounding objects.

If the device is not properly shielded, the effects of proximity to surrounding objects and pickup from high-voltage conductors can introduce large uncertainties into the measured value of the divider ratio. In such cases, the measurement of the ratio for one configuration would not necessarily be valid for another configuration. Consequently, a meaningful calibration of the device is difficult or impossibie.

Therefore, we recommended that the following two preliminary proximity tests be performed before an ac 
divider is submitted for test to determine the suitability of the device as a transfer standard. The divider should be placed about $2.0 \mathrm{~m}$ from a vertical ground plane as measured from the center of the device. The divider should then be energized to some safe voltage level and the divider ratio should be measured. The measurement should then be repeated with the vertical ground plane (or divider) moved into a position $1.2 \mathrm{~m}$ from the center of the divider. If the divider ratio, at the same applied high voltage, changes by 0.1 percent or more, the device has excessive capacitive coupling and is not suitable as a transfer standard.

To test for pickup, remove the high-voltage connection to the top of the divider and then connect the top of the divider to ground with a thin wire. Measure the output voltage of the divider under these conditions both with and without the highvoltage source energized. If the resulting change in the output voltage exceeds 0.1 percent of the expected output voltage when the high voltage is connected to the divider, then again there is excessive coupling indicating that the device is not suitable as a transfer standard.

Whenever a high-voltage ac divider is sent to NBS, it will first be subjected to tests like those described above. If such tests show variations in the measured ratio of more than 0.1 percent for either proximity or pickup, then no further tests will be performed and the device will be returned. The customer will be charged for the cost of these tests.

The NBS calibration of voltage transformers at $60 \mathrm{~Hz}$ is generally more accurate than its calibration of dividers at the same frequency. Therefore, customers having a requirement for a calibrated divider may find it advantageous to use a voltage transformer as the transfer standard and to use that transformer to calibrate the divider in their own facilities.

Dividers can be hand-carried or shipped to NBS. Shipped dividers should be packaged in sturdy reusable containers. The design of many high voltage dividers makes them vulnerable to shear-type forces, so provisions should be made to minimize the likelihood of damage due to such forces when the device is in the shipping container.

Resistive divider ratios are also determined under pulsed high-voltage conditions. Determinations employ special-design pulse dividers and calibrated Kerr cells as reference standards. A variety of pulses may be applied to simulate the conditions under which the divider will be used. Calibrations are made at selected voltage intervals from $20 \mathrm{kV}$ to $300 \mathrm{kV}$ as requested and up to $500 \mathrm{kV}$ with certain pulse shapes. The typical uncertainty is $\pm 3 \%$ of the voltage ratio although smaller uncertainties can occasionally be reported as a special test.

Routine tests are carried out for voltages between $10 \mathrm{kV}$ and $200 \mathrm{kV}$ and are performed with a measurement system having an uncertainty of $0.05 \%$ in the determination of the ratio and \pm 0.5 milliradian in the determination of the phase angle.

\section{References-Resistive Dividers}

Evaluation of a Multimegavolt Impulse Measurement System, R. E. Hebner, D. L. Hillhouse, and R. A. Bullock, Natl. Bur. Stand. (U.S.), Int. Report, NBSIR 79-1933 (Nov. 1979). Calibration of High-Voltage Pulse Measurement Systems Based on the Kerr Effect, Natl. Bur. Stand. (U.S.), Int. Report, NBSIR 77-1317 (Sept. 1977).

Special Shielded Resistor for HighVoltage Measurements, J. H. Park, J. Res. Natl. Bur. Stand. (U.S.), 66C, No. 1, 19 (Jan.-Mar. 1962). 


\section{Precision Ratio Measurements \\ D.3 Capacitive Dividers Electrosystems Division Center for Electronics and Electrical Engineering}

Technical Contacts:

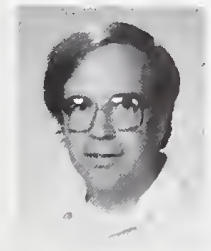

William E, Anderson Tel:301/921-3121

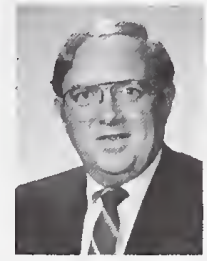

Robert E. Hebner, Jr. Tel: 301/921-3121
Mailing Address: B344 Metrology, National Bureau of Standards, Gaithersburg, MD 20899

Shipping Address: National Bureau of Standards, I-270 at Quince Orchard Road, Gaithersburg, MD 20899

[Attn: W. E. Anderson, Bld. 202, Room 167]

Test No. Items

54310S Capacitive Dividers

\section{Capacitive Dividers (54310S)}

Capacitive divider ratios are determined under both pulsed high-voltage and ac conditions. Determinations under high-voltage pulse conditions employ special-design pulse dividers and calibrated Kerr cells as reference standards. A variety of pulses may be applied to simulate the conditions under which the divider will be used. Calibrations are made at selected voltage intervals from $20 \mathrm{kV}$ to 300 $\mathrm{kV}$ as requested and up to $500 \mathrm{kV}$ with certain pulse shapes. The typical uncertainty is $\pm 3 \%$ of the voltage ratio although smaller uncertainties can occasionally be reported as a special test.

Determinations at $60 \mathrm{~Hz}$ ac employ the same equipment used for the calibration of ac resistive dividers (see $54210 \mathrm{C}$ ). The same limitations pertain to shielding (proximity and pickup effects). The NBS measurement system imposes a negligible burden on the divider if its output voltage is 100 volts or less. Otherwise, the burden is equivalent to a 1000 picofarad capacitor.

\section{References-Capacitive Dividers}

Evaluation of a Multimegavolt Impulse Measurement System, R. E. Hebner, D. L. Hillhouse, and R. A. Bullock, Natl. Bur. Stand. (U.S.), Int. Report, NBSIR 79-1933 (Nov. 1979). Calibration of High-Voltage Pulse Measurement Systems Based on the Kerr Effect, Nat1. Bur. Stand. (U.S.), Int. Report, NBSIR 77-1317 (Sept. 1977).

Special Shielded Resistor for HighVoltage Measurements, J. H. Park, J. Res. Natl. Bur. Stand. (U.S.), 66C, No. 1, 19 (Jan.-Mar. 1962).

High Voltage Divider and Resistor Calibrations, M. Misakian, Natl. Bur. Stand. (U.S.), Tech. Note 1215 (July 1985). 
D.

\section{Precision Ratio Measurements}

D.4 Mixed Dividers

Electrosystems Division

Center for Electronics and Electrical Engineering

Technical Contacts:

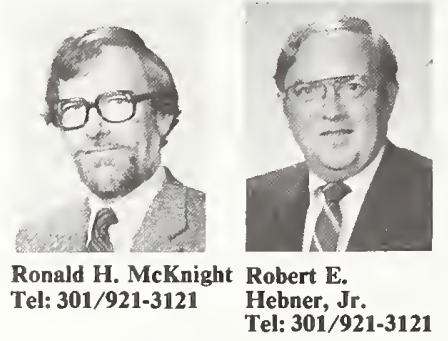

Mailing Address: B344 Metrology, National Bureau of Standards, Gaithersburg, MD 20899

Test No. Items

54410S Pulse-Voltage-Measuring Systems, Including Kerr Cells

54420S X-Ray Unit, Voltage Dividers (Two dividers in same container)

Mixed Dividers (54410S and 54420S)

A mixed divider is one constructed of resistors and capacitors. Ratios of mixed-voltage dividers are determined under pulsed high-voltage conditions. Determinations employ special-design pulse dividers and calibrated Kerr cells as reference standards. A variety of pulses may be applied to simulate the conditions under which the divider will be used. Calibrations are made at selected voltage intervals from $20 \mathrm{kV}$ to $300 \mathrm{kV}$ as requested and up to $500 \mathrm{kV}$ with certain pulse shapes. The typical uncertainty is $\pm 3 \%$ of the voltage ratio although smaller uncertainties can occasionally be reported as a special test.

A special set of tests has been developed to evaluate the mixed dividers used to measure the voltage pulses in diagnostic $\mathrm{x}$-ray units. These tests involve measurement of the variation of the ratio with a change in the frequency of the applied voltage in the frequency range from dc to $10,000 \mathrm{~Hz}$; a determination of the ratio under direct voltage at $25 \mathrm{kV}$; a measurement of any voltage induced variation of the ratio in the voltage range from 20 to $70 \mathrm{kV}$. If the device under test is designed to operate continuously under full rated voltage, this last test is performed at three dc voltages between 20 and $70 \mathrm{kV}$. For devices that cannot operate continuously, a preselected number of half cycles of $60-\mathrm{Hz}$ voltage with peak voltage ranging from 20 to 70 $\mathrm{kV}$ are applied.

Routine tests are performed with an uncertainty of $\pm 0.1 \%$ of the indicated value of the dc ratio at $25 \mathrm{kV}$, and an uncertainty of $\pm 1 \%$ of the indicated value of the frequency dependence. Generally the ratio varies by less than $\pm 1 \%$ as the applied voltage is varied over the full range.

This calibration service was developed to assist in compliance with the U. S. Food and Drug Administration's regulations on good manufacturing practice for medical devices (Federal Register, Vol. 43, 31508, 1978).

\section{References-Mixed Dividers}

X-CAL-A Calibration System for Electrical Measurement Devices Used With Diagnostic X-Ray Units, R. H. McKnight and R. E. Hebner, Natl. Bur. Stand. (U.S.), Int. Report, NBSIR 79-2072, (June 1980).

Evaluation of a Multimegavolt Impulse Measurement System, R. E. Hebner, D. L. Hillhouse, and R. A. Bullock, Natl. Bur. Stand. (U.S.), Int. Report, NBSIR 79-1933, (Nov. 1979). Calibration of High-Voltage Pulse Measurement Systems Based on the Kerr Effect, Natl. Bur. Stand. (U.S.), Int. Report, NBSIR 77-1317, (Sept. 1977).

Special Shielded Resistor for HighVoltage Measurements, J. H. Park, J. Res. Natl. Bur. Stand. (U.S.), 66C, No. 1, 19 (Jan.-Mar. 1962). 
Precision Ratio Measurements

D.5 Voltage and Current Transformers Electrosystems Division Center for Electronics and Electrical Engineering

Technical Contacts:
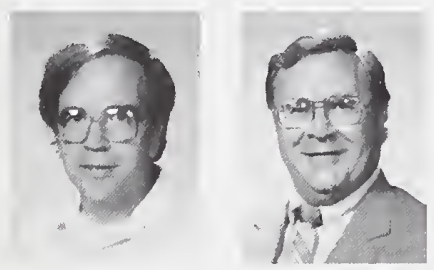

William E.

Anderson

(Voltage

John D. Ramboz

(Current Transformers)

Transformers)

Tel: 301/921-3121

Mailing Address: B344 Metrology, National Bureau of Standards, Gaithersburg, MD 20899

Shipping Addresses: National Bureau of Standards, I-270 at Quince Orchard Road, Gaithersburg, MD 20899

For 54510C-54513C:

[Attn: W. E. Anderson, Bld. 202, Room 167]

For 54520C-54522C:

[Attn: J.D. Ramboz, Bld. 220, Room B165]

Test No. Items

54510C Voltage Transformer, Ratio \& Phase Angle, at $60 \mathrm{~Hz}$ on 1 Range, 1 Secondary Voltage, 1 Burden Primary $\mathrm{V}_{\mathrm{rms}} \leq 150 \mathrm{kV}$

54511C Same as 54510C, Additional Similar Transformer at Same Time

54512C Same as 54510C and 54511C, Additional Burden or Range

54513C Same as 54510C-54512C, at Each Additional Secondary Voltage

54520C Current Transformer, Ratio \& Phase Angle, 1 Range at 1 Frequency and 1 Burden, Secondary Currents 0.5, 1, 2, 3, 4, 5 A, Primary Current Not Over 8000 A

54521C Current Transformer, Ratio \& Phase, 1 Secondary Current, Additional Combination of Range,

Frequency, and Burden, Primary Current Not Over $8000 \mathrm{~A}$

54522C Current Transformer, Ratio \& Phase at Each Additional Secondary Current, Same Combination of Range, Frequency, and Burden as $54520 \mathrm{C}$ or $54521 \mathrm{C}$

54600 S Special Tests of Dividers and Transformers by Prearrangement
Voltage Transformers

(54510C-54513C)

NBS provides routine services for the measurement of complex voltage ratios (magnitude and phase angle) of transformers for primary voltages up to $150 \mathrm{kV}$ and for secondary voltages above $50 \mathrm{~V}$, subject to some constraints as to the maximum physical size of the device. Results of these routine tests are reported with an uncertainty of $\pm 0.03 \%$ for ratio and 0.3 $\operatorname{mrad}(1 \mathrm{mrad}=3.438 \mathrm{~min})$ for phase angle. If the test conditions and the device under test warrant, special tests with smaller uncertainties can be performed. These special tests may require an extra fee.

The customer must specify the secondary voltage and the secondary burden for each transformer or for each range of a multirange transformer. Ambiguity can be avoided if the impedance and power factor, or the resistance and reactance are specified rather than the volt-ampere rating of each burden. The customer should note that the NBS calibration system represents a minimum burden of $1000 \mathrm{pF}$ for routine calibrations. The customer should give some care to the specification of a burden recognizing that the use of the transformer with a burden different from that used in the calibration can result in significant error.

Calibrations of voltage transformers are performed routinely only at 60 $\mathrm{Hz}$. Measurements are made with one side of both the primary and secondary windings connected to ground.

NBS does have some capability to perform measurements at voltages, frequencies, and burdens outside of 
the ranges described above. Calibrations can occasionally be provided at these nonroutine test points as a special test for an increased fee.

\section{Current Transformers (54520C-54522C)}

Normally NBS calibrates only current transformers of high quality for use as reference standards. The NBS equipment is designed to test current transformers with a rated secondary current of $5 \mathrm{~A}$, with test points chosen to be one or more of the following values: $0.5,1,2,3,4,5 \mathrm{~A}$.

Routine tests are carried out at 50 , 60 and $400 \mathrm{~Hz}$. For measurements at 50 or $60 \mathrm{~Hz}$, the results are generally reported with an uncertainty of $\pm 0.01 \%$ in ratio and $\pm 100 \mu \mathrm{rad}$ in phase angle. For measurements at 400 $\mathrm{Hz}$, the reported uncertainty is $\pm 0.03 \%$ in ratio and $\pm 300 \mu \mathrm{rad}$ in phase angle.

The customer must specify the test frequency, the secondary currents, and the secondary burdens for each transformer or for each range of a multirange transformer. Current transformers should be tested with burdens equivalent to those which are imposed when the device is used as a transfer standard. Routine calibration using the burdens specified in the American National Standards Institute (ANSI) Standard C-57.13 is not recommended unless these burdens are subsequently used in the customer's factory or laboratory. Large errors can result if the values of ratio and phase angle obtained with an ANSI recommended burden are used for the transformer when it is connected to a different burden.

Preferably the burden should be specified in terms of the measured resistance and inductance. These values should include the effects of the leads used to make a connection to the transformer secondary. An alternative, which is sometimes feasible, is to submit the transformer together with its normal leads and connected burden for calibration as a unit. If neither of the above are possible, the burden may be stated in terms of the voltampere product and the power factor of the secondary circuit at the test frequency. For reference, it should be noted that the test equipment regularly used at NBS represents a minimum test burden of about $0.03 \mathrm{ohms}$ with an inductance of about $10 \mu \mathrm{h}$.

Because of contact resistance and current rectification, loose or dirty primary and secondary terminations 
may affect the measurement results. These surfaces should be clean when the transformer is shipped to NBS to minimize this source of error.

Unless otherwise specified, current transformers are demagnetized prior to calibration. If it is desired to have a transformer tested as submitted (without demagnetization), this equipment should be stated on the purchase order and NBS staff should be informed by telephone before the transformer is shipped.

Many current transformers are not designed to be used as transfer standards and most of these do not require calibration at NBS. The NBS staff can provide some assistance in the assessment of the appropriateness of the device for NBS calibration and in the identification of alternative calibration sources. If NBS is required to perform laboratory measurements to determine whether or not a particular device can be calibrated, a charge for the cost of these measurements will be made.

\section{Special Tests of Dividers and} Transformers (54600S)

The Electrosystems Division maintains an active program of research and development in the area of electrical measurements at high voltage levels. For this reason, NBS often is able to provide measurement support for high voltage devices other than those listed above in this section. Special tests will generally be conducted by NBS, if the following criteria are met:

A. The requested tests are fully developed and documented.

B. There is a significant technical or economic justification for traceability of the test on the item to national standards.

C. There has not been a routine or recurrent need for the test.

\section{References-Voltage and Current} Transformers

A Wide Range High-Voltage Capacitance Bridge With One ppm Accuracy, O. Petersons and W. E. Anderson, IEEE Trans. Instrum. Meas., IM-24, No. 4, 336 (Dec. 1975).

An Electronic Ratio Error Set for Current Transformer Calibrations, $\mathbf{R}$. L. Kahler, IEEE Trans. Instrum. Meas., IM-28, No. 2, 162 (June 1979). A Wide Range Current Comparator System for Calibrating Current Transformers, T. M. Souders, IEEE Trans. Power Appar. Syst. PAS-90 No. 1, 318 (Jan.-Feb. 1971).

Wide-Band Two-Stage Current Transformers of High Accuracy, T. M. Souders, IEEE Trans. Instrum. Meas. IM-21, No. 4, 340 (Nov. 1972). 
Phase Angle Measurements

\section{E.1 Phase Angle Meters}

\section{Electrosystems Division \\ Center for Electronics and Electrical Engineering}

Technical Contacts:

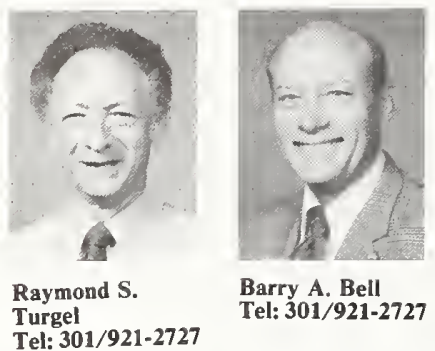

Mailing Address: B162 Metrology, National Bureau of Standards, Gaithersburg, MD 20899

Test No. Items

55110 Special Tests of Phase Angle Meters, by Prearrangement

Special Tests of Phase Angle Meters, by Prearrangement (55110S)

NBS has recently developed a capability for characterizing audio frequency phase meters over a frequency range of $1 \mathrm{~Hz}$ to $50 \mathrm{kHz}$. The standard used is a microcomputerbased system that synthesizes two sinusoidal voltages by means of digital techniques. The two signals are displaced relative to one another by a precisely known phase angle. Phase angles can be set with a resolution of 0.002 degree up to $5 \mathrm{kHz}$ and 0.005 degree above $5 \mathrm{kHz}$. The amplitude of the two output signals can be varied independently from 0.5 volt to 100 volts rms. At power frequencies, one of the inputs can be a current from 0.5 to 5 amperes. The uncertainty in setting the standard is less than \pm 0.01 degree below $5 \mathrm{kHz}$ and increases to \pm 0.04 degree at $50 \mathrm{kHz}$ if the two output signals have the same amplitude. For unequal outputs, this uncertainty increases to \pm 0.015 degree and \pm 0.090 degree respectively, if the amplitude ratio is less than 10:1.

Although the accuracy of the phase angle standard does not rely on the stability of the frequency, the generated output, which can be varied in

Figure 16. Estimated Total Uncertainties of the NBS Phase Angle Calibration Standard

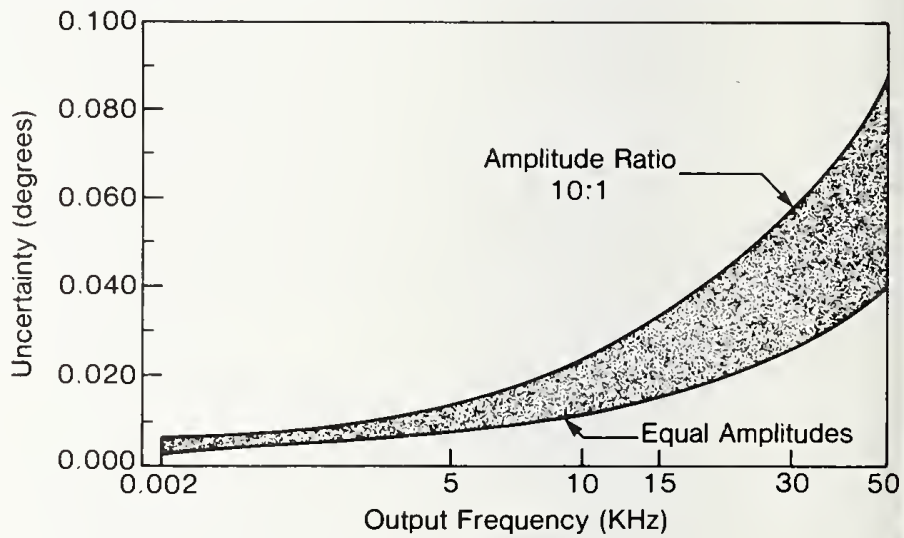

steps of $1 \mathrm{~Hz}$, is locked to a crystal controlled frequency synthesizer.

Figure 16 shows a plot of the total estimated uncertainty of the NBS Phase Angle Calibration Standard as a function of frequency for two limiting amplitude ratios.

This service is being offered on a trial basis under NBS Special Test procedures. If sufficient interest is shown, NBS will consider upgrading this trial service to full "Calibration Service" status. Special requirements for this service are as follows:

A. The voltage inputs of phase meter to be tested must have impedances such that the current is limited to a few milliamperes at any applied voltage requested. Current inputs 
must have impedances low enough so that the compliance voltage does not exceed 2 volts.

B. NBS will test the instrument in the as-received condition, without making any zero or gain adjustments.

C. In some cases, the response of phase meters involves significant time constants; therefore, readings will be taken 30 seconds after the setting of the standard.

D. For given voltage and frequency settings, at least three readings will be taken at each specified phase angle. The order of readings will be randomized.

E. The experimental data are fitted to a mathematical model from which the phase meter response can be predicted. From the closeness of fit to the model, it can be determined whether observed deviations from the predicted values are significant.

F. Each phase meter will be operated under power for at least 2 hours before test data are taken.

G. Meters that are not in operating condition upon receipt at NBS will be returned to the owner without repairs.

The fee for this service will be based on the actual cost. Prior arrangements are essential.

\section{References-Phase Angle Meters} High-Precision Audio-Frequency Phase Calibration Standard, R. S. Turgel and N. M. Oldham, IEEE Trans. Instrum. Meas., Vol. IM-27, No. 4, 460 (Dec. 1978).

NBS Phase Angle Calibration Standard, R. S. Turgel, N. M. Oldham, G. N. Stenbakken, and T. H. Kibalo, Natl. Bur. Stand. (U.S.), Tech. Note 1144, (July 1981).

A Power Factor Standard Using Digital Waveform Generation, N. M. Oldham and R. S. Turgel, IEEE Trans. Power Appar. Syst., PAS-100, No. 11, 4435 (Nov. 1981).

NBS $50 \mathrm{kHz}$ Phase Angle Calibration Standard, R. S. Turgel, Natl. Bur. Stand. (U.S.), Tech. Note 1220 (in press).

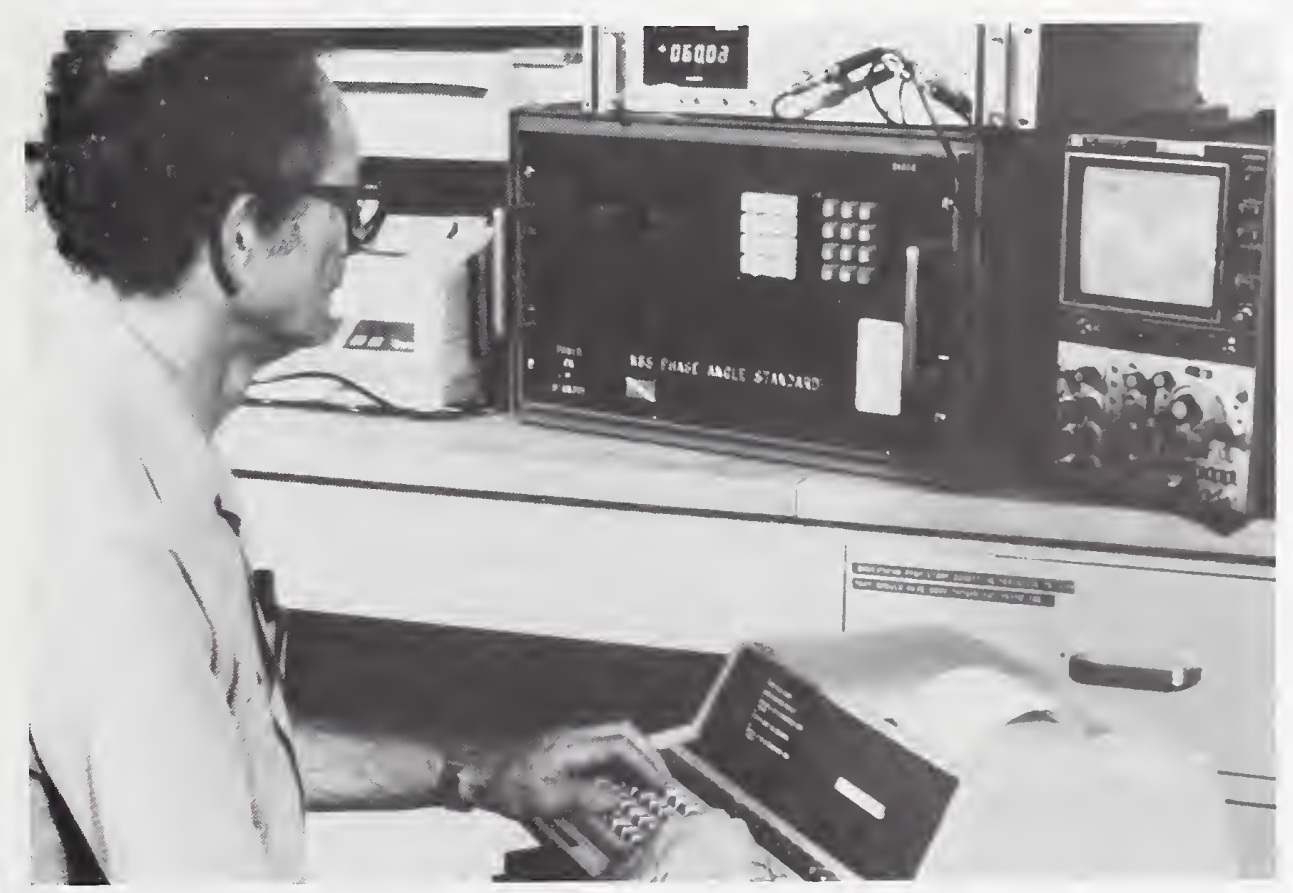

IR-100 winner Raymond Turgel with his NBS phase-angle standard. 
Phase Angle Measurements

\section{E.2 Very-High-Frequency Omnidirectional Range (VOR) Measurements Electromagnetic Fields Division Center for Electronics and Electrical Engineering}

Technical Contacts:

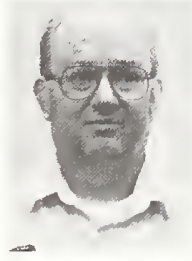

Neil T. Larsen Tel: 303/497-3711

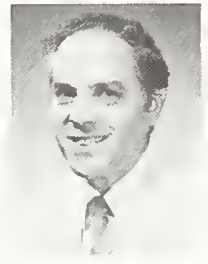

Cletus A. Hoer Tel: 303/497.3705

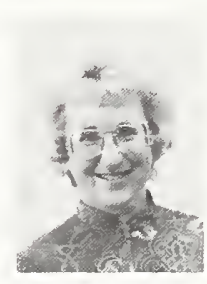

Edina M. Jones Administrative and Logistics Tel: $303 / 497-3753$
Mailing Address: M.C. 723.10, National Bureau of Standards, 325 Broadway, Boulder, CO 80303

Test No. Items

55210C VOR Bearing-Angle Indicators, 12 Bearing Angles Over the Range 0 to 330 Degrees

$55211 \mathrm{C}$ Calibration of VOR Bearing-Angle Indicator at Each Additional Angle

55220C VOR Generators, 12 Bearing-Angle Equivalent Signals Over the Range 0 to 330 Degrees

55221C Calibration of VOR Generator at Each Additional Angle

55230S Special VOR Tests

\section{VOR Measurements-General} Information

The NBS calibration services for VOR air navigation signals is described in detail in the April 1985

NBS Technical Note 1069, "VOR
Calibration Services" by N. T. Larsen, et al.

Two services are offered to support the calibration of VOR (Very-highfrequency Omnidirectional Range) instruments. NBS has designed and built a standard VOR audio generator, used to calibrate unknown VOR bearing-angle indicators, and a standard VOR bearing-angle indicator, used to calibrate unknown audio generators. Direct generation or measurement of standard VOR rf signals is not a part of the service.

Quality control of the NBS standards is accomplished by using each to measure the other. As a result of these measurements, the uncertainty of a calibration of either a generator or a bearing-angle indicator is given by the following statement, which is part of the calibration report:

"The assigned values of VOR phase angles are the nominal bearings from 0 to 360 degrees in increments of 0.01 degrees. The overall uncertainty of these values has been estimated from test data at bearings from 0 degrees to 360 degrees at 30 degree increments. Thus, each of the nominal bearings has been assigned a provisional overall uncertainty of \pm 0.0028 degrees, based on estimated bounds of \pm 0.0022 degrees on the systematic error and a computed standard error of 0.0002 degrees."

\section{VOR Bearing-Angle Indicators (55210C and 55211C)}

An unknown bearing-angle indicator is calibrated by connecting its input to the output of the NBS standard generator. The generator provides a composite audio signal that is the sum of two signals, each 1 volt rms ( \pm 
$1 \%$ ) in amplitude. The first signal is a $30 \mathrm{~Hz}$ sinusoid, and represents the variable phase signal recovered from the VHF carrier. The second is the frequency-modulated $9960 \mathrm{~Hz}$ subcarrier. NBS will calibrate at any set of 12 bearing-angles specified by the customer (if not specified, at 30 degree intervals over the inclusive range 0 to 330 degrees).

VOR Generators (55220C and 55221C) Only certain commercial VOR generators are suitable for calibration.

They should provide a composite audio signal of nominally 1 volt rms, per tone. They must have a shortterm phase jitter of less than 10 nsec. The modulation index for the 9960 $\mathrm{Hz}$ subcarrier must be equal to 16 $\pm 1 \%$. Most commercial generators do not meet these requirements and can best be calibrated by submitting a bearing-angle indicator for calibration instead. This can then be used to transfer the NBS calibration to the unknown generator with some loss of accuracy. An uncertainty statement for this transfer has not been developed due to lack of history. NBS will calibrate at any set of 12 bearingangle equivalent signals corresponding to bearing-angles specified by the customer (if not specified, at 30 degree intervals over the inclusive range 0 to 330 degrees).

\section{Special VOR Tests (55230S)}

The NBS standard bearing-angle indicator lends itself to the measurement of audio frequency periodic waveforms through the use of sampling techniques and time series analysis. It has been used for the accurate measurement of phase angles between two sinusoids. Special tests of this nature may be provided by prearrangement. The uncertainty depends upon the frequency; at $30 \mathrm{~Hz}$ it is about 0.0006 degrees ( 3 standard deviations).

\section{References-VOR Measurements} VOR Calibration Services, N. T. Larsen, D. F. Vecchia, and G. R. Sugar, Natl. Bur. Stand. (U.S.), Tech. Note 1069, (April 1985).

Fourier Transformation of the Nonlinear VOR Model to Approximate Linear Form, D. F. Vecchia, Natl. Bur. Stand. (U.S.), Tech. Note 1021, (June 1980). 
Power and Energy Measurements,

Low-Frequency

Electrosystems Division

Center for Electronics and Electrical Engineering

\section{Technical Contacts:}

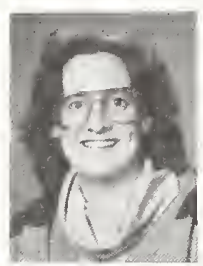

Elizabeth A.

Matthews

Tel: 301/921-3121

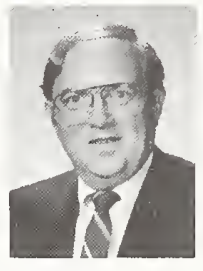

Robert E.

Hebner, Jr.

Tel: 301/921-3121
Mailing Address: B344 Metrology, National Bureau of Standards, Gaithersburg, MD 20899

Shipping Address: National Bureau of Standards, I-270 at Quince Orchard Road, Gaithersburg, MD 20899

[Attn: E. A. Matthews, Bld. 220, Room B165]

Test No. Items

56110 Special Tests of AC-DC Wattmeters by

Prearrangement

56120C Wattmeter Calibrations at Power-Frequencies

56200C Watthour Meter, Initial Two Determinations of Percentage Registration at $60 \mathrm{~Hz}$

56201C Each Additional Determination of Percentage Registration of Same Meter at $60 \mathrm{~Hz}$

56202C Initial Two Determinations of Percentage

Registration of One or Two Meters Run

Simultaneously with the First (56200C)

56203C Each Additional Determination of Percentage Registration of One or Two Meters Run as in 56202C

56210M Measurement Assurance Program for Watthour Meters
Power and Energy Measurements, Low-Frequency (56110S-56210M)

Only portable standard wattmeters and watthour meters (rotating standards and electronic types) are accepted for test. If necessary the meters should be cleaned or adjusted by the customer before they are shipped to NBS. NBS does not adjust meters and does not knowingly begin tests of faulty meters.

The test conditions must be specified by the customer. These include the current and voltage ranges to be tested, the frequency, the applied voltages, the applied currents, and the power factors. Values of these parameters which are available for routine testing are summarized in Table 14.

Table 14: Available Values of the Parameters for Routine Wattmeter and Watthour Meter Testing

\begin{tabular}{lllll}
\hline Parameter & \multicolumn{4}{c}{ Available Values } \\
\hline Voltage (V) & & 110 & 220 & 440 \\
& & 115 & 230 & 460 \\
& & $120^{*}$ & $240^{*}$ & 480 \\
& & 125 & 250 & 500 \\
& & 130 & 260 & 520 \\
& & & & \\
Current (A) & 0.50 & 2.50 & 7.50 & 25.00 \\
& 0.75 & 3.00 & 10.00 & 30.00 \\
& 1.25 & 3.75 & 12.50 & 37.50 \\
& 1.50 & 4.00 & 15.00 & 40.00 \\
Power Factor & 2.00 & $5.00^{*}$ & 20.00 & 50.00 \\
& & & & $1.0^{*}$ \\
& & & & $0.5^{*}$ lagging \\
& & & & $0.5^{*}$ leading \\
& & & & 50 \\
\hline
\end{tabular}

* Available values for Measurement Assurance Program (MAP) measurements

If necessary, measurements can sometimes be made at other values of these parameters. These would, however, be considered special tests. Separate, specific arrangements and a higher fee will be charged than for a routine calibration.

Unless otherwise specified, the duration of a test run on a wattmeter is of approximately 100 seconds. For a watthour meter, the test run duration is approximately 100 seconds for unity power factor and approximately 200 seconds duration for 0.5 power factor. Prior to the calibration, the meters are energized for between one and four hours at rated voltage and current on one range. A calibration consists of at least two sets of mea- 
surements taken over a minimum period of two days.

For wattmeters, the values of the reported corrections (in watts) generally have uncertainties of $\pm 0.05 \%$ of the full scale range in volt-amperes. For watthour meters, the reported values of the percentage registration generally have uncertainties of $\pm 0.05 \%$ of the indicated value. Special, higher accuracy tests can be arranged for an additional fee. The uncertainties for power or energy measurements in these special tests may be as low as $\pm 0.01 \%$ if the short-term standard deviation of the device under test is appropriately small.

Wattmeter calibrations at other than power frequencies are considered Special Tests and must be arranged on an individual basis. The following limitations apply:

A. Instruments must have separate voltage and current input terminals.

B. The instrument must have a self-contained power indicator, or provide a direct current signal which is proportional to power, or provide an output frequency (TTL compatible) which is proportional to the power.

C. Measurements are generally limited to sinusoidal signals at frequencies between $\mathrm{dc}$ and $100 \mathrm{kHz}$.
Signal levels should not exceed 240 volts and 5 amperes.

D. Instruments will be tested in the as-received condition, and test uncertainties will be based in part on the performance of the instrument during the test.

The Measurement Assurance Program for electric energy is designed to evaluate the performance of energy measuring systems at the customers laboratory. An NBS-owned, transport standard watthour meter of known stability is measured by NBS. It is then shipped to and measured by the customer, and then shipped back to NBS. NBS analyzes the data and provides a report to the customer indicating the total uncertainty of his measurement. This procedure enables customer's standards to be measured relative to NBS standards without the downtime encountered when the customer's standards are shipped to and calibrated by NBS. In addition, and more important to those who calibrate standard watthour meters, the NBS MAP standard can be used by customers to evaluate their measurement process in a convenient and cost-effective way.

The uncertainty of a MAP includes the effects of the long-term and shortterm instabilities of the NBS calibration system, the customer's calibration system, and the transport

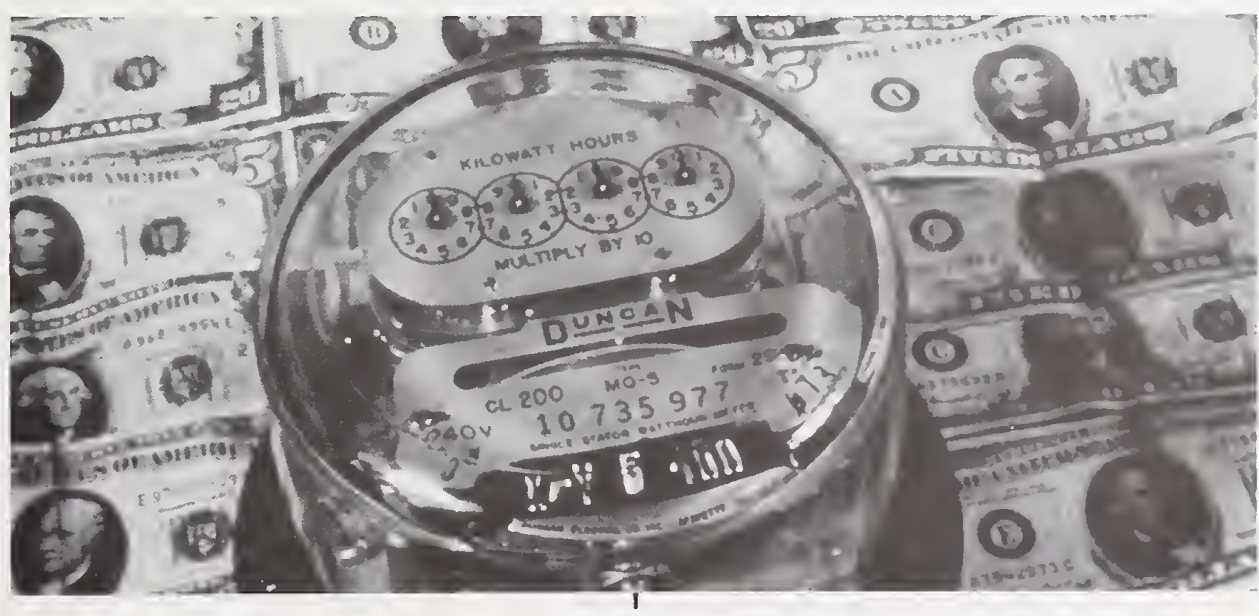

Customer's typical watthour meter. NBS provides reference measurements supporting metering of over $\$ 140$ billion dollars worth of electricity each year. 
standard. Typically, the uncertainty in a well-controlled comparison ranges between $\pm 0.03 \%$ and \pm $0.05 \%$.

The Electrosystems Division of the Center for Electronics and Electrical Engineering maintains an active program of research and development in the area of electric power and energy measurements. For this reason, this

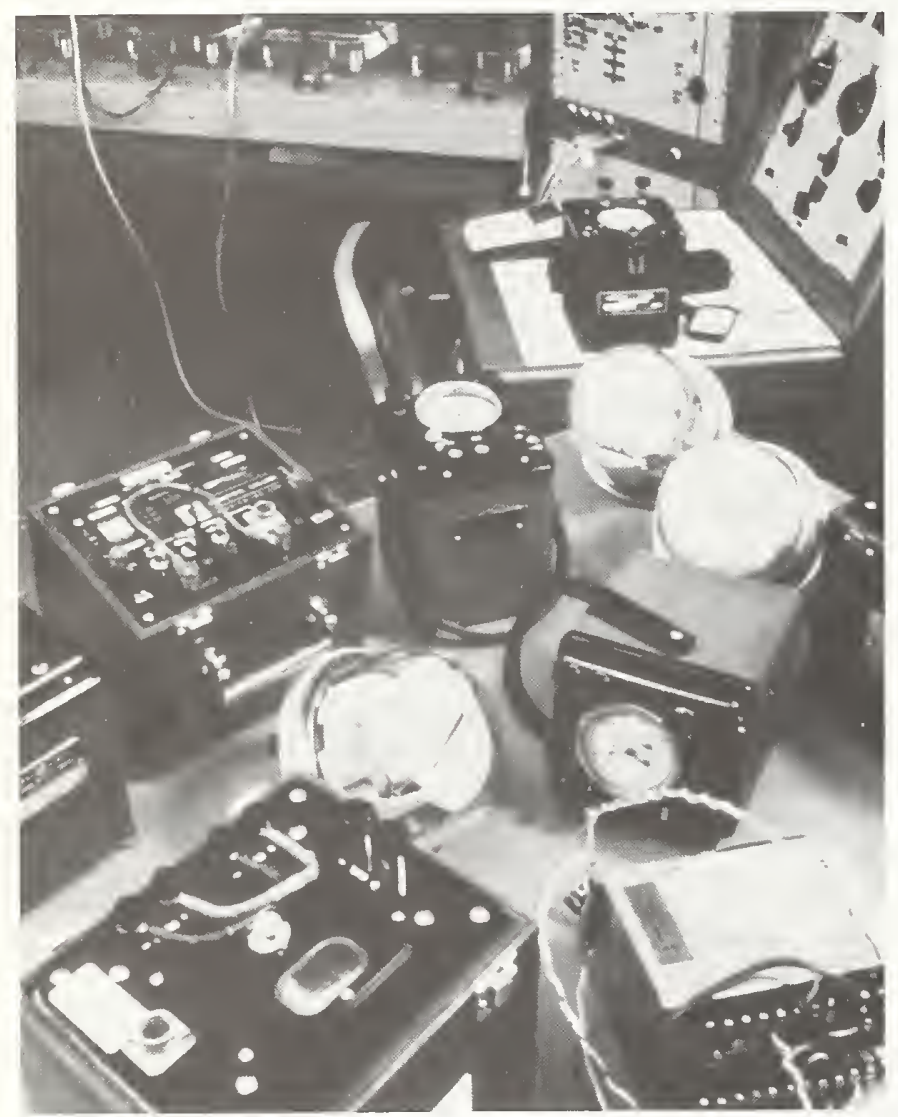

Foreground: NBS reference wattmeters, watthour meters. Background: NBS electrical power and energy measurement system. often enables NBS to provide measurement support for watt and watthour meters beyond that listed in this section. Special tests will generally be conducted when the following conditions prevail:

A. The requested tests are fully developed and documented.

B. There is a significant technical or economic justification for traceability of the test on the item to national standards.

C. There has not been a routine or recurrent need for the test.

\section{References-Power and Energy Measurements, Low Frequency} A Calibration Service for Wattmeters and Watthour Meters, J. D. Ramboz and R. C. McAuliff, Natl. Bur. Stand. (U.S.), Tech. Note 1179, (July 1983).

A Measurement Assurance Program for Electric Energy, N. M. Oldham, Natl. Bur. Stand. (U.S.), Tech. Note 930, (Sept. 1976).

Sampling Techniques for Electric Power Measurement, R. S. Turgel, Natl. Bur. Stand. (U.S.), Tech. Note 870, (June 1975).

Transfer of the Kilowatthour, S. R. Houghton, IEEE Trans. Power Appar. Syst. PAS-94, No. 4, 1232 (JulyAug. 1975).

A Current Comparator System to Establish the Unit of Electrical Energy at $60 \mathrm{~Hz}, \mathrm{~K}$. J. Lentner, IEEE Trans. Instrum. Meas. IM-23, No. 4, 334 (Dec. 1974).

A Wideband Sampling Wattmeter, G. N. Stenbakken, IEEE Trans. Power Apparatus and Systems, PAS-103, No. 10, 2919 (Oct. 1984). NBS Wideband Sampling Wattmeter, G. N. Stenbakken, O. B. Laug, A. G. Perry, B. A. Bell, and T. H. Kibalo, Natl. Bur. Stand. (U.S.), Tech. Note 1221 (in press). 


\section{Microwave Measurements - G. 1 Power Meters, RF and Microwave Electromagnetic Fields Division Center for Electronics and Electrical Engineering}

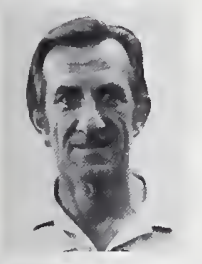

Leon F.

Saulsbery
Tel: 303/497-3970

\section{Technical Contacts:}

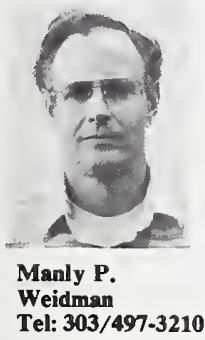

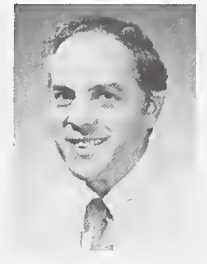

Cletus A. Hoer Tel: 303/497-3705

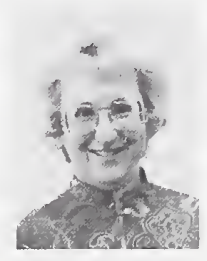

Edna M. Jones Administrative and Logistics Tel: $303 / 497-3753$
Mailing Address: M.C. 723.10, National Bureau of Standards, 325 Broadway, Boulder, CO 80303

Test No. Items

61110S Effective Efficiency and Reflection Coefficient of Coaxial Power Meters at Specified Frequency in Range 0.1 to $10 \mathrm{MHz}$

61111S Each Additional Frequency for 61110S

61120S Calibration Factor, Effective Efficiency, Efficiency Factor and Reflection Coefficient of Coaxial Power Meters at 10,50 , and $100 \mathrm{MHz}$

61121S Calibration Factor, Effective Efficiency, Efficiency Factor and Reflection Coefficient of Coaxial Power Meters at 100,500 , and $1000 \mathrm{MHz}$

61122S Calibration Factor, Effective Efficiency, Efficiency Factor and Reflection Coefficient of Coaxial Power Meters at $10,50,100,500$, and $1000 \mathrm{MHz}$

$61123 S$ Effective Efficiency, Efficiency Factor and Reflection Coefficient of Coaxial Power Meters at 50-MHz Intervals Within $1-2 \mathrm{GHz}$

61124S Effective Efficiency, Efficiency Factor and Reflection Coefficient of Coaxial Power Meters at $100-\mathrm{MHz}$ Intervals Within 2-4 GHz

61125S Effective Efficiency, Efficiency Factor, and Reflection Coefficient of Coaxial Power Meters at 200-MHz Intervals Within 4-8 GHz

61126S Effective Efficiency, Efficiency Factor, and Reflection Coefficient of Coaxial Power Meters at 200-MHz Intervals in the Range 8-12.4 GHz

$61127 \mathrm{~S}$ Effective Efficiency, Efficiency Factor, and Reflection Coefficient of Coaxial Power Meters at $250-\mathrm{MHz}$ Intervals in the Range $12.4-18 \mathrm{GHz}$
Test No. Items

61128S Effective Efficiency, Efficency Factor, and

Reflection Coefficient of Coaxial Power Meters at

$1-\mathrm{GHz}$ Intervals in the Range $1-18 \mathrm{GHz}$

61130S Effective Efficiency and Reflection Coefficient for Rectangular-Waveguide Power Meters at a Specified Frequency Within WR28 or WR42

61131S Each Additional Frequency for 61130S

61140S Effective Efficiency, Efficiency Factor and Reflection Coefficient of Rectangular-Waveguide Power Meters at 6 Frequencies $(2.6,2.85,3.0,3.25$, 3.55 , and $3.95 \mathrm{GHz}$ ) Within $2.6-4 \mathrm{GHz}$ (WR284)

61141S Effective Efficiency, Efficiency Factor and Reflection Coefficient of Rectangular-Waveguide Power Meters at 100-MHz Intervals Within 4.0-5.8 $\mathrm{GHz}$ (WR187)

61142S Effective Efficiency, Efficiency Factor and Reflection Coefficient of Rectangular-Waveguide Power Meters at $100-\mathrm{MHz}$ Intervals Within 5.8-8.0 $\mathrm{GHz}$ (WR137)

61143S Effective Efficiency, Efficiency Factor and Reflection Coefficient of Rectangular-Waveguide Power Meters at 200-MHz Intervals Within 7.0-10.0 $\mathrm{GHz}$ (WR112)

61144S Effective Efficiency, Efficiency Factor and

Reflection Coefficient of Rectangular-Waveguide

Power Meters at 200-MHz Intervals Within 8.2-12.4 $\mathrm{GHz}$ (WR90)

61145S Effective Efficiency, Efficiency Factor and

Reflection Coefficient of Rectangular-Waveguide

Power Meters at 250-MHz Intervals Within 10.0-15.0 $\mathrm{GHz}$ (WR75)

61146S Effective Efficiency, Efficiency Factor and

Reflection Coefficient of Rectangular-Waveguide

Power Meters at 250-MHz Intervals Within 12.4-18.0 $\mathrm{GHz}$ (WR62)

61147S Effective Efficiency, Efficiency Factor and Reflection Coefficient of Rectangular-Waveguide Power Meters at a Specified Frequency Within 18-26.5 GHz (WR42)

61148S Effective Efficiency, Efficiency Factor and Reflection Coefficient of Rectangular-Waveguide Power Meters at a Specified Frequency Within 26.5-40 GHz (WR28)

61150S Effective Efficiency, Efficiency Factor, and Reflection Coefficient of Rectangular-Waveguide Power Meters at a Specified Frequency Within 50-70 $\mathrm{GHz}$ (WR15)

61155S Effective Efficiency, Efficiency Factor and Reflection Coefficient of Rectangular-Waveguide Power Meters of Specified Frequency Within 94-96 $\mathrm{GHz}$ (WR10)

61160S Measurement of Output of Power Reference in TE Power Meters

61190S Special Microwave and RF Power Measurement Services by Prearrangement 
Power Meters, RF and Microwave (61110S-61190S)

The principal emphasis is on those calibrations and other tests requiring such accuracy as can be obtained only by direct comparison with NBS standards. However, in order to maintain efficient utilization of specialized equipment and skilled personnel, when workload permits NBS may calibrate devices requiring lesser accuracy but suitable for working standards in a plant or laboratory. Also, upon request, special measurements may be made. Inquiries should describe clearly the measurement desired and indicate the scientific or economic basis for the requirement.

Thermistor-type bolometer units have shown adequate stability over long periods of time (approximately $10 \mathrm{yr}$.) and warrant long recalibration intervals. Two- or three-year recalibration intervals are recommended once the stability of a bolometer unit has been verified. Thermoelectric power-meter sensor units are calibarated at a nominal level of $10 \mathrm{~mW}$. No linearity checks are performed.

Assistance is available for applying published, technically valid measurement techniques in lieu of previously available NBS calibration services for coaxial and waveguide calorimeters, power meters, and bolometer coupler units. The attainable limits of measurement uncertainty using these techniques are comparable to those of the previously available calibration services for these devices.

The calibration reports give the amplitude of the reflection coefficient and either the effective efficiency, efficiency factor, or the calibration factor depending on the type of sensor and frequency range.

\section{Definitions:}

Calibration results are reported in the following units:

Effective Efficiency $\eta_{\mathrm{e}}$

The effective efficiency $\eta_{\mathrm{e}}$ is the ratio of the bolometrically substituted dc power in the bolometer unit to the net $\mathrm{cw}$ rf microwave power absorbed by the bolometer unit.

Bolometrically Substituted dc Power

The bolometrically substituted dc power is the change in dc (or audio frequency) bias power required to maintain the resistance of the bolometer element at a constant value following the application of $\mathrm{rf}$ or microwave power.

Calibration Factor, $\mathbf{K}_{\mathbf{B}}$

The calibration factor is the ratio of the bolometrically substituted dc power in the bolometer unit to the $\mathrm{cw}$ rf microwave power incident upon the bolometer unit. $\mathrm{K}_{\mathrm{B}}=\eta_{\mathrm{e}}\left(1-|\Gamma|^{2}\right)$.

Efficiency Factor

TE sensor-power meter units: Efficiency factor $(\mathrm{mW} / \mathrm{V})$ is the ratio of the net $\mathrm{rf}$ microwave power absorbed by the sensor head to the dc voltage at the recorder output of the meter on the $10 \mathrm{~mW}$ range.

Reflection Coefficient Amplitude, $|\Gamma|$

The reflection coefficient amplitude is the ratio of the reflected wave voltage amplitude to the incident wave voltage amplitude. The reflection coefficient amplitude is included in the Report of Calibration for all power measurements. All calibrations are performed under typical ambient laboratory conditions at $23^{\circ} \mathrm{C}$, and an atmospheric pressure of approximately $8.4 \pm 0.2 \times 10^{4} \mathrm{~Pa}$ at Boulder, Colorado. Services at ambient conditions other than these are not provided. Also, the power applied to any device being calibrated does not exceed 10 $\mathrm{mW}$.

\section{Coaxial Power Meters and Sensors (61110S-61127S)}

Only bolometer units designed for low frequency operation will be calibrated below $100 \mathrm{MHz}$.

Most TE sensor units can be calibrated below $100 \mathrm{MHz}$. 
Specify frequency in range 0.1 to $10 \mathrm{MHz}$ for special low frequency bolometer units (Test No. 61111S). Values for $\eta_{\mathrm{e}}$ and $|\Gamma|$ are calculated from voltage and resistance measurements.

$\eta_{\mathrm{e}}=\left(\mathbf{P}_{\mathrm{dc}}\right) /\left(\mathbf{P}_{\mathrm{r}}\right)$, where $P_{\mathrm{rf}}=V^{2} / \mathbf{R}_{\mathrm{P}}$, where $R_{\mathrm{P}}$ is the parallel equivalent resistance and $P_{d c}$ is the bolometrically substituted dc power in the bolometer. The uncertainty in measuring $\eta_{e}$ is \pm 0.3 percent.

Measurements are made at the following frequencies:

$\begin{array}{ll}\text { Range } & \text { Frequency or Interval } \\ 10-100 \mathrm{MHz} & 10,50, \& 100 \mathrm{MHz} \\ 100-1000 \mathrm{MHz} & 100,500, \text { \& } 1000 \mathrm{MHz} \\ 1-2 \mathrm{GHz} & 50 \mathrm{MHz} \text { intervals } \\ 2-4 \mathrm{GHz} & 100 \mathrm{MHz} \text { intervals } \\ 4-8 \mathrm{GHz} & 200 \mathrm{MHz} \text { intervals } \\ 8-12.4 \mathrm{GHz} & 200 \mathrm{MHz} \text { intervals } \\ 12.4-18 \mathrm{GHz} & 250 \mathrm{MHz} \text { intervals }\end{array}$

Measurement of the output power from the reference port on TE power meters can also be made.

The estimated limits of uncertainty in effective efficiency and calibration factor will vary from approximately \pm 0.5 to 1.5 percent depending on the frequency and the characteristics of the unit being calibrated such as connector type, reflection coefficient, and repeatability.

Waveguide Power Meters and Sensors (61130S-61155S)

Measurements of effective efficiency, efficiency factor and reflection coefficient are made for various waveguide sizes as follows:

\begin{tabular}{lll}
$\begin{array}{l}\text { Wave- } \\
\text { guide }\end{array}$ & $\begin{array}{c}\text { Frequency } \\
\text { Range } \\
\text { (GHz) }\end{array}$ & \multicolumn{1}{c}{$\begin{array}{c}\text { Measurement } \\
\text { Frequency or } \\
\text { Interval }\end{array}$} \\
\hline WR284 & $2.6-4.0$ & $\begin{array}{l}6 \text { frequencies: } 2.6, \\
2.85,3.0,3.25,\end{array}$ \\
& & $\begin{array}{l}3.55,3.95 \mathrm{GHz} \\
\text { 100 MHz intervals }\end{array}$ \\
WR187 & $4.0-5.8$ & $100 \mathrm{MHz}$ intervals \\
WR137 & $5.8-8.0$ & 200 MHz intervals \\
WR112 & $7.0-10.0$ & 200 MHz intervals \\
WR90 & $8.2-12.4$ & 250 MHz intervals \\
WR75 & $10.0-15.0$ & 250 MHz intervals \\
WR62 & $12.4-18.0$ & Specify frequency \\
WR42 & $18-26$ & Specify frequency \\
WR28 & $26.5-40$ & Not Available \\
WR22 & $33-50$ & Not Available \\
WR19 & $40-60$ & Specify frequency \\
WR15 & $50-70$ & Specify frequency
\end{tabular}

Effective efficiency is measured for bolometer units only. Efficiency factor is measured for TE sensor-power meter units only. The estimated limits 
of uncertainty in effective efficiency will vary from 1 to 3 percent depending on the frequency and the characteristics of the unit being calibrated.

\section{References-Power Meters, RF and Microwave}

A Refined X-Band Microwave Microcalorimeter, G. Engen, J. Res., Natl. Bur. Stand. (U.S.), 63C, 77 (1959).

WR-15 Microwave Calorimeter and Bolometer Unit, M. Harvey, Natl. Bur. Stand. (U.S.), Tech. Note 618 (May 1972).

WR-10 Millimeter Wave Microcalorimeter, $\mathrm{M}$. Weidman, and $\mathbf{P}$. Hudson, Natl. Bur. Stand. (U.S.), Tech. Note 1044 (June 1981).

A Bolometer Mount Efficiency Measurement Technique, G. Engen, J. Res. Natl. Bur. Stand. (U.S.), 65C, 113 (Apr.-June 1961).

A Transfer Instrument for the Intercomparison of Microwave Power Meters, G. Engen, IRE Trans. Instrum. Meas. 19, 202 (Sept. 1960).

A Semiautomated Six-Port for Measuring Millimeter-Wave Power and Complex Reflection Coefficient, $\mathbf{M}$. Weidman, IEEE Trans. Micro. Theory Tech. MTT-25, 12 (Dec. 1977).

Performance Characteristics of an Automated Broad-Band Bolometer Unit Calibration System, E. Komarek, IEEE Trans. Micro. Theory Tech. MTT-25, 12 (Dec. 1977).

Application of an Arbitrary Six-Port Junction to Power Measurement Problems, G. Engen, and C. Hoer, IEEE Trans. Instrum. Meas. IM-21, 470 (Nov. 1972).

Accurate Microwave High Power Measurements Using a Cascaded Coupler Method, K. E. Bramall, J.
Res. Natl. Bur. Stand. (U.S.), 75C, Nos. 3 and 4, 185 (July-Dec. 1971). Bolometric Microwave Power Calibration Techniques at the National Bureau of Standards, R. F. Desch, and R. E. Larson, IEEE Trans. Instrum. Meas. IM-12, 1 (June 1963). A Method of Determining the Mismatch Correction in Microwave Power Measurements, G. Engen, IEEE Trans. Instrum. Meas. IM-17, 4 (December 1968).

Theory of UHF and Microwave Measurements Using the Power Equation Concept, G. Engen, Natl. Bur. Stand. (U.S.), Tech. Note 637 (April 1973).

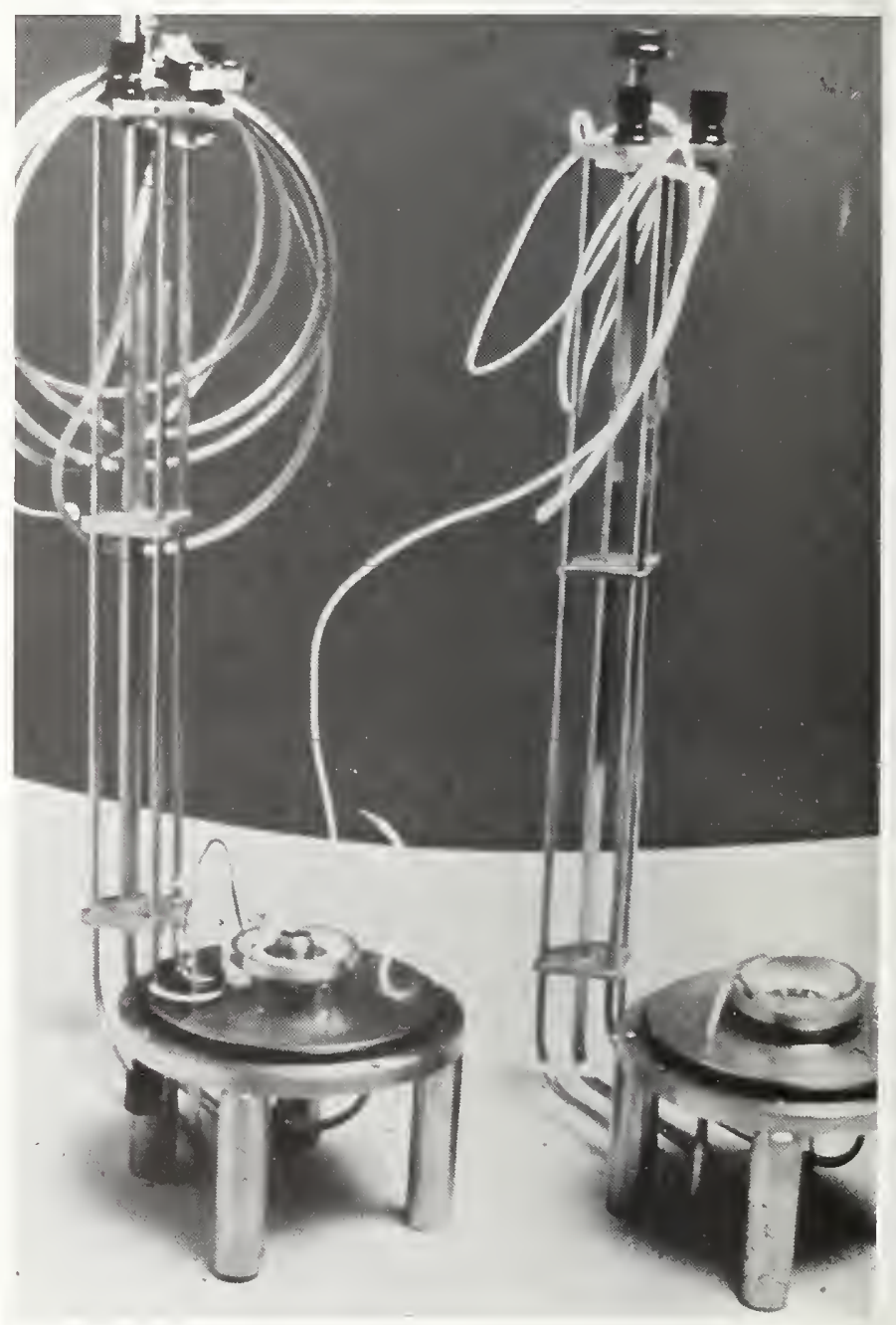

Microcalorimeter reference for microwave-power measurement. 
Microwave Measurements

G.2 Attenuators, RF and Microwave Electromagnetic Fields Division Center for Electronics and Electrical Engineering

\section{Technical Contacts:}

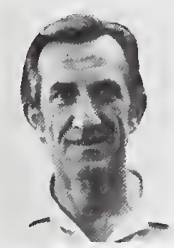

Leon F.

Saulsbery

Tel: 303/497-3970

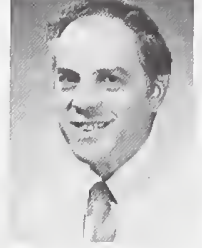

Cletus A. Hoer Tel: 303/497-3705

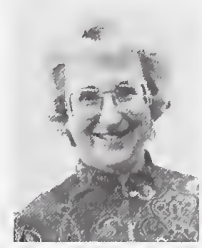

Edna M. Jones Administration and Logistics Tel: 303/497-3753

Mailing Address: M.C. 723.10, National Bureau of Standards, 325 Broadway, Boulder, CO 80303

Test No. Items

61210C Coaxial Fixed and Variable Attenuators Measured by ANA, Frequency Range 0.1 to $18 \mathrm{GHz}$, Attenuation 0 to $60 \mathrm{~dB}$

61211C Coaxial Fixed and Variable Attenuators, Measured at $30 \mathrm{MHz}$, Attenuation 0 to $120 \mathrm{~dB}$

61215C Waveguide Circular (Below Cutoff) (Piston) Attenuator, Coaxial Connector, Measured at $30 \mathrm{MHz}$, Attentuation 0-140 dB (Total Insertion Loss)

$61220 \mathrm{~S}$ Special Attenuation Measurements in Range $30 \mathrm{kHz}$ to $10 \mathrm{MHz}$, GR 874 Connectors, 0-10 dB

61230C Variable Rectangular Waveguide Attenuators, Attenuation Difference, Specify Frequencies for Waveguide Sizes, WR28, WR42, WR62, WR90, WR137, WR187, WR284, 0-50 dB

61240S Special Attenuation Measurements of Three-Port and Two-Port Devices at $1.25 \mathrm{MHz}, 0-6 \mathrm{~dB}$

61250 S Special Attenuation Measurements by Prearrangement

Attenuators, $\mathbf{R F}$ and Microwave (61210C-61250S)

Specific attenuation measurements currently available are listed below. Measurements not listed may possibly be provided (61250S) if sufficient advance notice is given and resources

permit. The cost of such services must be negotiated and will, in general, be higher than other established services. Consultation by telephone or written correspondence is suggested. Often a measurement technique can be suggested that will permit the customer to perform his calibrations inhouse with appropriate reference to other NBS supported standards.

Fixed and Variable Coaxial Attenuators (61210C and 61211C)

Coaxial fixed and variable attenuators are measured on the NBS modified automatic network analyzer (ANA) over the frequency range 0.1 to 18 $\mathrm{GHz}$.

All measurements are made by the substitution method, which requires that the connectors used be asexual or that the attenuator have a male connector at one port and a female at the other. If an adapter is required to comply with the foregoing, it must be supplied with the attenuator. The combination will be calibrated as one unit.

In addition to measurements performed on the ANA, measurements at a fixed frequency of $30 \mathrm{MHz}$ are available referenced to the NBS waveguide below cutoff standard at this frequency.

Coaxial attenuators are normally measured in a system having a characteristic impedance of $50 \mathrm{ohms}$. Limits of uncertainty depend upon the VSWR of the individual attenuator, 
quality of the attenuator and connectors, and the magnitude of the attenuation. Typical systematic uncertainties range from 0.03 to $0.05 \mathrm{~dB} / 10$ $\mathrm{dB}$ of attenuation up to $60 \mathrm{~dB}$.

\section{Waveguide Circular Piston Attenuator} Measurements at $30 \mathrm{MHz}$ (61215C)

Incremental attenuation is the change in attenuation of an adjustable attenuator between a reference setting (usually zero) and any other setting. The same restraints on system conditions apply as for attenuation. The term "differential attenuation" is sometimes applied to this case and usually refers to two non-zero settings.

Measurements on waveguidebelow-cutoff (piston) attenuators are performed at $30 \mathrm{MHz}$. These attenuators are normally quite stable and seldom need recalibration unless damaged or mechanically worn. Since any laboratory can perform independent checks to determine continuing repeatability and linearity of attenuation, we do not recommend periodic NBS recalibrations. This recommendation is also made because more damage can be suffered in transit than in daily use. In any measurement, the maximum power delivered to the test attenuator will not exceed $400 \mathrm{~mW}$. If the attenuator cannot tolerate this power level, some reduction of measurement range will be required.

Piston attenuators are normally calibrated in a system having a characteristic impedance of $50 \mathrm{ohms}$. Since only measurements of incremental attenuation are made on this type of attenuator, Type BNC, C, TNC, and similar connectors are acceptable, but precision connectors are preferred to reduce leakage. Limits of uncertainty depend upon the quality of the attenuator and connectors, as well as upon the VSWR of the attenuator, and the magnitude of attenuation. Typical systematic uncertainties range from 0.003 to $0.005 \mathrm{~dB} / 10 \mathrm{~dB}$ of attenuation. Total insertion loss must be less than 140 dB.

\section{Special Attenuation Measurements below $10 \mathrm{MHz}$ (61220S)}

Special tests may be performed over the frequency range $30 \mathrm{kHz}$ to 10 $\mathrm{MHz}$ using the voltage ratio measurement technique. These tests are limited to attenuators with GR 874 connectors and to $10 \mathrm{~dB}$ maximum.

\section{Rectangular Waveguide Variable Attenuators (61230C)}

Variable waveguide (usually rotary vane) attenuators are calibrated by the IF- substitution technique referenced to $30 \mathrm{MHz}$, direct rf substitution, or on the NBS modified ANA, as appropriate. Service is available for frequencies corresponding to waveguide sizes WR28, WR42, WR62, WR90, WR137, WR187, and WR284.

Requested measurements should be for a minimum number of settings at a single band-center frequency and be sufficient to determine the characteristics of the device. Previously calibrated units should not be resubmitted unless tests performed by the user indicate a shift in values.

The uncertainty is a function of resettability, internal leakage, and quality of flanges. Except for measurements made on the NBS modified ANA, the uncertainty is also a function of the VSWR of the waveguide ports. Devices submitted should be in the best possible condition to justify calibration and insure long-term stability of measured values. Typical systematic uncertainties range from 0.03 to $0.05 \mathrm{~dB} / 10 \mathrm{~dB}$ of attenuation up to $50 \mathrm{~dB}$.

\section{Special Attenuation Measurements at $1.25 \mathrm{MHz}$ (61240S)}

A provisional service is now available for attenuation measurements of special three-port devices at $1.25 \mathrm{MHz}$. 
A measurement system has been developed to measure the change in the ratio $\left|S_{21} / S_{31}\right|$ of special stable twoposition three- port devices, sometimes called voltage doublers, at 1.25 $\mathrm{MHz}$. The device must have an input for a $1.25 \mathrm{MHz}$ source (port 1), a reference output (port 3), and an output (port 2) with a level switchable to two different values. The two levels of the bi-level output have a nominal ratio of $6.0206 \mathrm{~dB}$.

If $P_{r 1}$ is the reference power level when the bi-level output is at level 1 $\left(P_{b 1}\right)$, and $P_{r 2}$ is the reference power level when the bi-level output is at level $2\left(P_{b 2}\right)$, then parameter measured is given by the following equation:

$$
10 \log _{10}\left(\frac{\mathbf{P}_{\mathrm{bl}}}{\mathbf{P}_{\mathrm{r} 1}}\right)-10 \log _{10}\left(\frac{\mathbf{P}_{\mathrm{b} 2}}{\mathbf{P}_{\mathrm{r} 2}}\right) \mathrm{dB}
$$

where the subscripts (1), and (2) refer to the switch positions 1 and 2, respectively. The above is equivalent to

$$
10 \log _{10}\left|\frac{S_{21}(1) / S_{31}(1)}{S_{21}(2) / S_{31}(2)}\right| 2
$$

The loads presented to the two outputs are $50 \mathrm{ohms}$. The device must allow the signal input to be of such strength that the bi-level output is at least $10 \mathrm{~mW}$ in the high level position.

The total uncertainty of the measurement system in measuring a $6 \mathrm{~dB}$ change in attenuation is estimated to have a systematic error no greater than $5 \mu \mathrm{B}$, and random error of about $3 \mu \mathrm{B}$, where $1 \mu \mathrm{B}=10^{-5} \mathrm{~dB}$ or about $2.3 \mathrm{ppm}$ of the power ratio. Two-port step attenuators having a nominal change in attenuation of $6 \mathrm{~dB}$ can also be measured by this system at $1.25 \mathrm{MHz}$.

\section{References-Attenuators, RF and Microwave}

Application of Waveguide and Circuit Theory to the Development of
Accurate Microwave Measurement Methods and Standards, R. W. Beatty, Natl. Bur. Stand. (U.S.), Monogr. 137 (Aug. 1973).

Basic Theory of Waveguide Junctions and Introductory Microwave Network Analysis, D. M. Kearns and R. W. Beatty, Intl. Ser. of Mongr. in Electromag. Waves, 13, 59, Pergammon Press, New York, NY (1967).

The Six-Port Reflectometer: An Alternative Network Analyzer, G. F. Engen, IEEE Trans. Micr. Theory Tech., MTT-25, 1075 (Dec. 1977).

A Network Analyzer Incorporating Two Six-Port Reflectometers, C. A. Hoer, IEEE Trans. Micr. Theory Tech., MTT-25, 1070 (Dec. 1977). “Thru-Reflect-Line": An Improved Technique for Calibrating the Dual Six-Port Automatic Network Analyzer, G. F. Engen and C. A. Hoer, IEEE Trans. Micr. Theory Tech., MTT-27, 987 (Dec. 1979).

Effects of Connectors and Adapters on Accurate Attenuation Measurements at Microwave Frequencies, R. W. Beatty, IEEE Trans. Instrum., IM-13, 272 (Dec. 1984).

Insertion Loss Concepts, R. W. Beatty, Proc. IEEE 55, 6, 663 (June 1964).

RF Attenuation, D. Russell, Proc. IEEE 55, 6, 942 (June 1967).

Specifications and Test Methods for Fixed and Variable Attenuators, dc to $40 \mathrm{GHz}$ IEEE Standard 474 (1973). 
Microwave Measurements

G.3 Coaxial and Waveguide Terminations, Reflection Coefficients

Electromagnetic Fields Division

Center for Electronics and Electrical Engineering

Technical Contacts:
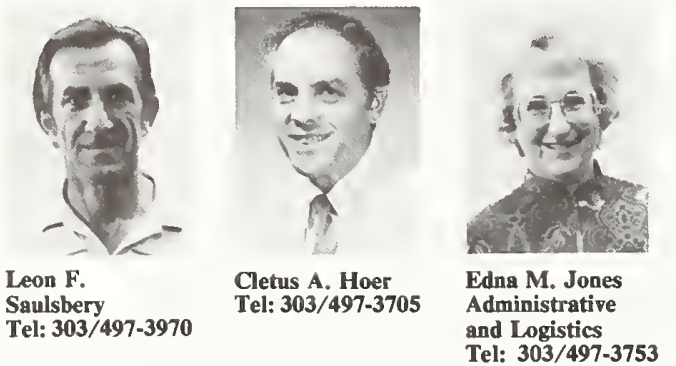

Mailing Address: M.C. 723.10, National Bureau of Standards, 325 Brnadway, Boulder, CO 80303

\section{Test No. Items}

61310C Complex Reflection Coefficient, Impedance, and

Voltage Standing Wave Ratio of Coaxial

Terminations by ANA Within 0.1 to $18 \mathrm{GHz}, \Gamma: 0.01$ to $0.6, \mathrm{Z}: 12.5-200 \Omega$

61320C Magnitude of Reflection Coefficient of Rectangular Waveguide Reflectors (Mismatches) with Standard Flange Connectors, Specify Frequency for Waveguide Sizes WR28, WR42, WR62, WR90, WR137, WR187, and WR284, Г: 0.025 to 0.2

61330C Magnitude of Reflection Coefficient of Nonreflecting Waveguide Ports and Matched Loads, Specify Frequency for Waveguide Sizes WR42, WR62, WR90, WR137, WR 187, Г: 0.0001 to 0.025

61331S Same as 61330C; Special Services for WR15, WR28, WR284 Only on Critical Need Basis
Coaxial and Waveguide Terminations, Reflection Coefficient (61310C-61331S)

Services provided in this category are for passive devices over the frequency range from $10 \mathrm{MHz}$ to 95 $\mathrm{GHz}$. Available calibration frequencies are listed in the test descriptions. Highest accuracy is obtained only for standards equipped with precision coaxial connectors or waveguide flanges. Standards submitted for calibration should be in good repair and, except for very minor cleaning of connector surfaces, should require no recalibration maintenance. NBS does not provide repair services. Items received requiring maintenance will be returned to the sender and a handling fee will be charged.

\section{Coaxial Terminations (61310C)}

Services are available for complex impedance, reflection coefficient, and voltage standing wave ratio (VSWR). Measurements on coaxial devices in the frequency range 0.1 to $18 \mathrm{GHz}$ are made on the NBS modified Automatic Network Analyzer (ANA) for $\Gamma$ in the range 0.01 to 0.6 and $Z$ in the range 12.5 to $200 \mathrm{ohms}$. The calibration services usually apply to determining the reflection coefficient or VSWR of standard terminations and mismatches. Typical uncertainties are \pm 0.005 to 0.01 in reflection coefficient.

\section{Waveguide Terminations} (61320C-61331S)

Waveguide terminations are measured in a reflectometer system relative to a 
quarter-guide wavelength short circuit and a precision transmission line.

Some measurements in waveguide bands below $18 \mathrm{GHz}$ can be performed on the NBS modified ANA while all of those above $18 \mathrm{GHz}$ are performed on manual fixed- frequency systems. (See test descriptions above.) Typical uncertainties are $\pm(0.001+0.0035 \Gamma)$.

Waveguide terminations are usually quite stable and need not be resubmitted unless tests performed by the user indicate a shift in values. The terminations must be fitted with standard waveguide flange connectors. The faces of these flanges should be machined flat and smooth and should not contain protrusions or indentations. Considerable care must be exercised in keeping the mating connector flange surfaces smooth and clean. Accurate alignment of the interior surfaces of the joining waveguides at the flange junction also is very important. The back of the flange which makes contact with the connecting bolts should be nominally flat and free of soft materials including paint. The connecting holes of the flange should be symmetrically and accurately aligned to the rectangular waveguide opening. These precautions must be observed when using a waveguide termination in a precision measurement system.

Assigned limits of uncertainty depend upon the quality of the flanges as well as the numerical value of reflection coefficient magnitude. Systematic errors assigned by NBS vary with waveguide size and depend on the absolute dimensions of the precision transmission lines.

References-Coaxial and Waveguide Terminations, Reflection Coefficients An NBS-Developed Automatic Network Analyzer, W. Little, et al., Conf. on Prec. Electromag. Meas., Boulder, CO., Digest, 130 (June 1976).

A Guide to the Use of the Modified Reflectometer Technique of VSWR Measurement, W. J. Anson, J. Res. Natl. Bur. Stand. (U.S.), 65C, 4, 217 (Oct.-Dec. 1961). (The measurement technique utilized in reflection measurements is described in this paper.) Millimeter Attenuation and Reflection Coefficient Measurement System, B. C. Yates and W. Larson, Natl. Bur. Stand. (U.S.), Tech. Note 619 (1972). 
Microwave Measurements

\section{G.4 Phase Shifters, RF and Microwave Electromagnetic Fields Division Center for Electronics and Electrical Engineering}

Technical Contacts:
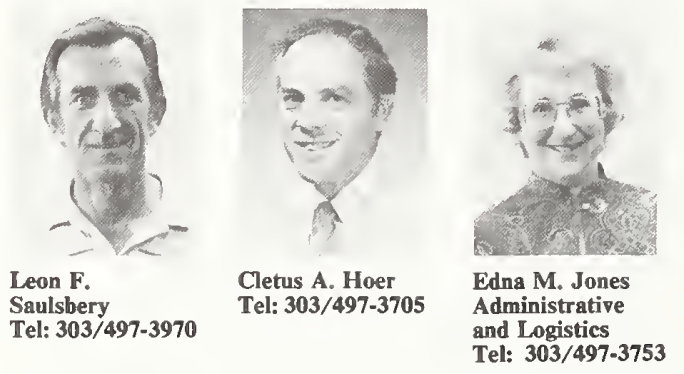

Mailing Address: M.C. 723.10, National Bureau of Standards, 325 Broadway, Boulder, CO 80303

\begin{tabular}{|c|c|}
\hline & \\
\hline $410 \mathrm{C}$ & $\begin{array}{l}\text { Coaxial Fixed and Variable Phase Shifters; } \\
\text { Characteristic Phase Shift Difference; Precision } \\
\text { Connectors; Measured at } 30 \mathrm{MHz} \text {, Range } 0-360^{\circ}\end{array}$ \\
\hline $61411 \mathrm{C}$ & $\begin{array}{l}\text { Coaxial Fixed and Variable Phase Shifters; } \\
\text { Characteristic Phase Shift Difference; } \\
\text { Precision Connectors; Measurement by ANA over } \\
1-18 \mathrm{GHz} \text {, Range } 0-360^{\circ}\end{array}$ \\
\hline $61420 \mathrm{C}$ & $\begin{array}{l}\text { Variable Rectangular Waveguide Phase Shifters; } \\
\text { Phase Shift Difference; VSWR < } 1.4 \text {; Specify } \\
\text { Frequencies for Waveguide Sizes WR } 62 \text {, WR } 90 \text {, } \\
\text { WR137, WR 187, WR284, Range } 0-720^{\circ}\end{array}$ \\
\hline $61450 S$ & Special Tests of Phase Shifters by Prearrangement \\
\hline
\end{tabular}

\section{Phase Shifters, RF and Microwave} (61410C-61450S)

The specific phase shift services listed below are available on a limited basis depending on other demands and staff availability. Measurements not listed may possibly be provided if sufficient advance notice is given. The cost of such services must be negotiated and will, in general, be higher than the established phase shift services. Consultation by telephone or written correspondence is suggested. Often a measurement technique can be suggested that will permit the customer to perform calibrations in-house with appropriate reference to other NBSsupported standards.

\section{Coaxial Phase Shifters (61410C and 61411C)}

Fixed and variable coaxial two-ports are measured on the NBS modified Automatic Network Analyzer (ANA) over the frequency range 0.1 to 18 $\mathrm{GHz}$. In addition, measurements can be performed with reference to a precision variable air line at $30 \mathrm{MHz}$. Because of the specialized nature of coaxial phase shifting components, prior discussions should be held with NBS staff before submission of any devices to NBS. Items to be calibrated must be fitted with connectors having a known plane of reference such as sexless precision connectors, or Type $\mathbf{N}$ connectors meeting Mil. Std. C39012. The phase angle measured is $\Psi+360 \mathrm{n}$ where $\mathrm{n}$ is an integer. The value of $n$ is not determined.

Limits of uncertainty are:

\begin{tabular}{lll} 
Frequency & Range & Uncertainty \\
\hline $30 \mathrm{MHz}$ & $0-360^{\circ}$ & $0.1-0.5^{\circ}$ \\
$0.1-18 \mathrm{GHz}$ & $0-360^{\circ}$ & $0.5^{\circ}$
\end{tabular}

These limits of uncertainty are the sums of systematic and random er-

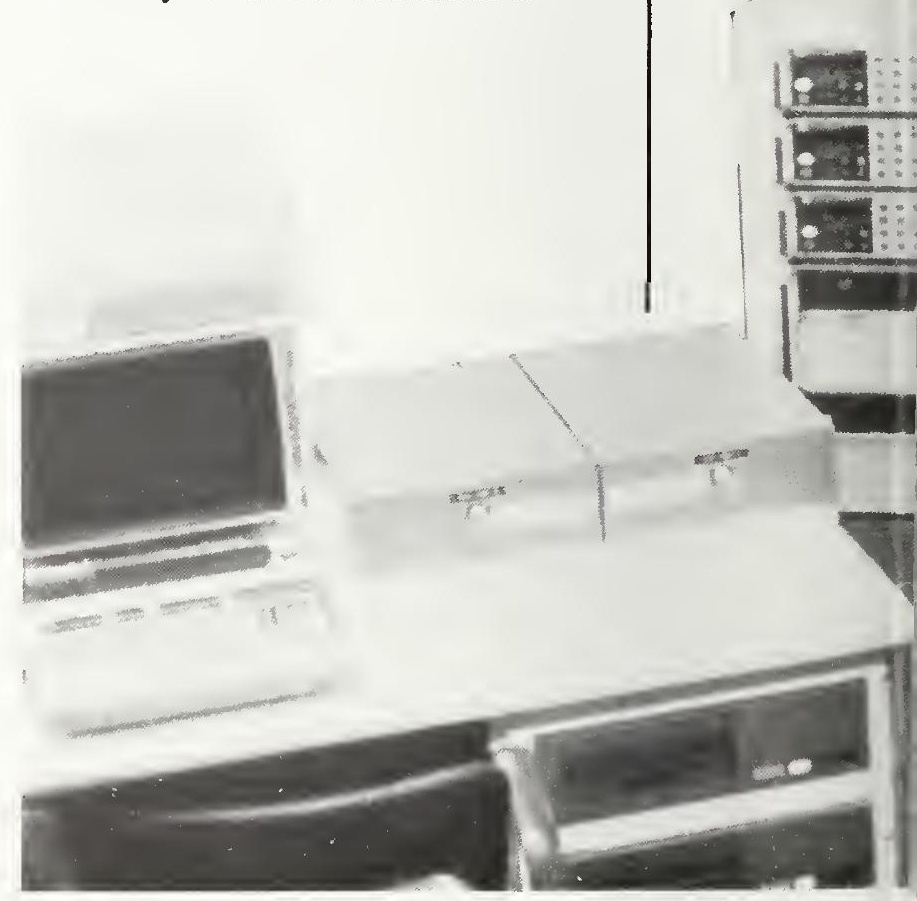


rors. The values are dependent upon the particular standard under calibration. The VSWR of the device and the quality of the connectors will contribute to the calibration uncertainties.

\section{Phase Shifters (61420C)}

For a rectangular waveguide, the measurement services are limited to phase shift difference at frequencies below $18 \mathrm{GHz}$. Measurements are made on continuously variable waveguide phase shifters with the zero value of the scale as the normal reference position. Since 360 mechanical degrees of rotation represent 720 electrical degrees, attention should be given to the relationship between dial indication and actual mechanical position of the rotating vane assembly.

The uncertainty is approximately the same as for coaxial devices.

\section{References-Phase Shifters, RF and Microwave}

UHF and Microwave Phase Shift Measurements, D. A. Ellerbach, Proc. IEEE 55, 6, 960 (June 1967).
New generation of reference microwave measurements: NBS dual six-port automatic network analyzer covering frequency range of $100 \mathrm{kHz}-1 \mathrm{GHz}$. Two sets of six ports-one on desk at left and one on console at right-are needed to cover this frequency range. 
Microwave Measurements

- G.5 N-Port Scattering Measurements Electromagnetic Fields Division Center for Electronics and Electrical Engineering

\section{Technical Contacts:}

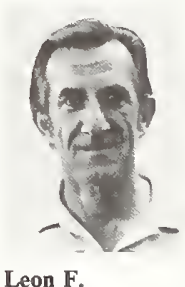

Leon $\mathbf{F}$.

Saulsbery

Tel: 303/497-3970
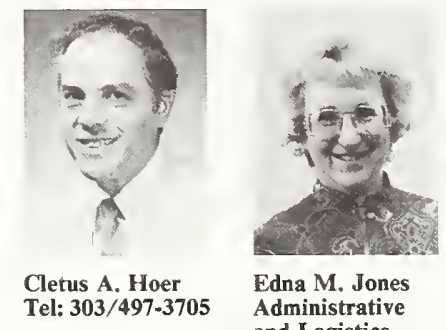

Edna M. Jones

Administrative

and Logistics

Tel: $303 / 497-3753$

Mailing Address: M.C. 723.10, National Bureau of Standards, 325 Broadway, Boulder, CO 80303

Test No. Items

61520S Linear, Reciprocal 2-Port Devices, 2-18 GHz

Scattering Parameters of Linear N-Port Devices-General

\section{Information}

The signal levels at the ports of a linear network having $\mathrm{N}$-ports is dependent on the impedances or loads presented to each of the N-ports. For example, the power at a load connected to a source of given level through an attenuator is not only dependent on the properties of the attenuator but on the generator and load impedances as well. In this example, insertion loss, as defined by the IEEE Dictionary of Electrical and Electronics Terms, is the ratio of the power in the load before insertion of the attenuator to that after insertion. Insertion loss, as given in this general definition, is a very poor measure of the property of the attenuator as it is generator and load dependent. To alleviate this problem, the parameters of the N-port network are measured when the ports are presented with reflectionless terminations. With such terminations, the network is said to be measured under matched conditions.

A particularly useful description of $\mathrm{N}$-port networks at higher frequencies where reflections are of importance in systems is the scattering of Sparameter description. It is couched 
in terms of the incident and reflected waves at each of the N-ports. The Sparameters have magnitude and phase and are defined as:

$$
S_{i j}=\frac{\text { emergent wave at port } i}{\text { incident wave at port } j}
$$

for $\mathrm{i} . \mathrm{j}=1,2 \ldots \mathrm{N}$, where all ports other than the input port $\mathrm{j}$ are terminated with non-reflecting (matched) terminations. Thus, for a two-port attenuator, $\left|S_{21}\right|^{2}$ is the insertion loss and the argument of $S_{21}$ is the insertion phase shift from port 1 to port 2 under matched conditions. $S_{11}$ and $\mathrm{S}_{22}$ are the respective reflection coefficients at ports 1 and 2; again, under matched conditions.

For a one-port, there is only a single $S$-parameter, $S_{11}$, where $S_{11}$ is the reflection coefficient, $\Gamma$.

The S-parameter fully describes the network (as a black box) since, given the S- parameters, one can completely determine the relative signal relationships at the ports for any set of terminations presented to the ports be they matched or not.

\section{Linear, Reciprocal 2-Port Devices (61520S)}

Presently, routine calibrations are provided only for linear, reciprocal, one- port and two-port networks and then only over limited frequency (2-18 GHz) and parameter ranges. NBS plans to greatly extend the coverage in the near future by providing all S-parameter measurements at most frequencies from $100 \mathrm{kHz}$ to 100 $\mathrm{GHz}$, and for $\left|\mathrm{S}_{12}\right|$ up to approximately $60 \mathrm{~dB}$ using 6-port ANA's.

References-Scattering Parameters of Linear N-Port Devices

The Six-Port Reflectometer: An Alternative Network Analyzer, G. F. Engen, IEEE Trans. Micr. Theory Tech., MTT-25, 1075 (Dec. 1977).

A Network Analyzer Incorporating Two Six-Port Reflectometers, C. A. Hoer, IEEE Trans. Micr. Theory Tech., MTT-25, 1070 (Dec. 1977).

“Thru-Reflect-Line": An Improved Technique for Calibrating the Dual Six-Port Automatic Network Analyzer, G. F. Engen, and C. A. Hoer, IEEE Trans. Micr. Theory Tech., MTT-27, 987 (Dec. 1979). 


\section{Noise Temperature Measurements Electromagnetic Fields Division Center for Electronics and Electrical Engineering}

\section{Technical Contacts:}

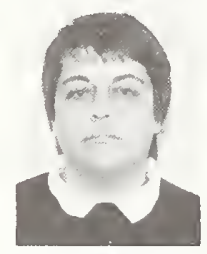

Sunchana Perera Tel: $303 / 497-3546$

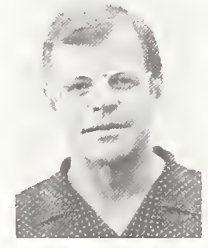

William C. Daywitt Tel: $303 / 497-3720$

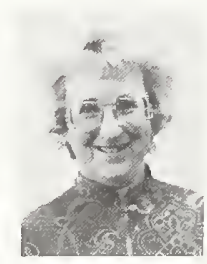

Fdna M. Jones Administrative and Logistics Tel: $303 / 497-3753$
Mailing Address: M.C. 723.10, National Bureau of Standards, 325 Broadway, Boulder, CO 80303

\section{Test No. Items}

62020S Special Noise Temperature Measurements (Electromagnetic) by Prearrangement

62100 S Noise Temperature of Coaxial Noise Generator, Type $\mathrm{N}$ Precision or $14 \mathrm{~mm}$ Connectors, at $30 \mathrm{MHz}$ or 60 $\mathrm{MHz}$; VSWR < 1.2, Temperature: $77 \mathrm{~K}-15,000 \mathrm{~K}$, ENR $<17 \mathrm{~dB}$

62101S Each Additional 62100S Item Tested at Same Frequency

62110S Noise Temperature of Coaxial Noise

Generator, Type N Precision, $14 \mathrm{~mm}, \mathrm{APC} 7$ or APC 3.5 Connector; Continuous Frequencies $2.0-4.0 \mathrm{GHz}$, Reflection Coefficient $<0.1$, Temperature:

$77 \mathrm{~K}-15,000 \mathrm{~K}$, ENR $<17 \mathrm{~dB}$

62111S Each Additional 62110S Item Tested at Same Frequency

62120 S Noise Temperature of Rectangular

Waveguide Noise Sources at Specific Frequencies in WR62 (12.4, 13.5, 14.0, 15.0, 16.0, 16.5, 17.0, 18.0 $\mathrm{GHz})$ and WR90 $(8.2,9.0,9.5,9.8,10.0,10.5,11.2$, $11.8,12.4 \mathrm{GHz}$ ); Reflection Coefficient $<0.09$, Temperature: 9,000 K-13,000 K, ENR $<16.5 \mathrm{~dB}$

62121S Each Additional 62120S Item Tested at Same Frequency

$62130 \mathrm{~S}$ Noise Temperature of WR10 (77 K-15,000 K) and WR 15 (700 K-15,000 K) Waveguide Noise

Generators at Specific Frequencies

62140S Special Services for Earth Terminals Used in Satellite Communications
Noise Temperature MeasurementsElectromagnetic (62020S)

Special test services for the measurement of electromagnetic noise are offered in limited frequency coverage from $30 \mathrm{MHz}$ to $94 \mathrm{GHz}$ and include measurements through adaptors and out-of-range noise temperatures. The type of service offered is determined by the frequency. In some frequency regions, only spot frequency measurements are available. However, some gaps in the frequency coverage exist. Depending on the frequency coverage available, noise sources submitted for measurement will be compared, via one of three different types of radiometers, against a hot or cold primary reference standard or a transfer standard. Since there are limitations which are a function of the noise standards and radiometer available, the customer should check with the technical contact listed at the beginning of this section before submitting a device for measurement.

\section{Noise Sources and Generators (62100S-62130S)}

Noise temperature measurements are available on single-port, coaxial, and rectangular waveguide noise sources under conditions of continuous, unmodulated operation. Precision coaxial connectors or clean, smooth, and flat standard EIA waveguide flanges are required. Complete operating instructions and special electronic connectors should be supplied, and pertinent operating conditions (voltages, circuits, etc.) specified for the noise source to be measured. Devices submitted that are not of sufficient quality or not mechanically compatible with the measuring system will be rejected and an appropriate fee charged. Availability of measurements at specific frequencies and for various connector types are specified above. Generally, an attempt is being made to expand services to include more types of precision connectors and waveguide sizes. However, the cost of measurements requiring the 
use of adaptors as part of the measurement process can be substantially greater than the cost of measurements on sources with connectors mating directly to the measurement system.

Furthermore, measurement results on devices submitted with adaptors attached may apply only to the source/ adaptor combination.

The limits of uncertainty vary with noise temperature, reflection coefficient, and source and connector stability, but typically lie between $1 \%$ and $3 \%$ of the noise temperature.

\section{Earth Terminals for Satellite Communications (62140S)}

Measurement and consultation services are available on a limited and special basis for characterizing the noise properties of earth terminals. Quantities such as G/T (gain to system noise temperature ratio) and system noise temperature are available. Special arrangements need to be made for these services.

\section{References-Noise Temperature Measurements}

Noise Standards, Measurements, and Receiver Noise Definitions, C. K. S. Miller, W. C. Daywitt, and M. G. Arthur, IEEE Proc. 55, 6, 865 (June 1967). (This reference describes noise standards, basic principles of noise measurements, and concepts of noise factor and noise temperature.)

Measurement of Effective Temperature in Microwave Noise Sources, J. S. Wells, W. C. Daywitt, and C. K. S. Miller, IEEE Trans. Instrum. Meas., IM-13, 1, 17 (Mar. 1964). (This reference describes the method of measurement and error analysis).

A Coaxial Noise Standard for the $1 \mathrm{GHz}$ to $12.4 \mathrm{GHz}$ Frequency

Range, W. C. Daywitt, NBS Tech. Note 1074 (Mar. 1984).

The NBS WR62 and WR90 Reference Noise Standards, C. K. S. Miller and W. C. Daywitt, NBSIR 84-3005 (May 1984).

The NBS Switching Radiometers, C. J. S. Miller and W. C. Daywitt, NBSIR 84-3004 (May 1984).

WR15 Thermal Noise Standard, W. C. Daywitt, W. J. Foote, and E. Campbell, NBS Tech. Note 615 (Mar. 1972).

Design and Error Analysis for the WR 10 Thermal Noise Standard, W. C. Daywitt, NBS Tech. Note 1071 (Dec. 1983).

A Derivation for the Noise Temperature of Horn-Type Noise Standards, W. C. Daywitt, Metrologia 21, 127 (Sept. 1985).

Precision Measurement of Antenna System Noise Using Radio Stars, D. F. Wait, IEEE Trans. Instrum. Meas., IM-32, 1 (Mar. 1983). 
Electromagnetic Field Strength and Antenna Measurements

\section{I.1 Microwave Antenna Parameter Measurements}

Electromagnetic Fields Division Center for Electronics and Electrical

\section{Engineering}

Technical Contacts:

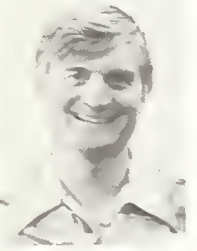

Allen C. Newell (631005-63+00S) Tel: $303 / 497-37+3$

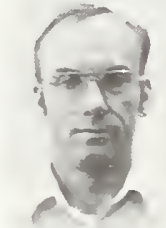

Carl F.

Stabenrauch

(631005)

Tel: $303 / 497-3927$

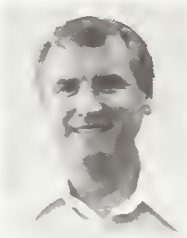

Andreक G. Repjar (632005)

Tel:303/497.5703

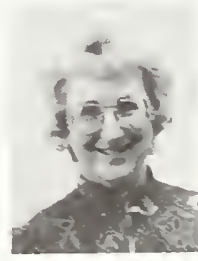

Edns M. Jones Administrative and Logistics Tel: $333 / 497-3753$
Mailing Address: M.C. 723.10, National Bureau of Standards, 325 Broadway, Boulder, CO 80303

Shipping Address: Room 1300. BIdg. 24. National Bureau of Standards, 325 Broadway. Boulder. CO 80303

Test No. Items

63100 S Gain and Polarization Calibrations of Standard Antennas Using Extrapolation Range

63200S Measurement of Pattern. Gain and Polarization of Arbitrary Antennas Using Near-Field Scanning Techniques

633005 Special Test Services for Calibration of Probes Used with Near-Field Scanning Facilities

63400S Special Consulting, Advisory, and Other Services

\section{Antenna Parameter \\ Measurements \\ (Microwave)-General \\ Information}

Accurate measurements of antenna gain, pattern, and polarization are generally available from about 750 $\mathrm{MHz}$ to about $75 \mathrm{GHz}$. However. because the measurement accuracy, capability, and cost depend on the frequency, type and size of antenna, and the parameters to be measured, a particular measurement service must be negotiated in advance. Antennas submitted for evaluation should be mechanically and electrically stable in order to retain a calibration for a significant length of time. Antennas with either coaxial or waveguide connectors can be measured; however, if coaxial connectors are employed, they should be precision connectors to minimize uncertainties due to a lack of connector repeatability. In particular, the use of SMA connectors is strongly discouraged because of poor connector repeatability. The following methods and facilities are used for these measurements.

Gain and Polarization Calibrations of Standard Antennas Using Extrapolation Range (63200S)

This calibration service is offered primarily for determining the absolute on-axis gain and polarization of standard gain horns which, in turn, are used as reference standards in determining the gain and polarization of other antennas by the gain comparison technique. In the extrapolation method, three antennas are normally utilized and three pairwise combinations are defined. The received signal transmitted between each pair of antennas is measured as a function of the separation distance between the antennas. The antennas need not be identical, and no assumptions concerning the polarization are required. The method is not well suited for pattern measurements, but is the most accurate technique known for absolute gain and polarization measurements. Above $1 \mathrm{GHz}$, the accuracies are typically $\pm 0.10 \mathrm{~dB}$ for gain measurements, and $\pm 0.05 \mathrm{~dB} / \mathrm{dB}$ for polarization axial ratio measurements. There are antenna size limitations associated with existing 
NBS extrapolation ranges. These limitations depend on the type of antenna, the frequency, and the desired measurements and accuracies. Therefore, negotiations must be conducted prior to submitting antennas for calibration to ascertain whether all requirements can be met.

Measurement of Pattern Gain, and Polarization of Arbitrary Antennas Using Near-Field Scanning Techniques (63200S).

With this technique, gain, pattern, and polarization parameters are calculated from near-field amplitude and phase measurements taken over a surface close to the test antenna. The absolute gain can be determined to within about $0.15 \mathrm{~dB}$, the polarization axial ratio to within about $0.10 \mathrm{~dB} /$ $\mathrm{dB}$, and side lobe levels can be obtained down to -50 or $-60 \mathrm{~dB}$. The exact uncertainties in these parameters will depend on such factors as the frequency, type and size of antenna. Antennas with apertures up to

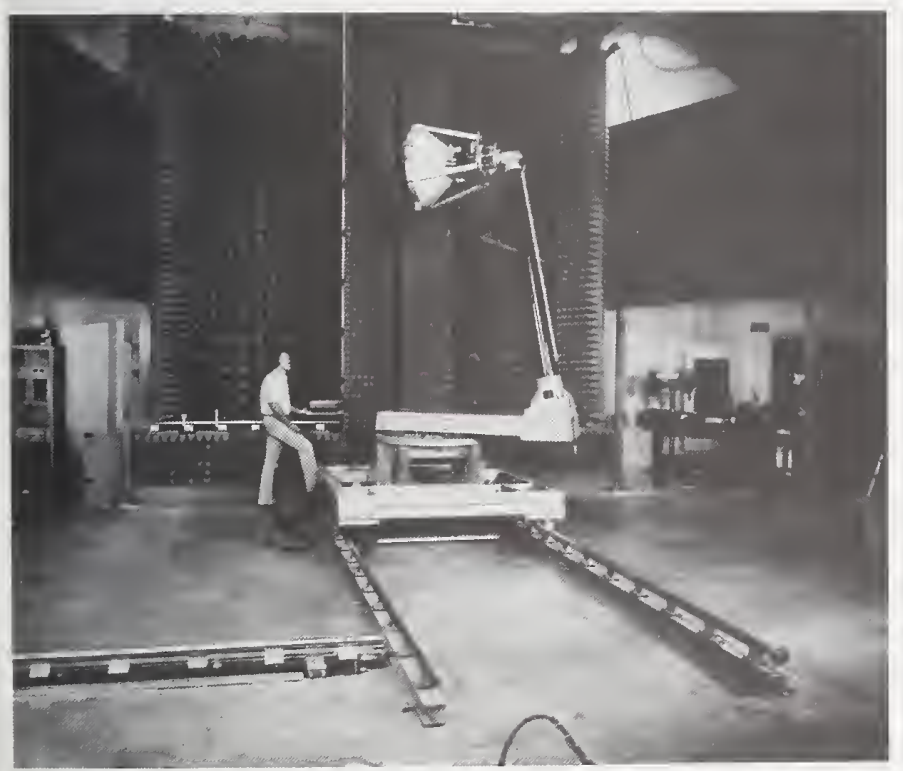

NBS Near-Field Scanning Antenna Range. The wellcharacterized probe rides on a dual-carriage system covering a plane. The carriage that moves left and right appears as a large vertical rectangle with a slot in the long direction (background). The dark-appearing material absorbs microwave energy and prevents unwanted reflections. The antenna under test is a simple conical antenna. about 3.5 meters in diameter can be managed. Measurements can be made from about $750 \mathrm{MHz}$ to about 75

GHz. Measurements are most commonly made over a plane surface in front of the antenna being evaluated, but the capability also exists for measuring over a cylindrical surface surrounding the antenna when it is advantageous to do so. Calibrated probes are normally required for these measurements. These near-field scanning measurements are offered as a special-test service because nearly every measurement is unique and it is difficult to build up a statistical history as required for a regular calibration service.

\section{Special-Test Service for Calibrating Probes Used with Near-Field Scanning} Facilities (63300S)

This special-test service is available to support those organizations that have established their own near-field measurement facilities and need to characterize the probes used in performing the near-field measurements. In order to achieve accurate results with either the planar, cylindrical, or spherical near-field method, the transmitting or receiving properties of the probe must be known. With this information, the measured data can be corrected for the non-ideal pattern and polarization properties of the probe. Probes are characterized by a 
three-step process: (1) The on-axis gain and polarization properties are measured using the extrapolation technique described above; (2) the far-field amplitude and phase patterns are measured for two nominally orthogonal polarizations of the incident field; and (3) the on-axis and pattern data are combined to obtain the probe correction coefficients at the desired lattice points on the measurement surface as specified by the customer. The final output consists of a computer tape containing the measured far-field patterns and the calculated probe coefficients. Typical types of probes are open-ended waveguides and small horns. Both linearly and circularly polarized probes can be evaluated.

Special Consulting, Advisory, and Other Services (63400S)

A variety of special consultation and advisory services related to the measurements described above are available upon request. These services are offered to disseminate NBS technologies and to assist other organizations in establishing their own measurement facilities and capabilities. Included are cooperative measurement programs. A customer actually participates directly in the measurement of his device in order to become familiar with the measurement methods and assist in the analysis of the results. This is a useful approach when one is attempting to establish a new measurement capability that is related to or based upon NBS measurement techniques.

\section{References-Microwave Antenna Parameter Measurements}

Accurate Measurement of Antenna Gain and Polarization at Reduced Distances by an Extrapolation Technique, A. C. Newell, R. C. Baird, and P. F. Wacker, IEEE Trans. Antennas Propagat. AP-21, 4, 418 (July 1973).

Determination of Both Polarization and Power Gain of Antennas by a Generalized 3-Antenna Measurement Method, A. C. Newell and D. M. Kerns, Electronics Letters, 7, 7, 68 (Feb. 1971).

Correction of Near-Field Antenna Measurements Made With an Arbitrary but Known Measuring Antenna, D. M. Kerns, Electronics Letters 6, 11, 346 (May 1970).

New Method of Gain Measurement Using Two Identical Antennas, D. M. Kerns, Electronics Letters 6, 11, 348 (May 1970).

Plane-Wave Scattering-Matrix Theory of Antennas and AntennaAntenna Interactions: Formulation and Applications, D. M. Kerns, J. Res. Natl. Bur. Stand. (U.S.), 80B, 1, 5051 (Jan.-Mar. 1976).

Plane-Wave Scattering-Matrix Theory of Antennas and Antenna-

Antenna Interactions, D. M. Kerns, Natl. Bur. Stand. (U.S.), Monograph 162 (June 1981).

Upper-Bound Errors in Far-Field Antenna Parameters Determined from Planar Near- Field Measurements, A. D. Yaghjian, Natl. Bur. Stand. (U.S.), Tech. Note 667 (Oct. 1975). 
Electromagnetic Field Strength and Antenna Measurements

I.2 Field Strength Parameter Measurements Electromagnetic Fields Division Center for Electronics and Electrical Engineering

\section{Technical Contacts:}

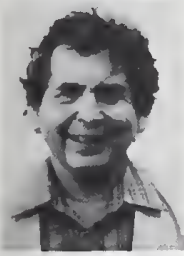

Jose E, Cruz Tel: 303/497-3763

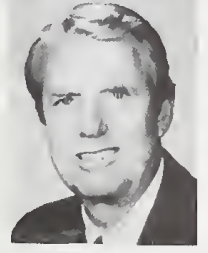

Ezra B. Larsen Tel: 303/497-354

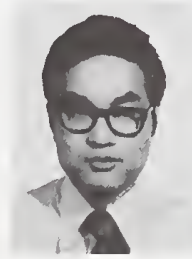

Motohisa Kanda Tel: 303/497-5320

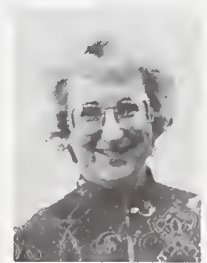

Edna M. Jones Administrative and Logistics Tel: $303 / 497-3753$
Mailing Address: M.C. 723.10, National Bureau of Standards, 325 Broadway, Boulder, CO 80303

\section{Test No. Items}

64100S Special-Test Service for Antenna/Field Strength Measurements, Using the Transverse Electromagnetic (TEM) Cell Method, $(10 \mathrm{kHz}-300 \mathrm{MHz})$

64200S Special-Test Service for Antennas/Field Strength Measurements, Utilizing the Open-Field Method

64300S Special-Test Service for Antennas/Field Strength Reflectivity Measurements, Utilizing the Anechoic-Chamber Method

64400S Special-Test Service for Electromagnetic Interference

Special-Test Service for Antennas/ Field Strength Measurements, Utilizing the Transverse Electromagnetic (TEM) Cell Method (64100S)

Standard electromagnetic fields are generated in TEM cells and used to calibrate electrically small antennas and antenna systems used for electromagnetic field probes in the frequency range $10 \mathrm{kHz}$ to $300 \mathrm{MHz}$.

\section{Special-Test Service for Antennas/}

Field Strength Measurements, Utilizing the Open Field Method (64200S)

These measurements include calibration of antenna factor and gain of antennas used in conjunction with field strength meters, and of electrically small antennas used in electromagnetic field probes. The following methods and facilities are used for these measurements:

A. Dipoles, log-periodic and other antennas (25 to $1000 \mathrm{MHz}$ ) are used to generate electromagnetic fields which are used for calibrating various antennas and electromagnetic field probes. The field strength is established using the standard receiving antenna method.

B. Monopoles (30 to $300 \mathrm{MHz}$ ) are used to generate standard electric fields for calibrating antennas and electromagnetic field probes.

C. Loop antennas $(14 \mathrm{kHz}$ to 50 $\mathrm{MHz}$ ) are used to generate standard magnetic fields for calibrating loop antennas used in conjunction with field strength meters.

Special-Test Service for Antennas/ Field Strength/Reflectivity Measurements, Utilizing the Anechoic-Chamber Method (64300S)

A. Open-ended waveguides (200 to $450 \mathrm{MHz}$ ) are used to generate standard electromagnetic fields for 
calibrating antennas and electromagnetic field probes.

B. Pyramidal horns $(0.45$ to 18 $\mathrm{GHz}$ ) are used to generate standard electromagnetic fields for calibrating antennas and electromagnetic field probes, and for measuring reflectivity of materials.

Table 15 summarizes the field parameters, frequency ranges, and radiating antenna sources for the various NBS field strength measurement facilities.

Table 15: Summary of NBS Standard Field Strength Facilities

\begin{tabular}{|c|c|c|c|}
\hline $\begin{array}{c}\text { Field } \\
\text { Parameter }\end{array}$ & $\begin{array}{c}\text { Type of } \\
\text { Measurement } \\
\text { Facility }\end{array}$ & $\begin{array}{c}\text { Frequency } \\
\text { Range }\end{array}$ & $\begin{array}{l}\text { Radiating } \\
\text { Antenna } \\
\text { Source }\end{array}$ \\
\hline $\mathrm{H}$ & $\begin{array}{l}\text { Wood } \\
\text { building }\end{array}$ & $\begin{array}{l}14 \mathrm{kHz} \text { to } \\
50 \mathrm{MHz}\end{array}$ & Loop $(20 \mathrm{~cm})$ \\
\hline E(vertical) & $\begin{array}{l}\text { Open site } \\
\text { (ground screen) }\end{array}$ & $\begin{array}{l}30 \mathrm{kHz} \text { to } \\
30 \mathrm{MHz}\end{array}$ & $\begin{array}{l}\text { Short } \\
\text { Monopole }\end{array}$ \\
\hline $\mathrm{E}$ (vertical) & $\begin{array}{l}\text { Open site } \\
\text { (ground screen) }\end{array}$ & $\begin{array}{l}30 \text { to } \\
300 \mathrm{MHz}\end{array}$ & $\begin{array}{l}\text { Quarter wave } \\
\text { length } \\
\text { monopole }\end{array}$ \\
\hline E (horizontal) & Open site & $\begin{array}{l}25 \text { to } \\
1000 \mathrm{MHz}\end{array}$ & $\begin{array}{l}\text { Dipole, log- } \\
\text { periodic } \\
\text { antenna, etc. }\end{array}$ \\
\hline Power Density & $\begin{array}{l}\text { Anechoic } \\
\text { chamber }\end{array}$ & $\begin{array}{l}200 \text { to } \\
450 \mathrm{MHz}\end{array}$ & $\begin{array}{l}\text { Open-end } \\
\text { waveguide }\end{array}$ \\
\hline Power Density & $\begin{array}{l}\text { Anechoic } \\
\text { chamber }\end{array}$ & $\begin{array}{l}0.45 \text { to } \\
18 \mathrm{GHz}\end{array}$ & $\begin{array}{l}\text { Pyramidal } \\
\text { horn }\end{array}$ \\
\hline $\begin{array}{l}\text { Material re- } \\
\text { flectivity }\end{array}$ & $\begin{array}{l}\text { Anechoic } \\
\text { chamber }\end{array}$ & $\begin{array}{l}0.45 \text { to } \\
18 \mathrm{GHz}\end{array}$ & $\begin{array}{l}\text { Pyramidal } \\
\text { horn }\end{array}$ \\
\hline
\end{tabular}

Special-Test Services for Electromagnetic Interference (64400S)

This service includes evaluating equipment used for measuring the electromagnetic environment, performing radiated-field susceptibility (immunity) and emission testing, and performing conducted interference testing. In special cases, measurements will be made to evaluate facilities used to perform electromagnetic interference tests (susceptibility, emission, or conducted) and to evaluate localized electromagnetic environments.

\section{References-Electromagnetic Field} Strength Parameter Measurements Methodology for Standard Electromagnetic Field Mesurements, N. S. Nahman, M. Kanda, E. B. Larsen, and M. L. Crawford, IEEE Trans. Instrum. Meas. IM-34, 4 (Dec. 1985)

A Review of Electromagnetic Compatibility/Interference Measurement Methodologies, M. T. Ma, M. Kanda, M. L. Crawford, and E. B. Larsen, Proc. IEEE, 73, 3, 388 (Mar. 1985). 
Pulse Waveform Measurements

Electromagnetic Fields Division

Center for Electronics and Electrical

\section{Engineering}

Technical Contacts:

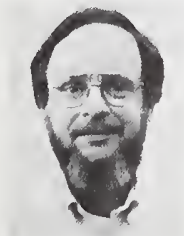

William L. Gans Tel: 303/497-3538

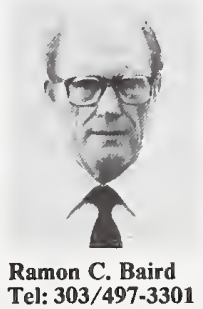

Tel: 303/497-3301

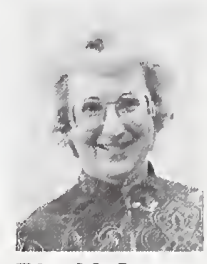

Edna M. Jones

Administrative

and Logistics

Tel: $303 / 497-3753$
Mailing Address: M.C. 723.10, National Bureau of Standards, 325 Broadway, Boulder, CO 80303

Test No. Items

65100S Impulse Generator Spectrum Amplitude (50 Ohm)

65200S Fast Repetitive Broadband Pulse Parameters (50 Ohm)

65300S Network Impulse Response (Frequency Domain Parameter $S_{21}$ ) of Coaxial Networks, $10 \mathrm{MHz}$ to 10.0 $\mathrm{GHz}, 0$ to $\pm 40 \mathrm{~dB}$

65301S Additional 65300S Item Tested at Same Time as First

65400S Pulse Time Delay Through Coaxial Transmission Lines

\section{Pulse Waveform}

Measurements-General Information

NBS offers special test services for a number of baseband pulse parameters. These are broken down into four categories; impulse generator spectrum amplitude, fast repetitive baseband pulse parameters, network impulse response, and pulse time delay. All of these special test services are performed on the NBS Automatic Pulse
Measurement System (APMS) consisting of a sampling oscilloscope interfaced to a minicomputer. In addition, all of these special tests are performed at cost. References pertaining to these four services are located at the end of this section.

Impulse Generator Spectrum Amplitude, 50 Ohms (65100S)

In response to calibration needs from the electromagnetic interference (EMI) community, NBS has developed a special test service to calibrate the broadband spectrum amplitude output from impulse generators. Such a generator can then be used as a transfer standard of broadband impulsive noise for field calibration of spectrum analyzers and field intensity

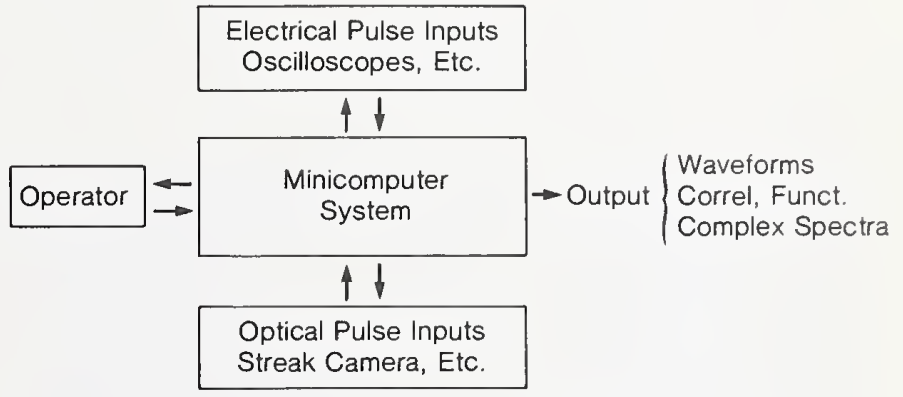

meters. The NBS special test service uses the time domain measurement/ frequency domain deconvolution computational method for calibration of impulse generators. A wideband (dc-18 GHz) sampling oscilloscope is 
used to measure the time domain waveform from the impulse generator. A dedicated minicomputer then computes the spectrum amplitude, $S(f)$, versus frequency using the fast Fourier transform (FFT). NBS will provide 50 to 100 data points over a wide frequency range for a single fee.

NBS impulse generator spectrum amplitude measurement service capabilities shown in Table 16.
Table 16: NBS Impulse Generator Spectrum Amplitude Measurement Service Capabilities

\begin{tabular}{|c|c|c|}
\hline Parameter & Limits & Notes \\
\hline $\begin{array}{l}\text { Maximum impulse } \\
\text { amplitude without } \\
\text { attenuators }\end{array}$ & $\pm 600 \mathrm{mV}$ & $1,2,3$ \\
\hline $\begin{array}{l}\text { Maximum impulse } \\
\text { amplitude with } \\
\text { external attenuators }\end{array}$ & $\pm 1.2 \mathrm{kV}$ & 3,4 \\
\hline Spectrum amplitude & $\begin{array}{l}-15 \mathrm{~dB} \mu \mathrm{V} / \mathrm{MHz}<[\mathrm{S}(\mathrm{f}) \\
\left.-\mathrm{S}_{0}\right]<+5 \mathrm{~dB} \mu \mathrm{V} / \mathrm{MHz}\end{array}$ & $5,6,7$ \\
\hline$S(f)$ uncertainty & $\begin{array}{l}\text { Nominally f }<1 \mathrm{GHz} \\
\pm 0.6 \mathrm{~dB} \\
1 \mathrm{GHz}<\mathrm{f}<4 \mathrm{GHz} \\
\pm 1.2 \mathrm{~dB} \\
4 \mathrm{GHz}<\mathrm{f}<10 \mathrm{GHz} \\
\pm 2.0 \mathrm{~dB}\end{array}$ & $\begin{array}{l}5, \\
6,7 \\
8 \& 9\end{array}$ \\
\hline Frequency range & $5 \mathrm{MHz}$ to $10 \mathrm{GHz}$ & $5,6,7 \& 10$ \\
\hline Frequency spacing & $\begin{array}{l}\Delta f=5,10,20,50, \text { or } \\
100 \mathrm{MHz}\end{array}$ & 5,10 \\
\hline Frequency uncertainty & of the order of $\pm 1 \%$ & 7 \\
\hline Load impedance & $50.0 \Omega$ & \\
\hline $\begin{array}{l}\text { Load impedance } \\
\text { uncertainty }\end{array}$ & $\begin{array}{l}\text { Nominally } \pm 0.1 \Omega \text { at dc } \\
\text { VSWR }<1.3 \text { up to } 10 \mathrm{GHz}\end{array}$ & 8,11 \\
\hline $\begin{array}{l}\text { Trigger pulse } \\
\text { amplitude }\end{array}$ & $>100 \mathrm{mV}$ & 12 \\
\hline $\begin{array}{l}\text { Trigger pulse } \\
\text { transition duration }\end{array}$ & $<5 \mathrm{~ns}$ & 12 \\
\hline $\begin{array}{l}\text { Trigger to impulse } \\
\text { delay }\end{array}$ & $75 \mathrm{~ns}<\mathrm{t}_{1}<100 \mathrm{~ns}$ & 12 \\
\hline $\begin{array}{l}\text { Trigger to impulse } \\
\text { jitter }\end{array}$ & $<20$ ps & 12 \\
\hline
\end{tabular}

Notes: 1. The impulse generator is characterized by its impulse output waveform into $50 \mathrm{ohms}$ of peak amplitude $\left(\mathrm{V}_{\mathrm{pk}}\right), 50$ percent level duration $(\tau)$, and low frequency spectrum amplitude $\left(\mathrm{S}_{0} \sim 2 \mathrm{~V}_{\mathrm{pk}} \tau\right)$.

2. Impulse generator with an adjustable amplitude impulse output will be calibrated with the generator adjusted to give a peak amplitude in the range of 200 to $400 \mathrm{mV}$.

3. Impulse generators with fixed outputs greater than \pm 400 $\mathrm{mV}$ must have the impulse attenuated to the $200-400 \mathrm{mV}$ level by 50-ohm wideband coaxial attenuators.

4. Either customer supplied or NBS attenuators may be used.

5. Depends upon actual generator characteristics.

6. Data will not be given in the first spectrum null or at frequencies above. Typically 100 data points are supplied

7. Subject to revision.

8. Only for impulse amplitudes less than $\pm 400 \mathrm{mV}$.

9. If external attenuators and/or a $6 \mathrm{~dB}$ tee and delay line are used then the uncertainty associated with the attenuator calibration is added to these values.

10. Lower frequencies ( $<5 \mathrm{MHz}$ ) are available as a special test. used.

11. Depends upon input impedance of external attenuators when

12. If the impulse generator does not supply a trigger output or if the trigger output does not have the proper characteristics then a 6 $\mathrm{dB}$ tee and a delay line will be used to provide a suitable trigger pulse. 
Fast Repetitive Baseband Pulse Parameters, 50 Ohms (65200S)

NBS offers a special test service for selected pulse parameters. These parameters are measured with the NBS Automatic Pulse Measurement System (APMS), which consists of a calibrated wideband (nominally dc-18 $\mathrm{GHz}$ ) equivalent-time sampling oscilloscope custom interfaced to a dedicated minicomputer system. The parameters, ranges, and estimated uncertainty limits for this service are listed in Table 17.

Table 17: Limits of Uncertainty for Calibration of Fast Repetitive Baseband Pulse Parameters

\begin{tabular}{lcc}
\multicolumn{1}{c}{ Parameter } & Range & $\begin{array}{c}\text { Typical } \\
\text { Limits of } \\
\text { Uncertainty* }\end{array}$ \\
\hline Pulse Baseline (0\% level) & $\pm 500 \mathrm{mV}$ & $\pm(1 \%+3 \mathrm{mV})$ \\
Pulse Topline (100\% level) & $\pm 500 \mathrm{mV}$ & $\pm(1 \%+3 \mathrm{mV})$ \\
Pulse Amplitude & $\pm 500 \mathrm{mV}$ & $\pm(1 \%+3 \mathrm{mV})$ \\
Pulse Overshoot/Undershoot & $\pm 500 \mathrm{mV}$ & $\pm(1 \%+3 \mathrm{mV})$ \\
$\begin{array}{l}\text { Pulse First Transition } \\
\text { Duration (Rise Time) }\end{array}$ & $10 \mathrm{ps}-100 \mathrm{~ns}$ & $\pm(1 \%+5 \mathrm{ps})$ \\
$\begin{array}{l}\text { Pulse Second Transition } \\
\text { Duration (Fall Time) }\end{array}$ & $10 \mathrm{ps}-100 \mathrm{~ns}$ & $\pm(1 \%+5 \mathrm{ps})$ \\
$\begin{array}{l}\text { Pulse Duration (Between } \\
\text { 50\% levels) }\end{array}$ & $10 \mathrm{ps}-100 \mathrm{~ns}$ & $\pm(1 \%+5 \mathrm{ps})$ \\
\hline
\end{tabular}

* Smaller limits of uncertainty are achievable in some cases.

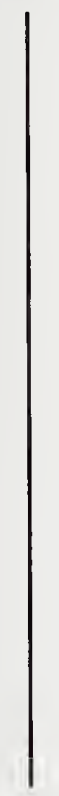

Restrictions: 1. Customer's device must generate a repetitive pulse with repetition rate between $100 \mathrm{~Hz}$ and 1 $\mathrm{GHz}$.

2. Customer's device must have a 50 ohms nominal output impedance.

3. Customer's device should have a precision coaxial output connector, e.g., SMA, APC-7, or Type "N".

4. Pulse topline is only measured for "step-like" pulses.

5. Pulse second transition duration and pulse duration are only measured for "impulse-like" pulses.

6. Pulse overshoot/ undershoot is estimated as a percent of pulse amplitude.

This measurement service includes the previously offered measurement service referred to in prior editions of

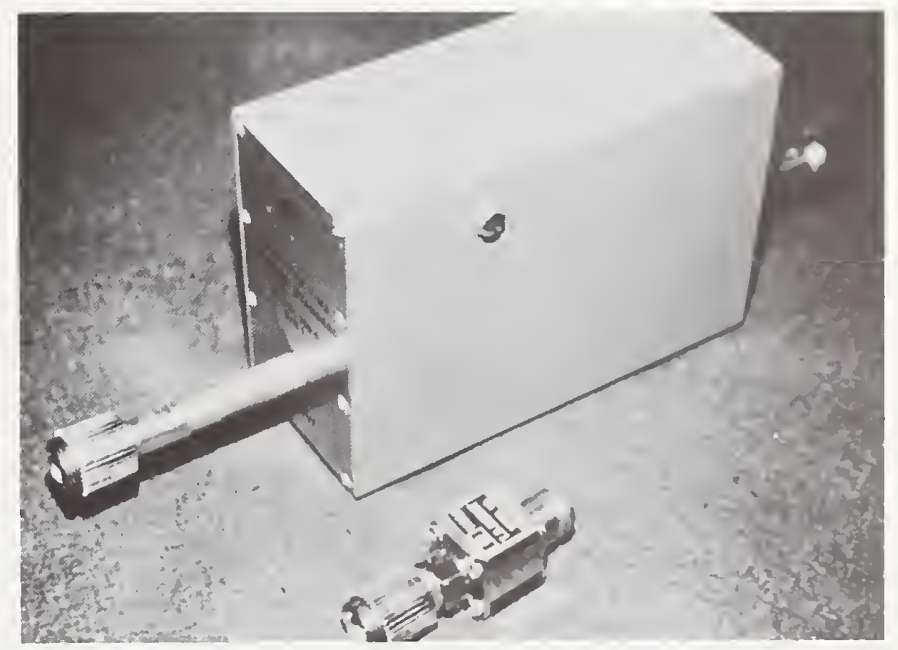

NBS pulse rise-time reference for 100 ps. The small unit produces a pulse which is filtered by the liquid delay line in the standard. 
the NBS SP250 Appendix as "LowPass Filter Transition Duration."

Measurements of other pulse parameters or parameter ranges may be provided by special arrangement. Consulting and advisory services also are available.

Network Impulse Response (65300S) A network time domain impulse response measurement service for coaxial networks is offered at NBS. The resulting data are in the form of a discrete waveform vector, normally 1024 points in length, with a time window range of from $2 \mathrm{~ns}$ to $100 \mathrm{~ns}$. Also, using discrete Fourier transforms, the associated frequency domain data $\left(S_{21}[\mathrm{f}]\right)$ are provided over a frequency range of $10 \mathrm{MHz}$ to 10 $\mathrm{GHz}$ and a gain or loss range of 0 to $40 \mathrm{~dB}$.

These measurements are accomplished by use of the NBS Automatic Pulse Measurement System, which consists of a fast transition duration pulse generator, a $20 \mathrm{ps}, 50 \mathrm{ohm}$ sampling oscilloscope and a minicomputer. Two waveforms are measured, one with the pulse generator connected directly to the oscilloscope, and the other with the unknown network inserted between the generator and the oscilloscope. The time domain network impulse response function and/or the frequency domain scattering parameter, $S_{21}(f)$, are then calculated using an NBSdeveloped deconvolution algorithm. A wide variety of connectors can be accommodated. The approximate limits of uncertainty are less than $\pm 2 \%$ for all parameters.

This measurement service includes the previously offered measurement service referred to in prior editions of NBS SP250 as "Wideband Attenuation or Gain of Coaxial Networks."

\section{Pulse Time Delay Through Coaxial} Transmission Lines (65400S)

NBS offers a special test service for pulse time delay using the same measurement system described in item $65300 \mathrm{~S}$ above. The pulse time delay is measured in the range of $100 \mathrm{ps}-100$ ns with typical limits of uncertainty of $\pm(1 \%+10 \mathrm{ps})$. Smaller limits of uncertainty are achievable in some cases.

Restrictions: 1. Customer's device must utilize precision coaxial connectors for both delay ports.

2. Customer should provide driving pulse generator if possible. First transition duration (rise time) of driving pulse generator 
should not exceed $10 \%$ of pulse time delay to be measured.

3. Customer's device should have nominal input and output impedances of $50 \mathrm{ohms}$.

Measurements for other ranges and configurations may be made by special arrangement. Consulting and advisory services are available.

\section{References-Pulse Waveform Measurements}

Impulse Generator Spectrum Amplitude Measurement Techniques, J. R. Andrews, IEEE Trans. Instrum. Meas. IM-25, 4, 280 (Dec. 1976). Spectrum Amplitude Definition, Generation and Measurement, J. R. Andrews and M. G. Arthur, Natl. Bur. Stand. (U.S.), Tech. Note 699 (Oct. 1977).

Pulse Techniques and Apparatus, Part 1: Pulse Terms and Definitions; Part 2: Pulse Measurements and Analysis, General Considerations. IEC Publications 469-1 and 469-2, Intl. Electrotech. Com. (IEC) Geneva, (1974).

IEEE Standard Pulse Terms and Definitions, IEEE Std. 194-1977; and IEEE Standard on Pulse Measurement and Analysis by Objective Techniques, IEEE Std. 181-1977, Inst. Electrical and Electronic Engrs., New York, (July 1977).

Time Domain Automatic Network Analyzer for Measurement of $\mathrm{RF}$ and Microwave Components, W. L. Gans and J. R. Andrews, Natl. Bur. Stand. (U.S.), Tech. Note 672 (Sept. 1975).

Present Capabilities of the NBS Auto- matic Pulse Measurement System, W. L. Gans, IEEE Trans. Instrum. Meas., IM-25, 384 (Dec. 1976).

Pulsed Wavemeter Timing Reference for Sampling Oscilloscope Calibration, J. R. Andrews and W. L. Gans, IEEE Trans. Instrum. Meas., IM-24, 82 (Mar. 1975).

Modeling of the Feed-Through Wideband (dc to $12.4 \mathrm{GHz}$ ) Sampling Head, S. M. Riad and N. S. Nahman, Digest. 1978 IEEE-MTT-S Intl. Microwave Symp., Ottawa (June 1978).

Deconvolution of Time Domain Waveforms in the Presence of Noise, N. S. Nahman and M. E. Guillaume, Natl. Bur. Stand. (U.S.), Tech. Note 1047 (Oct. 1981).

The Measurement and Deconvolution of Time Jitter in Equivalent-Time Waveform Samplers, W. L. Gans, IEEE Trans. Instrum. Meas., IM-32, 1, 126 (March 1983). 


\section{Chapter}

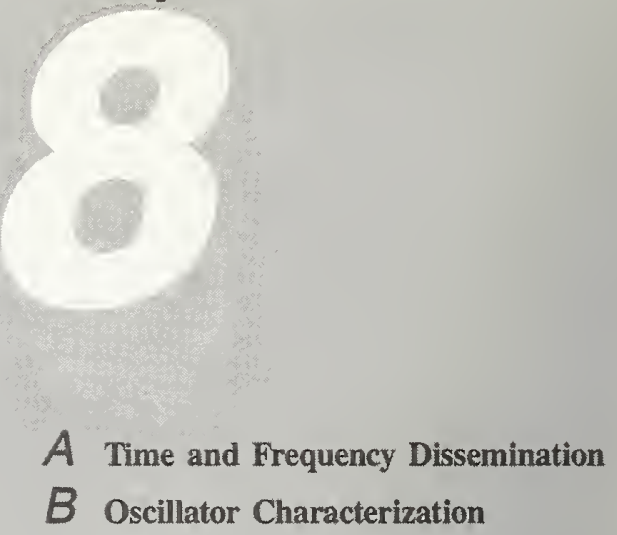




\section{Time and Frequency Measurements}

\section{Time and Frequency Dissemination Time and Frequency Division Center for Basic Standards}

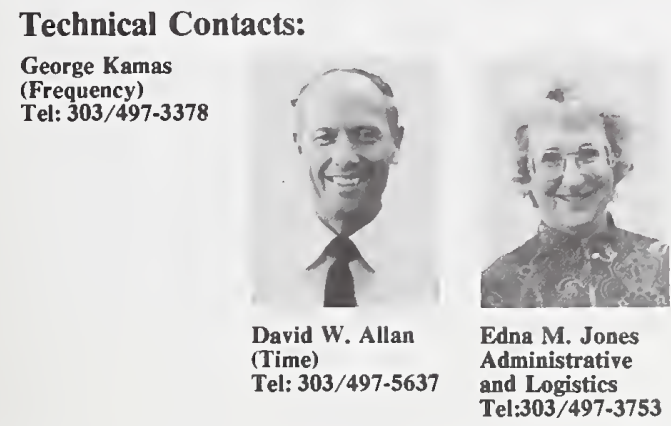

Mailing Address: M.C. 524.00, National Bureau of Standards, 325 Broadway, Boulder, CO 80303

Shipping Address: M.C. 524.06, Room 4039, National Bureau of Standards, 325 Broadway, Boulder, CO 80303

Test No. Items

$76100 \mathrm{~S}$ Special Tests of Time and Frequency; Frequency Measurement Service-(Frequency delivered to user's site)

$76110 \mathrm{~S}$ Special Tests of Time and Frequency; Global Time Service. (Frequency and Time delivered to user's site)

NBS Broadcast of Time and Frequency Signals (No Test No.) NBS offers several continuous time and frequency dissemination services that are freely available to the general public. These services are provided via the radio broadcasts of stations WWV, WWVH and WWVB and a time-code disseminated from the GOES satellites. WWV's signal is also available by dialing (303) 499-7111. A similar service from WWVH is available by dialing (808) 335-4363. (These numbers are not toll free.)

Broadcasts from WWV (Fort Collins, Colorado) and WWVH (Kauai, Hawaii) can be received on conventional shortwave receivers nearly anywhere in the world. Broadcast frequencies are $2.5,5,10$ and $15 \mathrm{MHz}$ for both stations and $20 \mathrm{MHz}$ for WWV only. Accuracies of 1 to 10 milliseconds in time and $1 \times 10^{-6}$ in frequency are typical from these broadcasts. These stations provide standard frequencies, standard time intervals, time-of-day announcements, a binary-coded-decimal (BCD) time code, astronomical time corrections, and certain public service announcements for other government agencies. For individuals without receivers, the telephone service provides the same NBS time and frequency signals. The time signal by telephone is accurate to only 30 milliseconds or better due to unpredictable delays in crosscountry telephone line routings.

WWVB (Ft. Collins, Colorado) offers accuracies of 0.5 milliseconds in time and $1 \times 10^{-11}$ in frequency, but requires a special $60 \mathrm{KHz}$ low frequency receiver. WWVB's time-code signal is a BCD type needing special decoding equipment. The GOES satellites broadcast an NBS time code accurate to 100 microseconds to the western hemisphere. These are geostationary weather satellites located at nominally $75^{\circ}$ west and $135^{\circ}$ west longitude.

NBS broadcast services are coordinated with similar operations in other countries. Commercial receivers designed to receive (and decode) NBS broadcasts are available from several manufacturers. A number of publications are available to assist users to properly record the time and frequency information available from these broadcast services.

\section{Special Frequency Measurement Service (76100S)}

Frequency calibration requirements at the part in $10^{11}$ to a part in $10^{12}$. level 
can be satisfied using low frequency radio signals from broadcast stations such as WWVB or Loran-C. This service involves the location at the user's site of a low frequency receiver and data logger system. The typical system contains a receiver, microcomputer, disc units and printerplotter. The user's responsibility is to provide a dedicated phone line and modem so that his data can be compared with that obtained at NBS, thus providing assurance that the measurements are valid. The user will also receive a bulletin, either by telephone transfer or by mail, which reports the performance of many of the accurate signal sources accessible by the system. To assist the user in getting the maximum benefit from the service, NBS provides specific training on the actual equipment.

Special Global Time Service (76110S) This service uses the Global Positioning System (GPS) satellites and an NBS-designed receiver which provides much higher precision time and frequency data and a high degree of automation. The data from a receiver, which is located at the user's facility, are automatically sent to an NBS computer. The NBS computer then stores the raw data, determines which data are suitable for time transfer calculations, and provides an optimally filtered value for the time and frequency of the user's clock with respect to the NBS atomic time scale.
The results are communicated to the user in a monthly report. The user is also given an account on one of the NBS computers through which he may access a preliminary NBS analysis which is calculated daily. Tests between receivers in California, Colorado, Washington, D.C., France, Germany, Spain and Canada have demonstrated an ability to perform time comparisons with a precision of less than 10 nanoseconds and frequency comparisons with a precision of $1 \times 10^{-14}$ or better $(1 \sigma)$ for averaging times of 4 days and longer. While useful characterization of frequency stability is available to at least this latter level, frequency accuracy is limited to $8 \times 15^{14}$, the accuracy of the NBS primary frequency standard.

\section{References-Time and Frequency Dissemination}

NBS Time and Frequency Dissemination Services, Natl. Bur. Stand. (U.S.) Spec. Publ. 432 (Sept. 1979). New Time and Frequency Services at the National Bureau of Standards, S. R. Stein, G. Kamas, and D. W. Allan, Proc. 15th Annual Precise Time and Time Interval (PTTI) Applications and Planning Meeting, 17 (Dec. 1983).

Accuracy of International Time and Frequency via Global Positioning System Satellites in Common View, D. W. Allan, et al., IEEE Trans. Instrum. and Meas., IM-34, 2, 118 (June 1985). 


\section{Oscillator Characterization \\ Time and Frequency Division Center for Basic Standards}

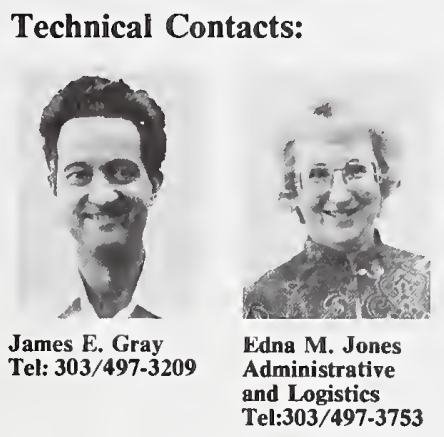

Mailing Address: M.C. 524.06, National Bureau of Standards, 325 Broadway, Boulder, CO 80303

Shipping Address: M.C. 524.06, Room 019, National Bureau of Standards, 325 Broadway, Boulder, CO 80303

\section{Test No. Items}

$77100 \mathrm{C}$ Precision Oscillator Frequency Calibration

77110C Characterization of Atomic Time and Frequency Standards

77120C Characterization of Precision Oscillators: Time Domain

77130C Characterization of Precision Oscillators: Frequency Domain

77140S Special Time/Frequency Measurements: Oscillators and Other Components

\section{Precision Oscillator Frequency Calibration (77100C)}

Precision oscillators can be readily calibrated in the frequency range from 1 to $100 \mathrm{MHz}$. Reference calibration accuracy is nominally that of the NBS primary frequency standard, that is, $8 \times 10^{-14}$. The accuracy level transferable to the oscillator depends upon the stability and noise properties of the oscillator.

Characterization of Atomic Time and Frequency Standards (77110C)

An atomic standard is characterized by introducing it as a member of the NBS time scale system. The clock output is sampled every two hours in sequence with the other regular clocks in the time scale. The data are logged in the NBS time scale computer and the characteristics of the standard are readily determined in relation to the performance of the time scale ensemble of clocks. At additional cost, the user can be given an account on the NBS time scale computer through which the data may be accessed in real time. The standard test involves 30 days of data acquisition. The square root of the Allan variance, $\sigma_{y}(\tau)$ is measured to $\pm 2 \times 10^{-12} \tau^{-1 / 2}$ for averaging times of about 7200 to $10^{6}$ seconds. The time scale accuracy is about $1 \times 10^{-13}$ and frequency drift is less than one part in $10^{15}$ per day. The actual values transferable to the standard depend on its stability and noise properties.

\section{Characterization of Precision} Oscillators: Time Domain (77120C)

For oscillator frequencies of 5,10 and $100 \mathrm{MHz}$, the stability in terms of $\sigma_{y}(\tau)$, the square root of the Allan 
variance, is determined by repeated measurements at 3 second intervals. $\sigma_{y}(\tau)$ is measured to $\pm 2 \times 10^{-12} \tau^{-1 / 2}$ for averaging times of 3 to approximately 10,000 seconds and frequency offset is measured to about $1 \times 10^{-13}$. As noted under the description of tests $77100 \mathrm{C}$ and $77110 \mathrm{C}$, the transferable accuracy depends upon the stability and noise properties of the calibrated oscillator.

\section{Characterization of Precision Oscillators: Frequency Domain (77130C)}

For oscillator frequencies of 5, 10 and $100 \mathrm{MHz}$, phase noise, $\mathbf{S}_{\varphi}(\mathrm{f})$, can be determined for Fourier frequency offsets from the carrier of $0.1 \mathrm{~Hz}$ to 50 $\mathrm{KHz}$ (higher by special request). The phase noise is measured for only a few user-specified frequency offsets. For an offset of $1 \mathrm{~Hz}, \mathrm{~S}_{\varphi}(\mathrm{f})$ can be measured to $-115 \mathrm{~dB}$ (relative to 1 $\operatorname{radian}^{2} /$ Hertz) and for an offset of 10 $\mathrm{KHz}, \mathrm{S}_{\varphi}(\mathrm{f})$ is measured to $-175 \mathrm{~dB}$.

Special Time/Frequency

Measurements: Oscillators and Other Components (77140S)

Frequency and time domain measurements can be made at frequencies other than those cited in tests $77120 \mathrm{C}$ and $77130 \mathrm{C}$, but the accuracy and cost is dependent upon the value of the frequency. Given two or more oscillators, frequency multipliers, dividers, synthesizers or amplifiers, relative phase noise can be measured to a very high precision and the frequency for the measurement is not as restrictive as above. Also, the one PPS (pulse per second) output of atomic frequency standards can be measured with an accuracy of 0.5 nanoseconds given an adequately defined, fast pulse.

\section{References-Oscillator Characterization}

Properties of Signal Sources and Measurement Methods, D. A. Howe, D. W. Allan and J. A. Barnes, Proc. 35th Ann. Freq. Control Symp., A.1, Phil. (May 1981). 


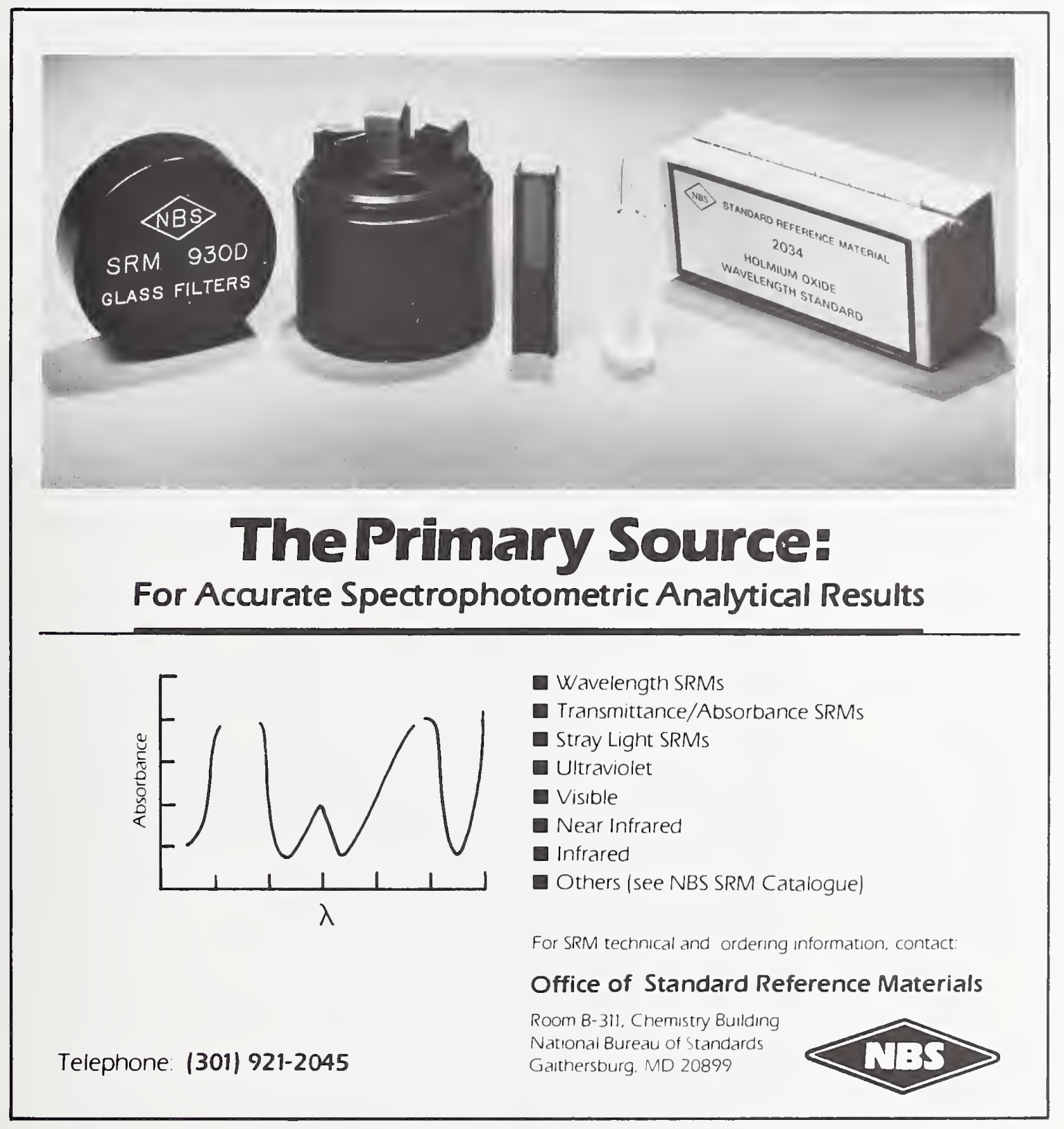




\section{ADDENDUM}

\section{Numerical Cross-Index}

\section{Old vs. New NBS Test Numbers}

Old Test No. New Test No.

$1.1 \mathrm{~A}$

$1.1 \mathrm{~B}$

$1.1 \mathrm{C}$

1.1D

$1.1 \mathrm{E}$

$1.1 \mathrm{G}$

$1.1 \mathrm{H}$

$1.1 \mathrm{P}$

$1.1 \mathrm{Q}$

$1.1 \mathrm{R}$

$1.3 \mathrm{~A}$

$1.3 \mathrm{C}$

$1.3 \mathrm{H}$

$1.3 \mathrm{~J}$

$1.3 \mathrm{~K}$

$1.3 \mathrm{M}$

$1.4 \mathrm{~A}$

$1.4 \mathrm{~B}$

$1.4 \mathrm{C}$

$1.4 \mathrm{D}$

$1.4 \mathrm{E}$

$1.4 \mathrm{~F}$

$1.5 \mathrm{~A}$

$1.5 \mathrm{~B}$

$1.5 \mathrm{C}$

$1.5 \mathrm{E}$

$1.5 \mathrm{~F}$

$1.5 \mathrm{G}$

$1.5 \mathrm{~J}$

$1.6 \mathrm{~A}$

$1.6 \mathrm{~F}$

$1.6 \mathrm{G}$

$1.6 \mathrm{H}$

$1.7 \mathrm{~A}$

$1.7 \mathrm{~B}$

1.7D

$1.7 \mathrm{~F}$

$1.7 \mathrm{G}$

$1.7 \mathrm{H}$

$1.8 \mathrm{~A}$

$1.8 \mathrm{~B}$

$1.8 \mathrm{C}$

$1.9 \mathrm{C}$

$2.1 \mathrm{~A}$

2.1B

$2.1 \mathrm{C}$

2.1D
22170S

$22180 \mathrm{M}$

22010C-22030C

22040C-22120C

22130C-22160C

$17020 \mathrm{~S}$

$17010 \mathrm{C}$

$17030 \mathrm{~S}$

$17040 \mathrm{~S}$

$16010 \mathrm{C}$

$10050 \mathrm{~S}$

$10010 \mathrm{C}$

$10020 \mathrm{C}$

$10030 \mathrm{C}$

$10040 \mathrm{~S}$

$10060 \mathrm{~S}$

$11060 \mathrm{~S}$

$11070 \mathrm{~S}$

$11010 \mathrm{~S}$

$11020 \mathrm{C}$

$11030 \mathrm{~S}$

$11040 \mathrm{~S}$

$12020 \mathrm{~S}$

$12030 \mathrm{~S}$

$12010 \mathrm{C}$

$12040 \mathrm{~S}$

$12050 \mathrm{~S}$

$12060 \mathrm{~S}$

$12070 \mathrm{~S}$

$13010 \mathrm{~S}$

$13020 \mathrm{~S}$

$13030 \mathrm{~S}$

$14010 \mathrm{C}$

$14020 \mathrm{~S}$

$14040 \mathrm{~S}$

$14030 \mathrm{~S}$

$14050 \mathrm{~S}$

$14060 \mathrm{~S}$

$15010 \mathrm{C}$

$15020 \mathrm{C}$

$15030 \mathrm{C}$

38090 S

25060S

$25010 \mathrm{C}$

25020C

$25030 \mathrm{C}$

\section{Description of Test}

Special Mass Measurement Services

Measurement Assurance Prog. for Mass

Weight Sets (1 mg to $30 \mathrm{~kg}$ )

Single Weights

Weights for Dead-Weight Pres.

Volume Standards, Special Tests

Volume Standards

Density of Solids

Density of Liquids

Reference Standard Hydrometers

Length Standards

Gage Blocks

Line Standards

Surveying and Oil Gaging Tapes

Surveying Leveling Rods

Sieves

End Standards

Step Gages

Plug Gages

Measuring Wires for Threads and Gears

Spherical Diameter Standards

Internal Diameter Standards

Plain Conical Plug and Ring Gages

Threaded Plug and Ring Gages

API Threaded Plug and Ring Gages

Calipers and Gages

Micrometer Screws and Dial Micrometers

Penetration Needles

Two Dimensional Gages

Optical Reference Planes (Flats)

Roundness Standards

Roundness Calibration Specimens

Test no longer available

Angle Gage Blocks

Optical Polygons

Wedges

Rotary and Indexing Tables

Autocollimators

Angle Generators

Roughness Calibration Specimens

Surface Roughness Comparison Specimens

Step Height Measurements

Photographic Step Tablets

Acoustic Devices

Microphone WE Type 640AA or Equivalent $(50-10,000 \mathrm{~Hz})$

Microphone WE Type 640AA or Equivalent $(50-20,000 \mathrm{~Hz})$

Pressure Response: Tokyo Riko Type ECL MR112, B\&K Types $4134(50-10,000 \mathrm{~Hz})$ 
2.1E

$2.1 \mathrm{~F}$

$2.1 \mathrm{H}$

2.1R

$2.1 \mathrm{~S}$

$2.1 \mathrm{~T}$

$2.2 \mathrm{~A}$

$2.2 \mathrm{~B}$

$2.2 \mathrm{C}$

2.2D

$2.2 \mathrm{E}$

$2.2 \mathrm{~F}$

$2.2 \mathrm{G}$

$2.3 \mathrm{~A}$

2.3B

2.3C

$2.3 \mathrm{~F}$

$2.3 \mathrm{G}$

$2.3 \mathrm{H}$

$2.3 \mathrm{I}$

$2.5 \mathrm{~A}$

2.5B

2.5D

$2.5 \mathrm{E}$

$2.5 \mathrm{G}$

$2.5 \mathrm{H}$

$2.5 \mathrm{~J}$

$2.5 \mathrm{~K}$

$2.5 \mathrm{M}$

$2.5 \mathrm{~N}$

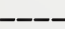

2.7A

2.7B

2.7C

2.7D

$2.7 \mathrm{E}$

$2.9 \mathrm{~A}$

2.9B

$2.9 \mathrm{C}$

$2.9 \mathrm{E}$
$25040 \mathrm{C}$

$25050 \mathrm{C}$

$25070 \mathrm{~S}$

26030S

$26010 \mathrm{C}$

26020C

24010C

$24020 \mathrm{C}$

$24030 \mathrm{C}$

24060S

$24050 \mathrm{~S}$

$24040 \mathrm{~S}$

$36070 \mathrm{~S}$

$36010 \mathrm{C}$

$36020 \mathrm{C}$

$36030 \mathrm{C}$

$36040 \mathrm{C}$

$36050 \mathrm{C}$

$36060 \mathrm{C}$

$23010 \mathrm{C}$

$23040 \mathrm{C}$

$23070 \mathrm{C}$

$23100 \mathrm{C}$

$23130 \mathrm{C}$

$23160 \mathrm{C}$

$23190 \mathrm{C}$

$23220 \mathrm{C}$

$23250 \mathrm{C}$

$23260 \mathrm{~S}$

$23270 S$

$18050 \mathrm{~S}$

$18010 \mathrm{C}$

$18020 \mathrm{C}$

$18030 \mathrm{C}$

$18040 \mathrm{C}$

$19030 \mathrm{~S}$

$19010 \mathrm{C}$

$19020 \mathrm{C}$
Same as $25030 \mathrm{C}(50-20,000 \mathrm{~Hz})$

Free Field Response: Tokyo Riko

Type ECL MR112, B\&K Types 4133, 4134, 4165 and $4166(2,500-20,000 \mathrm{~Hz})$

Earphones

Ultrasonic Amplitude Reference Blocks

Ultrasonic Transducer Power and Frequency

Acoustic Emission Sensors

Vibration Pickup Sensitivity, $2-100 \mathrm{~Hz}$

Test No Longer Available

Vibration Pickup Sensitivity, $10-3,500 \mathrm{~Hz}$

Vibration Pickup Sensitivity, $10-10,000 \mathrm{~Hz}$

Special Vibration Measurement Services

Special Vibration Pickup Sensitivity Tests

Special Shock Measurement Services

Humidity Measurement Services

Dewpoint Hygrometers, -25 to $-15^{\circ} \mathrm{C}$

Dewpoint Hygrometers, -15 to $-70^{\circ} \mathrm{C}$

Electric Hygrometer

Coulometric Hygrometer

Aspirated Hygrometer

Pneumatic Bridge Hygrometer

Force Transducers, to $25,000 \mathrm{lbf}, 1$ mode

Force Transducers, to $25,000 \mathrm{lbf}, 2$ modes

Force Transducers, 25,001 to $112,000 \mathrm{lbf}$, 1 mode

Force Transducers, 25,001 to $112,000 \mathrm{lbf}$, 2 modes

Force Transducers, 112,001 to $300,000 \mathrm{lbf}$, 1 mode

Force Transducers, 112,001 to $300,000 \mathrm{lbf}$, 2 modes

Force Transducers, 300,001 to $1,000,000 \mathrm{lbf}$, 1 mode

Force Transducers, 300,001 to $1,000,000 \mathrm{lbf}$, 2 modes

Force Transducers, Over 1,000,000 lbf, compression only

Special Force Measurement Services

Pattern Evaluation Tests of Load Cells in Compression

Liquid and Gas Flow Rates

Single Turbine Meters

Tandem Turbine Meters

Flow Rate Meters, Direct Reading

Head Class Flow Measurement Devices

Test no longer available

Airspeed Measurements

Pitot-static Tubes

Low Airspeed Instruments 
$3.1 \mathrm{~A}$

$3.1 \mathrm{~B}$

$3.1 \mathrm{C}$

3.1D

\subsection{E-3.1 J}

3.10

3.1P

$3.1 \mathrm{Q}$

3.1R-3.1T

\section{$3.1 \mathrm{U}$}

$3.1 \mathrm{~V}-3.1 \mathrm{Z}$

$3.2 \mathrm{C}$

3.2Q-3.2R

$3.2 \mathrm{~V}-3.2 \mathrm{~W}$

$3.3 \mathrm{~A}$

3.3B

3.3C-3.3D

3.3E-3.3G

\subsection{H-3.3I}

$3.3 \mathrm{~J}$

$3.3 \mathrm{~K}-3.3 \mathrm{~L}$

$3.3 \mathrm{M}-3.3 \mathrm{~N}$

3.3X-3.3Y

$3.4 \mathrm{~A}$

3.4B

3.4C-3.4D

$3.4 \mathrm{E}$

$3.4 \mathrm{~F}$

$3.4 \mathrm{G}$

$3.4 \mathrm{H}-3.4 \mathrm{I}$

$3.5 \mathrm{~A}$

3.5B-3.5D

$3.6 \mathrm{~A}$
$51100 \mathrm{~S}$

$51110 \mathrm{M}$

$51130 \mathrm{C}$

$51131 \mathrm{C}$

51132C-51142C

51143C-51150C

51151C-51154C

$51100 \mathrm{~S}$

51160C-51163C

$51100 \mathrm{~S}$

51133C-51141C

$54110 \mathrm{~S}$

$54120 \mathrm{C}-54131 \mathrm{C}$

$52110 S$

$52180 \mathrm{C}-52181 \mathrm{C}$

$52140 \mathrm{C}-52150 \mathrm{C}$

$52130 \mathrm{C}$

$52160 \mathrm{C}-52161 \mathrm{C}$

$52170 \mathrm{C}-52171 \mathrm{C}$

$52610 \mathrm{C}$

$53110 \mathrm{~S}$

$53120 \mathrm{M}$

$53130 \mathrm{C}-53131 \mathrm{C}$

$53140 \mathrm{C}$

$53150 \mathrm{C}$

$53160 \mathrm{C}-53161 \mathrm{~S}$

$53310 \mathrm{~S}$

$53340 \mathrm{C}-53343 \mathrm{C}$

54600S; 54310S;

56120C; 51410S;
Special Resistance Measurement Services

Measurement Assurance Program Services for Resistance

Standard Resistor, Thomas-Type, $1 \Omega$

Standard Resistor, Evanohm Wirewound High Precision, $10 \mathrm{k} \Omega$

Standard Resistors, Two- and Four-

Terminal, $0.0001 \Omega$ to $1 \mathrm{M} \Omega$, Even Decades

Standard Resistors, $10 \mathrm{M} \Omega-10 \mathrm{G} \Omega$

Standard Resistors, $100 \mathrm{G} \Omega-1 \mathrm{~T} \Omega$

Pressure Coefficient, Thomas Resistors

Standard Resistors for Current Measurements (Shunts), Service Only in May and Nov.

Adjustible Low Resistance Standard

Standard Resistors, Two- and FourTerminal, $0.001 \Omega$ to $.1 \mathrm{M} \Omega$, Odd Decades

Special Ratio Measurements and Tests of Inductive Voltage Dividers

by Prearrangement

Inductive Voltage Dividers

Test No Longer Available

Special LF Impedance Measurements by Prearrangement

Temporarily Discontinued

Fixed Inductors, Self or Manual-Mutual (check 7.1B)

Fixed Three-Terminal High Precision Standard Capacitors with Coaxial Connectors, High Accuarcy Test

Tests No Longer Available

Standard Fixed, Fused Silica Dielectric Capacitor

Fixed, Three-Terminal Standard Capacitors with Coaxial Connectors

Two- or Three-Terminal Solid Dielectric Standard Capacitors

Eddy Current Conductivity Standards

Special DC Voltage Measurements by Prearrangement

Measurement Assurance Program for DC Voltage

Saturated Standard Cells

Platinum Resistance Thermometer

Temperature Determination for Standard Cell Calibration

Unsaturated Standard Cells

Test No Longer A vailable

Tests of Solid State Voltage

Reference Standards

Special AC-DC Measurement Services

by Prearrangement

AC-DC Thermal Voltage and Current

Converters (to $1 \mathrm{MHz}$ )

Special Tests of Dividers,

Transformers, and AC Resistors 
3.6B-3.6E

$3.6 \mathrm{~F}-3.6 \mathrm{H}$

$3.6 \mathrm{I}$

$3.6 \mathrm{~J}-3.6 \mathrm{M}$

$3.6 \mathrm{~N}$

3.60

$3.6 \mathrm{P}$

$3.6 \mathrm{Q}$

$3.8 \mathrm{~A}$

$3.8 \mathrm{~B}$

$3.8 \mathrm{C}$

3.9A

3.9B-3.9F

4.1A

4.1B

4.1C

4.1D

----

4.1E

4.2A

4.2B-4.2C

4.3A

4.3B
$53500 \mathrm{~S}$

53510C-53540S

64100S-64400S

54510C-54513C

54520C-54522C

$56210 \mathrm{M}$

56200C-56203C $54210 \mathrm{C}$

$51210 \mathrm{C}$

$52400 \mathrm{C}$

$54410 \mathrm{~S}$

$54420 \mathrm{~S}$

$51410 \mathrm{~S}$

$56110 S$

$53200 S$

$61250 \mathrm{~S}$

61210C-61211C

$61215 \mathrm{C}$

$61230 \mathrm{C}$

$61240 S$

65300S-65301S

63100S-63400S

52210C-52310S

(52710C-52711C; 51310C)

$52210 \mathrm{~S}$

(52211C)
Voltage Transformers, Ratio and Phase Angle

Current Transformers, Ratio and Phase

Angle

Measurement Assurance Program for Watthour Meters

Watthour Meters, Percentage Registration

Resistors and Resistive Dividers,

Total Resistance or Voltage Ratio

High-Voltage Standard Resistors

Power-Frequency Capacitors

Pulse-Voltage-Measuring Systems Including Kerr Cells

$\mathrm{X}$-ray Unit, Voltage Dividers

Special Tests of Resistors by Prearrangment

Special Tests of AC-DC Wattmeters

by Prearrangement

Low-Frequency AC Voltmeters and Sources, $0.1 \mathrm{~Hz}$ to $10 \mathrm{~Hz}, 0.5 \mathrm{~V}$ to $7 \mathrm{~V}$, by

Prearrangement

Special Data Converter Services by Prearrangement

A/D or D/A Converters-Linearity Errors, Correction Coefficients, Superposition Errors; Differential Linearity Errors, Equivalent RMS Input Noise; and Offset/Gain Errors (Relative to Legal Volt)

Special Attenuator Measurements by Prearrangement

Coaxial Fixed and Variable Attenuators, $30 \mathrm{MHz}$ and $100 \mathrm{MHz}$ to $18 \mathrm{GHz}$ (ANA)

Waveguide Circular Below Cutoff(Piston) Attenuators, Coaxial Connectors

Variable Rectangular WaveguideAttenuators, Attenuation Difference

Special Attenuation Measurements of Three-Port and Two-Port Devices at $1.25 \mathrm{MHz}$

Network Impulse Response of Coaxial Networks, $100 \mathrm{kHz}$ to $12.5 \mathrm{GHz}$

Special Test Services for Microwave Antenna and Probe Parameter Measurements, Including Special Consulting, Advisory, and Other Services for Antennas

Special Test Services for Electromagnetic Field Strength and Antenna Measurements, Including SpecialTest Services for Electromagnetic Interference

High-Frequency Standard Capacitors and Inductors (Calibration Services: High-Frequency Standard Resistors, Q-Standards)

Special Test of Two-Terminal, Low-Loss $\mathrm{S}^{+}$andard Capacitors, $1 \mathrm{MHz}$ (Calibration Service: High Accuracy Capacitors of Same Type 


$\begin{array}{ll}4.3 \mathrm{C} & 52220 \mathrm{C}-52221 \mathrm{C} \\ 4.3 \mathrm{D} & 52222 \mathrm{C}-52223 \mathrm{C} \\ 4.3 \mathrm{E} & 52710 \mathrm{C}-52711 \mathrm{C} \\ 4.3 \mathrm{~F} & 61310 \mathrm{C} \\ & \\ 4.3 \mathrm{G}-4.3 \mathrm{H} & 61320 \mathrm{C}-61331 \mathrm{~S}\end{array}$

4.4A

4.4B

4.5A

4.5B

4.6A

$4.6 \mathrm{~B}-4.6 \mathrm{C}$

4.6D-4.6E
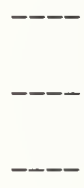

4.7A

4.7B

4.7C

4.7D

4.8A

4.8B
42010S

42020M-42090M

$41010 \mathrm{~S}$

$41020 \mathrm{~S}$

$62020 S$

62100S-62111S

62120S-62130S

$62140 \mathrm{~S}$

$55110 \mathrm{~S}$

$55210 \mathrm{C}-55221 \mathrm{C}$

$55230 \mathrm{~S}$

$61450 S$

61410C-61411C

$61420 \mathrm{C}$

$65400 \mathrm{~S}$

$61190 S$

61110S-61111S
Calibration Services for Three-Terminal, Low-Loss Standard Capacitors

Special Tests of Three-Terminal (MacLeod and Hanopol) Capacitors, $465 \mathrm{kHz}$

Inductive Q-Standards, $50 \mathrm{kHz}-45 \mathrm{MHz}$

Complex Reflection Coefficient, Impedance, and Voltage Standing Wave Ratio of Coaxial Terminations by ANA, $0.1-18 \mathrm{GHz}$

Magnitude of Reflection Coefficient of Rectangular Waveguide (Mismatches) Reflectors and Nonreflecting Waveguide Ports and Matched Loads

Special Tests of Laser Power and Energy by Prearrangement

Measurement Assurance Program for Laser Power and Energy

Special Tests for Attenuation of Telecommunication-Grade Multimode Optical-Fibers

Special Tests for Bandwidth of Telecommunication-Grade Multimode Optical Fibers

Special Electromagnetic Noise Temperature Measurements by Prearrangement

Special Tests for Effective Noise Temperature of Coaxial Noise Generators

Special Tests for Effective Noise Temperature of Waveguide Noise Generators

Special Services for Earth Terminals Used in Satellite Communications

Special Tests of Phase Angle Meters by Prearrangement

Special Tests of Very-High Frequency Omnidirectional Range Instrument Parameters

Special VOR Tests

Special Tests of Phase Shifters by Prearrangement

Coaxial Fixed and Variable Phase Shifters

Variable Rectangular Waveguide Phase Shifters

Special Tests for Pulse Time Delay Through Coaxial Transmission Lines

Special Microwave and RF Power Measurement Services by Prearrangement

Special Tests for Coaxial Power Meters (Effective Efficiency and Reflection Coefficient) at Selected Single Frequency in Range 0.1 to $10 \mathrm{MHz}$

Special Test for Output of Power Reference in TE Power Meters 
Special Tests for Coaxial Power Meters (Calibration Factor, EffectiveEfficiency, Efficiency Factor, Reflection Coefficient) at Specified Frequencies in Range 10 to $1000 \mathrm{MHz}$

Special Tests for Coaxial Power Meters (Effective Efficiency, EfficiencyFactor, Reflection Coefficient) atSpecified Frequencies in Range 1 to $18 \mathrm{GHz}$ Special Tests for Rectangular-Wave-guide Power Meters (Effective Efficiency, Efficiency Factor, Reflection Coefficient) at Specified Intervals in FrequencyBands Covering 2.6 to $18 \mathrm{GHz}$

Special Tests for Rectangular-Wave-guide Power Meters (Effective Efficiency, Reflection Coefficient)at Selected Single Frequency Within $18 \mathrm{GHz}$ to $40 \mathrm{GHz}$ (WR42, WR28)

Special Tests for Rectangular-Wave-guide Power Meters (EffectiveEfficiency, Efficiency Factor,Reflection Coefficient) at Specified Intervals in FrequencyBands Covering Total Range 18 to $96 \mathrm{GHz}$ (WR42, WR28, WR15, WR10)

Test No Longer Available

Special Tests of AC Thermal and Current Voltage Converters $(100 \mathrm{~Hz} 1 \mathrm{GHz})$ by Prearrangement

Low-Frequency TVCs, total range $0.1 \mathrm{kHz}$ to $100 \mathrm{MHz}$

High-Frequency TVCs, total range 10 to $1000 \mathrm{MHz}$

RF Micropotentiometer Calibrations

Special Tests for Impulse GeneratorSpectrum Amplitude (50 $\Omega$ )

Special Tests for Fast Repetitive Baseband Pulse Parameters

Special Tests for Peak-to-Peak Detectors

Special Frequency Measurement Service

Special Global Time Service

Special Time/Frequency Measurements

Precision Oscillator Frequency Calibration

Characterization of Precision OscillatorsTime Domain andFrequency Domain

Time Pulses

Characterization of Atomic Time and Frequency

Special Tests of Cryogenic Liquid Flow

Test No Longer Available

Special Thermometry Services by Prearrangement 


$\begin{array}{ll}7.1 \mathrm{~B}-7.1 \mathrm{~F} & 31010 \mathrm{C}-31061 \mathrm{C} \\ 7.1 \mathrm{G} & 31070 \mathrm{C}-31071 \mathrm{C} \\ 7.1 \mathrm{H} & 31080 \mathrm{C}-31081 \mathrm{C} \\ 7.1 \mathrm{I} & 31200 \mathrm{~S} \\ & \\ 7.1 \mathrm{~J} & 31250 \mathrm{~S} \\ 7.1 \mathrm{~K}-7.10 & 31100 \mathrm{~S}-31161 \mathrm{~S} \\ 7.2 \mathrm{~A} & 32150 \mathrm{~S} \\ 7.2 \mathrm{~B}-7.2 \mathrm{~F} & 32010 \mathrm{C}-32044 \mathrm{C} \\ 7.2 \mathrm{G} & 32070 \mathrm{C} \\ 7.2 \mathrm{H} & 32050 \mathrm{C}-32051 \mathrm{C} \\ 7.2 \mathrm{~K}-7.2 \mathrm{M} & 32090 \mathrm{C}-32092 \mathrm{C} \\ 7.2 \mathrm{~N}-7.2 \mathrm{O} & 32100 \mathrm{C}-32101 \mathrm{C} \\ 7.2 \mathrm{R}-7.2 \mathrm{U} & 32110 \mathrm{C}-32147 \mathrm{C}\end{array}$

$\begin{array}{ll}7.3 \mathrm{~A} & 33100 \mathrm{~S} \\ 7.3 \mathrm{~B}-7.3 \mathrm{C} & 33010 \mathrm{C}-33020 \mathrm{C} \\ 7.3 \mathrm{D} & 33030 \mathrm{C} \\ 7.3 \mathrm{E}-7.3 \mathrm{~F} & 33040 \mathrm{C}-33050 \mathrm{C} \\ 7.3 \mathrm{G}-7.3 \mathrm{H} & 33070 \mathrm{C}-33080 \mathrm{C} \\ 7.3 \mathrm{I} & 33090 \mathrm{C} \\ & \\ 7.3 \mathrm{~J} & 33120 \mathrm{M} \\ & \\ 7.3 \mathrm{~K} & 33110 \mathrm{~S} \\ 7.3 \mathrm{P} & 33060 \mathrm{~S} \\ & \\ 7.4 \mathrm{~A} & 35070 \mathrm{~S} \\ 7.4 \mathrm{~B}-7.4 \mathrm{E} & 35010 \mathrm{C}-35040 \mathrm{C} \\ 7.4 \mathrm{~F}-7.4 \mathrm{G} & 35050 \mathrm{C}-35060 \mathrm{C} \\ 7.5 \mathrm{~A} & 39070 \mathrm{~S} \\ 7.5 \mathrm{~B}-7.5 \mathrm{D} & 39010 \mathrm{C}-39030 \mathrm{C} \\ 7.5 \mathrm{G} & 39040 \mathrm{C} \\ 7.5 \mathrm{H} & 39060 \mathrm{C} \\ & \\ 7.5 \mathrm{~J} & 39050 \mathrm{C} \\ 7.6 \mathrm{~A} & 40040 \mathrm{~S} \\ 7.6 \mathrm{~B} & 40010 \mathrm{~S} \\ 7.6 \mathrm{C} & 40020 \mathrm{~S} \\ 7.6 \mathrm{D} & 40030 \mathrm{~S} \\ 7.7 \mathrm{~A} & 37180 \mathrm{~S} \\ 7.7 \mathrm{~B}-7.7 \mathrm{H} & 37010 \mathrm{C}-37070 \mathrm{C} \\ 7.7 \mathrm{I}-7.7 \mathrm{M} & 37080 \mathrm{C}-37120 \mathrm{C}\end{array}$

Laboratory Thermometers

Calorimetric Thermometers

Beckman Thermometers

Preliminary Examination of Ineligible Thermometer

Additional Copy of Report

Special Tests of Thermometers

Special Tests of Thermocouples and Thermocouple Materials

Thermocouple Comparison Calibration, Temperature Measured with Thermocouple

TC Materials Tested Against Platinum Standard

Comparison Calibrations, Additional Point for $32050 \mathrm{C}$

Thermocouple Calibration at Metal Freezing Points

Calibration of Pyrometer Indicators

Comparison Calibration of Thermocouple Materials; Tested Against Pt Thermoelectric Standard, Temperature Measured with Pt Resistance Thermometers

Special Tests of Resistance Thermometers

Long Stem PRTs

Calorimetric Type PRTs

Capsule Type PRTs

Additional Copies of PRT Data Tables

Minimum Charge for Unsuitable Thermometers

Measurement Assurance Program for Temperature

Special Tests of Thermometric Fixed Point Devices

Special Tests of Germanium Resistance Thermometers ( 2 to $20 \mathrm{~K}$ )

Special Tests of Radiation Pyrometers

Optical Pyrometers

Ribbon Filament Lamps

Special Tests of Radiometric Sources

Spectral Radiance Ribbon Filament Lamps

Spectral Radiance QuartzzHalogen Lamps

Photodiode Spectral Response Rental Package

Spectral Irradiance Deuterium Lamps

Special Tests of Radiometric Devices in the Near and Vacuum Ultraviolet

Spectral Irradiance Standard, Argon Mini-Arc

Spectral Radiance Standard, Argon Mini-Arc Spectral Irradiance Standard, Deuterium Arc Lamp

Special Photometric Tests

Luminous Intensity Standards, Frosted Tungsten Lamps

Luminous Flux Standards, Tungsten Vacuum and Gas Filled Lamp 


\begin{tabular}{|c|c|c|}
\hline 7..7N-7.7P & $37140 \mathrm{C}-37160 \mathrm{C}$ & Airway Beacon Lamps for Color Temperature \\
\hline $7.7 \mathrm{Q}$ & $37130 \mathrm{C}$ & Luminous Flux Standards, Miniature Lamps \\
\hline $7.7 \mathrm{R}$ & $37170 \mathrm{C}$ & $\begin{array}{l}\text { Opal Glass Luminous Directional Trans- } \\
\text { mittance Standards }\end{array}$ \\
\hline $7.8 \mathrm{~A}$ & $38060 \mathrm{~S}$ & $\begin{array}{l}\text { Special Tests of Spectral Transmittance and } \\
\text { Reflectance }\end{array}$ \\
\hline $7.8 \mathrm{~B}-7.8 \mathrm{E}$ & $38010 \mathrm{C}-38040 \mathrm{C}$ & $\begin{array}{l}\text { Spectral Transmittance Standards, } \\
390-750 \mathrm{~nm}\end{array}$ \\
\hline $7.8 \mathrm{~F}$ & $38070 \mathrm{M}-38074 \mathrm{M}$ & $\begin{array}{l}\text { Measurement Assurance Programs for } \\
\text { Luminous Intensity of Retroreflectors }\end{array}$ \\
\hline $7.8 \mathrm{I}$ & $38050 \mathrm{C}$ & $\begin{array}{l}\text { Wavelength Standards (Holmium Oxide } \\
\text { Glass) }\end{array}$ \\
\hline---- & $38080 \mathrm{M}$ & $\begin{array}{l}\text { Measurement Assurance Program for } \\
\text { Transmittance }\end{array}$ \\
\hline $7.9 \mathrm{~A}$ & $\begin{array}{l}30040 S ; 30050 S \\
29040 S\end{array}$ & $\begin{array}{l}\text { Special Tests of Pressure and Vacuum } \\
\text { Gages }\end{array}$ \\
\hline $7.9 \mathrm{~B}$ & $29010 \mathrm{C}$ & Deadweight Piston Gages \\
\hline $7.9 \mathrm{C}$ & $29020 \mathrm{C}$ & Controlled Clearance Piston Gages \\
\hline 7.9D & $29035 \mathrm{C}$ & Mercurial Barometers and Manometers \\
\hline $7.9 \mathrm{E}$ & $29030 \mathrm{C}$ & Pressure Gages and Transducers \\
\hline $7.9 \mathrm{G}$ & $30010 \mathrm{C}-30020 \mathrm{C}$ & $\begin{array}{l}\text { Low Absolute and Differential Pressure } \\
\text { Gages }\end{array}$ \\
\hline $7.9 \mathrm{H}$ & $30030 \mathrm{C}$ & High Vacuum Gages \\
\hline $8.1 \mathrm{~A}$ & $44100 \mathrm{~S}$ & $\begin{array}{l}\text { Special Tests of Neutron Sources and } \\
\text { Dosimters }\end{array}$ \\
\hline $8.1 \mathrm{~B}-8.1 \mathrm{C}$ & $44010 \mathrm{C}-44020 \mathrm{C}$ & $\begin{array}{l}\text { Natural Standard Neutron Sources } \\
\left(10^{5}-10^{10} \mathrm{n} / \mathrm{s}\right)\end{array}$ \\
\hline $8.1 \mathrm{H}-8.1 \mathrm{~K}$ & $44040 S-44070 S$ & $\begin{array}{l}\text { Special Tests of Neutron Dosimeters--Ther- } \\
\text { mal Beam, Filtered Beam, Californium, and } \\
\text { Van de Graff Sources }\end{array}$ \\
\hline 8.1P & $44030 \mathrm{~S}$ & $\begin{array}{l}\text { Activated Foil Irradiation with Thermal } \\
\text { Neutrons }\end{array}$ \\
\hline $8.1 \mathrm{Q}-8.1 \mathrm{R}$ & $44080 \mathrm{C}-44090 \mathrm{C}$ & $\begin{array}{l}\text { Activated Foil } \\
\text { Irradiation-Californium and Cavity } \\
\text { Fission Sources }\end{array}$ \\
\hline $8.2 \mathrm{~A}$ & $43060 \mathrm{~S}-43090 \mathrm{~S}$ & Special Tests of Radioactive Solution Sources \\
\hline $8.2 \mathrm{C}$ & $43010 \mathrm{C}$ & $\begin{array}{l}\text { Gamma-Ray-Emitting Radionuclides in } \\
\text { Solution-Half Lives Greater than } 15 \text { Days }\end{array}$ \\
\hline $8.2 \mathrm{D}$ & $43020 \mathrm{C}$ & $\begin{array}{l}\text { Gamma-Ray-Emitting Radionuclides in } \\
\text { Solution-Half Lives Less than } 15 \text { Days }\end{array}$ \\
\hline $8.2 \mathrm{H}-8.2 \mathrm{~J}$ & $43030 \mathrm{C}-43050 \mathrm{C}$ & $\begin{array}{l}\text { Alpha-Particle-Emitting Solid Sources } \\
\text { Various Counting Systems }\end{array}$ \\
\hline $8.2 \mathrm{P}$ & $43060 \mathrm{~S}$ & $\begin{array}{l}\text { Special Tests of Beta-Particle-Emitting } \\
\text { Solution-Liquid } \\
\text { Scintillation Counting }\end{array}$ \\
\hline $8.2 \mathrm{Q}-8.2 \mathrm{R}$ & $43070 \mathrm{~S}$ & $\begin{array}{l}\text { Special Tests of Beta-Particle Emitting } \\
\text { Solution Sources-Other Techniques }\end{array}$ \\
\hline $8.3 \mathrm{~A}$ & $46050 \mathrm{~S}$ & $\begin{array}{l}\text { Special Tests of X-Ray and Gamma-Ray } \\
\text { Measuring Instruments }\end{array}$ \\
\hline $8.3 \mathrm{~B}-8.3 \mathrm{C}$ & $46010 \mathrm{C}-46011 \mathrm{C}$ & $\begin{array}{l}\text { Radiation Detectors-Calibration/Correction } \\
\text { Factors, Various Beam Qualities }\end{array}$ \\
\hline $8.3 \mathrm{D}$ & $46030 \mathrm{~S}$ & $\begin{array}{l}\text { Special Tests of High-Gain Electrometers- } \\
\text { Charge Sensitivity }\end{array}$ \\
\hline $8.3 \mathrm{M}-3.3 \mathrm{~N}$ & $46020 \mathrm{C}-46021 \mathrm{C}$ & Irradiation of Passive Dosimeters \\
\hline $8.3 \mathrm{R}$ & $46040 \mathrm{~S}$ & $\begin{array}{l}\text { Special Tests of X-Ray Penetrameters, } \\
\text { Ardran-Crookes Type }\end{array}$ \\
\hline $8.4 \mathrm{~A}$ & $47040 S$ & $\begin{array}{l}\text { Special Tests of Gamma-Ray and Beta- } \\
\text { Particle Sources }\end{array}$ \\
\hline $8.4 \mathrm{E}-8.4 \mathrm{~F}$ & $47010 \mathrm{C}-47011 \mathrm{C}$ & $\begin{array}{l}\text { Gamma-Ray Sources-Exposure Rates } \\
0.1-100(\mu \mathrm{R} / \mathrm{S}) \mathrm{m}^{2}\end{array}$ \\
\hline $8.4 \mathrm{~K}$ & $47030 \mathrm{C}$ & $\begin{array}{l}\text { Beta-Particle Sources Calibrated forSurface } \\
\text { Dose Rate }\end{array}$ \\
\hline $8.5 \mathrm{~A}$ & $48020 \mathrm{~S}$ & Special Tests of Electron-BeamDosimters \\
\hline $8.5 \mathrm{~B}-8.5 \mathrm{C}$ & $48010 \mathrm{C}-48011 \mathrm{C}$ & Irradiation of Ferrous-Ferric Dosimeters \\
\hline $8.6 \mathrm{~A}$ & $49010 \mathrm{~S}$ & $\begin{array}{l}\text { Special Tests of Customer Supplied } \\
\text { Dosimeters Irradiated with Cobalt-60 } \\
\text { Gamma-Rays }\end{array}$ \\
\hline $8.6 \mathrm{~B}-8.6 \mathrm{C}$ & $49020 \mathrm{~S}-49030 \mathrm{~S}$ & $\begin{array}{l}\text { Dose interpretation of NBS-Packaged } \\
\text { Dosimeters Irradiated by Customer }\end{array}$ \\
\hline $8.6 \mathrm{D}-8.6 \mathrm{E}$ & 49040S-49041S & Spectrophotometric Reading of Dosimeters \\
\hline $8.6 \mathrm{~F}$ & $49050 \mathrm{~S}$ & $\begin{array}{l}\text { Special Measurement Services for Dosimeter } \\
\text { Response }\end{array}$ \\
\hline
\end{tabular}




\section{ALPHABETICAL CROSS-INDEX}

Item

Test Number

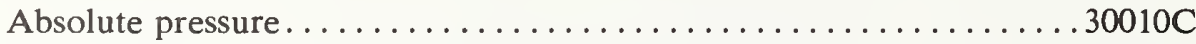

Ac resistors ....................................

Ac-dc thermal converters (to $1 \mathrm{MHz}$ )................... 53310S-53343C

Ac-dc thermal converters $(100 \mathrm{~Hz}$ to $1 \mathrm{GHz}) \ldots \ldots \ldots \ldots \ldots \ldots . \ldots \ldots 5405 \mathrm{~S}-53445 \mathrm{~S}$

Ac voltmeters, low-frequency .......................53200S

Ac-dc wattmeters..............................56110S-56210M

Acoustic emission sensors.........................26020C

Acoustic devices..............................25060S

Activated foil irradiation with thermal neutrons ...............44030S

Activated foil irridiation-Californium and cavity fission sources ... 44080C-44090C

$\mathrm{A} / \mathrm{D}$ and $\mathrm{D} / \mathrm{A}$ data converters ...................... 53500S-53540S

Air-speed indicators.............................. 19010C-19030S

Alpha-particle-emitting solid sources . . . . . . . . . . . . . . . 43030C-43050C

Aluminum ultrasound reference blocks ...................26030S

American Petroleum Institute gages . . . . . . . . . . . . . . . 12010C

Analog-to-digital data converters . . . . . . . . . . . . . . . 53500S-53540S

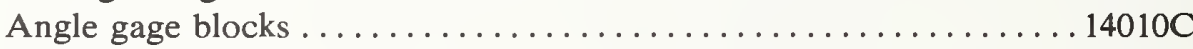

Angle generators .........................................

Angle measurements ............................ . 14010C-14060S

Antenna parameter measurements, microwave............63100S-63400S

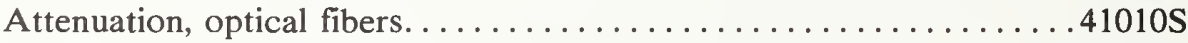

Attenuators, $\mathrm{rf}$ and microwave .....................61210C-61250S

Audio-frequency phase meter.............................

Autocollimators ...........................................

Bandwidth, optical fibers .......................41020S

Barometers.....................................30010C

Beckman thermometers............................ 31080C-31081C

Beta-particle-emitting sources ....................43060S-47030C

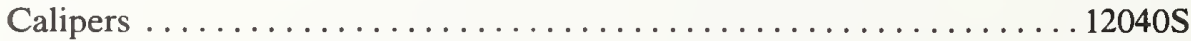

Calorimeter thermometers ...........................31070C-31071C

Capacitance and inductance measurements, low-frequency ........52110S-52150C

Capacitors, dielectric............................52130C

Capacitors, high-frequency........................52210C-52223C

Capacitors, low-frequency ..................................

Capacitors, power frequency ......................52400C

Capacitive dividers. ................................54310s

Coaxial attenuators..............................61210C-61211C

Coaxial power meters ..........................61110S-61128S

Coaxial terminations and reflection coefficients ............61310C

Color temperature ..............................37140C-37160C

Conductivity, eddy current ......................52610C

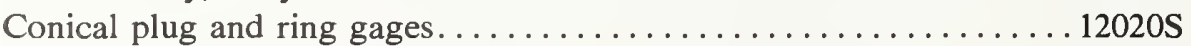

Converters, A/D and D/A ........................... 53500S-53540S

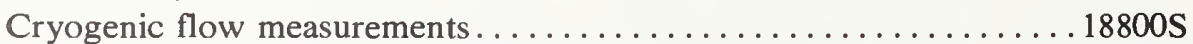

Cryogenic temperature measurements ....................33030C-33100S

Current and voltage transformers .................... 54510C-54600S 
Data converters, A/D and D/A

$53500 \mathrm{~S}-53540 \mathrm{~S}$

Dc resistance measurements.........................51100S-51163C

Dc voltage measurements.........................53110S-53190S

Deadweight piston gages ........................29010C

Density measurements, liquids ........................... 17040S

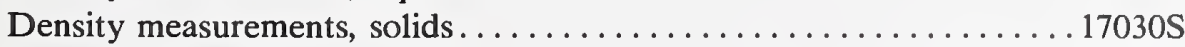

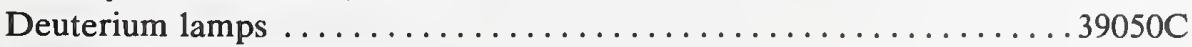

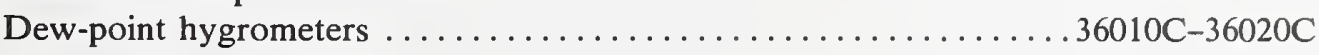

Diameter measurements ..........................11010S-11080S

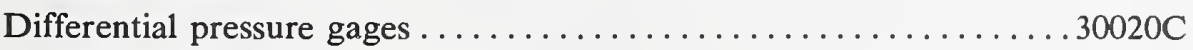

Digital-to-analog data converters .....................53500S-53540S

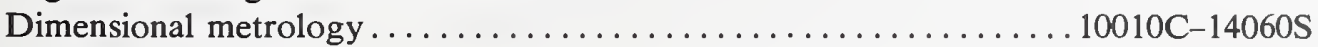

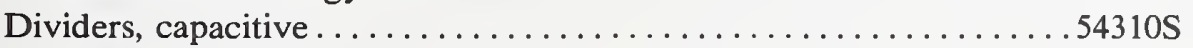

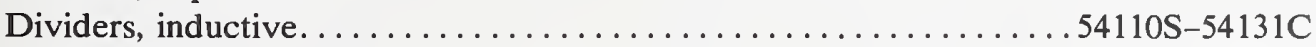

Dividers, mixed . . . . . . . . . . . . . . . . . . . . . . . . . . . 54410S-54420S

Dividers, resistive............................. 54210C

Dosimeters, electron beam ...........................48010C-48020S

Dosimeters, high dose . . . . . . . . . . . . . . . . . . . . . . . . . 49010S-49050S

Dosimeters, neutron. . . . . . . . . . . . . . . . . . . . . . . . . .44040S-44070S

Dosimeters, radiochromic............................49020S-49030S

Dosimeters, spectrophotometric reading . . . . . . . . . . . . . . 49040S-49041S

Dosimeters, $x$ and gamma-ray......................... .46010C-46021C

Earphones .....................................25070S

Eddy Current Conductivity .......................52610C-52611C

Electromagnetic field-strength parameter measurements ........64100S-64400S

Electrometers .................................46030S

Electron beam dosimetry .......................48010C-48020S

Energy and power measurements, low frequency ............56110S-56210M

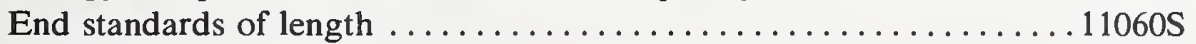

Ferris-ferric dosimeters . . . . . . . . . . . . . . . . . . . . . . . . . 48010C-48011C

Field strength measurements, electromagnetic . . . . . . . . . . . 64100S-64400S

Filament lamps, ribbon ............................. 35050C\&39010C

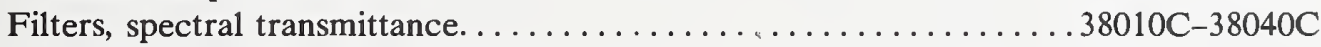

Fixed-point devices, thermometric .........................

Flats, optical .......................................

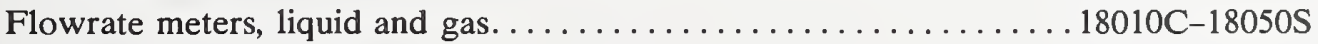

Flux standards, luminous. ...........................37080C-37130C

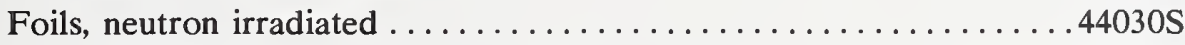

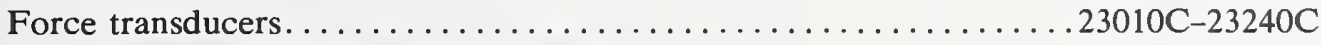

Frequency and time measurement services ...............76100S-76110S

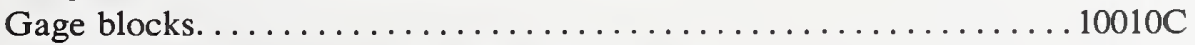

Gage block, Measurement Assurance Program .............. 10070M

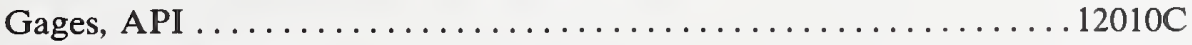

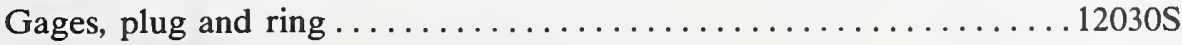

Gages, pressure...............................29010C-29040S

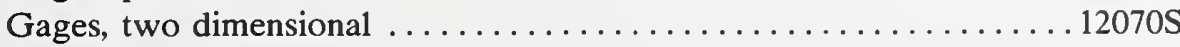

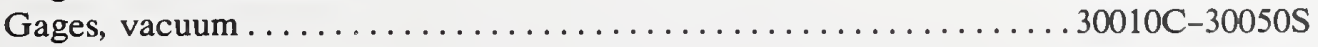

Gamma-ray dosimeters . . . . . . . . . . . . . . . . . . . . 46010C-46021C

Gamma-ray-emitting sources.................... $43010 \mathrm{C} \&$

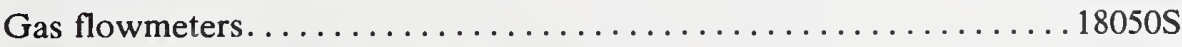

Germanium resistance thermometers $\ldots \ldots \ldots \ldots \ldots \ldots \ldots \ldots \ldots$. $\ldots \ldots 60$. 
High dose dosimetry . . . . . . . . . . . . . . . . . . . . . 49010S-49050S

High-frequency standard capacitors and inductors. . . . . . . . . 52210C-52223C

High-frequency standard resistors ................... 51310C

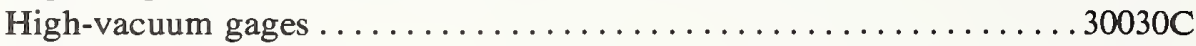

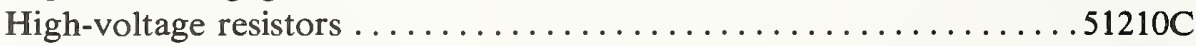

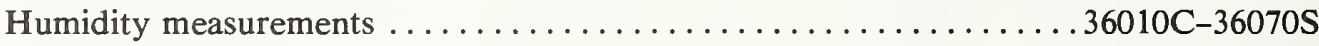

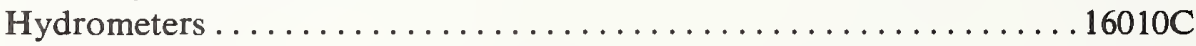

Hygrometers .....................................

Impulse generator spectrum amplitude.................65100s

Impulse response of coaxial networks.................6. 65300 S

Inductance and capacitance measurements, low-frequency . . . . . .52110S-52150C

Inductance and capacitance measurements, high-frequency . . . . . . 52210C-52223C

Inductive voltage dividers . . . . . . . . . . . . . . . . . . 54110S-54131C

Intensity standards, luminous . . . . . . . . . . . . . . . . . . 37010C-37070C

Internal diameter standards. . . . . . . . . . . . . . . . . . 11040s

Irradiance sources . . . . . . . . . . . . . . . . . . . . . . 40010S-40040S;

39040C; 39050C

Kerr cells.................................54410S

Laboratory thermometers ......................... 31010C-31161S

Lamps, deuterium arc . . . . . . . . . . . . . . . . . . . 39050C-40030S

Lamps, incandescent ................................

Lamps, quartz halogen ... . . . . . . . . . . . . . . . . . . . . . . 39040C

Lamps, ribbon filament .......................... 35050C\&39010C

Laser power and energy measurements . . . . . . . . . . . . . 42010S-42090M

Length measurements ............................. 10010C-10070M

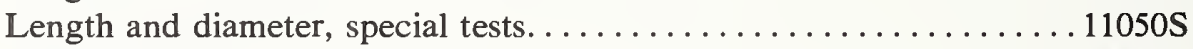

Line standards. . . . . . . . . . . . . . . . . . . . . . . . . . . . . . 10020C

Liquid flowmeters ........................... 18010C-18050C

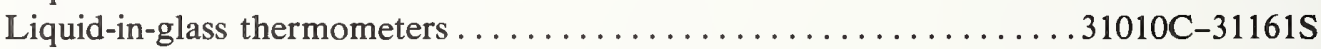

Load cells ..................................23010C-23270s

Luminous directional transmittance standards. . . . . . . . . . . . . 37170C

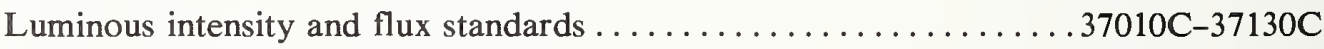

Luminous intensity of retroreflectors .................... 38070M

Luminous transmittance filters...................... 37170C

Mass measurements ..........................22010C-22180M

\section{MEASUREMENT ASSURANCE PROGRAMS}

Dc resistance....................................

Dc voltage.............................. 53120M

Gage blocks.................................. 10070M

Laser power and energy...................... 42020M-42090M

Mass .........................................22180M

Platinum resistance thermometry...................... 33120M

Retroreflectors, luminous intensity . . . . . . . . . . . . . 38070M-38074M

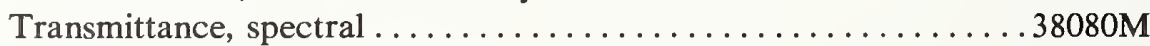

Watthour meters.............................56210M

Mercurial Barometer and Manometers..................29035C

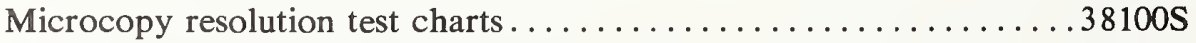

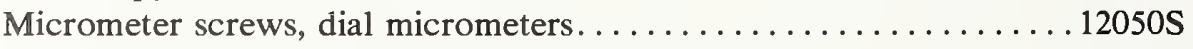

Microphones, pressure and free-field response ............. 25010C-25050C

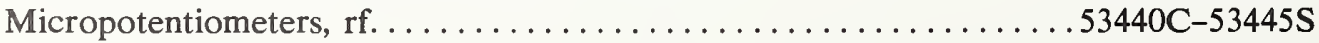


Microwave antenna parameter measurements..............663100S-63400S

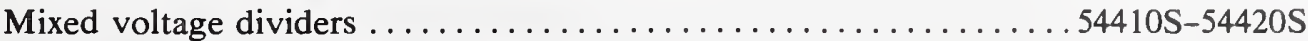

$\mathrm{N}$-port scattering measurements......................61520S

Neutron dosimeters ..............................44040S-44070S

Neutron sources ............................44010C-44020C

Noise temperature measurements, coaxial and waveguide .......62020S-62140S

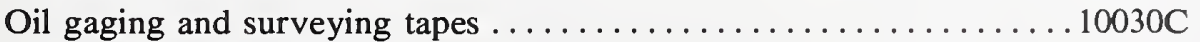

Opal glass transmittance standard ......................

Optical fiber attenuation and bandwidth .................41010S-41020S

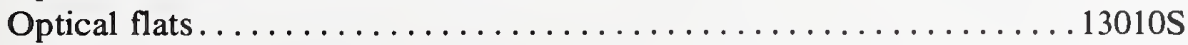

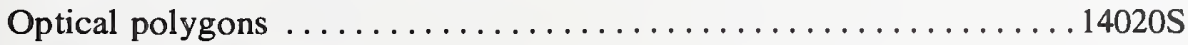

Optical pyrometers...................................

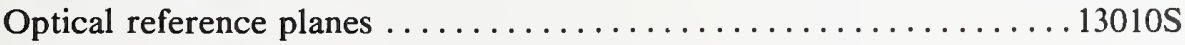

Oscillator characterization ........................... 77100C-77140S

Penetrameters, $x$-ray .............................46040S

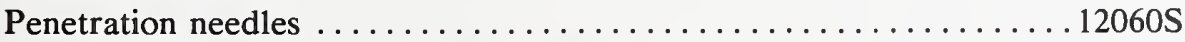

Phase angle standard and phase meters, audio-frequency .........55110S

Phase shifters, $\mathrm{rf}$ and microwave.....................61410C-61450S

Photodiode spectral response........................39060C

Photographic step tablets ...........................38090S

Photometry ..........................................

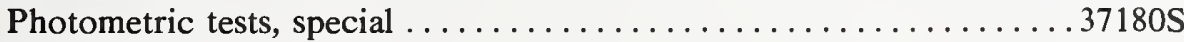

Pickup sensitivity ................................. 24010C-24030C

Piston gages, controlled clearance......................29020C

Piston gages, dead weight. ......................... 29010C

Pitot-static tubes................................ $19010 \mathrm{C}$

Platinum resistance thermometers .....................33010C-33050C

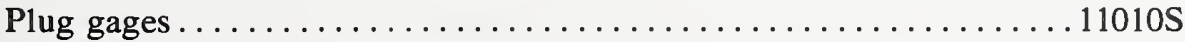

Pneumatic bridge hygrometers . . . . . . . . . . . . . . . . 36060C

Polygons, optical ..............................

Power and energy measurements, low-frequency............56110S-56210M

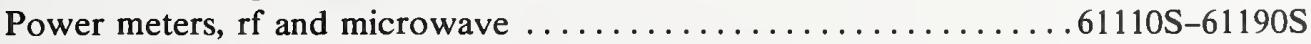

Pressure gages and transducers . . . . . . . . . . . . . . . . 29030 C

Pressure gages, low absolute ....................... 30010 C

Pressure gages, low differential . . . . . . . . . . . . . . . . 30020C

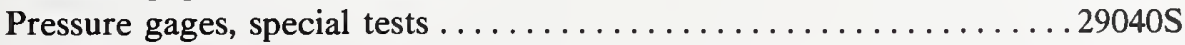

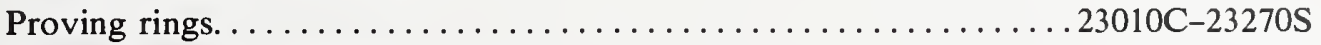

Pulse waveform measurements .......................65100S-65400S

Pulse voltage measuring systems ...........................

Pyrometer indicators . . . . . . . . . . . . . . . . . . . . . . .

Pyrometers, optical . . . . . . . . . . . . . . . . . . . . . . 35010C-35040C

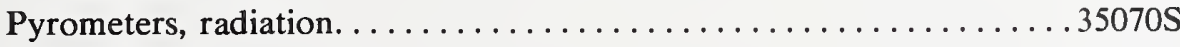

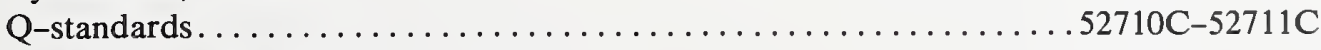

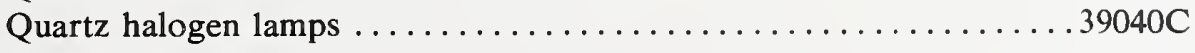

Radiance standard sources ........................... 39010C-39050C;

$40020 \mathrm{~S}$

Radiant energy detectors ............................ 39060C

Radiation detectors ............................46010C-46011C

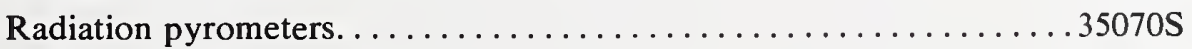

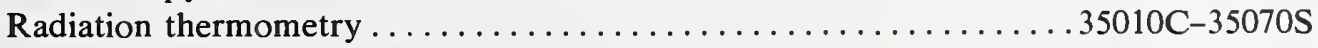

Radioactive sources, alpha-emitting .................43030C-43050C 
Radioactive sources, beta-emitting ...................43060S-43070s

Radioactive sources, gamma-emitting. . . . . . . . . . . . . . . .43010C-43020C

Radioactive sources, neutron-emitting . . . . . . . . . . . . . . 44010C-44030S

Radiochrometric dosimeters..........................49020S-49030S

Radiometry sources, special tests. . . . . . . . . . . . . . . 39070s

Radionuclides ..............................43010C-43090s

Reflection coefficients, coax. and waveguide terminals.........61310C-61331S

Resistance measurements, $\mathrm{dc}$......................51100S-51163C

Resistance thermometers............................33010C-33100s

Resistive voltage dividers.......................54210C

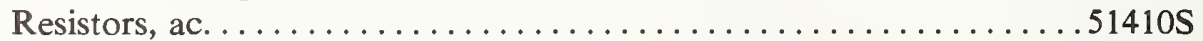

Resistors for current measurements. . . . . . . . . . . . . 51160C-51163C

Resistors, high-voltage .......................51210C

Resistors, high-frequency ........................51310C

Resistors, megohm ............................51142C-51150C

Resistors, high-precision standard, dc...................51130C-51154C

Retroreflectors, coefficient of luminous intensity . . . . . . . . . . . 38070M

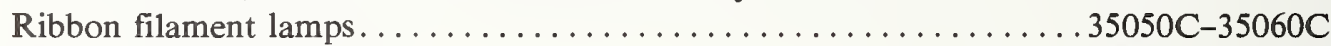

Rods, surveying leveling.............................. 10040s

Rotary and indexing tables..................................

Roughness calibration standards ...................... 15010C

Roundness measurements ... . . . . . . . . . . . . . . . . . 13020S-13030S

Saturated standards cells......................... . 53130C-53131C

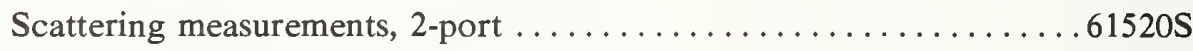

Shock tests...................................24040s

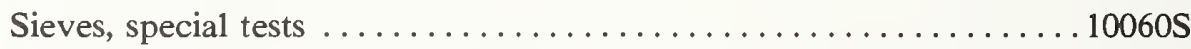

Sources, low-frequency, ac voltage..................53200s

Spectral irradiance lamps ......................... 39040C-39050C

Spectral irradiance...............................40010S;40030S;

$39040 \mathrm{C} ; 39050 \mathrm{C}$

Spectral radiance ................................40020S;

$39010 \mathrm{C}-39030 \mathrm{C}$

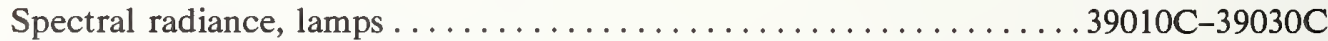

Spectral response, photodiode .......................39060C

Spectral transmittance filters . . . . . . . . . . . . . . . . . . . . . .38010C-39040C

Spectrophotometric standards . . . . . . . . . . . . . . . . . . . 39010C-39060S

Spherical diameter standards . . . . . . . . . . . . . . . . . . . 11030s

Standard voltage cells . . . . . . . . . . . . . . . . . . . . 53130C-53150C

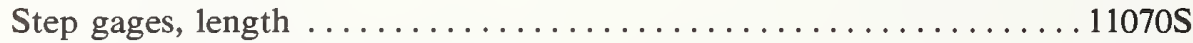

Step height measurements, surface ...................15030C

Step tablet density, photographic ......................... 38090S

Surface roughness standards.......................15020C

Surveying and oil gaging tapes ......................

Surveying leveling rods. ............................. 


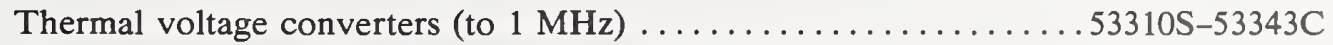

Thermal voltage and current converters $(100 \mathrm{~Hz}-1 \mathrm{GHz}) \ldots \ldots \ldots$.... 53405S-53445S

Thermocouples................................32010C-32044C

Thermocouple materials .........................32070C-32110C

Thermometers, calorimetric type ....................33030C

Thermometers, cryogenic type ...............................

Thermometers, germanium resistance....................33060S

Thermometers, laboratory ............................ 31010C-31161s

Thermometers, platinum resistance....................33010C-33050C

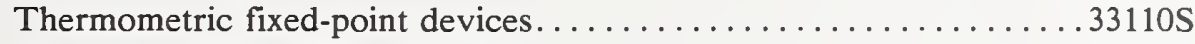

Thermometry, radiation ............................ 35010C-35070S

Thread measuring wires ..............................

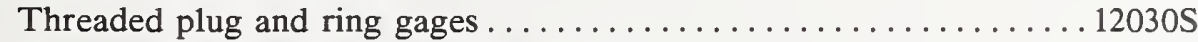

Time and frequency measurement services ................76100S-76110S

Transformers, voltage and current .................... 54510C-54600S

Transmittance filters, spectral ....................... 38010C-38040C

Transmittance, luminous directional .................... 37170C

Two-port scattering measurements ...................61520S

Turbine flow meters .............................. 18010C-18020C

Ultrasonic transducer power, special test.................26070S

Ultrasonic transducers, power and frequency...............26010C

Unsaturated standard cells .........................53150C

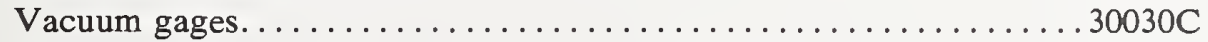

Vacuum measurements ............................30010C-30050S

Vacuum ultraviolet radiometric measurements.............40010S-40040S

Very-high-frequency omnidirectional range (VOR) meas.........55210C-55230S

Vibration and shock measurements...................24010C-24060S

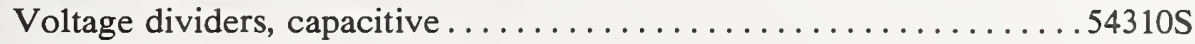

Voltage dividers, inductive..............................

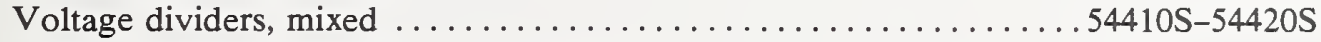

Voltage dividers, resistive......................... 54210C

Voltage reference standards, solid state................53160C-53161C

Voltage and current transformers .......................... $44510 \mathrm{C}-54600$ S

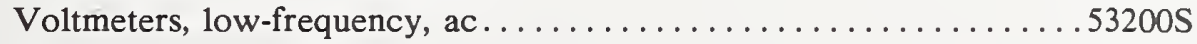

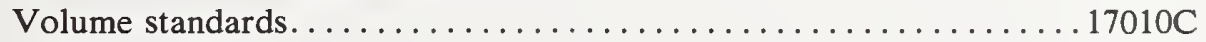

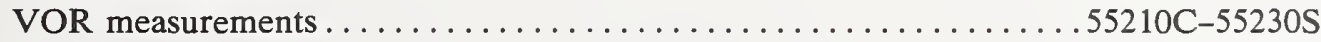

Watthour meters..............................56120C-56210M

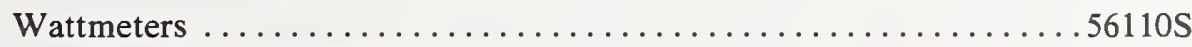

Waveform measurements, pulse.....................65100S-65400S

Waveguide power meters .............................61130S-61155S

Waveguide terminations and reflection coefficients ...........61320C-61331S

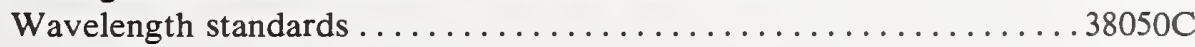

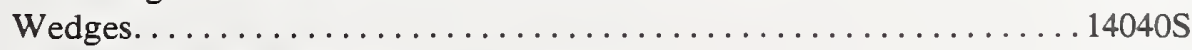

Weights (mass standards) ...........................22010C-22180M

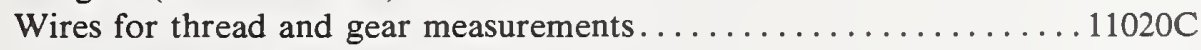

X-ray dosimeters. . . . . . . . . . . . . . . . . . . . . . . . . . . . 46010C-46050S

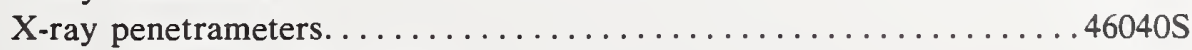

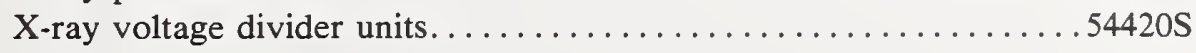




U.S. Department of Commerce

National Bureau of Standards

Office of Physical Measurement Services

Rm. B362, Physics Bldg.

Gaithersburg, MD 20899

Return Postage Guaranteed

Official Business

Penalty for Private Use, $\$ 300$
Bound Printed Matter

Postage \& Fees Paid NBS

PERMIT No. G195

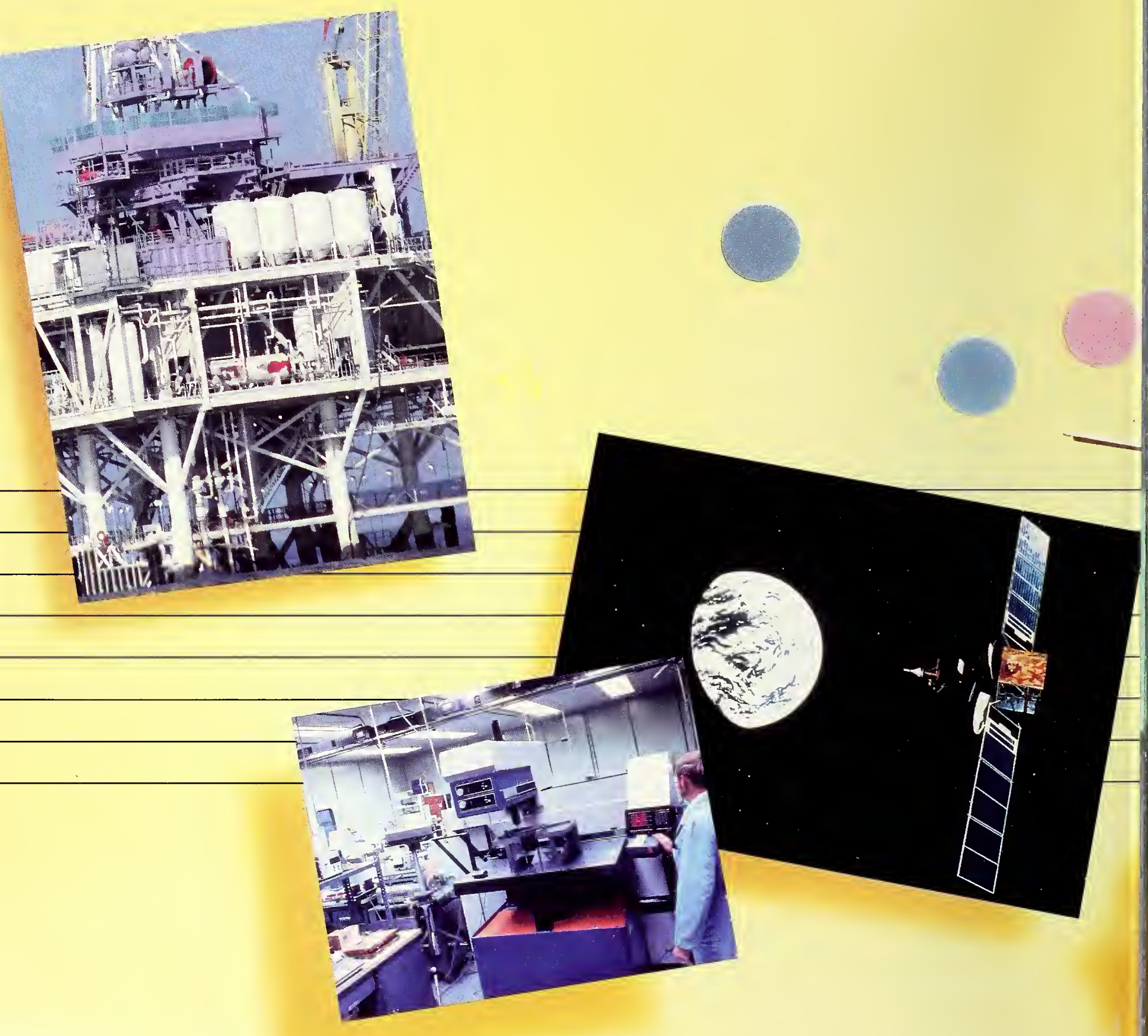

